$19802 / B$

8

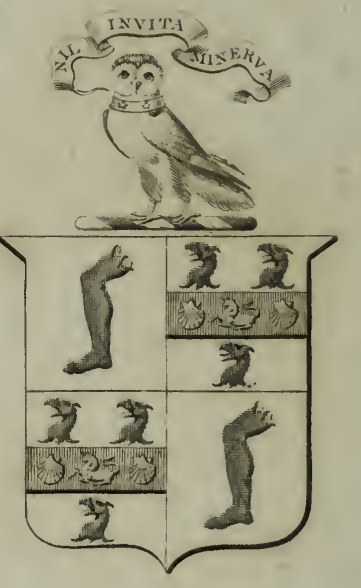

- Pirfererel. Pierene. 


$$
\text { . }
$$

,

1) 




\title{
ELEMENTS
}

OP

\section{agrícultural Cbemistry,}

IN

\author{
A COURSE OF LECTURES
}

FOR

\section{THE BOARD OF AGRICULTURE.}

\section{SECOND EDITION.}

BY

\section{SIR HUMPHRY DAVY, LL. D.}

\author{
F. R. S. L. \& E. V.P.R. I.
}

MEMBER OF THE BOARD OF AGRICULTURE, OF THE ROYAL IRISH ACADEMY, OF THE ACADEMUES OF ST. PETERSBURGH, STOCKHOLM, BERLIN, PHILADELPHIA, \&C; AND HONORARY PROEESSOR OF CHEMISTRY TO THE ROYAL INSTITUTION.

\section{Hantran:}

PRINTED FOR LONGMAN, HURST, REES, ORME, AND BROWN, PATERNOSTER-ROW;

AND A. CONSTABLE AND CO. EDINBURGH.

1814. 


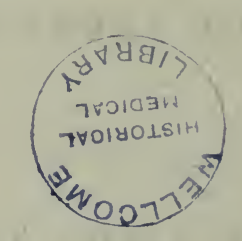


TO THE

\section{PRESIDENT AND MEMBERS}

OF

\section{THE BOARD OF AGRICULTURE}

FOR THE YEAR 1812,

\section{THESE LECTURES,}

PUBLISHED AT THEIR REQUEST, ARE INSCRIBED AS A

TESTIMONY OF THE RESPECT OF THE AUTHOR, AND OF

AIS GRATITUDE FOR THE ATTENTION WITH WHICH THEY HAVE BEEN RECEIVED. 


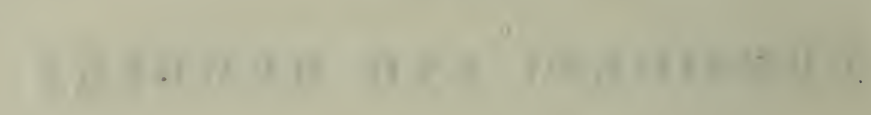

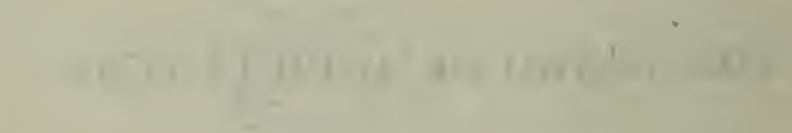

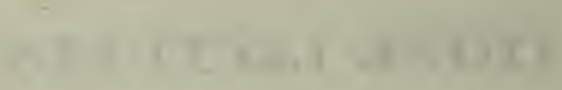




\section{ADVERTISEMENT.}

During ten years, since 1802, I have had the honour, every Session, of delivering Courses of Thectures before the Board of Agriculture. I have endeavoured, at all times, to follow in them the progress of chemical discovery; they have therefore varied every year: and such is the rapidity with which Chemistry is extending, that some alterations and improvements were rendered necessary at the time they were preparing for the press.

The Duke of Bedford has enabled me to stamp a value upon this Work, by permitting me to add to it the results of the experiments 
instituted by His Grace upon the quantity of produce afforded by the different grasses.

I am indebted for much useful information to many members of the Board; of which acknowledgments will be found in the body of the Work. If there are any omissions on this head, I trust they will be attributed to defect of recollection, and not to any want of candour or of gratitude.

Where I have derived any specific statements from books, I have always quoted the authors; but I have not always made references to such doctrines as are become current, the authors of which are well known; and which may be almost considered as the property of all enlightened minds.

Amongst books to which I have not referred for any particular facts, but which contain much useful general information, I shall 
mention the Earl of Dundonald's Treatise on the Connection of Chemistry with Agriculture; Dr. Rennie's Dissertations on Peat; and the General Report of the Agriculture of Scotland. This last work did not come into my hands till the concluding sheets of these Lectures were printing. Had it been in circulation before, I should have profited by many statements given in it, particularly those of the opinions of the cnlightened Professor of Agriculture in the University of Edinburgh: and I should have dwelt with satisfaction on the importance given to some chemical doctrines by his experience.

BERKELEY SQUARE,

March. 21, 1813. 



\section{CONTENTS.}

\section{LECTURE I.}

Introduction. General Views of the Objects of the Course, and of the Order in which they are to be discussed

\section{LECTURE II.}

Of the general Powers of Matter which infiuence Vegetation; of Gravitation, of Cohesion, of Chemical Attraction, of Heat, of Light, of Electricity, ponderable Substances, Elements of Matter, particularly those found in Vegetables, Laws of their Combinations and Arrangements.

\section{LECTURE III.}

On the Organization of Plants. Of the Roots, Trunk, and Branches; of their Structure. Of the Epidermis. Of the cortical and alburnous Parts of Leaves, Flowers, and Seeds. Of the chemical Constitution of the Organs of Plants, and the Substances found in them. 'Of mucilaginous, saccharine, extractive, resinous, and oily Substances, and other vegetable Compounds, their Arrangements in the Organs of Plants, their Composition, Changes, and Uses ...................... 


\section{LECTURE IV.}

On Soils : their constituent Parts. On the Analysis of Soils. Of the Uses of the Soil. Of the Rocks and Strata found beneath Soils. Of the Improvement of Soils

\section{LECTURE V.}

On the Nature and Constitution of the Atmosphere, and its Influence on Vegetables. Of the Germination of Seeds. Of the Functions of Plants in their different Stages of Growth; with a general View of the Progress of Vegetation

\section{LECTURE VI.}

Of Manures of vegetable and animal Origin. Of the Manner in which they become the Nourishment of the Plant. Of Fermentation and Putrefaction. Of the different Species of Manures of vegetable Origin; of the different Species of animal Origin. Of mixed Manures. General Principles with respect to the Use and Application of such Manures ............... 269

\section{LECTURE VII.}

On Manures of mineral Origin, or fossile Manures; their Preparation, and the Manuer in which they act. Of Lime in its different States; Operation of Lime as a Manure and a Cement; different Combinations of Lime. Of Gypsum; Ideas respecting its Use. Of other Neutro-saline Compounds, employed as Manures. Of Alkaliøs and alkaline Salts; of common Salt......... 


\section{LECTURE VIII.}

On the Improvement of Lands by burning; chemical Principles of this Operation. On Irrigation and its Effects. On Fallowing; its Disadvantages and Uses. On the convertible Husbandry founded on regular Rotations of different Crops. On Pasture. On various Agricultural Objects connected with Chemistry. Conclusion...... 344

\section{APPENDIX.}

An Account of the Results of Experiments on the Produce and Nutritive Qualities of different Grasses, and other Plants, used as the Food of Animals. 


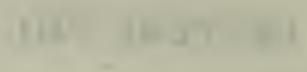

+

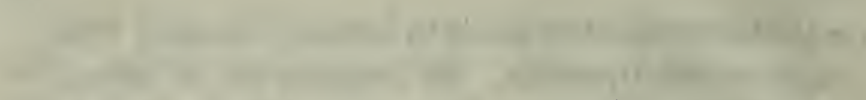

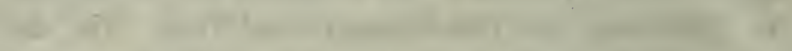

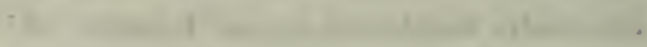

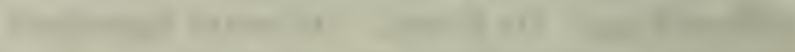

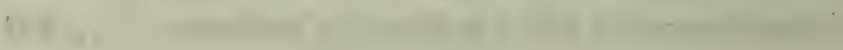

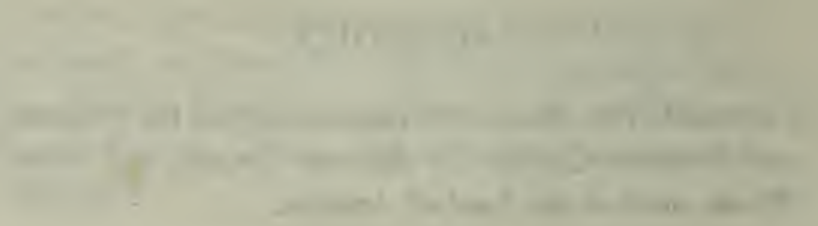




\section{A \\ COURSE OF LECTURES}

oN

\section{THE ELEMENTS}

OF

\section{AGRICULTURAL CHEMISTRY.}




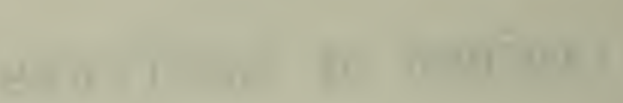

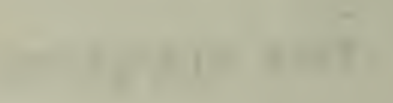

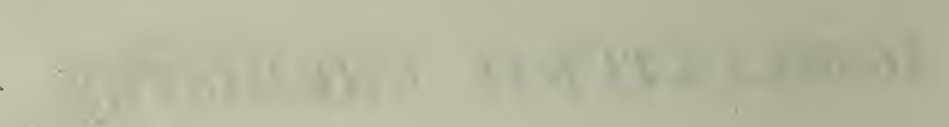




\section{I. \\ COURSE OF LECTURES, \&C.}

\section{LECTURE I.}

Introduction. General Views of the Objects of the Course, and of the Order in which they are to be discussed.

$\mathbf{I}_{\mathbf{T}}$ is with great pleasure that I receive the permission to address so distinguished and enlightened an Audience on the subject of Agricultural Chemistry.

That any thing which I am able to bring forward, should be thought worthy the attention of the Board of Agriculture, I consider as an honour; and I shall endeavour to prove my gratitude, by employing every exertion to illustrate this department of knowledge, and to point out its uses.

In attempting these objects, the peculiar state of the enquiry presents many difficulties to a Lecturer. Agricultural Chemistry has not yet received a re- 
gular and systematic form. It has been pursued by competent experimenters for a short time only; the doctrines have not as yet been collected into any elementary treatise; and on an occasion when I am obliged to trust so much to my own arrangements, and to my own limited information, I cannot but feel diffident as to the interest that may be excited, and doubtful of the success of the undertaking. I know, however, that your candour will induce you not to expect any thing like a finished work upon a science as yet in its infaricy; and I an sure you will receive with indulgence the first attempt made to illustrate it, in a distinct course of public lectures.

Agricultural Chemistry has for its objects all those changes in the arrangements of matter connected with the growth and nourishment of plants; the comparative values of their producc as food; the constitution of soils; the manner in which lands are enriched by manure, or rendered fertile by the different processes of cultivation. Enquiries of such a nature cannot but be interesting and important, both to the theoretical agriculturist, and to the practical farmer. 'To the first, they are necessary in supplying most of the fundamental principles on which the theory of the art depends. To the second, they are useful in affording simple and casy experiments for directing his labours, and for enabling him to pursue a certain and systematic plan of improvement, 
It is scarcely possible to enter upon any investigation in agriculture without finding it connected, more or less, with doctrines or elucidations derived from chemistry.

If land be unproductive, and a system of ameliorating it is to be attempted, the sure method of obtaining the object is by determining the cause of its sterility, which must necessarily depend upon some defect in the constitution of the soil, which may be easily discovered by chemical analysis.

Some lands of good apparent texture are yet sterile in a high degree; and common observation and common practice afford no means of ascertaining the cause, or of removing the effect. The application of chemical tests in such cases is obvious: for the soil must contain some noxious principle which may be easily discovered, and probably easily destroyed.

Are any of the salts of iron present? they may be decomposed by lime. Is there an excess of siliceous sand? the system of improvement must depend on the application of clay and calcareous matter. Is there a defect of calcareous matter? the remedy is obvious. Is an excess of vegetable matter indicated? it may be removed by liming, paring, and burning. Is there a deficiency of vegetable matter? it is to be supplied by manure.

$\Lambda$ question concerning the different kinds of limestone to be empicyed in cultivation often occurs. 'To determine this fully in the common way of ex- 
perience, -would demand a considerable time, perhaps some years, and trials which might be injurious to crops; but by simple chemical tests the nature of a limestone is discovered in a few minutes; and the fitness of its application, whether as a manure for different soils, or as a cement, determined.

Peat earth of a certain consistence and composition is an excellent manure; but there are some varieties of peats which contain so large a quantity of ferruginous matter as to be absolutely poisonous to plants. Nothing can be more simple than the chemical operation for determining the nature, and the probable uses of a substance of this kind.

There has been no question on which more difference of opinion has existed, than that of the state in which manure ought to be ploughed into the land; whether recent, or when it has gone through the process of fermentation? and this question is still a subject of discussion; but whoever will refer to the simplest principles of chemistry, cannot entertain a doubt on the subject. As soon as dung begins to decompose, it throws off its volatile parts, which are the most valuable and most efficient. Dung which has fermented, so as to become a mere soft cohesive mass, has generally lost from one third to one half of its most useful constituent elements. It evidently should be applied as soon as fermentation begins, that it may exert its full action upon the plant, and lose none of its gutritive powers. 
It would be easy to adduce a multitude of other instances of the same kind; but sufficient I trust has been said to prove, that the connexion of Chemistry with Agriculture is not founded on mere vague speculation, but that it offers principles which ought to be understood and followed, and which in their progression and ultimate results, can hardly fail to be highly beneficial to the community.

A view of the objects in this Course of Lectures, and of the manner in which they are to be treated, will not, I hope, be coasidered as an improper introduction. It will inform you what you are to expect; it will afford a general idea of the connexion of the different parts of the subject, and of their relative importance; it will enable me to give some historical details of the progress of this branch of knowledge, and to reason from what has been ascertained, concerning what remains to be investigated and discovered.

The phenomena of vegetation must be considered as an important branch of the science of orgauized nature; but though exalted above inorganic matter, vegetables are yet in a great measure dependent for their existence upon its laws. They receive their nourishment from the external elements; they assimilate it by means of peculiar organs: and it is by examining their physical and chemical constitution, and the substances and powers which act upon them, and the modifications 
which they undergo, that the scientific principles of Agricultural Chemistry are obtained.

According to these ideas, it is evident that the study ought to be commenced by some general enquiries into the composition and nature of material bodies, and the laws of their changes. The surface of the earth, the atmosphere, and the water deposited from it, must either together or separately. afford all the principles concerned in vegetation; and it is only by examining the chemical nature of these principles, that we are capable of discovering what is the food of plants, and the manner in which this food is supplied and prepared for their nourishment. Thie priuciples of the constitution of bodies, consequently, will form the first subject for our consideration.

By methods of analysis dependent upon chemical and electrical instruments discovered in late times, it has been ascertained that all the varieties of material substances may be resolved into a comparatively small number of bodies, which, as they are not capable of being decompounded, are considered in the present state of chemical knowledge as elements. The bodies incapable of decomposition at present known are forty-seven. Of these, thirtyeight are metals; six are inflammable bodies; and three substances which unite with metals and inflammable bodies, and form with them acids, alkalies, earths, or other analogous compounds. 
The chemical elements acted upon by attractive powers combine in different aggregates. In their simpler combinations, they produce various crystalline substances, distinguished by the regularity of their forms. In more complicated arrangements they constitute the varieties of vegetable and animal substances, bear the higher character of organization, and are rendered subservient to the purposes of life. And by the influence of heat, light, and electrical powers, there is a constant series of changes; matter assumes new forms, the destruction of one order of beings tends to the conservation of another, solution and consolidation, decay and renovation, are connected, and whilst the parts of the system continue in a state of fluctuation and change, the order and harmony of the whole remain unalterable.

After a general view has been taken of the nature of the elements, and of the principles of chemical changes, the next object will be the structure and constitution of plants. In all plants there exists a system of tubes or vessels, which in one extremity terminate in roots, and at the other in leaves. It is by the capiliary action of the roats that fluid matter is taken up from the soil. The sap in passing upwards becomes denser, and more fitted to deposit solid matter: it is modified by exposure to heat, ligbt, and air in the leaves; descends through the bark, in its progress produces new or- 
ganized matter; and is thus in its vernal and autumnal flow, the cause of the formation of new parts, and of the more perfect evolution of parts already formed.

In this part of the enquiry I shall endeavour to connect together into a general view, the observation of the most enlightened philosophers who have studied the physiology of vegetation. Those of Grew, Malpighi, Sennebier, Darwin, and, above all, of Mr. Knight. He is the latest enquirer into these interesting subjects, and his labours have tended most to illustrate this part of the economy of nature.

The chemical composition of plants has within the last ten years, been elucidated by the experiments of a number of chemical philosophers, both in this, and in other countries; and it forms a beautiful part of general chemistry; it is too extensive to be treated of minutely; but it will be necessary to dwell upon such parts of it, as afford practical inferences.

If the organs of plants be submitted to chemical analysis, it is found that their almost infinite diversity of form, depends upon difierent arrangements and combinations of a very few of the elements; seldom more than seven or eight belong to them, and three constitute the greatest part of their organized matter; and according to the manner in which these elements are disposed, arise the differ- 


\section{1}

ent properties of the products of vegetation, whether cmployed as food, or for other purposes and wants of life.

'The value and uses of every species of agricultural produce, are most correctly estimated and applied, when practical knowledge is assisted by principles derived from chemistry. The compounds in vegetables really nutritive as the food of animals, are very few ; farina or the pure matter of starch, gluten, sugar, vegetable jelly, oil, and extract. Of these the most nutritive is gluten, which approaches nearest in its nature to animal matter, and which is the substance that gives to wheat its superiority over other grain. The next in order as to nourishing power is oil, then sugar, then farina; and last of all gelatinous and extractive matters. Simple tests of the relative nourishing powers of the different species of food, are the relative quantities of these substances that they afford by analysis; and though taste and appearance must influence the consumption of all articles in years of plenty, yet they are less attended to in times of scarcity, and on such occasions this kind of knowledge may be of the greatest importance. Sugar and farina or starch, are very similar in composition, and are capable of being converted into each other by simple chemical processes. In the discussion of their relations, I shall detail to you the results of some recent experiments, which will be found possessed of applications both to the 
econony of vegetation, and to some important processes of manufacture.

All the varities of substances found in plants, are produced from the sap, and the sap of plants is derived from water, or from the fluids in the soil, and it is altered by, or combined with principles derived from the atmosphere. The influence of the soil, of water, and of air, will therefore be the next subject of consideration. Soils in ail cases consist of a mixture of different fincly divided earthy matters ; with animal or vegetabie substances in a state of decomposition, and certain saline ingredients. The earthy matters are the true basis of the soil; the other parts, whether natural, or artificially introduced, operate in the same manner as manures. Four earths generally abound in soils, the aluminous, the siliceous, the calcareous, and the magnesian. These earths, as I have discovered, consist of highly inflammable metals mited to pure air or oxygene; and they are not, as far as we know, decomposed or altered in regetation.

The great use of the soil is to afford support to the plant, to enable it to fix its roots, and to derive nourishment by its tubes slowly and gradually, from the soluble and dissolved substances mixed with the earths.

That a particular mixture of the earths is connected with fertility, cannot be doubted: and almost all sterile soils are capable of being improved, by a modification of their earthy constituent parts. I 
shall describe the simplest method as yet discovered of analysing soils, and of ascertaining the constitution and chemical ingredients which appear to be connected with fertility; and on this subject many of the former difficulties of investigation will be found to be removed by recent enquiries.

The necessity of water to vegetation, and the luxuriancy of the growth of plants connected with the presence of moisture in the southern countries of the old continent, led to the opinion so prevalent in the early schools of philosophy, that water was the great productive element, the substance from which all things were capable of being composed, and into which they were finally resolved. The

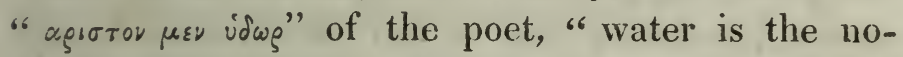
blest," seems to have been an expression of this opinion, adopted by the Greeks from the Egyptians, taught by Thales, and revived by the alchemists in late times. Van Helmont in 1610 , conceived that he had proved by a decisive experiment, that all the products of vegetables were capable of being generated from water. His results were shewn to be fallacious by Woodward in 1691; but the true use of water in vegetation was unknown till 1785 ; when Mr. Cavendish made the grand discovery, that it was composed of two elastic fluids or gases, inflammable gas or hydrogene, and vital gas or oxygene.

Air, like water, was regarded as a pure element by most of the ancient philosophers: a few of the 
chemical enquirers in the sixteenth and seventeenth centuries, formed some happy conjectures respecting its real nature. Sir Kenelm Digby in 1660, supposed that it contained sone saline matter, which was an' essential food of plants. Boyle, Hooke, and Mayow, hetween 1665 and 1680, stated, that a small part of it only was consumed in the respiration of animals, and in the combustion of inflammable bodies; but the true statical analysis of the atmosphere is comparatively a recent labour, achieved towards the end of the last century by Scheele, Priestley, and Lavoisier. These celebrated men shewed that its principal elements are two gases, oxygene and azote, of which the first is essential to flame, and to the life of animals, and that it likewise contains small quantities of aqueous vapour, and of carbonic acid gas; and Lavoisier proved that this last body is itself a compound elastic fluid, consisting of charcoal dissolved in oxygene.

Jethro Tull, in his treatise on Horse-hoeing, published in 1733 , advanced the opinion that minute earthy particles supplied the whole nourishment of the vegetable world; that air and water were chiefly useful in producing these particles from the land; and that manures acted in no other way than in ameliorating the texture of the soil, in short, that their agency was mechanical. This ingenious author of the new system of agriculture having observed the excellent effects produced in 
farming by a minute division of the soil, and the pulverisation of it hy exposure to dew and air, was misled by carrying his principles too far. Dulamel, in a work printed in 1754, adopted the opinion of 'Tull, and stated that by finely dividing the soil, any number of crops might be raised in succession from the same land. He attempted also to prove, by direct experiments, that vegetables of every kind were capable of being raised without manure. This celebrated horticulturist lived, however, sufficiently long to alter his opinion. The results of his later and most refined observations led him to the conclusion, that no single material afforded the food of plauts. The general experience of farmers had long before convinced the unprejudiced of the truth of the same opinion, and that manures were absolutely consumed in the process of vegetation. The exhaustion of soils by carrying off corn crops from them, and the effects of feeding cattle on lands, and of preserving their manure, offer faniliar illustrations of the principle; and several philosophical enquirers, particularly Hassenfratz and Saussure, have shewn by satisfactory experiments, that animal and vegetable matters deposited in soils are absorbed by plants, and become a part of their organized matter. But though neither water, nor air, nor earth, supplies the whole of the food of plants, yet they all operate in the process of vegetation. 'I'he soil is the laboratory in which the food is prepared. No manure can be taken up by the roots of 
plants unless water is present; and water or its elements exist in all the products of vegetation. The germination of seeds does not take place without the presence of air or oxygene gas; and in the sunshine vegetables decompose the carbonic acid gas of the atmosphere, the carbon of which is absorbed, and becomes a part of their organized matter, and the oxygene gas, the other constituent, is given off; and in consequence of a variety of agencies, the economy of vegetation is made subservient to the general order of the system of nature.

It is shewn by various researches, that the constitution of the atmosphere has been always the same since the time that it was first accurately analysed; and this must in a great measure depend upon the powers of plants to absorb or decompose the putrifying or decaying remains of animals and vegetables, and the gaseous effluvia which they are constantly emitting. Carbonic acid gas is formed in a variety of processes of fermentation and combustion, and in the respiration of animals; and as yet no other process is known in nature by which it can be consumed, except vegetation. Animals produce a substance which appears to be a necessary food of vegetables; vegetables evolve a principle necessary to the existence of animals; and these different classes of beings seem to be thus connected together in the exercise of their living functions, and to a certain extent made to depend upon each other for their existence. Water is raised from the 
ocean, diffused through the air, and poured down upon the soil, so as to be applied to the purposes of life. The different parts of the atmosphere are mingled together by winds or changes of temperature, and successively brought in contact with the surface of the earth, so as to exert their fertilizing influence. The modifications of the soil, and the application of manures are placed within the power of man, as if for the purpose of awakening his industry and of calling forth his powers.

The theory of the general operation of the more compound manures may be rendered very obvious by simple chemical principles; but there is still much to be discovered with regard to the best methods of rendering animal and vegetable substances soluble; with respect to the processes of decomposition, how they may be accelerated or retarded, and the means of producing the greatest effects from the materials employed: these subjects will be attended to in the Lecture on Manures.

Plants are found by analysis to consist principally of charcoal and aeriform matter. They give out by distillation volatile compounds, the elements of which are pure air, inflammable air, coally matter, and azote, or that elastic substance which forms a great part of the atmosphere, and which is incapable of supporting combustion. These elements they gain either by their leaves from the air, or by their roots from the soil. All manures from organized substances contain the principles of vegetable mat- 
ter, which during putrefaction are rendered either soluble in water or aeriform-and in these states they are capable of being assimilated to the vegetable organs. No one principle affords the pabulum of vegetable life; it is neither charcoal nor hydrogene, nor azote nor oxygene alone; but all of them together in various states and various combinations. Organic substances as soon as they are deprived of vitality, begin to pass through a series of changes which ends in their complete destruction, in the entire separation and dissipation of the parts. Animal matters are the soonest destroyed by the operation of air, heat, and light. Vegetable substances yield more slowly, but finally obey the same laws. The periods of the application of manures from decomposing animal and vegetable substances depend upon the knowledge of these principles, and I shall be able to produce some new and important facts founded upon them, which I trust will remove all doubt from this part of agricultural theory.

The chemistry of the more simple manures; the manures which act in very small quantities, such as. gypsum, alkalies, and various saline substances, has hitherto been exceedingly obscure. It has been generally supposed that these materials act in the vegetable economy in the same manner as condiments or stimulants in the animal economy, and that they render the common food more nutritive. It seems, however, a much more probable idea, 
that they are actually a part of the true food of plants, and that they supply that kind of matter to the vegetable fibre, which is analogous to the bony matter in animal structures.

The operation of gypsum, it is well known, is extremely capricious in this country, and no certain data have hitherto been offered for its application.

There is, however, good ground for supposing that the subject will be fully elucidated by chemical inquiry. Those plants which seem most benefited by its application, are plants which always afford it on analysis. Clover, and most of the artificial grasses, contain it, but it exists in very minute quantity only in barley, wheat, and turnips. Many peat ashes which are sold at a considerable price, consist in great part of gypsum, with a little iron, and the first seems to be their most active ingredient. I have examined several of the soils to which these ashes are successfully applied, and I have found in them no sensible quantity of gypsum. In general, cultivated soils contain sufficient of this substance for the use of the grasses; in such cases, its application cannot be advantageous. For plants require only a certain quantity of manure; an excess may be detrimental, and cannot be useful.

The theory of the operation of alkaline substances, is one of the parts of the chemistry of agriculture, most simple and distinct. They are c 2 
found in all plants, and thefore may be regarded as amongst their essential ingredients. From their powers of combination likewise, they may be useful in introducing various principles into the sap of vegetables, which may be subservient to their nourishment.

The fixed alkalies which were formerly regarded as elementary bodies, it has been my good fortune to decompose. They consist of pure air, united to highly inflammable metallic substances; but there is no reason to suppose that they are reduced into their elements in any of the processes of vegetation.

In this part of the Course I shall dwell at considerable length on the important subject of Lime, and I shall be able to offer some novel views.

Slacked lime was used by the Romans for manuring the soil in which fruit trees grew. This we are informed by Pliny. Marle had been employed by the Britons and the Gauls from the earliest times, as a top dressing for land. But the precise period in which burnt lime first came into general use in the cultivation of land, is, I believe, unknown. The origin of the application from the early practices is sufficiently obvious; a substance which had been used with success in gardening, must have been soon tried in farming; and in countries where marle was not to be found, calcined limestone would be naturally employed as a substitute. 
'The elder writers on agriculture had no correct notions of the nature of lime, limestone and marle, or of their effects; and this was the necessary consequence of the imperfection of the chemistry of the age. Calcareous matter was considered by the alchemists as a peculiar earth, which in the fire became combined with inflammable acid; and Evelyn and Hartlib, and, still later, Lisle, in their works on husbandry, have characterized it merely as a hot manure of use in cold lands. It is to Dr. Black of Edinburgh that our first distinct rudiments of knowledge on the subject are owing. About the year 1755, this celebrated professor proved, by the most decisive experiments, that limestone and all its modifications, marbles, chalks, and marles, consist principally of a peculiar earth united to an aerial acid: that the acid is given out in burning, occasioning a loss of more than $\mathbf{4 0}$ per cent., and that the lime in consequence becomes caustic.

These important facts immediately applied with equal certainty to the explanation of the uses of lime, both as a cement and as a manure. As a cement, lime applied in its caustic state acquires its hardness and durability, by absorbing the aerial (or as it has been since called carbonic) acid, which always exists in small quantities in the atmosphere, it becomes as it were again limestone.

Chalks, calcareous marles, or powdered limestones, act merely by forming an useful earthy in- 
gredient of the soil, and their efficacy is proportioned to the deficiency of calcareous matter, which in larger or smaller quantities seems to be an essential ingredient of all fertile soils; necessary perhaps to their proper texture, and as an ingredient in the organs of plants.

Burnt lime, in its first effect, acts as a decomposing agent upon animal or vegetable matter, and seems to bring it into a state on which it becomes more rapidly a vegetable nourishment; gradually, however, the lime is neutralized by carbonic acid, and converted into a substance analogous to chalk; but in this case it more perfectly mixes with the other ingredients of the soil, is more generally diffused and finely divided; and it is probably more useful to land than any calcareous substance in its natural state.

The most considerable fact made known with regard to limestone within the last few years, is owing to Mr. Tennant. It had been long known that a particular species of limestone found in different parts of the North of England, when applied in its burnt and slacked state to land in considerable quantities, occasioned sterility, or considerably injured the crops for many years. Mr. Tennant in 1800 , by a chemical examination of this species of limestone, ascertained, that it differed from common limestones by containing magnesian earth; and hy several experiments he proved that this earth was prejudicial to vegetation, when ape 
plied in large quantities in its caustic state. Under common circumstances the lime from the magnésian limestone is, however, used in moderate quantities upon fertile soils in Leicestershire, Derbyshire, and Yorkshire, with good effect; and it may be applied in greater quantities to soils containing very large proportions of vegetable matter. Magnesia when combined with carbonic acid gas, seems not to be prejudicial to vegetation, and in soils rich in manure, it is speedily supplied with this principle from the decomposition of the manure.

After the nature and operation of manures have been discussed, the next and the last subject for our consideration, will be some of the operations of husbandry capable of elucidation by chemical principles.

The chemical theory of fallowing is very simple. Fallowing affords no new source of riches to the soil. It merely tends to produce an accumulation of decomposing maiter, which in the common course of crops would be employed as it is formed, and it is scarcely possible to imagine a single instance of a cultivated soil, which can be supposed to remain fallow for a year with advantage to the farmer. The only cases where this practice is beneficial seems to be in the destruction of weeds, and for cleansing foul soils.

'The chemical theory of paring and burning, I shall discuss fully in this part of the Course.

It is obvious that in all cases it must destroy a certain quantity of vegetable matter, and must be 
principally useful in cases in which there is an excess of this matter in soils. Burning, likewise render's clays less coherent, and in this way greatly improves their texture, and causes them to be less permeable to water.

The instances in which it must be obviously prejudicial, are those of sandy dry siliceous soils, containing little animal or vegetable matter. Here it can only be destructive, for it decomposes that on which the soil depends for its productiveness.

The advantages of irrigation, though so lately a subject of much attention, were well known to the ancients; and more than two centuries ago the practice was recommended to the farmers of our country by Lord Bacon; " meadow-watering," according to the statements of this illustrious personage, (given in his Natural History, in the article Vegetation), acts not only by supplying useful moisture to the grass; but likewise the water carries nourishnent dissolved in it, and defends the roots from the effects of cold.

No general principles can be laid down respecting the comparative merit of the different systems of cultivation, and the different systems of crops adopted in different districts, unless the chemical nature of the soil, and the physical circumstances to which it is exposed are fully known. Stiff coherent soils are those most benefited by minute division and aeration, and in the drill system of husbandry, these effects are produced to the greatest 
extent; but still the labour and expense connected with its application in certain districts, may not be compensated for by the advantages produced. Moist climates are best fitted for raising the artificial grasses, oats, and broad-leaved crops; stiff aluminous soils, in general, are most adapted for wheat crops, "and calcareous soils produce excellent sain-foin and clover.

Nothing is more wanting in agriculture, than experiments in which all the circumstances are minutely and scientifically detailed. This art will advance with rapidity in proportion as it becomes exact in its methods. As in physical researches all the causes should he considered; a difference in the results may be produced, even by the fall of a half an inch of rain more or less in the course of a season, or a few degrees of temperature, or even by a slight difference in the sub-soil, or in the inclination of the land.

Information collected after views of distinct enquiry, would necessarily be more accurate, and more capable of being connected with the general principles of science; and a few histories of the results of truly philosophical experiments in agriculiural chemistry, would be of more value in enlightening and benefiting the farmer, than the greatest possible accumulation of imperfect trials, conducted merely in the empirical spirit. It is no unusual occurrence for persons who argue in favour of practice and experience, to condemn generally all at- 
tempts to improve agriculture by philosophical enquiries and chemical methods. That much vague speculation may be found in the works of those who have lightly taken up agricultural chemistry, it is impossible to deny. It is not uncommon to find a number of changes rung upon a string of technical terms, such as oxygene, hydrogene, carbon, and azote, as if the science depended upon words, rather than upon things. But this is in fact an argument for the necessity of the establishment of just principles of chemistry on the subject. Whoever reasons upon agriculture, is obliged to recur to this science. He feels that it is scarcely possible to advance a step without it: and if he is satisfied with insufficient views, it is not because he prefers them to accurate knowledge, but generally because they are more current. If a person journeying in the night wishes to avoid being led astray by the ignis fatuus, the most secure method is to carry a lamp in his own hand.

It has been said, and undoubtedly with great truth, that a philosophical chemist would most probably make a very unprofitable business of farming; and this certainly would be the case, if he were a mere philosophical chemist; and unless he had served his apprenticeship to the practice of the art, as well as to the theory. But there is reason to believe, that he would be a more successful agriculturist than a person equally uninitiated in farming, but iguorant of chemistry altogether; his 
science, as far as it went; would be useful to him. But chemistry is not the only kind of knowledge required, it forms a small part of the philosophical basis of agriculture; but it is an important part, and whenever applied in a proper manner must produce advantages.

In proportion as science advances all the principles become less complicated, and consequently more useful. And it is then that their application is most advantageously made to the arts. The common labourer can never be enlightened by the general doctrines of philosophy, but he will not refuse to adopt any practice, of the utility of which he is fully convinced, because it has been founded upon these principles. The mariner can trust to the compass, though he may be wholly unacquainted with the discoveries of Gilbert on magnetism, or the refined principles of that science developed by the genius of Aipinus. The dyer will use his bleaching liquor, even though he is perhaps ignorant not only of the constitution, but even of the name of the substance on which its powers depend. 'The great purpose of chemical investigation in Agriculture, ought undoubtedly to be the discovery. of improved methods of cultivation. But to this end, general scientific principles and practical knowledge, are alike necessary. The germs of discovery are often found in rational speculations; and industry is never so efficacious as when assisted by science. 
It is from the ligher classes of the community, from the proprietors of land; those who are fitted by their education to form enlightened plans, and by their fortunes to carry such plans into execution; it is from these that the principles of improrement must flow to the labouring classes of the community; and in all cases the benefit is mutual; for the interest of the tenantry must be always likewișe the interest of the proprietors of the soil. 'T'he attention of the labourer will be more minute, and he will exert himself more for improvement when he is certain he cannot deceive his employer, and has a conviction of the extent of his knowledge. Ignorance in the possessor of an estate of the manuer in which it ought to be treated, generally leads either to inattention or injudicious practices in the tenant or the bailiff. "Ayrum pessimum mulctari cujus Dominus non docet sed audit villicum."

There is no idea more unfounded than that a great devotion of time, and a minute knowledge of general chemistry is necessary for pursuing experiments on the nature of soils or the properties of manures. Nothing can be more easy than to discover whether a soil effervesces, or changes colour by the action of an acid, or whether it burns when heated; or what weight it loses by heat: and yet these simple indications may be of great importance in a system of cultivation. The expence connected with chemical enquiries is extremely trifling; a small closet is sufficient for containing all the ma- 
terials required. The most important experiments may be made by means of a small portable apparatus; a few phials, a few acids, a lamp and a crucible are all that are necessary, as I shall endeavour to prove to you, in the course of these lectures.

It undoubtedly happens in agricultural chemical experiments conducted after the most refined theoretical views, that there are many instances of failure, for one of success; and this is inevitable from the capricious and uncertain nature of the causes that operate, and from the impossibility of calculating on all the circumstances that may interfere; but this is far from proving the inutility of such trials; one happy result which can generally improve the methods of cultivation is worth the labour of a whole life; and an unsuccessful experiment well observed, must establish some truth, or tend to remove some prejudice.

Even considered merely as a philosophical science, this department of knowledge is highly worthy of cultivation. For what can be more delightful than to trace the forms of living beings and their adaptations and peculial purposes; to examine the progress of inorganic matter in its different processes of change, till it attain its ultimate and highest destination; its subserviency to the purposes of man.

Many of the sciences are ardently pursued, and considered as proper objects of study for all refined minds, merely on account of the intellectual pleasure they afford; merely because they enlarge our 
views of nature, and enable us to think more correctly with respect to the beings and objects surrounding us. How much more then is this department of enquiry worthy of attention, in which the pleasure resulting from the love of truth and of knowledge is as great as in any other branch of philosophy, and in which it is likewise connected with much greater practical benefits and advantages. "Nihil est melius, nihil uberius, nihil homine libero dignius."

- Discoveries made in the cultivation of the earth, are not merely for the time and country in which they are developed, but they may be considered as extending to future ages, and as ultimately tending to benefit the whole human race; as affording subsistence for generations yet to come; as multiplying life, and not only multiplying life, but likewise providing for its enjoyment. 


\section{LECTURE II.}

Of the general Powers of Matter which infuence Vegetation. Of Gravitation, of Cohesion, of Chemical Attraction, of Heat, of Light, of Electricity, ponderable Substances, Elements of Matter, particularly those found in Vegetables, Laws of their Combinations and Arrangements.

'He great operations of the farmer are directed towards the production or improvement of certain classes of vegetables; they are either mechanical or chemical, and are, consequently, dependent upon the laws which govern common matter. Plants themselves are, to a certain extent, submitted to these laws; and it is necessary to study theireffects, both in considering the phænomena of vegetation, and the cultivation of the vegetable kingdom.

Onee of the most important properties belonging to matter is gravitation, or the power by which. masses of matter are attracted towards each other. It is in consequence of gravitation that bodies: thrown into the atmosphere fall to the surface of 
the earth, and that the different parts of the globe are preserved in their proper positions. Gravity is exerted in proportion to the quantity of matter. Hence all bodies placed above the surface of the earth fall to it in right lines, which if produced would pass through its centre; and a body falling near a high mountain, is a little bent out of the perpendicular direction by the attraction of the mountain, as has been shewn by the experiments of Dr. Maskelyne on Schehallien.

Gravitation has a very important influence on the growth of plants; and it is rendered probable, by the experiments of Mr. Knight, that they owe the peculiar direction of their roots and branches almost entirely to this force.

That gentleman fixed some seeds of the garden bean on the circumference of a wheel, which in one instance was placed vertically, and in the other horizontally, and made to revolve, by means of another wheel worked by water, in such a manner, that the number of the revolutions could be regulated; the beans were supplied with moisture, and were placed under circumstances favourable to germination. The greatest velocity of motion given to the wheel was such, that it performed two hundred and fifty revolutions in a minute. It was found that in all cases the beans grew, and that the direction of the roots and stems was influenced by the motion of the wheel. When the centrifugal force was made superior to the force of gravitation, 


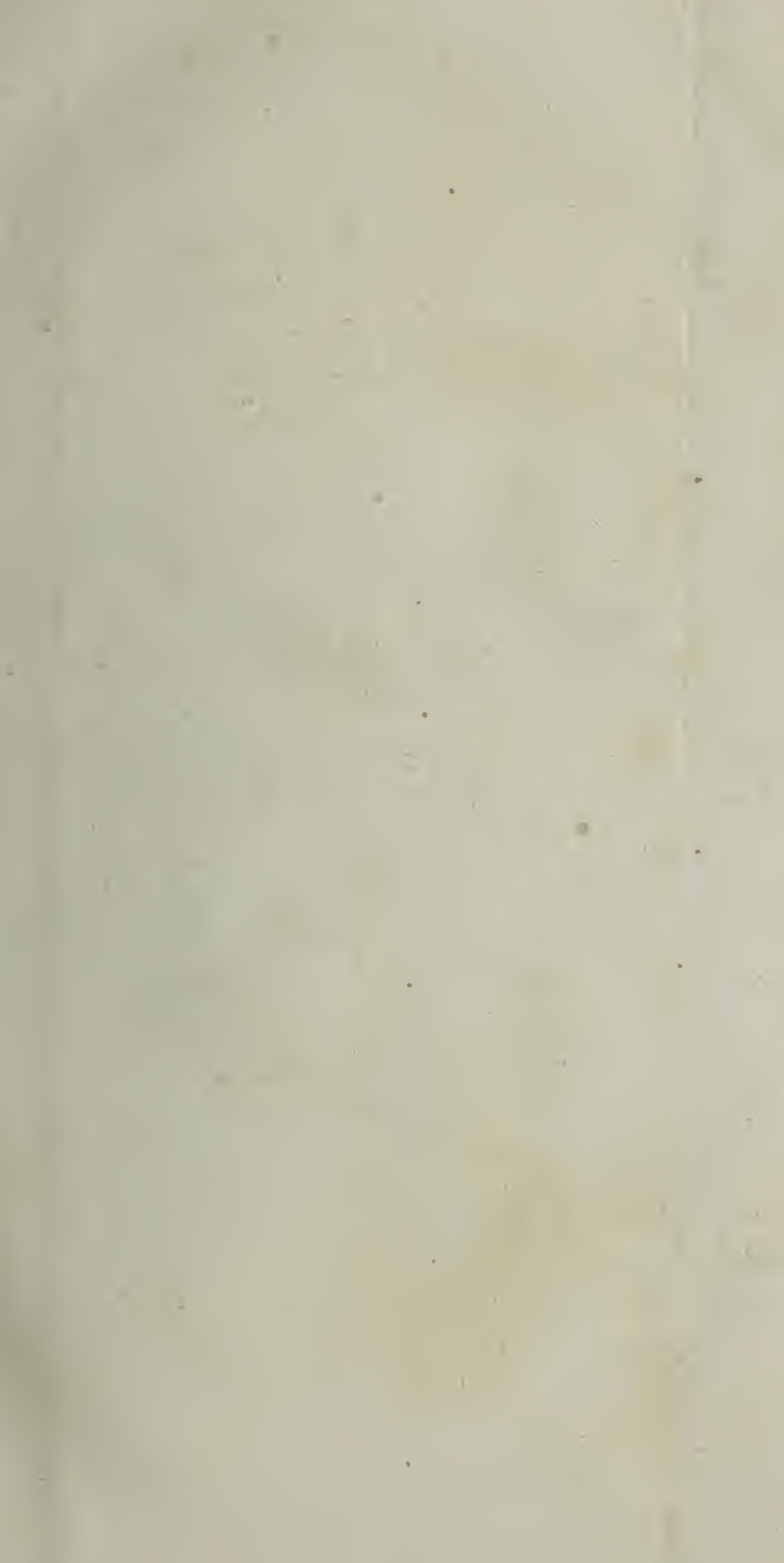



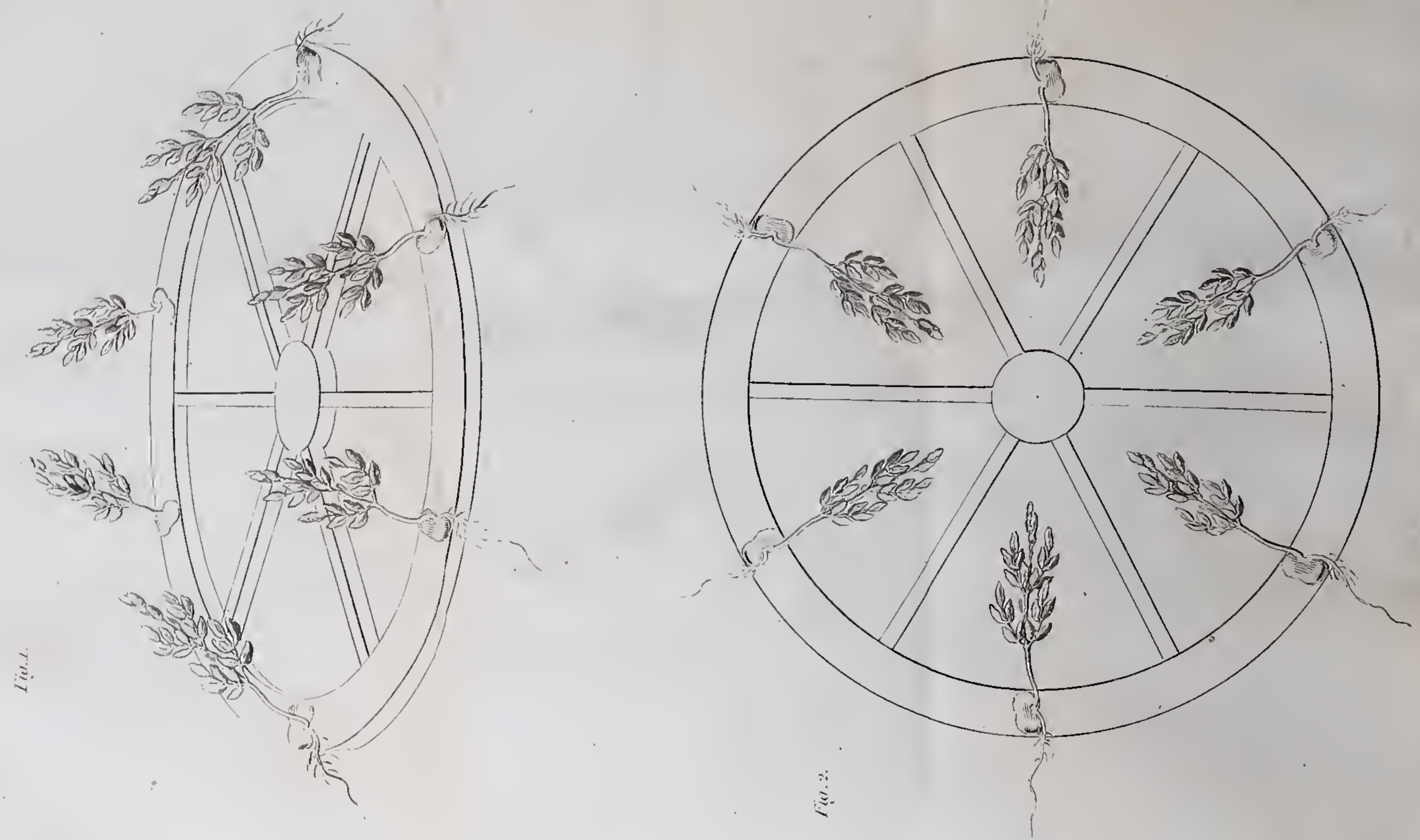
which was supposed to be done when the vertical wheel performed 150 revolutions in a minute, all the radicles, in whatever way they were protruded from the position of the seeds, turned their points outwards from the circumference of the wheel, and in their subsequent growth receded nearly at right angles from its axis; the germens, on the contrary, took the opposite direction, and in a few days their points all met in the centre of the wheel.

When the centrifugal force was made merely to modify the force of gravitation in the horizontal wheel, where the greatest velocity of revolution was given, the radicles pointed downwards about ten degrees below, and the germens as many degrees above the horizontal line of the wheel's motion; and the deviation from the perpendicnlar was less in proportion, as the motion was less rapid *.

These facts afford a rational solution of this curious problem, respecting which different philosophers have given such different opinions; some referring it to the nature of the sap, as De la Hire, others, as Darwin, to the living powers of the plant, and the stimulus of air upon the leaves, and of moisture upon the roots. The effect is now

* Fig. 1 represents the form of the experiment when the horizontal wheel was made to perform 250 revolutions in a minute.

Fig. 2 represents the case in which the vertical wheel performed 150 revolutions. 
shewn to be connected with mechanical causes; and there seems no other power in nature to which it can with propriety be referred but gravity, which acts universally, and which must tend to dispose the parts to take a uniform direction.

If plants in general owe their perpendicular direction to gravity, it is evident that the number of plants upon a given part of the earth's circumference, cannot be increased by making the surface irregular, as some persons have supposed. Nor can more stalks rise on a hill than on a spot equal to its base; for the slight effect of the attraction of the hill, would be only to make the plants deviate a very little from the perpendicular. Where horizontal layers are pushed forth, as in certain grasses, particularly such as the fiorin, lately brought into notice by Dr. Richardson, more food may, however, be produced upon an irregular surface; but the principle seems to apply strictly to corn crops.

The direction of the radicles and germens is such, that both are supplied with food, and acted upon by those external agents which are necessary for their development and growth. The roots come in contact with the fluids in the ground; the leaves are exposed to light and air; and the same grand law which preserves the planets in their orbits, is thus essential to the functions of regetable life.

When two pieces of polished glass are pressed together they adhere to each other, and it requires 
some force to separate them. This is said to depend upon the attraction of cohesion. The same attraction gives the globular form to drops of water, and enables fluids to rise in capillary tubes; and hence it is sometimes called capillary attraction. This attraction, like gravitation, seems common to all matter, and may be a modification of the same general force; like gravitation, it is of great importance in vegetation. It preserves the forms of aggregation of the parts of plants, and it seems to be a principal cause of the absorption of fluids by their roots.

If some pure magnesia, the calcined magnesia of druggists, be thrown into distilled vinegar, it gradually dissolves. This is said to be owing to chemical attraction, the power by which different species of matter tend to unite into one compound. Various kinds of matter unite with different degrees of force: thus sulphuric acid and magnesia unite with more readiness than distilled vinegar and magnesia; and if sulphuric acid be poured into a mixture of vinegar and magnesia, in which the acid properties of the vinegar have been destroyed by the magnesia, the vinegar will be set free, and the sulphuric acid will take its place. This chemical attraction is likewise called chemical affinity. It is active in most of the phænomena of vegetation. The sap consists of a number of ingredients, dissulved in water by chemical attraction; and it appears to be in consequence of the operation of

D 2 
this power, that certain principles derived from the sap are united to the vegetable organs. By the laws of chemical attraction, different products of vegetation are changed, and assume new forms: the food of plants is prepared in the soil; vegetable and animal remains are changed by the action of air and water, and made fuid or aeriform; rocks are broken down and converted into soils; and soils are more finely divided and fitted as receptacles for the roots of plants.

The different powers of attraction tend to preserve the arrangements of matter, or to unite them in new forms. If there were no opposing powers, there would soon be a state of perfect quiescence in nature, a kind of eternal sleep in the physical world. Gravitation is continually counteracted by mechanical agencies, by projectile motion, or the centrifugal force; and their joint agencies occasion the motion of the heavenly bodies. Cohesion and chemical attraction are opposed by the repulsive energy of heat, and the harmonious cycle of terrestrial changes is produced by their mutual operations.

Heat is capable of being communicated from one body to other bodies; and its common effect is to expand them, to enlarge them in all their dimensions. This is easily exemplified. A solid cylinder of metal after being heated will not pass through a ring barely sufficient to receive it when cold. When water is heated in a globe of glass having 2 
long slender neck, it rises in the neck; and if heat be applied to air confined in such a vessel inverted above water, it makes its escape from the vessel and passes through the water. Thermometers are instruments for measuring degrees of heat by the expansion of fluids in narrow tubes. Mercury is generally used, of which 100,000 parts at the freezing point of water become 101,835 parts at the boiling point, and on Fahrenheit's scale these parts are divided into 180 degrees. Solids, by a certain increase of heat, become fluids, and fluids gasses, or elastic fluids. Thus ice is converted by heat into water, and by still more heat it becomes steam : and heat disappears, or, as it is called, is rendered latent during the conversion of solids into fluids, or fluids into gasses, and reappears or becomes sensible when gasses become fluids, or fluids solids: hence cold is produced during evaporation, and heat during the condensation of steam.

There are a few exceptions to the law of expansion of bodies by heat, which seem to depend either upon some change in their chemical constitution, or on their becoming crystallized. Clay contracts by heat, which seems to be owing to its giving off water. Cast iron and antimony, when melted, crystallize in cooling and expand. Ice is much lighter than water, Water expands a little even before it freezes, and it is of the greatest density at about $41^{\circ}$ or $42^{\circ}$, the freezing point being $32^{\circ}$; and this circumstance is of considerable importance in the ge- 
neral economy of nature. The influence of the changes of seasons and of the position of the sun on the phenomena of vegetation, demonstrates the effects of heat on the functions of plants. The matter absorbed from the soil must be in a fluid state to pass into their roots, and when the surface is frozen they can derive no nourishment from it. The activity of chemical changes likewise is increased by a certain increase of temperature, and even the rapidity of the ascent of fluids by capillary attraction.

This last fact is easily shewn by placing in each of two wine glasses a similar hollow stalk of grass, so bent as to discharge any fluid in the glasses slowly by capillary attraction; if hot water be in one glass, and cold water in the other, the hot water will be discharged much more rapidly than the cold water. The fermentation and decomposition of animal and vegetable substances require a certain degree of heat, which is consequently necessary for the preparation of the food of plants; and as evaporation is more rapid in proportion as the temperature is higher, the superfluous parts of the sap are most readily carried off at the time its ascent is quickest.

Two opinions are current respecting the nature of heat. By some philosophers it is conceived to be a peculiar subtile fluid, of which the particles repel each other, but have a strong attraction for the particles of other matter. By others it is consi. 
dered as a motion or vibration of the particles of matter, which is supposed to differ in velocity in different cases, and thus to produce the different legrees of temperature. Whatever decision be ultimately made respecting these opinions, it is certain that there is matter moving in the space between us and the heavenly bodies capable of communicating heat; the motions of which are rectilineal: thus the solar rays produce heat in acting on the surface of the earth. The beautiful experiments of Dr. Herschel have shewn that there are rays transmitted from the sun which do not illuminate; and which yet produce more heat than the visible rays; and Mr. Ritter and Dr. Wollaston have shewn that there are other invisible rays distinguished by their chemical effects.

The different influence of the different solar rays on vegetation have not yet been studied; but it is certain that the rays exercise an influence independent of the heat they produce. Thus plants kept in the dark in a hot-house grow luxuriantly, but they never gain their natural colours; their leaves are white or pale, and their juices watery and peculiarly saccharine.

When a piece of sealing-wax is rubbed by woollen cloth, it gains the power of attracting light bodies, such as feathers or ashes. In this state it is said to be electrical; and if a metallic cylinder, placed upon a rod of glass, is brought in contact with the sealing-wax, it likewise gains the momen- 
tary power of attracting light bodies, so that electricity, like heat, is communicable. When two light bodies receive the same electrical influence, or are electrified by the same body, they repel each other. When one of them is acted on by sealingwax, and the other by glass that has been rubbed by woollen, they attract each other; hence it is said, that bodies similarly electrified repel each other, and bodies dissimilarly electrified attract each other: and the electricity of glass is called vitreous or positive electricity, and that of sealingwax resinous or negative electricity.

When of two bodies made to rub each other one is found positively electrified, the other is always found negatively electrified, and, as in the common electrical machine, these states are capable of being communicated to metals placed upon rods or pillars of glass. Electricity is produced likewise by the contact of bodies; thus a piece of zinc and of silver give a slight electrical shock when they are made to touch each other, and to touch the tongue: and when a number of plates of copper and zinc, 100 for instance, are arranged in a pile with cloths moistened in salt and water, in the order of zinc, copper, moistened clath, zinc, copper, moistened cloth, and so on, they form an electrical battery which will give strong shocks and sparks, and which is possessed of remarkable chemical powers. 'The luminous phænomena produced by common electricity are well known. It would be 
improper to dwell upon them in this place. They are the most impressive effects occasioned by this agent; and they offer illustrations of lightning and thunder.

Electrical changes are constantly taking place in nature, on the surface of the earth, and in the atmosphere; but as yet the effects of this power in vegetation have not been correctly estimated. It has been shewn by experiments made by means of the Voltaic' battery (the instrument composed of zinc, copper, and water), that compound bodies in general are capable of being decomposed by electrical powers, and it is probable, that the various electrical phænomena occurring in our system, must influence both the germination of seeds and the growth of plants. I found that corn sprouted much more rapidly in water positively electrified by the Voltaic instrument, than in water negatively electrified; and experiments made upon the atmosphere shew that clouds are usually negative; and as when a cloud is in one state of electricity, the surface of the earth beueath is brought into the opposite state, it is probable that in common cases the surface of the earth is positive.

Different opinions are entertained amongst scientific men respecting the nature of electricity; by some, the phænomena are conceived to depend upon a single subtile fluid in excess in the bodies, said to be positively electrified, in deficiency in the bodies said to be negatively electrified. A second 
class suppose the effects to be produced by two different fluids, called by them the vitreous fluid and the resinous fluid; and others regard them as affections or motions of matter, or an exhibition of attractive powers, similar to those which produce chemical combination and decomposition; but usually exerting their action on masses.

The different powers that have been thus generally described, continually act upon common matter, so as to change its form, and produce arrangements fitted for the purposes of life. Bodies are either simple or compound. A borly is said to be simple, when it is incapable of being resolved into any other forms of matter. Thus gold, or silver, though they may be melted by heat, or dissolved in corrosive menstrua, yet are recovered unchanged in their properties, and they are said to be simple bodies. A body is considered as compound, when two or more distinct substances are capable of being produced from it; thus marble is a compound body, for by a strong heat, it is converted into lime, and an elastic fluid is disengaged in the process : and the proof of our knowledge of the true composition of a body is, that it is capable of being reproduced by the same substances as those into which it had been decomposed; thus by exposing lime for a long while to the elastic fluid, disengaged during its calc uation, it becomes converted into a substance similar to powdered marble. The term element has the same meaning as simple or unde- 
compounded body; but it is applied merely with reference to the present state of chemical knowledge. It is probable, that as yet we are not acquainted with any of the true elements of matter; many substances, formerly supposed to be simple, havé been lately decompounded, and the chemical arrangement of bodies must be considered as a mere expression of facts, the results of accurate statical experiments.

Vegetable substances in general are of a very compound nature, and consist of a great number of elements, most of which belong likewise to the other kingdoms: of nature, and are found in various forms. Their more complicated arrangements are best understood after their simpler forms of combination have been examined.

The number of bodies which I shall consider as at present undecomposed, are, as was stated in the introductory lecture, three acidifying - and solvent substances, six inflammable bodies, and thirty-eight metals.

In most of the inorganic compounds, the nature of which is well known, into which these elements enter, they are combined in definite proportions; sa that if the elements be represented by numbers, the proportions in which they combine are expressed either by those numbers, or by some simple multiples of them.

I shall mention, in a few words, the characteristic properties of the most important simple sub- 
stances, and the numbers representing the proportions in which they combine in those cases, where they have been accurately ascertained.

1. Oxygene forms about one-fifth of the air of our atmosphere. It is an elastic fluid, at all known temperatures. Its specific gravity is to that of air as 10967 to 10000 . It supports combustion with much more vividness than common air; so that if a small steel wire, or a watch-spring, having a bit of inflamed wood attached to it, be introduced into a bottle filled with the gas, it burns with great splendour. It is respirable. It is very slightly soluble in water. The number representing the proportion in which it combines is 15 . It may be made by heating a mixture of the mineral called manganese, and sulphuric acid together, in a proper vessel, or by heating strongly red lead, or red precipitate of mercury.

2. Chlorine, or oxymuriatic gas, is, like oxygene, a permanent elastic fluid. Its colour is yellowish green; its smell is very disagreeable; it is not respirable; it supports the combustion of all the common inflammable bodies except charcoal; its specific gravity is to that of air as 24677 to 10000 ; it is soluble in about half its volume of water, and its solution in water destroys vegetable colours. Many of the metals (such as arsenic or copper) take fire spontaneously when introduced into a jar or bottle filled with the gas. Chlorine may be procured by heating together a mixture of spirits of 
salt or muriatic acid, and manganese. The number representing the proportion in which this gas enter's into combination is 67.

3. Fluorine, or the fluoric principle. This substance has such strong tendencies of combination, that as yet, no ressels have been found capable of containing it in its pure form. It may be obtained combined with hydrogen, by applying heat to a mixture of fluor or Derbyshire spar, and sulphuric acid, and in this state it is an intensely acid compound, a little heavier than water, and which becomes still denser by combining with water.

4. Hydrogene, or inflammable air, is the lightest known substance; its specific gravity is to that of air as 732 to 10000 . It burns by the action of an inflamed taper, when in contact with the atmosphere. Tha proportion in which it combines is represented by unity, or $\mathbf{I}$. It is procured by the action of diluted oil of vitriol, or hydro-sulphuric acid on filings of zinc or iron. It is the substance employed for filling air balloons.

5. Azote is a gaseous substance, not capable of being condensed by any known degree of cold: its specific gravity is to that of common air as 9516 to 10000. It does not enter into combustion under common circumstances, but may be made to unite with oxygen by the agency of electrical fire. It forms nearly four-fifths of the air of the atmosphere; and may be procured by burning phosphorus in a 
confined portion of air. The number representing the proportion in which it combines is 26.

6. Carbon is considered as the pure matter of char. coal, and it may be procured by passing spirits of wine throigh a tube heated red. It has not yet been fused; but rises in vapour at an intense heat. Its specific gravity cannot be easily ascertained; but that of the diamond, which cannot chemically be distinguished from pure carbon, is to that of water as 3500 to 1000 . Charcoal has the remarkable property of absorbing several times its volume of different elastic fluids, which are capable of being expelled from it by heat. The number representing it is 11.4.

7. Sulphur is the pure substance so well known by that name: its specific gravity is to that of water as 1990 to 1000 . It fuses at about $220^{\circ} \mathrm{Fah}$ renheit; and at between $500^{\circ}$ and $600^{\circ}$ takes fire, if in contact with the air, and burns with a pale blue flame. In this process it dissolves in the oxygene of the air, and produces a peculiar acid elastic fluid. The number representing it is 30 .

8. Phosphorus is a solid of a pale red colour, of specific gravity 1750 . It fuses at $90^{\circ}$, and boils at $550^{\circ}$. It is luminous in the air at common temperatures, and burns with great violence at $150^{\circ}$, so that it must be handled with great caution. The number representing it is 20 . It is procured by digesting together bone ashes and oil of vitriol, and 
strongly heating the fluid substance so produced with powdered cliarcoal.

9. Boron is a solid of a dark olive colour, infusible at any known temperature. It is a substance very lately discovered, and procured from boracic acid. It burns with brilliant sparks, when heated in oxygene, but not in chlorine. Its specific gravity, and the number representing it, are not yet accurately known.

10. Platinum is one of the noble metals, of rather a duller white than silver, and the heaviest body in nature; its specific gravity being 21500 . It is not acted upon by any acid menstrua except such as contain chlorine: it requires an intense degree of heat for its fusion.

11. The properties of gold are well known. Its specific gravity is 19277 . It bear's the same relation to acid menstrua as platinum: it is one of the characteristics of both these bodies, that they are very difficultly acted upon by sulphur.

12. Silver is of specific gravity 10400 , it burns more readily than platinum or gold, which require the intense heat of electricity. It readily unites to sulphur. The number representing it is 205 .

13. Mercury is the only known metal fluid at the common temperature of the atmosphere; it boils at $660^{\circ}$, and freezes at 39 below 0 . Its specific gravity is 13560 . The number representing it is 380 .

14. Copper is of specific gravity 8890 . It burns 
when strongly heated with red flame tinged with green. The number representing it is $\mathbf{1 2 0}$.

15. Cobalt is of specific gravity 7700. Its point of fusion is very high, nearly equal to that of iron. In its calcined or oxidated state, it is employed for giving a blue colour to glass.

16. Nickel is of a white colour: its specific gravity is 8820 . This metal and cobalt agree with iron, in being attractible by the magnet. The number representing nickel is 111 .

17. Iron is of specific gravity $7 \% 00$. Its other properties are well known. The number representing it is 103 .

18. Tin is of specific gravity 7291 ; it is a very fusible metal, and burns when ignited in the air : the number representing the proportion in which it combines is 110 .

19. Zinc is one of the most combustible of the common metals. Its specific gravity is about 7210 . It is a brittle metal under common circumstances; but when heated may be hammered or rolled into thin leaves, and after this operation is malleable. The number representing it is 66 .

20. Lead is of specific gravity 11352 ; it fuses at a temperature rather higher than tin. The number representing it is 398 .

21. Bismuth is a brittle metal of specific gravity 9822. It is nearly as fusible as tin; when cooled slowly it crystallizes in cubes. The number representing it is 135 . 
22. Antimony is a metal capable of being volatilized by a strong heat. Its specific gravity is 6800 . It burns when ignited with a faint white light. The number representing it is $\mathbf{1 7 0}$.

23. Arsenic is of a blueish white colour, of specific gravity $8: 310$. It may be procured by heating the powder of common white arsenic of the shops strongly in a Florence flask with oil. The metal rises in vapour, and condenses in the neck of the flask. The number representing it is $\mathbf{9 0}$.

21. Manganesum may be procured from the mineral called manganese, by intensely igniting it in a forge mixed with charcoal powder. It is a metal very difficult of fusion, and very combustible; its specific gravity is 6850 . The number representing it is $17 \%$.

25. Potassium is the lightest known metal, being only of specific gravity 850 . It fuses at about $150^{\circ}$, and rises in vapour at a heat a little below redness. It is a highly combustible substance, takes fire when thrown upon water, burns with great brilliancy, and the product of its combustion dissolves in the water. The number representing it is 75. It may be made by passing fused caustic vegetable alkali, the pure kali of druggists, through iron turnings strongly ignited in a gun barrel, or by the electrization of potash by a strong Voltaic battery.

26. Sodium may be made in a similar manner to potassium. Soda, or the mineral alkali, being substituted for the vegetable alkali. It is of specific 
gravity 940. It is very combustible. When thrown upon water, it swims on its surface, hisses violently, and dissolves, but does not inflame. The number representing it is 88 .

27. Barium has as yet been procured only by electrical powers and in very minute quantities, so that its properties have not been accurately cxamined. "The number representing it appears to be 130.

Strontium the 2Sth, Calcium the 29th, Magnesium the 30th, Silicum the 31st, Aluminum the 32d, Zirconum the 33d, Glucinum the 34th, and Ittrium the 35th of the undecompounded bodies, like barium, have either not been procured absolutely pure, or only in such minute quantities that their properties are little known; they are formed either by electrical powers, or by the agency of potassium, from the different earths whose names they bear, with the change of the termination in $u \mathrm{~m}$; and the numbers representing them are believed to be 90 strontium, 40 calcium, 38 magnesium, 31 silicum, 33 aluminum, 70 zirconum, 39 glucinum, 111 ittritum.

Of the remaining simple bodies, twelve are metals, most of which, like those just mentioned, can only be procured with very great difficulty; and the substances in general from which they are procured are very rare in nature. They are Palladium, Rhodium, Osmium, Iridium, Columbium, Chromium, Molybdenum, Cerium, Tellurium, Tungs- 


\section{1}

tenum, Titanium, Uranium. The numbers repre senting these last bodies have not yet been determined with sufficient accuracy to render a reference to them of any utility.

The undecompounded substances unite with each other, and the most remarkable compounds are formed by the combinations of oxygene and chlorine with inflammable bodies and metals: and these combinations usually take place with much energy, and are associated with fire.

Combustion in fact, in common cases, is the process of the solution of a body in oxygene, as happens when sulphur or charcoal is burnt; or the fixation of oxygene by the combustible body in a solid form, which takes place when most metals are burnt, or when phosphorus inflames; or the production of a fluid from both bodies, as when hydrogene and oxygene unite to form water.

When considerable quantities of oxygene or of chlorine unite to metals or inflammable bodies, they often produce acids : thus sulphureous, phosphoric, and boracic acids are formed by a union of considerable quantities of oxygene with sulphur, phosphorus, and boron: and muriatic acid gas is formed by the union of chlorine and hydrogene.

When smaller quantities of oxygene or chlorine unite with inflammable bodies or metals, they form substances not acid, and more or less soluble in water; and the metallic oxides, the fixed alkalies, 
and the earths, all bodies connected by analogies, are prorluced by the union of metals with oxygene.

The composition of any compounds, the nature of which is well known, may be easily learnt from the numbers representing their elements; all that is necessary, is to know how many proportions enter into union. Thus potassa, or the pure caustic vegetable alkali, consists of one proportion of potassium and one of oxygene, and its constitution is consequently 75 potassium, 15 oxygene.

Carbonic acid is composed of two proportions of oxygene 30 , and one of carbon 11.4.

Again, lime consists of one proportion of calcium and one of oxygene, and it is composed of 40 of calcium and 15 of oxygene. And carbonate of lime, or pure chalk, consists of one proportion of carbonic acid 41.4 , and one of lime 55 .

Water consists of two proportions of hydrogene 2 , and one of oxygene 15; and when water unites to other bodies in definite proportions, the quantity is 17 , or some multiple of $17, i . e .34$ or $5 !$, or 68 , \&c.

Soda, or the mineral alkali, contains two proportions of oxygene to one of sodium.

Ammonia, or the volatile alkali, is composed of six proportions of liydrogene and one of azote.

Amongst the earths, Silica, or the earth of flints, probably consists of two proportions of oxygene to one of silicum; and Magnesia, Strontia, Baryta or 
Barytes, Alumina, Zircona, Glucina, and Ittria, of one proportion of metal and one of oxygene.

The metallic oxides in general consist of the metals united to from one to four proportions of oxygene; and there are, in some cases, many different oxides of the same metal; thus there are three oxides of lead; the yellow oxide, or massicot, contains two proportions of oxygene; the red oxide, or minium, three; and the puce coloured oxide four proportions. Again there are two oxides of copper, the black and the orange; the black contains two proportions of oxygene, the orange one.

For pursuing such experiments on the composition of hodies as are connected with agricultural chemistry, a few only of the undecompounded substances are necessary ; and amongst the compounded bodies, the common acids, the alkalies, and the earths, are the most essential substances. The elements found in vegetables, as has been stated in the introductory lecture, are very few. Oxygene, hydrogene, and carbon, constitute the greatest part of their organized matter. Azote, phosphorus, sulphur, manganesum, iron, silicum, calcium, aluminum, and magnesium likewise, in different arrangements, enter into their composition, or are found in the agents to which they are exposed; and these twelve undecompounded substances are the elements, the study of which is of the most importance to the agricultural chemist.

The doctrine of definite combinations, as will be 
shewn in the following lectures, will assist us in gaining just views respecting the composition of plants, and the economy of the vegetable kingdom; but the same accuracy of weight and measure, the same statical results which depend upon the uniformity of the laws that govern dead matter, cannot be expected in operations where the powers of life are concerned, and where a diversity of organs and of functions exists. The classes of definite inorganic bodies, even if we include all the crystalline arrangements of the mineral kingdom, are few, compared with the forms and subsitances belonging to animated nature. Life gives a peculiar character to all its productions; the power of attraction and repulsion, combination and decomposition, are subservient to it; a few elements, by the diversity of their arrangement, are made to form the most different substances; and similar substances are produced from compounds, which, when superficially examined, appear entirely different. 


\section{5}

\section{LECTURE III.}

On the Organization of Plants. Of the Roots, Trunk, and Branches. Of their Structure. Of the Epidermis. Of the cortical and alburnous Parts of Leaves, Floners, and Seeds. Of the chemical Constitution of the Organs of Plants, and the Substances found in them. Of mucilaginous, saccharine, extractive, resinous, and oily Substances, and other vegetable Compounds, their Arrangements in, the Organs of Plants, their Composition, Changes, and Uses.

VARIETY characterises the vegetable kingdom, yet there is an analogy between the forms and the functions of all the different classes of plants, and on this analogy the scientific principles relating to their organization depend.

Vegetables are living structures distinguished from animals by exhibiting no signs of perception, or of voluntary motion; and their organs are either organs of nourishment or of reproduction; organs for the preservation and increase of the individual, or for the multiplication of the species.

In the living vegetable system there are to be 
considered, the exterior form, and the interior constitution.

Every plant examined as to external structure, displays at least four systems of organs, or some analogous parts. First, the Root; secondly, the Trunk and Branches, or Stem; thirdly, the Leaves; and, fourthly, the Flowers or Seeds.

The root is that part of the regetable which least impresses the eye; but it is absolutely necessary. It attaches the plant to the surface, is its organ of nourishment, and the apparatus by which it imbibes food from the soil. The roots of plants, in their anatomical division, are very similar to the trunk and branches. The root may indeed be said to be a continuation of the trunk terminating in minute ramifications and filaments, and not in leaves; and by burying the branches of certain trees in the soil, and elevating the roots in the atmosphere, there is, as it were, an inversion of the functions, the roots produce buds and leaves, and the branches shoot out into radical fibres and tubes. This experiment was made by Woodward on the willow, and has been repeated by a number of physiologists.

When the branch or the root of a tree is cut transversely, it usually exhibits three distinct bodies: the bark, the wood, and the pith; and these again are individually susceptible of a new division.

The bark, when perfectly formed, is covered by a thin cuticle or epidermis, which may be easily 
separated. It is generally composed of a number of laminæ or scales, which in old trees are usually in a loose and decaying state. The epidermis is not vascular, and it merely defends the interior parts fiom injury. In forest trees, and in the largei shrubs, the bodies of which are firm, and of strong texture, it is a part of little importance; but in the reeds, the grasses, canes, and the plants having hollow stalks, it is of great use, and is exceedingly strong, and in the microscope secms composed of a kind of glassy net-work, which is principally siliceous earth.

This is the case in wheat, in the oat, in different species of equisetum, and, abrove all, in the rattan, the epidermis of which contains a sufficient quantity of flint to give light when struck by steel; or two pieces rubbed together produce sparks. This fact first occurred to me in 1798, and it led to experiments, by which $I$ ascertained that siliceous earth existed generally in the epidermis of the hollow plants.

The siliceous epidermis serves as a support, protects the bark from the action of insects, and seems to perform a part in the economy of these feeble vegetable tribes, similar to that performed in the animal kingdom by the shell of the crustaceous insects.

Immediately beneath the epidermis is the parenchyma. It is a soft substance consisting of cells flled with fluid, having almost always a greenish 
tint. The cells in the parenchymatous part, when examined by the microscope, appear hexagonal. This form, indeed, is that usually affected by the cellular membranes in vegetables, and it seems to be the result of the general re-action of the solid parts, similar to that which takes place in the honey-comb. This arrangement, which has usually been ascribed to the skill and artifice of the bee, seems, as Dr. Wollaston has observed, to be merely the result of the mechanical laws which influence the pressure of cylinders composed of soft materials, the nests of solitary bees heing uniformly circular.

The innermost part of the bark is constituted by the cortical layers, and their numbers vary with the age of the tree. On cutting the bark of a tree of several years standing, the productions of different periods may be distinctly seen, though the layer of every particular year can seldom be accurately defined.

'The cortical layers are composed of fibrous parts which appear interwoven, and which are transverse and longitudinal. 'T'he transverse are membranous and porous, and the longitudinal are generally composed of tubes.

The functions of the parenchymatous and cortical parts of the bark are of great importance. The tubes of the fibrous parts appear to be the organs that receive the sap; the cells seem destined for the elaboration of its parts, and for the exposure of them to the action of the atmosphere, and the new 

Vi:MY

MII:-

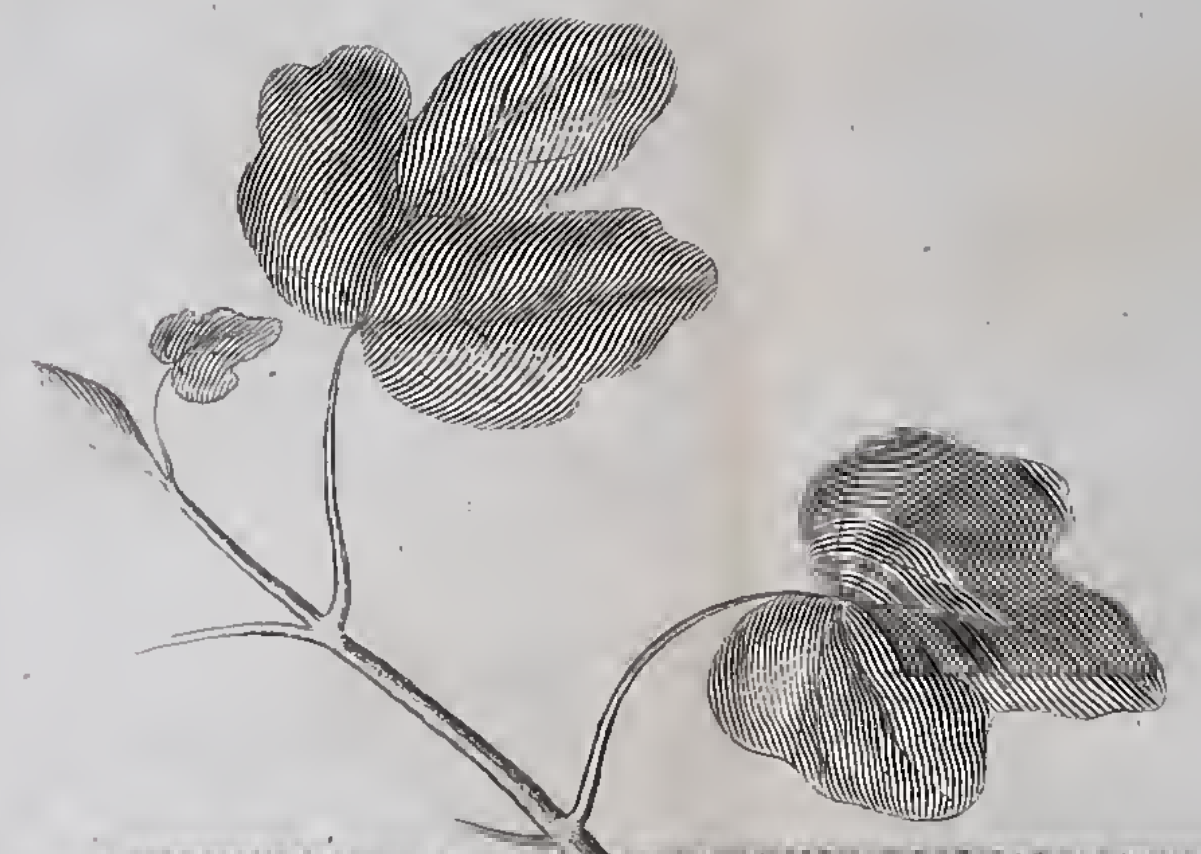

ㅂ.MII:

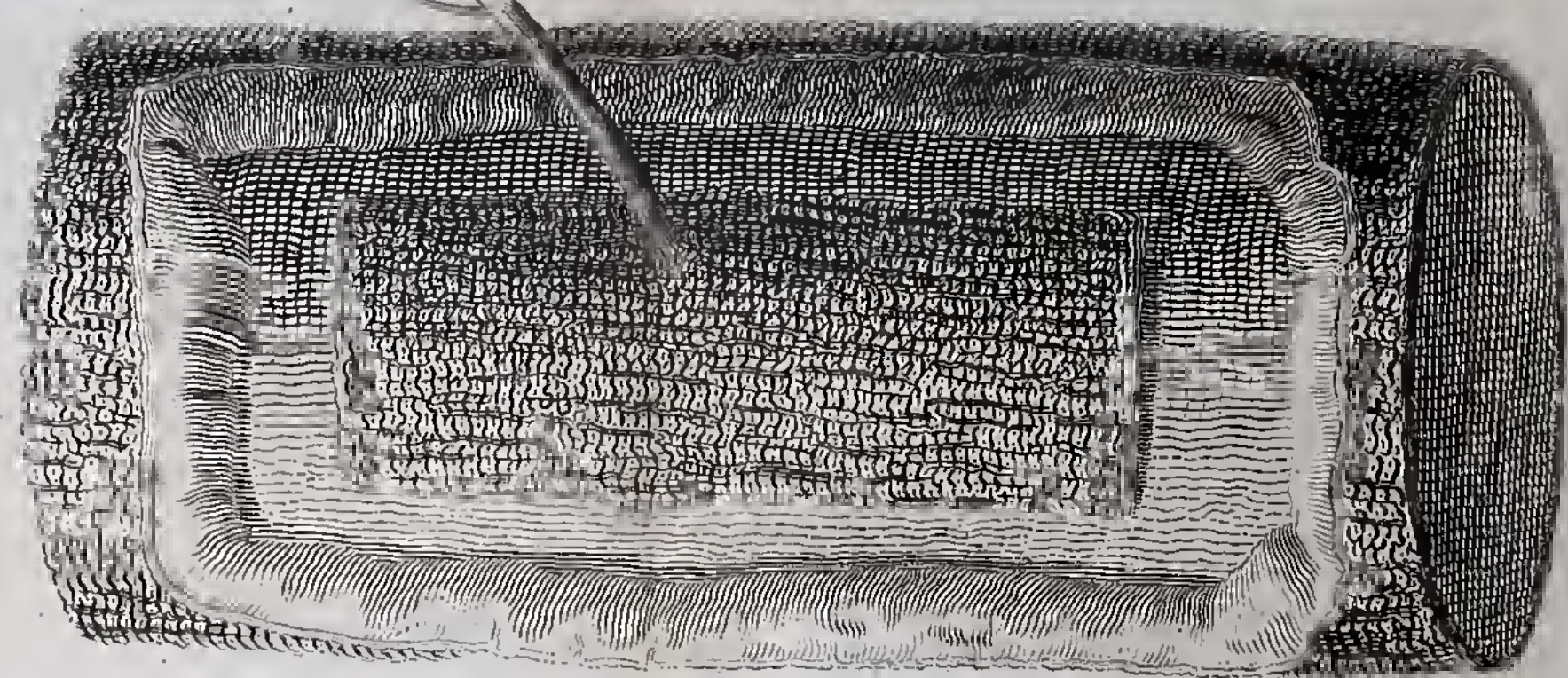

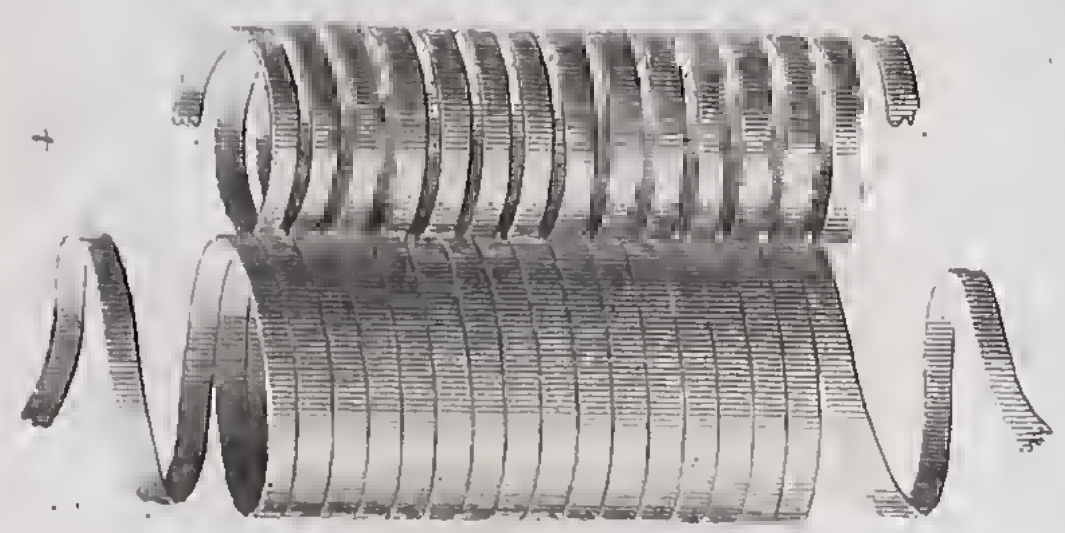

今 
matter is annually produced in the spring, immediately on the inner surface of the cortical layer of the last year.

It has been shewn by the experiments of Mr. Knight, and those made by other physiologists, that the sap descending through the bark after being modified in the leaves, is the principal cause of the growth of the tree; thus, if the bark is wounded, the principal formation of new bark is on the upper edge of the wound; and when the wood has been removed, the formation of new wood takes place immediately beneath the bark: yet it would appear from the late observations of $\mathbf{M}$. Palisot de Beauvois, that the sap may be transferred to the bark, so as to exert its nutritive functions, independent of any general system of circulation. That gentleman separated different portion of bark from the rest of the bark in several trees, and found that in most instances the separated bark grew in the same manner as the bark in its natural state. The experiment was tried with most success on the lime-tree, the maple, and the lilac; the layers of bark were removed in August 1810, and in the spring of the next year, in the case of the maple and the lilac, small annual shoots were prodnced in the parts where the bark was insulated.*

The wood of trees is composed of an external

* Fig. 3 represents the result of the experiment on the maple. Journal de Physique, September 1811, page 210. 
or living part, called alburnum, or sap-wood, and of an internal or dead part, the heart-wood. The alburnum is white, and full of moisture, and in young trees and annual shoots it reaches even to the pith. The alburnum is the great vascular system of the vegetable through which the sap rises, and the vessels in it extend from the leaves to the minutest filaments in the roots.

There is in the alburnum a membranous substance composed of cells, which are constantly filled with the sap of the plant, and there are in the vascular system several different kinds of tubes; Mirbel has distinguished four species, the simple tubes, the porous tubcs, the trachea, and the false trachea.*

The tubes, which he has called simple tubes, seem to contain the resinous or oily fluids peculiar to different plants.

The porous tubes likewise contain these fluids; and their use is probably that of conveying them into the sap for the production of new arrangements.

The tracheæ contain fluid matter, which is always thin, watery, and pellucid, and these organs, as well as the false tracheæ, probably carry off water from the denser juices, which are thus enabled to consolidate for the production of new wood.

In the arrangement of the fibres of the wood,

* Fig. 4, 5, 6, and 7, represent Mirbel's idea of the simple tubes, the porous tubes, the tracher, and the false tracher. 

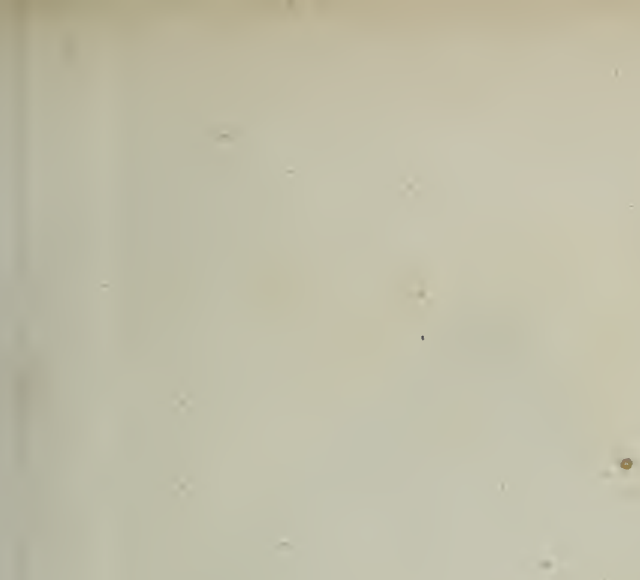


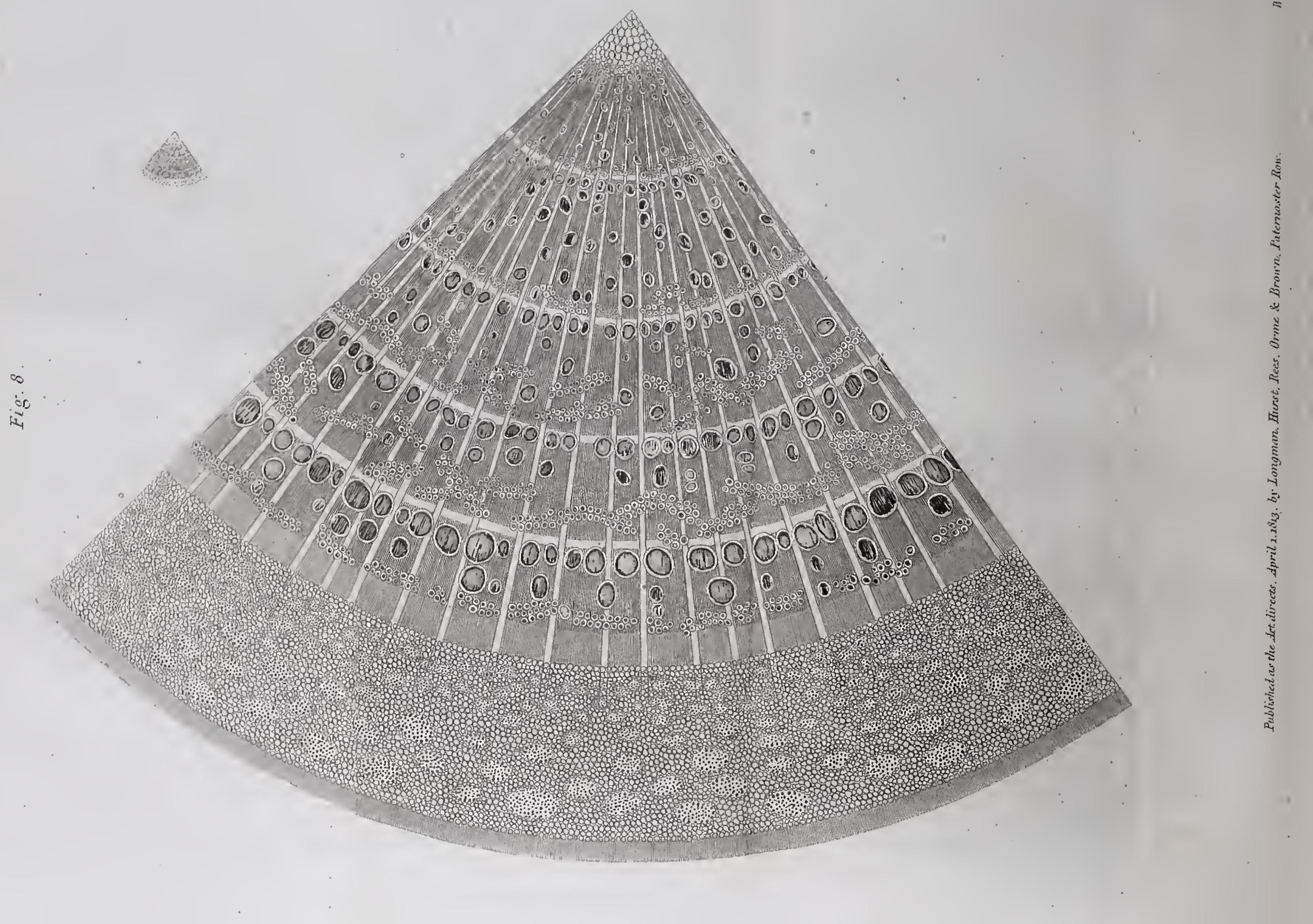





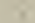

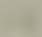
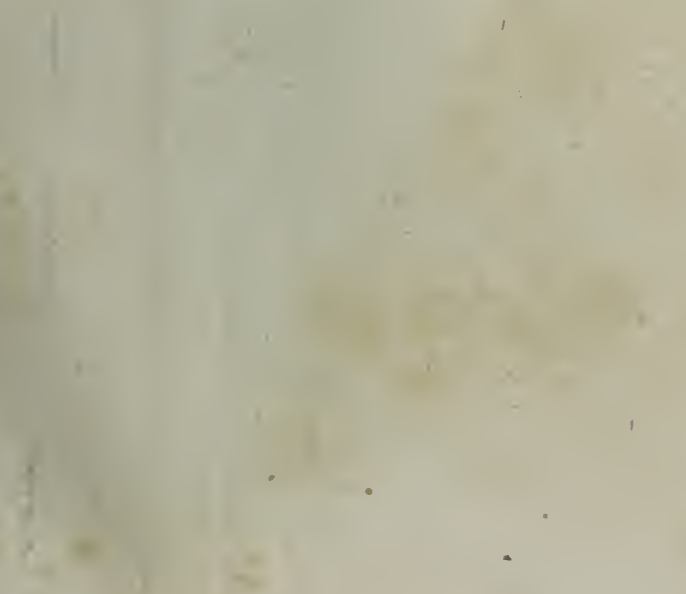

15

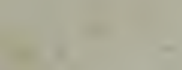




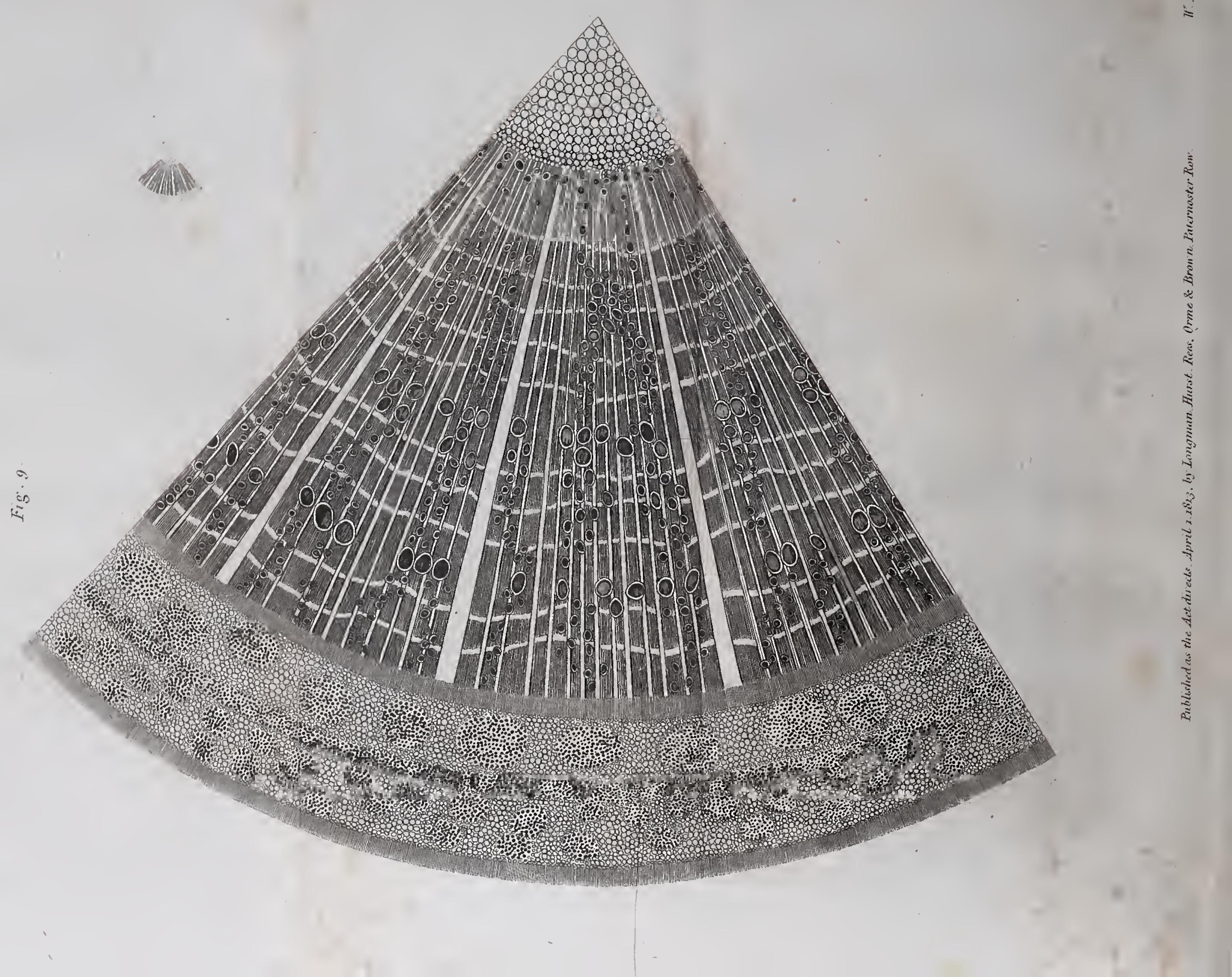


there are two distinct appearances. There are series of white and shining laminæ which shoot from the centre towards the circumference, and these constitute what is called the silver grain of the wood.

There are likewise numerous series of concentric layer's which are usually called the spurious grain, and their number denotes the age of the tree.*

The silver grain is elastic and contractile, and it has been supposed by $\mathbf{M r}_{\mathrm{r}}$. Knight, that the change of volume produced in it by change of temperature is one of the principal causes of the ascent of the sap. The fibres of it seem always to expand in the morning, and contract at night; and the ascent of the juices, as was stated in the last Lecture, depends jrincipally on the agency of heat.

The silver grain is most distinct in forest trees; but even anuual shrubs have a system of fibres similar to it. The analogy of nature is constant and unform, and similar effects are usually produced by similar organs.

The pith occupies the centre of the wood; its texture is membranous; it is composed of cells, which are circular towards the extremity, and hexagoual in the centre of the substance. In the first infancy of the vegetable, the pith occupies but a

* Fig. 8 represents the section of an elm branch, which exhibits the tubular structure and the silver and spurious grain. Fig. 9 represents the section of part of the branch of an oak. Fig. 10, that of the branch of an ash. 
small space. It gradually dilates, and in annual shoots and young trees offers a considerable diameter. In the more advanced age of the tree, acted on by the heart-wood, pressed by the new layers of the alburnum, it begins to diminish, and in very old forest trees disappears altogether.

Many different opinions have prevailed with regard to the use of the pith. Dr. Hales supposed, that it was the great cause of the expansion and development of the other parts of the plant; that being the most interior, it was likewise the most acted upon of all the organs, and that from its reaction the phenomena of their development and growth resulted.

Linnæus, whose lively imagination was continually employed in endeavours to discover analogies between the animal and vegetable systems, conceived " that the pith performed for the plant the same functions as the brain and nerves in animated beings." He considered it as the organ of irritability, and the seat of life.

The latest discoveries have proved, that these two opinions are equally erroneous. Mr. Knight has removed the pith in several young trees, and they continued to live and to increase.

It is evidently then only an organ of secondary importance. In early shoots, in vigorous growth, it is filled with moisture, and it is a reservoir, perhaps, of fluid nourishment at the time it is most wanted. As the heartwood forms, it is more and more separated from the living part, the alburnum; 


\section{(n)}




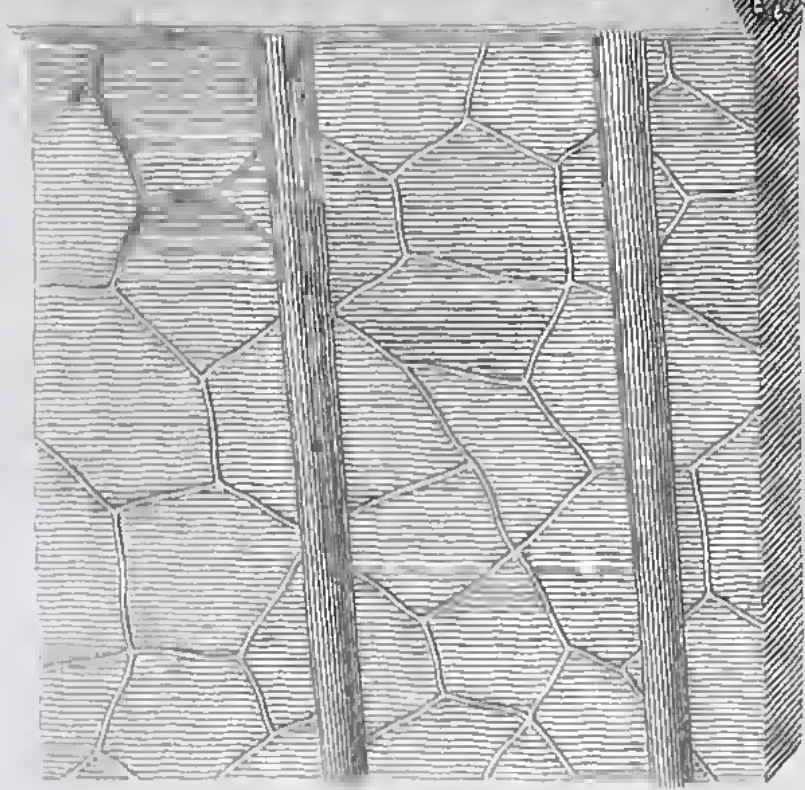

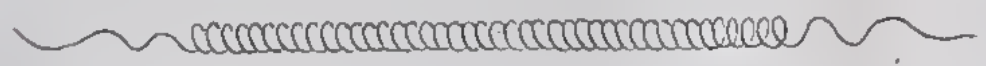

(1) 管

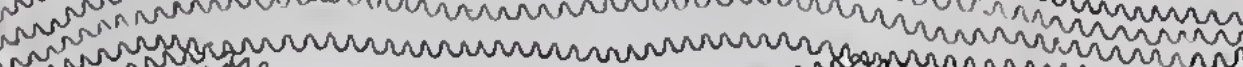

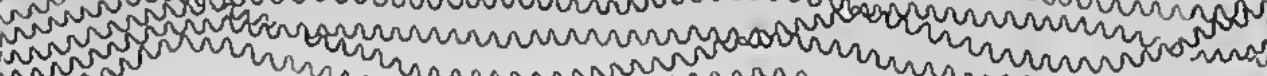
烈

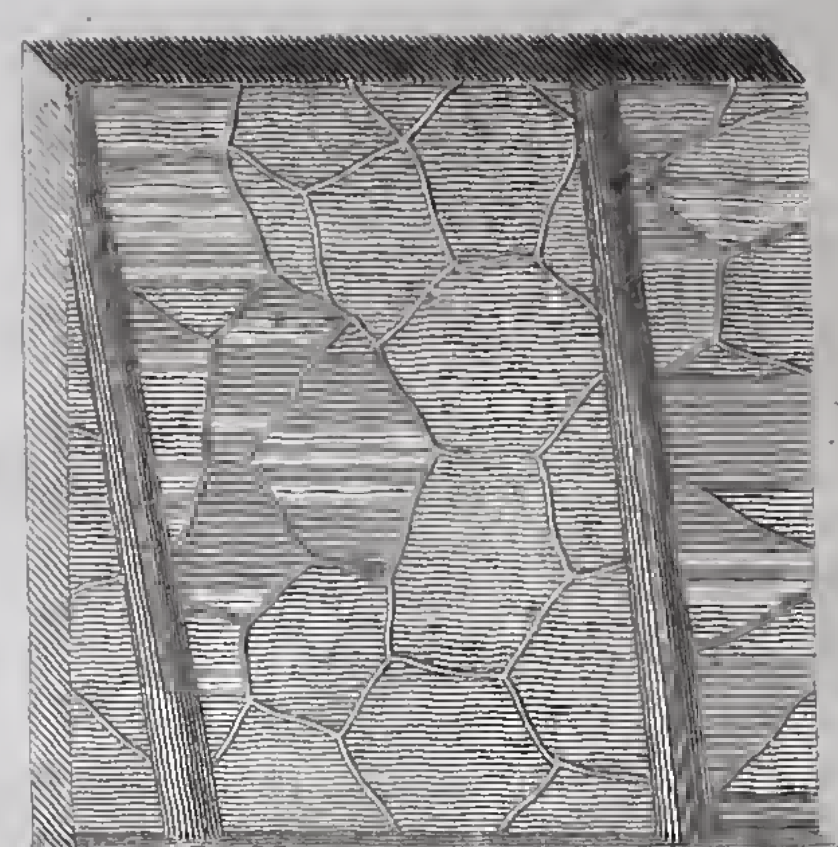

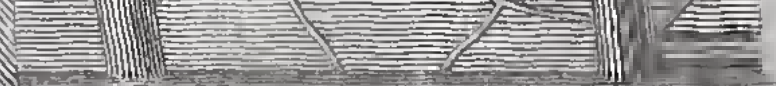

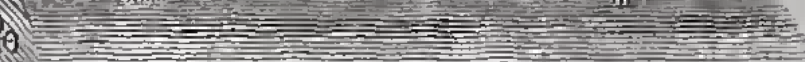

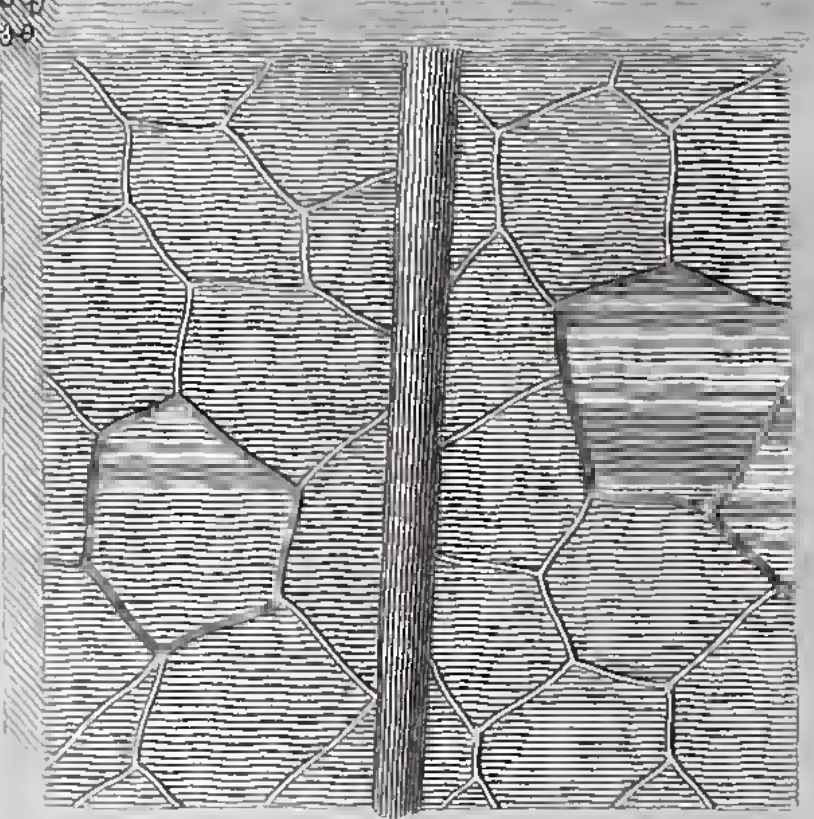




\section{3}

its functions become extinct, it diminishes, dies, and at last disappears.

'The tendrils, the spines, and other similar parts of plants, are analogous in their organization to the branches, and offer a similar cortical and alburnous organization. It has been shown, by the late observations of $\mathbf{M r}$. Knight, that the directions of tendrils, and the spiral form they assume, depend upon the unequal action of light upon them, and a similar reason has been assigned by M. Decandolle to account for the turning of the parts of plauts towards the sun; that ingenious physiologist supposes that the fibres are shortened by the chemical agency of the solar rays upon them, and that, consequently, the parts will move towards the light.

The leaves, the great sources of the permanent beauty of vegetation, though infinitely diversified in their forms, are in all cases similar in interior organization, and perform the same functions.

The alburnum spreads itself from the foot-stalks into the very extremity of the leaf; it retains a vascular system and its living powers; and its peculiar tubes, particularly the tracheæ, may be distinctly seen in the leaf.*

The green membranous substance may be consi-

* Fig. 11 represents part of a leaf of a vine magnified and cut, so as to exhibit the trachex; it is copied, as are also the preceding figures, from Grew's Anatomy of Plants. 
dered as an extension of the parenchyma, and the fine and thin covering as the epidermis. Thus the organization of the roots and branches may be traced into the leaves, which present, however, a more perfect, refined, and minute structure.

One great use of the leaves is, for the exposure of the sap to the influence of the air, heat, and light. Their surface is extensive, the tubes and cells very delicate, and their texture porous and transparent.

In the leares much of the water of the sap is evaporated; it is combined with new principles, and fitted for its organizing functions, and prohably passes, in its prepared state, from the extreme tubes of the alburnum into the ramifications of the cortical tubes, and then descends through the bark.

On the upper surface of leaves, which is exposed to the sun, the epidermis is thick but transparent, and is composed of matter possessed of little organization, which is either principally earthy, or consists of some homogeneous chemical substance. In the grasses it is partly siliceous, in the laurel resinous, and in the maple and thorn, it is principally constituted by a substance analogous to wax.

By these arrangements any evaporation, except from the appropriated tubes, is prevented.

On the lower surface the epidermis is a thin transparent membrane full of cavities, and it is probably altogether by this surface that moisture and 


\section{5}

the principles of the atmosphere necessary to vege. tation are absorbed.

If a leaf be turned, so as to present its lower surface to the sun, its fibres will twist so as to bring it as much as possible into its original position; and all leaves elevate themselves on the foot-stalk during their exposure to the solar light, and as it were move towards the sun.

This effect seems in a great measure dependent upon the mechanical and chemical agency of light and heat. Bonnet made artificial leaves, which, when a moist sponge was held undei the lower surface, and a heated iron above the upper surface, turned exactly in the same manner as the natural leaves. This however can be considered only as a very rude imitation of the natural process.

What Linnæus has called the sleep of the leaves, appears to depend wholly upon the defect of the action of light and heat, and the excess of the operation of moisture.

This singular but constant phenomenon had never been scientifically observed, till the attention of the botanist of Upsal was fortunately directed. to it. He was examining particularly a species of lotus, in which four flowers had appeared during the day, and he missed two in the evening; by accurate inspection, he soon discovered that these two were hidden by the leaves which had closed round them. Such a circumstance could not be lost upon so acute an observer. He immediately took 
a lantern, went into his garden, and witnessed a series of curious facts before unknown. All the simple leaves of the plants he examined, had an arrangement totally different from their arrangenient in the day: and the greater number of them were seen closed or folded together.

The sleep of leaves is, in some cases, capable of being produced artificially. Decandolle made this experiment on the sensitive plant. By confining it in a dark place in the day time, the leaves soon closed; but on illuminating the chamber with many lamps, they again expanded. So sensible were they to the effects of light and radiant heat.

In the greater number of plants the leaves annually decay, and are reproduced; their decay takes place either at the conclusion of the summer, as in very hot climates, when they are no longer supplied with sap, in consequence of the dryness of the soil, and the evaporating power's of heat; or in the autumn, as in the northern climates at the commencement of the frosts. The leaves preserve their functions in common cases no longer than there is a circulation of fluids through them. In the decay of the leaf, the colour assumed seems to depend upon the nature of the chemical change, and as acids are generally developed, it is usually either reddish brown or yellow; yet there are great varieties. Thus in the oak, it is a bright brown; in the beech, orange; in the elm, yellow; in the vine, red; in the sycamore, dark brown; in 
the cornel tree,-purple; and in the woodbine, blue.

'The cause of the preservation of the leaves of evergreens through the winter is not accurately known. From the experiments of Hales, it appears that the force of the sap is much less in plants of this species, and probably there is a certain degree of circulation throughout the winter; their juices are less watery than those of other plants, and probably less liable to be congealed by cold, and they are defended by stronger coatings from the action of the elements.

The production of the other parts of the plant takes place at the time the leaves are most vigorously performing their functions. If the leaves are stripped off from a tree in spring, it uniformly dies, and when many of the leaves of forest trees are injured by blasts, the trees always become stag-headed and unhealthy.

The leaves are necessary for the existence of the individual tree, the flowers for the continuance of the species. Of all the parts of plants they are the most refined, the most beautiful in their structure, and appear as the master-work of nature in the vegetable kingdom. The elegance of their tints, the variety of their forms, the delicacy of their organization, and the adaptation of their parts are all calculated to awaken our curiosity, and excite our admiration. 
In the flower there are to be observed, 1 st, the calyx, or green membranous part forming the support for the coloured floral leaves. This is vascular, and agrees with the common leaf in its texture and organization; it defents, supports, and nourishes the more perfect parts. 2d. The corolla, which consists either of a single piece, when it is called monopetalous, or of many pieces, whien it is called polypetalous. It is ustally very vivid in its colours, is filled with an almost infinite variety of small tubes of the porous kind; it encloses and defends the essential parts in the interior, and supplies the juices of the sap to them. These parts are, $3 d$, the stamens and the pistils.

The essential part of the stamens are the summits or anthers, which are usually circular and of a highly vascular texture, and covered with a fine dust called the pollen.

The pistil is cylindrical, and surmounted by the style; the top of which is generally round and protuberant. *

In the pistil, when it is examined by the microscope, congeries of spherical forms may usually be perceived, which seem to be the bases of the future seeds.

It is upon the arrangement of the stamens and the pistils that the Linnean classification is founded.

* Fig. 12, represents the common lily, $a$, the corolla, $b b b b b$, the anthers, $c$, the pistil. 

'The numbers of the stamens and pistils in the same flower, their arrangements, or their division in different flowers, are the circumstances which guided the Swedish philosopher, and enabled him to form a system admirably adapted to assist the memory, and render botany of easy acquisition; and which, though it does not always associate together the plants most analogous to each in their general characters, is yet so ingeniously contrived as to denote all the analogies of their most essential parts.

The pistil is the organ which contains the rudiments of the seed; but the seed is never formed as a reproductive germ, without the influence of the pollen, or lust on the anthers.

This mysterious impression is necessary to the continued succession of the different vegetable tribes. It is a feature which extends the resemblances of the different orders of beings, and establishes, on a great scale, the beautiful analogy of nature.

The ancients had observed, that different date trees bore different flowers, and that those trees producing flowers which contained pistils bore no fruit, unless in the iumediate vicinity of such trees as produced flowers containing stamens. This long established fact strongly impressed the mind of Malpighi, who ascertained several analogous facts with regard to other vegetables. Grew, however, was the first person who attempted to generalize upon them, and much just reasoning on the subject 
may be found in his works. Linnæus gave a scientific and distinct form to that which Grew had only generally observed, and has the glory of establishing what has be n called the sexual system, upon the basis of minute observations and accurate experiments.

The seed, the last production of vigorous vegetation, is wonderfully diversified in form Being of the highest importance to the resources of nature, it is defended above all other parts of the plant; by soft pulpy substances, as in the esculent fruits, by thick membranes, as in the leguminous vegetables, and by hard shells, or a thick epidermis, as in the palms and grasses.

In every seed there is to be distinguished, 1 , the organ of nourishment; 2, the nascent plant, or the plume; 3 , the nascent root, or the radicle.

In the common garden bean, the organ of nourishment is divided into two lobes called cotyledons; the plume is the small white point between the upper part of the lobes; and the radicle is the small curved cone at their base. ${ }^{*}$

In wheat, and in many of the grasses, the organ of nourishment is a single part, and these plants are called monocotyledonous. In other cases it consists of more than two parts, when the plants are called polycotyledonous: In the greater number of in-

* Fig. 13, represents the garden bean, $a a$, the cotyledons, $b$, the plume, $c$, the radicle. 


\section{1}

stances, it is, however, simply divided into two, and is dicotyledonous.

The matter of the seed, when examined in its common state, appears dead and inert; it exhibits neither the forms nor the functions of life. But let it be acted upon by moisture, heat, and air, and its organized powers are soon distinctly developed. The cotyledons expand, the membranes burst, the radicle acquires new matter, descends into the soil, and the plume rises towards the free air. By degrees, the organs of nourishment of dicotyledonous plants become vascular, and are converted into seed leaves, and the perfect plant appears above the soil. Nature has provided the elements of germination on every part of the surface; water and pure air and heat are universally active, and the means for the preservation and multiplication of life, are at once simple and grand.

To enter into more minute details on the vegetable physiology would be incompatible with the objects of these Lectures. I have attempted only to give such general ideas on the subject, as may enable the philosophical agriculturist to understand the functions of plants; those who wish to study the anatomy of vegetables, as a distinct science, will find abundant materials in the works of the authors I have quoted, page 10, and likewise in the writings of Linnæus, Desfontaines, Decandolle, de Saussure, Bonnet, and Smith.

The history of the peculiarities of structure in the 
different vegetable classes, rather belongs to botanical than agricultural knowledge. As I mentioned in the commencement of this Lecture, their organs are possessed of the most distinct analogies, and are governed by the same laws. In the grasses and palms, the cortical layers are larger in proportion than the other parts; but their uses seem to be the same as in forest trees.

In bulbous roots, the alburnous substance forms the largest part of the vegetable; but in all cases it seems to contain the saj, or solid materials deposited from the sap.

The slender and comparatively dry leaves of the pine and the cedar perform the same functions as the large and juicy leaves of the fig-tree or the walnut.

Even in the cryptogamia, where no flowers are distinct, still there is every reson to believe that the production of the seed is effected in the same way as in the more perfect plants. The mosses and lichens, which belong to this family, have no distinct leaves or roots, but they are furnished with filaments which perform the same functions; and even in the fungus and the mushroom there is a system for the absorption and aeration of the sap.

It was stated in the last Lecture, that all the different parts of plants are capable of being decomposed into a few elements. Their uses as food, or for the purposes of the arts, depend upon compound arrangements of those elements which are capable of being produced either from their organized parts, 
or from the juices they contain ; and the examination of the nature of these substances, is an essential part of A gricultural Chemistry.

Oils are expressed from the fruits of many plants; resinous fluids exude from the wood; saccharine matters are afforded by the sap; and dyeing materials are furnished by leaves, or the petals of flowers : but particular processes are necessary to separate the different compound vegetable substances from each other, such as maceration, infusion or digestion in water, or in spirits of wine: but the application and the nature of these processes will be better understood when the chemical nature of the substances is known; the consideration of them will therefore be reserved for another place in this Lecture.

The compound substances found in vegetables are, 1 gum, or mucilage, and its different modifications; 2, starch ; 3, sugar; 4, albumen; 5 , gluten; 6 , gum elastic; 7, extract; 8 , tannin; 9 , indigo; 10, narcotic principle; 11 . bitter principle; 12. wax; 13. resins; 14 , camphor ; 15, fixed oils; 16. volatile oils; 17 , woody fibre; 18 , acids; 19 , alkalies; earths, metallic oxides, and saline compounds.

I shall describe generally the properties and composition of these bodies, and the mamer in which they are procured.

1. Gum is a substance which exudes from certain trees; it appears in the form of a thick fluid, but soon hardens in the air, and becomes solid; 
when it is white, or yellowish white, more or less transparent, and somewhat brittle; its specific gravity varies from 1300 to 1490 .

There is a great variety of gums, but the best known are gum arabic, gum senegal, gum tragacanth, and the gum of the plum or cherry tree. Gum is soluble in water, but not soluble in spirits of wine. If a solution of gum be made in water, and spirits of wine or alcohol be added to it, the gum separates in the form of white flakes. Gum can be made to inflame only with difficulty; much moisture is given off in the process, which takes place with a dark smoke and feeble blue flame, and a coal remains.

The characteristic properties of gum are its easy solubility in water, and its insolubility in alcohol. Different chemical substances have been proposed for ascertaining the presence of gum, but there is reason to believe that few of them afford accurate results; and most of them (particularly the metallic salts,) which produce changes in solutions of gum, may be conceived to act rather upon some saline compounds existing in the gum, than upon the pure vegetable principle. Dr. Thomson has proposed an aqueous solution of silica in potassa as a test of the presence of gum in solutions-he states that the gum and silica are precipitated together-this test, however, cannot be applied with correct results in cases when acids are present.

Mucilage must be considered as a variety of gum; 
it agrees with it in its most important properties, but seems to have less attraction for water.-According to Hermbstadt, when gum and mucilage are dissolved together in water, the mucilage may be separated by means of sulphuric acid-mucilage may be procured from linseed, from the bulbs of the hyacinth, from the leaves of the marshmallows; from several of the lichens, and from many other vegetable substances.

From the analysis of M. M, Gay Lussac and Thenard, it appears that gum arabic contains in 100 parts :

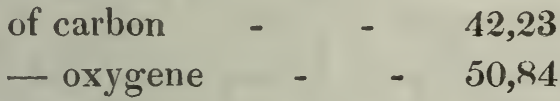

$$
\begin{aligned}
& \text { - hydrogene - - } 6,93
\end{aligned}
$$

with earthy matter a small quantity of saline and.

$$
\left.\begin{array}{l}
\text { or of carbon - - } 42,23 \\
\text { oxygene and hydrogene } \\
\text { in the proportions ne- } \\
\text { cessary to form water }
\end{array}\right\} 57,77
$$

This estimation agrees very nearly with the definite proportions of 11 of carbon, 10 of oxygene, and 20 of hydrogene.

All the varieties of gum and mucilage are nutritious as food. They either partially or wholly lose their solubility in water by being exposed to a heat of $500^{\circ}$ or $600^{\circ}$ Fahrenheit, but their nutritive powers are not destroyed unless they are decomposed. Gum and mucilage are employed in some of the 
arts, particularly in calico-printing: till lately, in this country, the calico-printers used gum arabic; but many of them, at the suggestion of Lord Dundonald, now employ the mucilage from lichens.

2. Starch is procured from different vegetables, but particularly from wheat or from potatoes. To make starch from wheat, the grain is steeped in cold water till it becomes soft, and yields a milky juice by pressure; it is then put into sacks of linen, and pressed in a val filled with water: as long as any milky juice exudes the pressure is continued; the fluid gradually becomes clear, and a white powder subsides, which is starch.

Starch is soluble in boiling water, but not in cold water, nor in spirits of wine. According to Dr. Thomson, it is a characteristic property of starch to be soluble in a warm infusion of nutgalls, and to form a precipitate when the infusion cools.

Starch is more readily combustible than gum; when thrown upon red hot iron, it burns with a kind of explosion, and scarcely any residuum remains. According to Mr. Gay Lussac and Thenard, 100 parts of starch are composed of

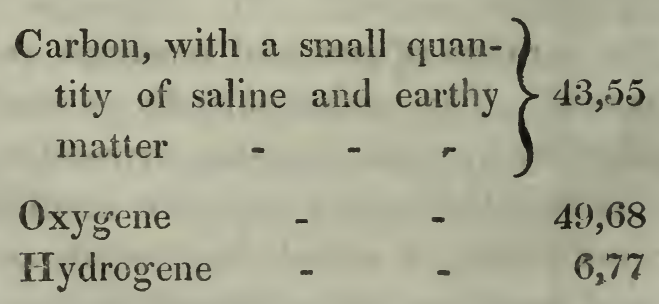


or,

Carbon - - - $\quad-43,55$

Oxygene and hydrogene in the proportions necessary $\} 56,15$ to form water - $\quad$ -

Supposing this estimation correct, starch may be conceived to be constituted by 15 proportions of carbon, 13 of oxygene, and 26 of hydrogene.

Starch forms a principal part of a number of esculent regetable substances. Sowans, cassava, salop, sago, all of them owe their nutritive powers principally to the starch they contain.

Starch has been found in the following plants:

Burdock (Arctium Lappa,) Deadly Nightshade (Atropa Belladonna,) Bistort (Polygomum Bistorta,) White Bryony (Bryonia alba, Deadow Saffron (Colchicum auiumnale:) Dropwort (Epivea Filipendula.) Buttercup (Ramunculus bu!bosus,) Fig'wort (Scrophularia nodosa,) Drvarf Eilder (Sambucus Ebulus,) Common Hider (Sambucus migra,) Foolstones (Orchis Morio,) Alexanders (Imperatoria Ostruthium,) Henbane (Hyoscycmensiger,) Broad-leaved Dock (Rumex obtusifolins,) Sharp-pointed Dock (Rumex acutus,) Water Dock (Rumex Aquaticus,) Wake Robin (Arum maca!atum,) Salep (Orchis mascula,) Flower de luce or Water Aag (Fris Pseudacorus,) Stinking Gladwyn (Tris fatidissima,) Earthnut (Busium Bulbocastanum.)

3. Sugar in its purest state is prepared from the 
expressed juice of the Saccharum officinarum, or sugar cane; the acid in this juice is neutralized by lime, and the sugar is crystallized by the evaporation of the aqueous parts of the juice, and slowcooling: it is rendered white by the gradual filtration of water through it. In the common process of manufacture, the whitening or refining of sugar is only effected in a great length of time; the water being gradually suffered to percolate through a stratum of clay above the sugar. As the colouring matter of sugar is soluble in a saturated solution of sugar, or syrup, it appears that refining may be much more rapidly and œconomically performed by the action of syrup on coloured sugar*. The sensible properties of sugar are well known. Its specific gravity, according to Fahrenheit, is about 1.6. It is soluble in its own weight of water at $50^{\circ}$; it is likewise soluble in alcohol, but in smaller proportions.

* A French gentleman lately in this country, stated to the West India planters, that he was in possession of a very expeditious and economical method of purifying and refining sugar, which he was willing to communicate to them for a very great pecuniary compensation. His terms were too high to be acceded to. Conversing on the subject with Sir Joseph Banks, I mentioned to him, that I thought it probable that raw sugar might be easily purified by passing syrup through it, which would dissolve the colouring matter. The same idea seems to have occurred about the same time, or before, to Edward Howard, Esq. who has since proved its efficacy experimentally, and has published an account of his process. 
Lavoisier concluded from his experiments, that sugar consists in 100 parts of

$$
\begin{aligned}
& 28 \text { carbon, } \\
& 8 \text { hydrogene, } \\
& 64 \text { oxygene. }
\end{aligned}
$$

Dr. Thomson considers 100 parts of sugar as composed of

27,5 carbon, 7,8 hydrogene,

64,7 oxygene.

According to the recent experinents of Gay Lussac and Thenard, sugar consists of 42,47 of carbon, and

57,53 of water or its elements.

Lavoisier's and Dr. Thomson's analyses agree very nearly with the proportions of

3 of carbon,

4 of oxygene,

and 8 of hydrogene.

Gay Lussac's and 'Thenard's estimation gives the same elements as in gum; 11 of carbon, 10 of oxygene, 20 of hydrogene.

It appears from the experiments of Proust, Achard, Goettling, and Parmentier, that there are many different species of sugar ready formed in the vegetable kingdom. The suyar which most nearly resembles that of the cane is extracted from the sap of the American maple, Acer saccharinum. This sugar is used by the North American farmers, who procure it by a kind of domestic manufacture. The 
trunk of the tree is bored early in spring, to the depth of about two inches: a wooden spout is introduced into the hole; the juice fiows for about five or six weeks. A common sized tree, that is, a tree from two to three feet in diameter, will yield about 200 pints of sap, and every 40 pints of sap afford about a pound of sugar. The sap is neutralized by lime, and deposits crystals of sugar by evaporation.

The suyar of grapes has been latcly enployed in France as a substitute for colonial singar. It is procured from the juice of ripe grapes by evaporation, and the action of pot-ashes; it is less sweet than common sugar, and its taste is peculiar: it produces a sensation of cold while dissolving in the mouth; and it is probable coutains a larger proportion of water or its elements.

The roots of the beet (Beta vulyaris und cicla), afford a peculiar sugar, by boiling, and the evaporation of the extract: it agrees in its general properties with the sugar of grapes, but has a slightly bitter taste.

Manna, a substance which exudes from various trees, particularly from the Fraximas Ornus, a species of ash, which grows abundantly in Sicily and Calabria, may be regarded as a variety of sugar, very analogous to the sugar of grapes. A substance analogous to manna has been extracted by Fourcroy and Vauquelin, from the juice of the common onion (Allium Cepa). 
Besides the crystallized and solid sugars, there appears to be a sugar which cannot be separated from water, and which exists only in a fluid form; it constitutes a principal part of melasses or treacle; and it is found in a variety of fruits: it is more soluble in alcohol than solid sugar.

The simplest mode of detecting sugar is that recommended by Margraaf. The vegetable is to be boiled in a small quantity of alcohol; solid sugar, if any exist, will separate during the cooling of the solution.

Sugar has been extracted from the following vegetable substances:

The sap of the Birch (Betula alba,) of the Sycamore (Acer Pseudoplatanus), of the Bamboo (Arundo Bambos), of the Maize (Zea mays), of the Cow Parsnip (Heracleum Sphondylium), of the Cocoanut tree (Cocos nucifera), of the Walnut tree (Juglans alba), of the American Aloe (Agave mericana), of the Dulse (Fucus palmatus), of the Common Parsnip (Pastinica sativa), of St. John's Bread (Ceratonia Siliqua); the fruit of the Common Arbutus (Arbutos Unedo), and other sweet-tasted fruits; the roots of the Turnip (Brassica Rapa), of the Carrot (Daucus Carota), of Parsley (Apium petroselinum), the flower of the Euxine Rhododendron (Rhododendron ponticum), and from the nectarium of most other flowers.

The nutritive properties of sugar are well known. Since the British market has been over-stocked 
with this article from the West India islands, proposals have been made for applying it as the food of eattle; experiments have been made, which prove that they may be fattened by it; but difficulties connected with the duties laid on sugar, have hitherto prevented the plan from being tried to any extent.

4. Albumen is a substance which has only lately been discovered in the vegetable kingdom. It abounds in the juice of the papaw-tree (Carica papaya): when this juice is boiled, the albumen falls down in a coagulated state. It is likewise found in mushrooms, and in different species of funguses.

Albumen in its pure form, is a thick, glairy, tasteless fluid; precisely the same as the white of the egg; it is soluble in cold water; its solution, when not too diluted, is coagulated by boiling, and the alhumen separates in the form of thin flakes. Albumen is likewise coagulated by acids and by alcohol: a solution of albumen gives a precipitate when mixed with a cold solution of nut-galls. Albumen, when burnt, produces a smell of volatile alkali, and affords curbonic acid and water; it is therefore evidently principally composed of carbon, hydrogene, oxygene, and azote.

According to the experiments of Gay Lussac and Thenard, 100 parts of albumen from the white of the egg are composed of 


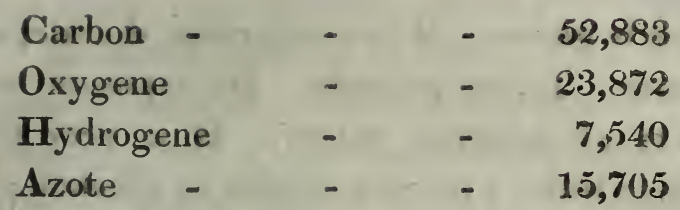

This estimation would authorize the supposition, that albumen is composed of 2 proportions of azote, 5 oxygene, 9 carbon, 22 hydrogene.

The principal part of the almond, and of the kernels of many other nuts, appears, from the experiments of Proust, to be a substance analogous to coagulated albumen.

The juice of the fruit of the Ochra (Hibiscus esculentus), according to Dr. Clarke, contains a liquid albumen in such quantities, that it is employed in Dominica as a substitute for the white of eggs in clarifying the juice of the sugar-cane.

Albumen may be distinguished from other substances by its property of coagulating by the action of heat or acids, when dissolved in water. According to Dr. Bostuck, when the solution contains only one grain of albumen to 100i) grains of water, it becouries cloudy by being heated.

Albumen is a substance common to the animal as well as to the vegetable kingdom, and much more abundant in the former.

5. Gluten may be obtained from wheaten flour by the following process: the flour is to be made into a paste, which is to be cautiously washed, by kneading it under a small stream of water, till the water has carried off from it all the starch; what

\section{G 2}


remains is gluten. It is a tenacious, ductile, elastic substance. It has no taste. By exposure to air it becomes of a brown colour. It is very slightly soluble in water; but not soluble in alkohol. When a solution of it in water is heated, the gluten separates in the form of yellow flakes; in this respect it agrees with albumen, but differs from it in being infinitely less soluble in water. The solution of albumen does not coagulate when it contains much less than 1000 parts of albumen; but it appears that gluten requires more than 1000 parts of cold water for its solution.

Gluten, when burnt, affords similar products to albumen, and probably differs very little from it in composition. Gluten is found in a great number of plants; Proust discovered it in acorns, chesnuts, horse-chesnuts, apples, and quinces; barley, rye, peas, and beans; likewise in the leaves of rue, cabbage, cresses, hemlock, borage, saffron, in the berries of the elder, and in the grape. Gluten appears to be one of the most nutritive of the vegetable substances; and wheat seems to owe its superiority to other grain, from the circumstance of its containing it in larger quantities.

6. Gum elastic, or Caoutchouc, is procured from the juice of a tree which grows in the Brazils, called Hævea. When the tree is punctured, a milky juice exudes from it, which gradually deposits a solid substance, and this is gum elastic.

Gum elastic is pliable and soft like leather, and 
becomes softer when heated. In its pure state it is white; its specific gravity is 93.35 . It is combustible, and burns with a white flame, throwing off a dense smoke, with a very disagreeable smell. It is insoluble in water, and in alcohol; it is soluble in ether, volatile oils, and in petroleum, and may be procured from ether in an unaltered state, by evaporating its solution in that liquid. Gum elastic seems to exist in a great variety of plants : arnongst them are, Jatropha elastica, Ficus indica, Artocarpus integrifolia, and Urceola elastica.

Bird-lime, a substance which may be procured from the holly, is very analogous to gum elastic in its properties. Species of gum elastic may be obtained from the misletoe, from gum-mastic, opinm, and from the berries of the Smilax caduca, in which last plant it has been lately discovered by $\mathrm{Dr}$. Barton.

Gum elastic, when distilled, affords volatile alkali, water hydrogene, and carbon in different combinations. It therefore consists principally of azote, hydrogene, oxygene, and carbon; but the proportions in which they are combined have not yet been ascertained. Gum elastic is an indigestible substance, not fitted for the food of animals; its uses in the arts are well known.

7. Extract, or the extractive principle, exists in almost all platits. It may be procured in a state of tolerable purity from saffron, by merely infusing it in water, and evaporating the solution. It may 
likewise be obtained from catechu, or T'erra japonica, a substance brought from India. This substance consists principally of astringent matter, and extract; by the action of water upon it, the astringent matter is first dissolved, and may be separated from the extract. Extract is always more or less coloured; it is soluble in alcohol and water, but not soluble in ether. It unites with alumina when that earth is boiled in a solution of extract; and it is precipitated by the salts of alumina, and by many metallic solutions, particularly the solution of muriate of tin.

From the products of its distillation, it seems to be composed principally of hydrogene, oxygene, carbon, and a little azote.

There appears to be almost, as many varieties of extract as there are species of plants. The difference of their properties probably, in many cases, depends upon their being combined with small quantities of other vegetable principles, or to their containing different saline, alkaline, acid, or earthy ingredients. Many dyeing substances seem to be of the nature of extractive principle, such as the red colouring matter of madder, and the yellow dye, procured from weld.

Extract has a strong attraction for the fibres of cotton or linen, and combines with these substances when they are boiled in a solution of it. The combination is made stronger by the intervention of mordants, which are earthy or metallic combina- 
tions that unite to the cloth, and enable the colouring matter to adhere more strongly to its fibres.

Extract, in its pure form, cannot be used as an article of food, but it is probably nutritive when united to starch, mucilage, or sugar.

8. Tannin, or the tanning principle, may be procured by the action of a small quantity of cold water on bruised grape-seeds, or pounded gall-nuts; and by the evaporation of the solution to dryness. It appears as a yellow substance, possessed of a highly astringent taste. It is difficult of combus: tion. It is very soluble both in water and alcohol, but insoluble in ether. When a solution of glue, or isinglass (gelatine), is mixed with an aqueous solution of tannin, the two substances, i. e. the animal and vegetable matters fall down in combination, and form an insoluble precipitate.

When tannin is distilled in close vessels, the principal products are charcoal, carbonic acid, and inflammable gasses, with a minute quartity of volatile alkali. Hence its elements seem the same as those of extract, but probably in different proportions. The characteristic property of tannin is its action upon solutions of isinglass or jelly; this particularly distinguishes it from extract, with which it agrees in most other chemical qualities.

There are many varieties of tannin, which probably owe the difference of their properties to combinations with other principles, especially extract, from which it is not easy to free tannin. The 
purest species of tannin is that obtained from the seeds of the grape; this forms a white precipitate, with solution of isinglass. The tannin from gallnuts resembles it in its properties. That from sumacil affords a yellow precipitate; that from kino a rose coloured; that from catechu a fawn coloured one. The colouring matter of Brazil wood, which M. Chevreul considers as a pecuisar principle, and which he has called Hematine, differs from other species of tannin, in affording a precipitate with gelatine, which is soluble in abundance of hot water. Its taste is much sweeter than that of the other varieties of tannin, and it may, perhaps, be regarded as a substance intermediate between tannin and extract.

Tannin is not a nutritive substance, but is of great importance in its application to the art of tanning. Skin consists almost entirely of jelly or gelatine, in an organized state, and is soluble by the long continued action of boiling water. When skin is exposed to solutions containing tannin, it slowly combines with that principle; its fibrous texture and coherence are preserved; it is ' rendered perfectly insoluble in water, and is no longer liable to putrefaction: in short, it becomes a substance in chemical composition precisely analogous to that furnished by the solution of jelly and the solution of tannin.

In general, in this country, the bark of the oak is used for affording tannin in the manufacture of 
leather; but the barks of some other trees, particularly the Spanish chesnut, have lately come into use. The following table will give a gen ral idea of the relative value of different species of barks. It is founded on the result of experiments made by myself.

Table of Numbers exhibiting the Quantity of Tannin afforded by 480lbs. of different Barks, which express nearly their relative Valuis.

\begin{tabular}{|c|c|}
\hline Average of entire bark of middle-sized Oak, cut in spring & $\begin{array}{l}\text { lb. } \\
29\end{array}$ \\
\hline - of Spanish Chesnut ... & 21 \\
\hline _L Leicester Willow, large size, & 33 \\
\hline L $\mathrm{E}$ Elm $\cdot \cdots$ & 13 \\
\hline - of Common Willow, large . & 11 \\
\hline —of Ash . . . . . . & 16 \\
\hline - of Beech . . & 10 \\
\hline —_ of Horse Chesnut & $\mathbf{9}$ \\
\hline — of Sycamore . . . . & 11 \\
\hline L of Lombardy Poplar. . & 15 \\
\hline L of Birch . . . . . & 8 \\
\hline — of Hazel . . & 14 \\
\hline _ of Black Thorn . . . & 16 \\
\hline - of Coppice Oak . . . & 32 \\
\hline — - of Oak cut in autumn . & 21 \\
\hline White interior cortical layers of Oak Bark . & 72 \\
\hline
\end{tabular}

The quantity of the tanning principle in barks differs in different seasons; when the spring has been very cold the quantity is smallest. $\mathrm{On}$ an 
average, four or five pounds of good oak bark are required to form one pound of leather. 'The inner cortical layers in all barks contain the largest quantity of tannin. Barks contain the greatest proportion of tannin at the time the buds begin to openthe smallest quantity in winter.

The extractive or colouring matters found in barks, or in substances used in tanning, influence the quality of leather. Thus skin tanned with gallnuts is much paler than skin tanned with oak bark, which contains a brown extractive matter. Leather made from catechu is of a reddish tint. It is probable that in the process of tanning, the matter of skin, and the tanning principle first enter into union, and that the leather at the moment of its formation unites to the extractive matter.

In general, skins in being converted into leather increase in weight about one third*; and the operation is most perfect when they are tanned slowly. When skins are introduced into very strong infusions of tannin, the exterior parts immediately combine with that principle, and defend the interior parts from the action of the solution: such leather is liable to crack and to decay by the action of water.

The precipitates obtained from infusions containing tannin by isinglass, when dried, contain at a

* This estimation must be considered as applying to $d r y$ skin and dry leather. 
medium rate about 40 per cent. of vegetable matter. It is easy to obtain the comparative value of different substances for the use of the tanner, by comparing the quantities of precipitate afforded by infusions of given weights mixed with solutions of glue or isinglass.

To make experiments of this kind, an ounce or 480 grains of the vegetable substance in coarse powder, should be acted upon by half a pint of boiling water. The mixture should be frequently stirred, and suffered to stand 24 hours; the fluid should then be passed through a fine linen cloth and mixed with an equal quantity of solution of gelatine, made by dissolving glue, jelly, or isinglass in hot water, in the proportion of a drachm of glue or isinglass, or six table spoonfuls of jelly, to a pint of water. The precipitate should be collected by passing the mixture of the solution and infusion through folds of blotting paper; and the paper exposed to the air till its contents are quite dry. If pieces of paper of equal weights are used, in cases in which different vegetable substances are employed, the difference of the weights of the papers when dried, will indicate with tolerable accuracy, the quantities of tannin contained by the substances, and their relative value, for the purposes of manufacture. Four tenths of the increase of weight, in grains, must be taken, which will be in relation to the weights in the table. 
Besides the barks already mentioned, there are a number of others which contain the tanning principle. Few barks indeed are entirely free from it. It is likewise found in the wood and leaves of a number of trees and shrubs, and is one of the most generally diffused of the vegetable principles.

A substance very similar to tannin has been formed by Mr. Hatchett, by the action of heated diluted nitric acid on charcoal, and evaporation of the mixture to dryness. From 100 grains of charcoal Mr. Hatchett obtained 120 grains of artificial tannin, which, like natural tannin, possessed the property of rendering skin insoluble in water.

Both natural and artificial tannin form compounds with the alkalies and the alkaline earths; and these compounds are not decomposable by skin. The attempts that have been made to render oak bark more efficient as a tanning material by infusion in lime water, are consequently founded on erroneous principles. Lime forms with tannin, a compound not soluble in water.

The acids unite to tannin, and produce compounds that are more or less soluble in water. It is probable that in some vegetable substances tannin exists, combined with alkaline or earthy matter; and such substances will be rendered more efficacious for the use of the tanner, by the action of diluted acids.

9. Indigo may be procured from woad (Isatis 
tinctoria, by digesting alcohol on it, and evaporating the solution. White crystalline grains are obtained, which gradually become blue by the action of the atmosphere: these grains are the substance in question.

The indigo of commerce is principally brought from America. It is procured from the Indigofera argentea, or wild indigo, the Indigofera disperma, or Gautimala indigo, and the Indigofera tinctoria, or French indigo. It is prepared by fermenting the leaves of those trees in water. Indigo in its common form appears as a fine, deep blue powder. It is insoluble in water, and but slightly soluble in alcohol: its true solvent is sulphuric acid: eight parts of sulphuric acid dissolve one part of indigo ; and the solution diluted with water forms a very fine blue dye.

Indigo, by its distillation, affords carbonic acid gas, water, charcoal, ammonia, and some oily and acid matter: the charcoal is in very large proportion. Pure indigo therefore most probably consists of carbon, hydrogene, oxygene, and azote.

Indigo owes its blue colour to combination with oxygene. For the uses of the dyers it is partly deprived of oxygene, by digesting it with orpiment and lime water, when it becomes soluble in the lime water, and of a greenish colour. Cloths steeped in this solution combine with the indigo; they are green when taken out of the liquor, but 
become blue by absorbing oxygene when exposed to air.

Indigo is one of the most valuable and most extensively used of the dyeing materials.

10. The narcotic principle is found abundantly in opium, which is obtained from the juice of the white poppy, (Papaver album). To procure the narcotic principle, water is digested upon opium: the solution obtained is evaporated till it becomes of the consistence of a syrup. By the addition of cold water to this syrup a precipitate is obtained. Alcohol is boiled on this precipitate; during the cooling of the alcohol crystals fall down. These crystals are to be again dissolved in alcohol, and again precipitated by cooling: and the process is to be repeated till their colour is white: they are crystals of narcotic principle.

The narcotic principle has no taste nor smell. It is soluble in about 400 parts of boiling water; it is insoluble in cold water : it is soluble in 24 parts of boiling alcohol, and in 100 parts of cold alcohol. It is very soluble in all acid menstrua.

It has been shewn by De Rosne, that the action of opium on the animal economy depends on this principle. Many other substances besides the juice of the poppy, possess narcotic properties; but they have not yet been examined with much attention. The Lactuca sativa, or garden lettuce, and most of the other lactucas yield a milky juice, 
which when inspissated has the characters of opium, and probably contains the same narcotic principle.

11. 'The bitter principle is very extensively diffased in the vegetable kingdom; it is found abundantly in the hop (Humilus lupilus), in the common broom (Spartium scoparium), in the chamomile (Anthemis nobilis), and in quassia, amara and excelsa. It is obtained from those substances by the action of water or alcohol, and evaporation. It is usually of pale yellow colour; its taste is intensely bitter. It is very soluble, both in water and alcohol; and has little or no action on alkaline, acid, saline, or metallic solution.

An artificial substance, similar to the bitter principle, has been obtained by digesting diluted nitric acid, on silk, indigo, and the wood of the white willow. This substance' has the property of dyeing cloth of a bright yellow colour; it differs from the natural bitter principle in its power of combining with the alkalies: in union with the fixed alkalies it constitutes crystallized bodies, which have the property of detonating by heat or percussion.

The natural bitter principle is of great importance in the art of brewing; it checks fermentation, and preserves fermented liquors; it is likewise used in medicine.

The bitter principle, like the narcotic principle, appears to consist principally of carbon, hydrogene, and oxygene, with a little azote. 
12. Wax is found in a number of vegetables; it is procurred in abundance from the berries of the wax myrtle (Myrica cerifera): it may be likewise obtained from the leaves of many trees; in its pure state it is white. Its specific gravity is 9,662 ; it melis at 155 degrees; it is dissolved by boiling alcohol; but it is not acted upon by cold alcohol: it is insoluble in water; its properties as a combustible body are well known.

'The wax of the vegetable kingdom seems to be precisely. of the same nature as that afforded by the bee.

From the experiments of M. M. Gay Lussac and Thenard, it appears that 100 parts of wax consist of

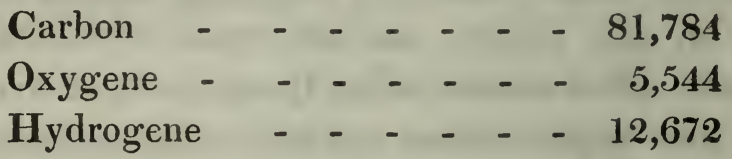

Or otherwise,

Carbon - - - - - 81,784

Oxygene and hydrogene in the proportions necessary to form $\} 6,300$

Hydrogene - - - - 11,916

which agrees very nearly with 37 proportions of hydrogene, 21 of charcoal, one of oxygene.

13. Resin is very common in the vegetable king- 
dom. One of the most usual species is that afforded by the different kinds of fir. When a portion of the bark is removed from a fir tree in spring, a matter exudes, which is called turpentine; by heating this turpentine gently, a volatile oil rises from it, and a more fixed substance remains; this substance is resin.

The resin of the fir is the substance commonly known by the name of rosin; its properties are well known. Its specific gravity is 1072. It melts readily, burns with a yellow light, throwing off much smoke. Resin is insoluble in water, either hot or cold; but very soluble in alcohol. When a solution of resin in alcohol is mixed with water, the solution becomes milky; the resin is deposited by the stronger attraction of the water for the alcohol.

Resins are obtained from many other species of trees. Mastich, from the Pistacia lentiscus, Elemi from the Amyris elemifera, Copal from the Rhus copallinum, Sandarach from the common juniper. Of these resins copal is the most peculiar. It is the most difficultly dissolved in alcohol; and for this purpose must be exposed to that substance in vapour; or the alcohol employed must hold camphor in solution. According to Gay Lussac and Thenard,

100 parts of common resin contain

Carbon - . . . . - 75,944 


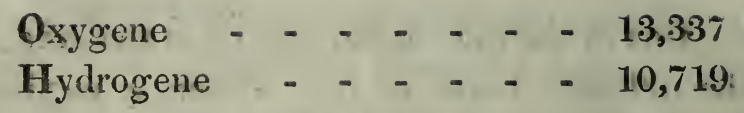

or of

Carbon - - - - - - 75,944

Oxygene and hydrogene in the proportions necessary to form $\} 15,156$ water - - - - - - -

Hydrogene in excess - - - 8,900 .

According to the same chemists, 100 parts of copal consist of

Carbon - - - - - 7 7,811

Oxygene - - - - - 10,606

Hydragene - - - - - 12,583.

or,

Carbon - - - - - 76,811

Water or its elements - - $12 ; 052$.

Hydrogene - - - - - 11,137

From these results, if resin be a definite compound, it may be supposed to consist of eight proportions of carbon, twelve of hydrogene, and one of oxygenem

Resins are used for a variety of purposes. Tar and pitch principally consist of resin, in a partially decomposed state. Tar is made by the slow combustion of the fir; and pitch by the evaporation of the more volatile parts of tar. Resins are em- 
ployed as varnishes, and for these purposes are dissolved in alcohol or oils. Copal forms one of the finest. It may be made by boiling it in powder with oil of rosemary, and then adding alcohol to the solution.

14. Camplior is procured by distilling the wood of the camphor tree (Laurus camphora, which grows in Japan. It is a very volatile body, and may be purified by distillation. Camphor is a white. brittle, semitransparent substance, having a peculiar odour, and a strong acrid taste. It is very slightly soluble in water; more than 100,000 parts of water are required to dissolve one part of camphor. It is very soluble in alcohol; and by adding water in small quantities at a time to the solution of camphor in alcohol, the camphor separates in a crystallised form. It is soluble in nitric acid, and is separated from it by water.

Camphor is very inflammable; it burns with a bright flame, and throws off a great quantity of carbonaceous matter. It forms in combustion water, carbonic acid, and a peculiar acid called camphoric acid. No accurate analysis has been made of camphor, but it seems to approach to the resins in its composition; and consists of carbon, hydrogene, and oxygene.

Camphor exists in other plants besides the Laurus camphora. It is procured from species of the laurus growing in Sumatra, Borneo, and other of the East 
Indian isles. It has been obtained from thyme (Thymus serpillum,) marjorum (Origanum majorana,) Ginger tree (Amomum Zingiber,) Sage (Salvia officinalis.) Many volatile oils yield camphor by being merely exposed to the air.

An artificial substance very similar to camphor has been formed by M. Kind, by saturating oil of turpentine with muriatic acid gas (the gaseous substance procured from common salt by the action of sulphuric acid). The camphor procured in well conducted experiments amounts to half of the oil of turpentine used. It agrees with common camphor in most of its sensible properties; but differs materially in its chemical qualities and composition. It is not soluble without decomposition in nitric acid. From the experiments of Gehlen, it appears to consist of the elements of oil of turpentine, carbon hydrogene and oxygene, united to the elements of muriatic gas, chlorine and hydrogene.

From the analogy of artificial to natural camphor, it does not appear improbable, that natural camphor may be a secondary vegetable compound, consisting of camphoric acid and volatile oil. Camphor is used medicinally, but it has no other application.

15. Fixed oil is obtained by expression from seeds and fruits; the olive, the almond, linseed and rape-seed afford the most common vegetable fixed oils. The properties of fixed oils are well known. 
Their specific gravity is less than that of water; that of olive and of rape-seed oil is 913 ; that of linseed and almond oil 932 ; that of palm oil 968; that of walnut and beech mast oil 923. Many of the fixed oils congeal at a lower temperature than that at which water freezes. They all require for their evaporation a higher temperature than that at which water hoils. The products of the combustion of oil are water, and carbonic acid gas.

From the experiments of Gay Lussac and Thenard, it appears that olive oil contains, in 100 parts,

$$
\begin{aligned}
& \text { Carbon - - - 77,213 } \\
& \text { Oxygene - - - } \mathbf{9 , 4 2 7} \\
& \text { Hydrogene - - 13,360 }
\end{aligned}
$$

This estimation is a near approximation to 11 proportions of carbon, 20 hydrogene, and one oxygene.

The following is a list of fixed oils, and of the trees that afford them.

Olive oil, from the Olive tree (Olea Europea.) Linseed oil, from the common and perennial Flax (Linum usitatissimum et perenne), Nut oil, from the Hazel nut (Coryllus aveilana), Walnut, (Juglans regia), Hemp oil, from the Hemp (Cannabis sativa), Almond oil, from the sweet Almond (Amygdalus communis), Beech oil, from the common Beech (Fagus sylvatica), Rape-seed oil, from the Rapes 
(Brassica napus et campestris), Poppy oil, from the Poppy (Papaver somniferum), oil of Sesamum, from the Sesamum (Sesamum orientale), Cucumber oil, from the Gourds (Cucurbita pepo et malapepo), oil of Mustard, from the Mustard (Sinapis nigra et arvensis), oil of Sunflower, from the annual and perennial Sunflower, (Helianthus annuus et perennis), Castor oil, from the Palma Christi (Ricinus communis), 'Tobacco-seed oil, from the Tobacco (Nicotiana tabacum et rustica), Plum kernel oil, from the Plum tree (Prunus domestica), Grape-seed oil, from the Vine (Vitis vinifera), Butter of cacoa, from the Cacoa tree (Theobroma cacao), Laurel oil, from the sweet Bay tree (Laurus nobilis).

The fixed oils are very nutritive substances; they are of great importance in their applications to the purposes of life. Fixed oil, in combination with soda, forms the finest kind of hard soap. The fixed oils are used extensively in the mechanical arts, and for the preparation of pigments and varnishes.

16. Volatile oil, likewise called essential oil, differs from fixed oil, in being capable of evaporation by a much lower degree of heat; in being soluble in alcohol, and in possessing a very slight degree of solubility in water.

There is a great number of volatile oils, distinguished by their smell, their taste, their specific gravity, and other sensible qualities. A strong and peculiar odour may however be considered as the 


\section{3}

great characteristic of each species; the volatile oils inflame with more facility than the fixed oils, and afford by their combustion different proportions of the same substances, water, carbonic acid, and carbon.

The following specific gravities of different volatile oils were ascertained by $\mathrm{Dr}$. Lewis.

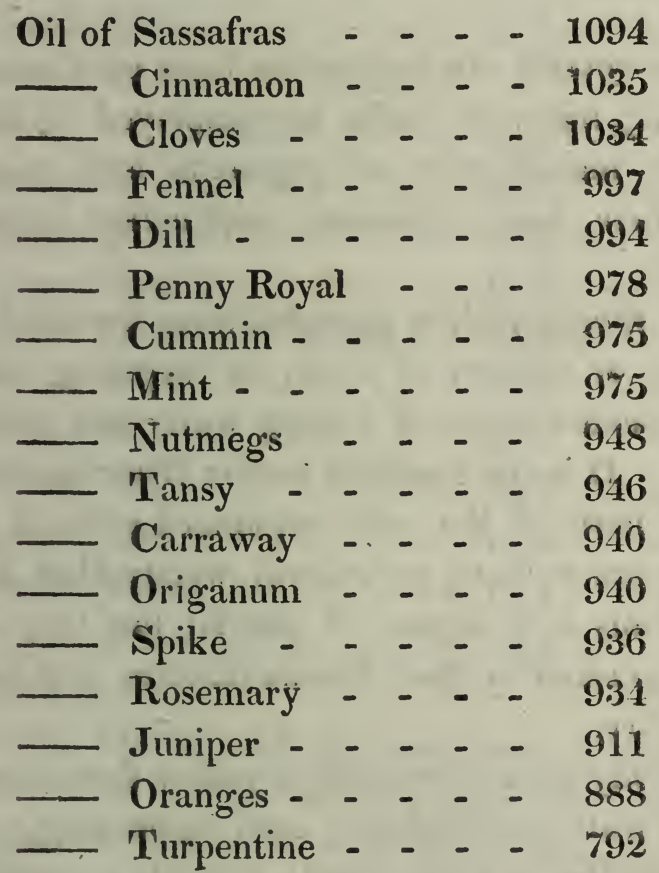

The peculiar odours of plants seem, in almost all cases, to depend upon the peculiar volatile oils they contain. All the perfumed distilled waters owe their peculiar properties to the volatile oils they hold 
in 'solution. By collecting the aromatic oils, the fragrance of flowers, so fugitive in the common course of nature, is as it were embodied and made permanent.

It cannot be doubted that the volatile oils consist of carbon, hydrogene, and oxygene; but no accurate experiments have as yet been made on the proportions in which these elements are combined.

The volatile oils have never been used as articles of food; many of them are employed in the arts, in the manufacture of pigments and varnishes; but their most extensive application is as perfumes.

17. Woody fibre is procured from the wood, bark, leaves, or flowers of trees, by exposing them to the repeated action of boiling water and boiling alcohol. It is the insoluble matter that remains, and is the basis of the solid organized parts of plants. There are as many varieties of woody fibre as there are plants and organs of plants; but they are all distinguished by their fibrous texture, and their insolubility.

Woody fibre burns with a yellow flame, and produces water and carbonic acid in burning. When it is distilled in close vessels, it yields a considerable residuum of charcoal. It is from woody fibre, indeed, that charcoal is procurerl for the purposes of life. 
The following table contains the results of experiments made by Mr. Mushet, on the quantity of charcoal afforded by different wood.

100 parts of Lignum Vitæ - - 26,8 of charcoal Mahogany - - - - 25,4 Laburnum - - - 24,5

Chesnut - - - - 23,2

Oak - . . . 22,6

American black

Beech - - - 21,4

Walnut - . - 20,6

Holly - - - - - 19,9

Beech - . - - 19,9

American Maple - - 19,9

Elm - - - - - 19,5

Norway Pine - - 19,2

Sallow - - . - 18,4

Ash - . - . - 17,0

Birch - . - . 17,4

Scottish Fir - - - 16,4

M. Gay Lussac and Thenard have concluded from their experiments on the wood of the oak and the beech, that 100 parts of the first contain:

$$
\begin{aligned}
& \text { of carbon - - } 52,53 \\
& \text { - oxygene - - 41,78 } \\
& \text { - hydrogene - } 5,69
\end{aligned}
$$




\section{6}

and 100 parts of the second:

$$
\begin{array}{r}
\text { of carbon - - - 51,45 } \\
\text { - oxygene - - 42,73 } \\
\text { - hydrogene - - 5,82 }
\end{array}
$$

Supposing woody fibre to be a definite compound, these estimations lead to the conclusion, that it consists of five proportions of carbon, three of oxygene, and six of hydrogene; or 57 carbon, 45 oxygene, and six hydrogene.

It will be unnecessary to speak of the applications of woody fibre. The different uses of the woods, cotton, linen, the barks of trees are sufficiently known. Woody fibre appears to be an indigestible substance.

18. The acids found in the vegetable kingdom are numerous; the true vegetable acids which exist ready formed in the juices or organs of plants, are the oxulic, citric, tartaric, benzoic, acetic, malic, gallic, and prussic acid.

All these acids, except the acetic, malic, and prussic acids, are white crystallized bodies. The acetic, malic, and prussic acids have been obtained in the only fluid state; they are all more or less soluble in water; all have a sour taste except the gallic and prussic acids; of which the first has an astringent taste, and the latter a taste like that of bitter almonds. 
The oxalic acid exists, uncombined, in the liquor which exudes from the Chich pea (Cicer arietinum), and may be procured from wood sorrel (Oxalis acetosella), common sorrel, and other species of Rumex; and from the Geranium acidum. Oxalic acid is easily discovered and distinguished from other acids by its property of decomposing all calcareous salts, and forming with lime a salt insoluble in water; and by its crystallizing in four-sided prisms.

The citric acid is the peculiar acid existing in the juice of lemons and oranges. It may likewise be obtained from the cranberry, whortleberry, and hip.

Citric acid is distinguished by its forming a salt insoluble in water with lime; but decomposable by the mineral acids.

The tartaric acid may be obtained from the juice of mulberries and grapes; and likewise from the pulp of the tamarind. It is characterized by its property of forming a difficultly soluble salt with potassa, and an insoluble salt decomposable by the mineral acids with lime.

Benzoic acid may be procured from several resinous substances by distillation; from benzoin, storax, and balsam of Tolu. It is distinguished from the other acids by its aromatic odour, and by its extreme volatility.

Malic acid may be obtained from the juice of apples, barberries, plums, elderberries, currants, 
strawberries, and raspberries. It forms a soluble salt with lime; and is ensily distinguished by this test from the acids alrearly named.

Acetic acid, or vinegar, may be obtained from the sap of different trees. It is distinguished from malic acid by its peculiar odour; and from the other vegetable acids by forming soluble salts with the alkalies and earths.

Gallic acid may be obtained by gently and gradually heating powdered gall-nuts, and receiving the volatile matter in a cool vessel. A number of white crystals will appear, which are distinguished by their property of rendering sclutions of iron, deep purple.

The vegetable prussic acid is procured by distilling laurel leaves, or the kernels of the peach, and cherry, or bitter almonds. It is characterized by its property of forming a blucish green precipitate, when a little alkali is added to it, and it is poured into solutions containing iron. It is very analogous in its properties to the prussic acid oltained from animal substances; or by passing ammonia over heated charcoal; but this last body forms, with the red oxide of iron, the deep, bright blue substance, called Prussian blue.

Two other vegetable acids have been found in the products of plants; the morolyxic acid in a saline exudation from the white mulberry tree, and the kinic acid in a salt afforded by Peruvian bark; but these two bodies have as yet been dis. 
covered in no other cases. The phosphoric acid is found free in the onion; and the phosphoric, sulphuric, muriatic, and nitric acids, exist in many saline compounds in the vegetable kingdom; but they cannot with propriety be considered as vegetable products. Other acids are produced during the combustion of vegetable compounds, or by the action of nitric acid upon them; they are the camphoric acid, the mucous or saclactic acid, and the suberic acid; the first of which is procured from camphor; the second from gum or mucilage; and the third from cork, by the action of nitric acid.

From the experiments that have been made upon the vegetable acids, it appears that all of them, except the prissic acid, are constituted by different proportions of carbon, hydrogene, and-oxygene; the prussic acid consists of carbon, azote, and hydrogene, with a little oxyggene. The gallic acid contains more carbon than any of the other vegetable acids.

The following estimates of the composition of some of the vegetable acids have been made by Gay Lussac and Thenard.

100 parts of oxalic acid contain :

Carbon - - 26,566

Hydrogene - 2,745

Oxygene - 70,689

Ditto of tartaric acid:

Carbon - - 24,050

Hydrogene - 6,629 
Ditto citric acid :

$$
\text { Oxygene - } 69,321
$$

Carbon - - 33,811

Hydrogene - 6,330

Oxygene - - 59,859

100 parts of acetic acid:

$$
\begin{aligned}
& \text { Carbon - - 50,224 } \\
& \text { Hydrogene - } 5,629 \\
& \text { Oxygene - - 44,147 }
\end{aligned}
$$

Ditto mucous or saclactic acid :

Carbon - - 33,69

Hydrogene - $\quad 3,62$

Oxygene - - 62,69

These estimations agree nearly with the following definite proportions, In oxalic acid 7 proportions of carbon, 8 of hydrogene, and 15 oxygene ; * in tartaric acid, 8 carbon, 28 hydrogene, 18 oxygene; in citric acid, 3 carbon, 6 hydrogene, 4 oxygene; in acetic acid, 18 carbon, 22 hydrogene, 12 oxygene; in mucous acid, 6 carbon, 7 hydrogene, 8 oxygene.

The applications of the vegetable acids are well known. 'The acetic and citric acids are extensively used. The agreeable taste and wholesomeness of various vegetable substances used as food, mate.

* According to Dr. Thomson's experiments, oxalic acid consists of 3 proportions of carbon, 4 of oxygene, and 4 of hydrogene, a result very different indeed from that of the French chemists. 
rially depend upon the vegetable acid they contain.

19. Fixed alkali may be obtained in aqueous solution from most plants by burning them, and treating the ashes with ruick lime and water. The vegetable alkali, or potassa, is the common alkali in the vegetable kingdom. This substance in its pure. state is white, and semi-transparent, requiring a strong heat for its fusion, and possessed of a highly caustic taste. In the matter usually called pure potassa by chemists, it exists combined with water, and in that commonly called pearl ashes, or potashes in commerce, it is combined with a small quantity of carbonic acid. Potassa in its uncombined state, as has been mentioned, page 41 , consists of the highly inflammable metal potassium, and oxygene, one proportion of each.

Soda, or the mineral alkali, is found in some plants that grow near the sea; and is obtained combined with water, or carbonic acid, in the same manner as potassa ; and consists, as.has been stated, page 41, of one proportion of sodium, and two proportions of oxygene. In its properties it is very similar to potassa ; but may be easily distinguished from it by this character: it forms a hard soap with ail : potassa forms a soft soap.

Pearl ashes, and barilla and kelp, or the impure soda obtained from the ashes of marine plants, are very valuable in commerce, principally on account of their uses in the manufacture of glass and soap. 


\section{2}

Glass is made from fixed alkali, flint, and certain metallic substances.

To know whether a vegetable yields alkali, it should be burnt, and the ashes washed with a small quantity of water. If the water, after being for some time time exposed to the air, reddens paper tinged with turmeric; or renders vegetable blues, green, it contains alkali.

'To ascertain the relative quantities of pot-ashes afforded by different plants, equal weights of them should be burnt: the ashes washed in twice their volume of water; the washings should be passed through blotting paper, and evaporated to dryness : the relative weights of the salt obtained will indicate very nearly the relative quantities of alkali they contain.

The value of marine plants in producing soda, may be estimated in the same manner, with sufficient correctness for all commercial purposes.

Herbs, in general, furnish four or five times, and shrubs two or three times as much pot-ashes as trees. The leaves produce more than the branches, and the branches mure than the trunk. Vegetables burnt in a green state produce more ashes than in a dry state.

The following table * contains a statement of the quantity of pot-ashes afforded by some common trees and plants.

* It is founded upon the experiments of Kirwan, Vauquelin, and Pertuis. 


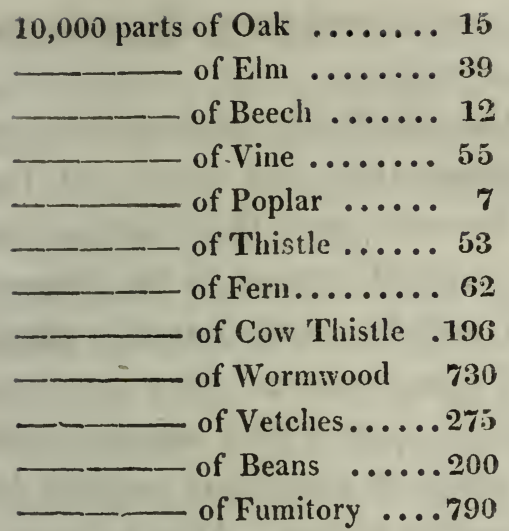

The earths found in plants are four: silica or the earth of flints, allumina or pure clay, lime, and magnesia. They are procured by incineration. The lime is usually combined with carbonic acid. This substance and silica are much more common in the vegetable kingdom than magnesia, and magnesia more common than alumina. The earths form a principal part of the matter insoluble in water, afforded by the ashes of plants. The silica is known by not being dissolved by acids; the calcareous earth, unless the ashes have been very intensely ignited, dissolves with effervescence in muriatic acid. Magnesia forms a soluble and crystallizable salt, and lime, a difficultly soluble one with sulphuric acid. Alumina is distinguished from the other earths, by being acted upon very slowly by acids; and in forming salts very soluble in water, and difficult of crystallization with them.

The earths appear to be compounds of the pecu- 
liar metals mentioned page 42 , and oxygene, one proportion of each.

The earths afforded by plants, are applied to no uses of common life; and there are few cases in which the knowledge of their nature can be of importance, or afford interest to the farmer.

The only metallic oxides found in plants are those of iron and manganesum: they are detected in the ashes of plants; but in very minute quantities only. When the ashes of plants are reddish brown, they abound in oxides of iron. When black or purple, in oxide of manganesum; when these colours are mixed, they contain both substances.

The saline compounds contained in plants, or afiorded by their incineration, are very various. The sulphuric acid combined with potassa, or sulphate of potassa, is one of the most usual. Common salt is likcwise very often found in the ashes of plants; likewise phosphate of lime, which is insoluble in water, but soluble in muriatic acid. Compounds of the nitric, muriatic, sulphuric, and phosphoric acids, with alkalies and earths, exist in the sap of many plants, or are afforded by their evaporation and incineration. The salts of potassa are distinguished from those of soda, by their producing a precipitate in solutions of platina: those of lime are characterized by the cloudiness they occasion in solutions containing oxalic acid; those of magnesia, by being rendered cloudy by solutions of ammonia. Sulphuric acid is detected in salts by the 


\section{$11 \dot{0}$}

dense white precipitate it forms in solutions of baryta. Muriatic acid by the cloudiness it communicates to solution of nitrat of silver; and when salts contain nitric acid, they produce scintillations by being thrown upon burning coals.

As no applications have been made of any of the neutral salts, or analogous compounds found in plants, in a separate state, it will be useless to describe them individually. The following tables are given from M. Th. de Saussure's Researches on Vegetation, and contain results obtained by that philosopher. They exhibit the quantities of soluble salts, metallic oxides, and earths afforded by the ashes of different plants. 


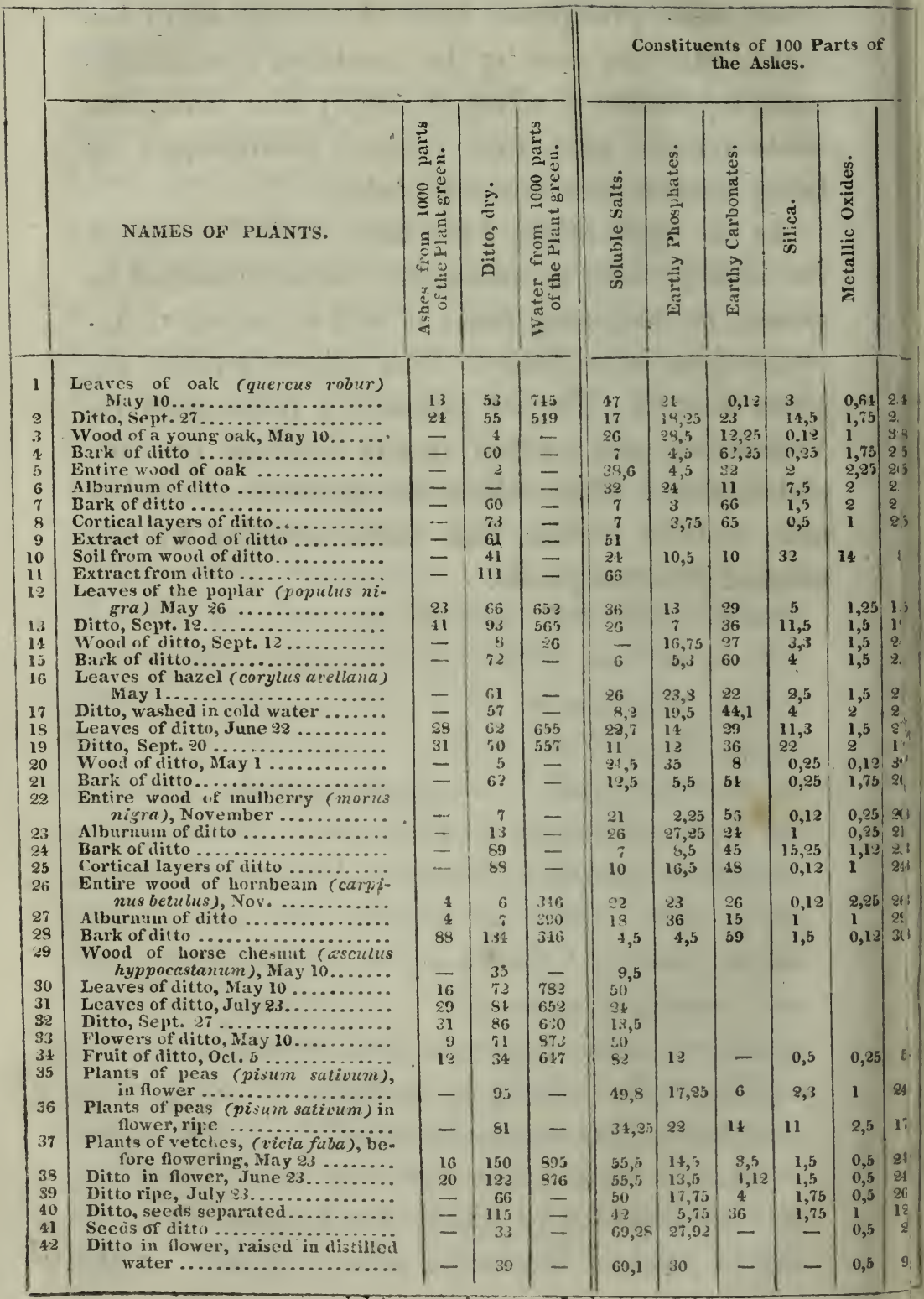




\section{7}

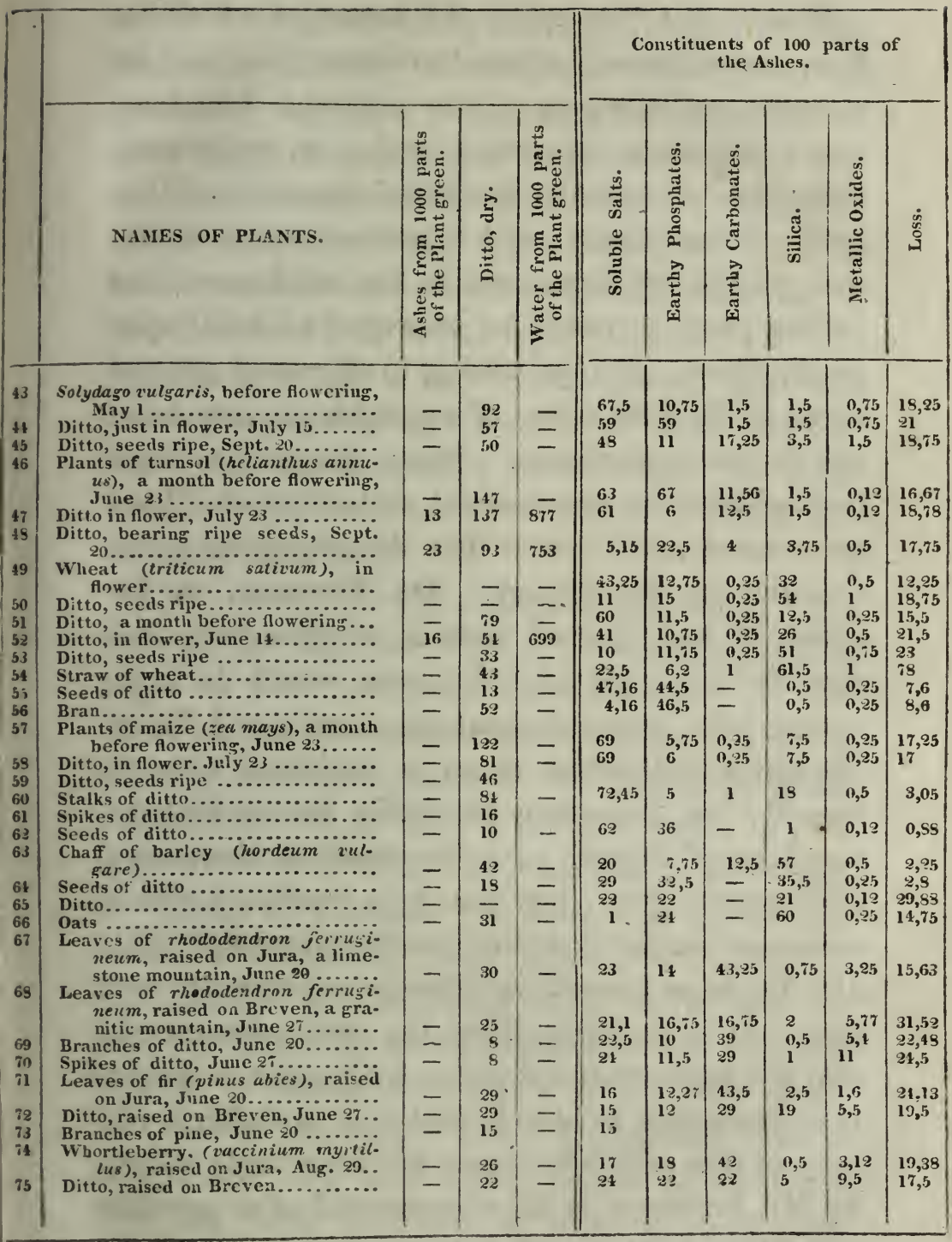


Besides the principles, the nature of which has been just discussed, others have been described by chemists as belonging to the vegetable kingdom: thus a substance, somewhat analogous to the muscular fibre of animals, has been detected by Vauquelin in the papaw; and a matter similar to animal gelatine by Braconnot in the mushroom; but in this place it would be improper to dwell upon peculiarities; my object being to offer such general views of the constitution of vegetables as may be of use to the agriculturist. Some distinctions have been adopted by systematical authors which $I$ have not entered into, because they do not appear to me essential to this enquiry. Dr. Thomson, in his elaborate and learned system of chemistry, has described six vegetable substances, which he calls mucus, jelly, sarcocol, asparagin, inulin, and ilmin. He states that mucus exists in its purest form in linșeed; but Vanquelin has lately shewn, that the mucilage of linseed is, in its essential characters, analogous to gum; but that it is combined with a substance similar to animal mucus : vegetable jelly, Dr. Thomson himself considers as a modification of gum. It is probable, from the taste of sarcocol, that it is gum combined with a little sugar. Inulin is so analogous to starch, that it is probably a variety of that principle : ulmin has been lately shewn by Mr. Smithson to be a compound of a peculiar extractive matter and potassa; and asparagin is probably a similar combination. If slight differ- 
ences in chemical and physical properties be considered as sufficient to establish a difference in the species of vegetable substances, the catalogue of them might be enlarged to almost any extent. No two compounds procured from different vegetables are precisely alike; and there are even differences in the qualities of the same compound, according to the time in which it has been collected, and the manner in which it has been prepared: the great use of classification in science is to assist the memory; and it ought to be founded upon the similarity of properties which are distinct, characteristic, and invariable.

The analysis of any substance containing mixtures of the different vegetable principles, may be made in such a manner as is necessary for the views of the agriculturist with facility. $\mathbf{A}$ given quantity, say 200 grains, of the substance should be powdered, made into a paste or mass, with a small quantity of water, and kneaded in the hands, or rubbed in a mortar for some time under cold water; if it contain much gluten, that principle will separate in a coherent mass. After this process, whether it has afforded gluten or not, it should be kept in contact with half a pint of cold water for three or four hours, being occasionally rubbed or agitated: the solid matter should be separated from the fluid by means of blotting paper: the fluid should be gradually heated; if any flakes appear, they are to be separated by the same means as 
the solid matter in the last process, $i$. e. by filtration. The fluid is then to be evaporated to dryness. The matter obtained is to be examined by applying moist paper, tinged with red cabbage juice, or violet juice to it; if the paper become red, it contains acid matter; if it become green, alkaline matter; and the nature of the acid or alkaline matter may be known by applying the tests described page 108, 109, 110. If the solid matter be sweet to the taste, it must be supposed to contain sugar; if bitterish, bitter principle, or extract; if astringent, tannin : and if it be nearly insipid, it must be principally gum or mucilage. To separate gum or mucilage from the other principles, alcohol must be boiled upon the solid matter, which will dissolve the sugar and the extract, and leave the mucilage; the weight of which may be ascertained.

To separate sugar and extract, the alcohol must be evaporated till crystals begin to fall down, which are sugar; but they will generally be coloured by some extract, and can only be purified by repeated solutions in alcohol. Extract may be separated from sugar by dissolving the solid, obtained by evaporation from alcohol, in a small quantity of water, and boiling it for a long while in contact with the air. The extract will gradually fall down in the form of an insoluble powder, and the sugar will remain in solution.

If tannin exist in the first solution made by cold 
water, is separation is easily effected by the process described page 91 . The solution of isinglass must be gradually addled, to prevent the existence of an excess of animal jelly in the solution, which might be mistaken for mucilage.

When the vegetable substance, the subject of experiment, will afford no more principles to cold water, it must be exposed to boiling water. This will unite to starch if there be any, and may likewise take up more sugar, extract, and tannin, piovided they be intimately combined with the other principles of the compound.

The mode of separating starch is similar to that of separating mucilage.

If after the action of hot water any thing remain, the action of boiling alcohol is then to be tried. This will dissolve resinous matter; the quantity of which may be known by evaporating the alcohol.

The last agent that may be applied is ether, which dissolves elastic gum, though the application is scarcely ever necessary; for if this principle be present, it may be easily detected by its peculiar qualities.

If any fixed oil or wax exist in the vegetable substance, it will separate during the process of boiling in water, and may be collected. Any substance not acted upon by water, alcohol, or ether, must be regarded as woody fibre. 
If volatile oils exist in any vegetable substancess it is evident they may be procured, and their quantity ascertained, by distillation.

When the quantity of fixed saline, alkaline, metallic, or earthy matter in any vegetable compound is to be ascertained, the compound must be decomposed by heat, by exposing it, if a fixed substance, in a crucible, to a long continued red heat; and if a volatile substance, by passing it through an ignited porcelain tube. The nature of the matter so produced, may be learnt by applying the tests mentioned in page $\mathbf{1 1 4 .}$

The only analyses in which the agricultural chemist can often wish to occupy himself, are those of substances containing principally starch, sugar, gluten, oils, mucilage, albumen, and tannin.

The two following statements will afford an idea of the manner in which the results of experiments may be arranged.

The first is a statement of the composition of ripe. peas, deduced from experiments made by Einhof; the second are of the products afforded by oak bark, deduced from experiments conducted by myself.

Parts.

3840 parts of ripe peas afford, of starch - 1265

Fibrous matter analogous to starch, with the coats of 840 the peas _. . . . 
Parts,

3840 parts of a substance analogous to

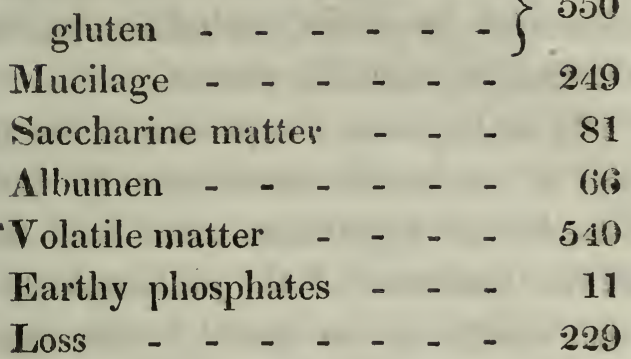

1000 parts of diy oak bark, from a small tree deprived of epidermis, contain,

Of woody fibre - - - - $\quad 876$

- tannin - - - - - - - 57

- extract - - - - - 31

- mucilage - - - - - - 18

- matter rendered insoluble during evaporation, probably a mix- $\{9$ ture of albumen and extract -

- loss, partly saline matter - - 30

To ascertain the primary elements of the different vegetable principles, and the proportions in which they are combined, different methods of analysis have been adopted. The most simple are their decomposition by heat, or their formation into new products by combustion.

When any vegetable principle is acted on by a strong red heat, its elements become newly arranged. Such of then as are volatile are expelled 
in the gaseous form; and are either condensed as finids, or remain permanently elastic. The fixed remainder is either carbonaceous, earthy, saline, alkaline, or metallic matter.

To make correct experiments on the decomposition of vegetable substances by lieat, requires a complicated apparatus, much time and labour, and all the resources of the philosophical chemist; but such results as are usefil to the agriculturist may be easily obtained. The apparatus necessary is a green glass retort, attached by cement to a receiver, connected with a tube passing under an inverted jar of known capacity, filled with water.* $\mathbf{A}$ given weight of the substance is to be heated to redness in the retort over a charcoal fire; the receiver is to be kept cool, and the process continued as long as any elastic matter is generated. The condensible fluids will collect in the receiver, and the fixed residuum will be found in the retort. The fluid products of the distillation of vegetable substances are principally water, with some acetous and mucous acids, and empyreumatic oil, or tar, and in some cases ammonia. Whe gasses are carbonic acid gas, carbonic oxide, and carburetted hydrogene; sometimes with olefiant gas, and hydrogene; and sometimes, but more rarely, with azote. Carbonic acid is the only one of those gasses rapidly absorbed by water; the rest are inflammable; olefiant gas 
burns with a bright white light ; carburetted hydrogene with a light like wax; carbonic oxide with a feeble, blue flame. 'The properties of hydrogene and azote have been described in the last Lecture. The specific gravity of carbonic acid gas, is to that of air as 20.7 to 13.7 , and it consists of one proportion of carbon 11.4, and two of oxygene 30. The specific gravity of gaseous oxide of carbon, is taking the same standard 13.2, and it consists of one proportion of carbon, and one of oxygene.

The specific gravities of carburetted hydrogene and olefiant gas are respectively eight and thirteen; both contain four proportions of hydrogene; the first contains one proportion, the second two proportions of carbon.

If the weight of the carbonaceous residuum be added to the weight of the fluids condensed in the receiver, and they be subtracted from the whole weight of the substance, the remainder will be the weight of the gaseous matter.

The aceious and mucous acids, and the ammonia formed are usually in very small quantities ; and by comparing the proportions of water and charcoal with the quantity of the grasses, taking into account their qualities, a general idea may be formed of the composition of the substance. The proportions of the elements in the greater number of the vegetable substances which can be used as food, have been already ascertained by philosophical chemists, and have been stated in the preceding pages; the ana- 
lysis by distillation may, however, in some cases, be useful in estimating the powers of manures, in a manner that will be explained in a future lecture.

The statements of the composition of vegetable substances, quoted from M. M. Gay Lussac and Thenard, were obtained by these philosophers by exposing the substances to the action of heated hyper-oxymuriate of potassa; a body that consists of potassium, chlorine, and oxygene; and which afforded oxygene to the carbon and the hydrogene. 'Their experiments were made in a peculiar apparafus, and required great caution, and were of a very delicate nature. It will not therefore be necessary to enter upon any details of them.

It is evident from the whole tenor of the statements which have been made, and the most essential vegetable substances consist of hydrogene, carbon, and oxygene in different proportions, generally alone, but in some few cases combined with azote. The acids, alkalies, earths, metallic oxides, and saline compounds, though nccessary in the regetable œconomy, must be considered as of less importance, particularly in their relation to agriculture, than the other principles : and as it appears from $M$. de Saussure's table, and from other experiments, they differ in the same species of vegetable when it is raised on different soils.

M. M. Gay Lussac and Thenard have deduced three propositions, which they have called laws from their experiments on vegetable substances. The 


\section{7}

first is, " that a vegetable substance is always acid whenever the oxygene it contains is to the hydrogene in a greater proportion than in water."

The second, " that a vegetable substance is always resinous or oily or spirituous whenever it contains oxygene in a smaller proportion to the hydrogene than exists in water."

The third, " that a vegetable substance is neither acid nor resinous; but is either saccharine or mucilaginous, or analogous to woody fibre or starch, whenever the oxygene and hydrogene in it are in the same proportions as in water."

New experiments upon other vegetable substances, besides those examined by M. M. Gay Lussac and Thenard, are required before these interesting conclusions can be fully admitted. Their researches establish, however, the close analogy between several vegetable compounds differing in their sensible qualities, and combined with those of other chemists, offer simple explanations of several processes in nature and art, by which different vegetable substances are converted into each other, or changed into new compounds.

Gum and sugar afford nearly the same elements by analysis; and starch differs from them only in containing a little more carbon. The peculiar properties of gum and sugar must depend chiefly upon the different arrangement, or degree of condensation of their elcments; and it would be natural to conceive from the composition of these 
bodies, as well as that of starch, that all three would be easily convertible one into the other ; which is actually the case.

At the time of the ripening of corn, the saccharine matter in the grain, and that carried from the sap vessels into the grain, becomes coagulated, and forms starch. And in the process of malting, the converse change occurs. The starch of grain is converted into sugar. As there is a little absorption of oxygene, and a formation of carbonic acid in this case, it is probable that the starch loses a little carbon, which combines with the oxygene to form carbonic acid; and probably the oxygene tends to acidify the gluten of the grain, and thus breaks down the texture of the starch; gives a new arrangement to its elements, and renders it soluble in water.

Mr. Cruikshank, by exposing syrup to a substance named phosphuret of lime, which has a great tendency to decompose water, converted a part of the sugar into a matier analogous to mucilage. And M. Kirchhoif, recently, has converted starch into sugar by a very simple process, that of boiling in very diluted sulphuric acid. The proportions are 100 parts of starch, 400 parts of water, and 1 part of strphuric acid by weight. This mixture is to be kept boiling for 40 hours; the loss of water by evaporation being supplied by new quantities. The acid is to be neutralized by lime; and the stgar crystallized by cooling. This experiment has 
been tried with success by many persons. Dr. Tuthill, from a pound and a. half of potatoe starch, procured a pound and a quarter of crystalline, brown sugar; which he conceives possessed properties intermediate between cane sugar and grape sugar.

It is probable that the conversion of starch into sugar is effected merely by the attraction of the acid for the elements of sugar; for various experiments have been made, which prove that the acid is not decomposed, and that no. elastic matter is set free; probably the colour of the sugar is owing to the disengagement, or new combination of a little carbon, the slight excess of which, as has been just stated, constitutes the only difference perceptible by analysis between sugar and starch.

M. Bouillon la Grange, by slightly roasting starch, has rendered it soluble in cold water; and the solution evaporated afforded a substance, having the characters of mucilage.

Gluten and albumen differ from the other vegetable products, principally by containing azote. When gluten is kept long in water it undergoes fermentation ; ammonia, (which contains its azote) is given off with acetic acid: and a fatty matter and a substance analogous to woody fibre remain.

Extract, tannin, and gallic acid, when their solutions are long exposed to air, deposit a matter similar to woody fibre; and the solid substances are rendered analogous to woody fibre by slight roast- 
ing; and in these cases it is probable that part of their oxygene and hydrogene is separated as water.

All the other vegetable principles differ from the vegetable acids in containing more hydrogene and carbon, or less oxygene ; many of them therefore are easily converted into vegetable acids by a mere subtraction of some proportions of hydrogene. 'The vegetable acids, for the most part, are convertible into each other by easy processes. The oxalic contains most oxygene; the acetic the least: and this last substance is easily formed by the distillation of other vegetable substances, or by the action of the atmosphere on such of them as are soluble in water; probably by the mere combination of oxygene with hydrogene and carbon, or in some cases by the subtraction of a portion of hydrogene.

Alcohol, or spirits of wine, has been often mentioned in the course of these Lectures. This substance was not described amongst the vegetable principles, because it has never been found ready formed in the organs of plants. It is procured by a change in the principles of saccharine matter, in a process called vinous fermentation.

The expressed juice of the grape contains sugar, mucilage, gluten, and some saline matter, principally composed of tartaric acid: when this juice, or must, as it is commonly called, is exposed to the temperature of about $70^{\circ}$, the fermentation begins : 


\section{1}

it becomes thick and turbid; its temperature increases, and carbonic acid gas is disengaged in abundance. In a few days the fermentation ceases; the solid matter that rendered the juice turbid falls to the bottom, and it clears; the sweet taste of the fluid is in great measure destroyed, and it is become spirituous.

Fabroni has shewn that the gluten in must is essential to fermentation; and that chemist has made saccharine matter ferment, by adding to its solution in water, common vegetable gluten and tartaric acid. Gay Lussac has demonstrated that must will not ferment when freed from air by boiling, and placed out of the contact of oxygene; but that fermentation begins as soon as it is exposed to the oxygene of air, a little of that principle being absorbed; and that it then continues independent of the presence of the atmosphere.

In the manufacture of ale and porter, the sugar formed during the germination of barley is made to ferment by dissolving it in water with a little yeast, which contains gluten in the state proper for producing fermentation, and exposing it to the requisite temperature; carbonic acid gas is given off as in the fermentation of must, and the liquor gradually becomes spirituous.

Similar phænomena occur in the fermentation of the sugar in the juice of apples and other ripe fruits. It appears that fermentation depends entirely upon a new arrangement of the elements of sugar; part 


\section{2}

of the carbon uniting to oxygene to form carbonic acid, and the remaining carbon, hydrogene, and oxygene combining as alcohol; and the use of the gluten or yeast, and the primary exposure to air seems to be to occasion the formation of a certain quantity of carbonic acid; and this change being once produced is continued; its agency may be compared to that of a spark in producing the inflammation of gunpowder; the increase of tempera-. ture occasioned by the formation of one quantity of carbonic acid occasions the combination of the elements of another quantity.

The results obtained by different chemists in experiments on the analysis of alcohol differ so much, that no general conclusions can be drawn from them. If it be supposed that one proportion of carbonic acid is formed in the fermentation of sugar, then, according to Dr. 'Thomson's analysis of sugar, which gives its composition as 3 proportions of carbon, 4 of oxygene, and 8 of hydrogene, alcohol wonld cousist of 2 proportions of carbon, 2 of oxygene, and 8 of hydrogene; and it might be considered as containing the same elements as two proportions of olefiant gas, with two proportions of oxyggene.

Alcohol in its purest known form, is a highly inflammable liquid, of specific gravity 796, at the temperature of $60^{\circ}$; it boils at about $170^{\circ}$ Fahrenheit. This alcohol is obtained by repeated distillation of the strongest common spirit from the salt 
ealled by chemists muriate of lime, it having been previously heated red hot.

The strongest alcohol obtained by the distillation of spirit without salts, has seldom a less specific gravity than 82.5 at $60^{\circ}$; and it contains, according to Lowitz's experiments, 89 parts of the alcohol of 796, and 11 parts of water. The spirit established as proof spirit by act of parliament passed in 1762, ought to have the specific gravity of 916 ; and this contains nearly equal weights of pure alcohol and water.

The alcohol in fermented liquors is in combination with water, colouring matter, sugar, mucilage, and the regetable acids. It has been often doubted whether it can be procured by any other process than distillation; and some persons have even supposed that it is formed by distillation. The recent experiments of Mr. Brande are conclusive against both these opinions. That gentleman has shewn that the colouring and acid matter in wines may be, for the most part, separated in a solid form by the action of a solution of sugar of lead (acetate of lead), and that the alcohol may be then obtained by aisstracting the water by means of hydrate of potassa or muriate of lime, without artificial heat.

The intoxicating powers of fermented liquors depend on the alcohol that they contain; but their action on the stomach is modified by the acid, saccharine, or mucilaginous substances they hold in 
solution. Alcohol probably acts with most efficacy when it is most loosely combined; and its energy seems to be impaired by union with large quantities of water, or with sugar or acid, or extractive matter.

The following table contains the results of $\mathrm{Mr}$. Brande's experiments on the quantity of alcohol of 825 at $60^{\circ}$, in different fermented liquors. 


\begin{tabular}{|c|c|c|c|}
\hline WINE. & 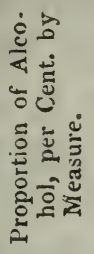 & WINls. & 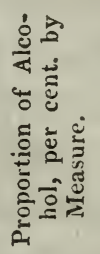 \\
\hline Port ........... & 21,40 & White Hermitage.. & 17,43 \\
\hline Ditto .......... & 22,30 & Red Hermitage ... & 12,32 \\
\hline Ditto .......... & 23,39 & Hock ........... & 14,37 \\
\hline Ditto ........... & 23,71 & Ditto .......... & 8,88 \\
\hline Ditto .......... & 24,29 & Vin de Grave .... & 12,80 \\
\hline Ditto ........... & 35,83 & Frontignac ..... & 12,79 \\
\hline Madeira ......... & 19,34 & Coti Roti ........ & 12,32 \\
\hline Ditto .......... & 21,40 & Rousillon........ & 17,26 \\
\hline Ditto . . . . . . . & 23,93 & Cape Madeira .... & 18,11 \\
\hline Ditto......... & 24,42 & Cape Muschat.... & 18,25 \\
\hline Sherry ......... & 18,25 & Constantia $\ldots . .$. & 19,75 \\
\hline Ditto .......... & 18,79 & Tent $\ldots . . . . . . .$. & 13,30 \\
\hline Ditto.......... & 19,81 & Sheraaz ........ & 15,52 \\
\hline Ditto.......... & 19,83 & Syracuse....... & 15,28 \\
\hline Claret ......... & 12,91 & Nice $\ldots . . . . . .$. & 14,63 \\
\hline Ditto.... & 14,08 & Tokay .......... & 9,88 \\
\hline Ditto $\ldots \ldots \ldots$ & 16,32 & Raisin Wine...... & 25,77 \\
\hline Calcavella ....... & 18,10 & Grape Wine....... & 18,11 \\
\hline Lishon .......... & 18,94 & Currant Wine .... & 20,55 \\
\hline Malaga.......... & 17,26 & Gooseberry IVine . & 11,84 \\
\hline Bucellas ........ & 18,49 & Elder Wine ...... & 9,87 \\
\hline Red Madeira .... & 18,40 & Cider ............ & 9,87 \\
\hline Malmsey Madeira . & 16,40 & Perry .......... & 9,87 \\
\hline Marsala ......... & 25,87 & Brown Stout ..... & 6,80 \\
\hline Ditto........ & $17,26 j$ & Ale $\ldots \ldots \ldots \ldots$ & 8,88 \\
\hline Red Champagne... & 11,30 & Prandy $\ldots . . . .$. & 53,39 \\
\hline White Champagne. & 12,89 & Rum ........... & 53,68 \\
\hline Burgundy ........ & 14,53 & Hollands ........ & 51,60 \\
\hline Ditto .......... & 11,$9 ;$ & & \\
\hline
\end{tabular}


The spirits distilled from different fermented liquors differ in their flavour : for peculiar odorous matter, or volatile oils, rise in most cases with the alcohol. The spirit from malt usually has an empyreumatic taste like that of oil, formed by the distillation of vegetable substances. The best brandies seem to owe their flavour to a peculiar oily matter, formed probably by the action of the tartaric acid on alcohol; and rum derives its characteristic taste from a principle in the sugar cane. All the common spirits may, I find, be deprived of their peculiar flavour by repeatedly digesting them with a mixture of well burnt charcoal and quicklime; they then afford pure alcohol by distillation. The cogniac brandies, I find, contain vegetable prussic acid, and their flavour may be imitated by arlding to a solution of alcohol in water of the same strength, a few drops of the ethereal oil of wine produced during the formation of ether*, and a similar quantity of regetable prussic acid procured from laurel leaves or any bitter kernels.

I have mentioned ether in the course of this Lecture; this substance is procured from alcohol by distilling a mixture of equal parts of alcohol and sulphuric acid. It is the lightest known liquid

* In the process of the distillation of alcohol and sulphuric acid after the ether is procured; by a higher degree of heat, a yellow fluid is produced, which is the substance in question. It has a fragrant smel! and an agreeable taste. 
substance, being of specific gravity 632 at $600^{\circ}$ It is very volatile, and rises in vapour even hy the heat of the hody. It is highly inflammable. In the formation of ether it is most probable that carbon and the elements of water are separated from the alcohol, and that ether differs from alcohol in containing less oxygene and carbon; but its composition has not yet been accurately ascertainer. Like alcohol it possesses intoxicating powers.

A number of the changes taking place in the vegetable principles depend upon the separation of oxygene and hydrogene as water from the compound; but there is one of very great importance, in which a new combination of the elements of water is the principal operation. This is in the manufacture of bread. When any kind of flour, which consists principally of starch, is made into a paste with water, and immediately and gradually heated to about $440^{\circ}$, it increases in weight, and is found entirely altered in its properties; it has lost its solubility in water, and its power of being converted into sugar. In this state it is unleavened bread.

When the flour of corn or the starch of potatoes, mixed with boiled potatoes, is made into a paste with water, kept warm, and suffered to remain 30 or 40 hours, it ferments, carbonic acid gas is disengaged from it, and it becomes filled with globules of elastic fluid. In this state it is raised dough, and affords by baking, leavened bread; but this bread is sour and disagreeable to the taste; and leavened bread for use is made by mixing a little dough, that 
has fermented, with new dough, and kneading them together, or by kneading the bread with a small quantity of yeast.

In the formation of wheaten bread more than $\frac{x}{4}$ of the elements of water combine with the flour; more water is consolidated in the formation of bread from barley, and still more in that from oats; but the gluten in wheat, being in much larger quantity than in other grain, seems to form a combination with the starch and water, which renders wheaten brearl more digestible than the other species of liread.

The arrangement of many of the vegetable principles in the different parts of plants has been incidentally mentioned in this Lecture; but a more particular statement is required to afford just views of the relation between their organization and chemical constitution, which is an object of great importance. The tubes and hexagonal cells in the vascular system of plants are composed of woody fibre; and when they are not filled with fluid matter they contain some of the solid materials which formed a constituent part of the fluids belonging to them.

In the rocts, trunk, and branches, the bark, alburnum, and heartwood, the leaves and flowers; the great basis of the solid parts is woody fibre. It forms by far the greatest part of the heartwood and bark; there is less in the alburnum, and still less in the leaves and flowers. The alburnum of the birch contains so much sugar and mucilage, that it is 
sometimes used in the North of Europe as a substitute for bread. The leaves of the cabbage, broccoli, and seacale, contain much mucilage, a little saccharine matter, and a little albumen. From 1000 parts of the leaves of common cabbage I obtained 41 parts of muciliage, 24 of sugar, and 8 of albuminous matter.

In bulbous roots, and sometimes in common roots, a large quantity of starch, albumen, and mucilage, are often found deposited in the ressels; and they are most abundant after the sap has ceased to flow; and afford a nourishment for the early shoots made in spring. The potatoe is the bulb that contains the largest quantity of soluble matter in its cells and vessels; and it is of most importance in its application as food. Potatoes in general afford from onefifth to one-seventh their weight of dry starch. From 100 parts of the common Kidney potatoe, Dr. Pearson obtained from 32 to 28 parts of meal, which contained from 23 to 20 of starch and mucilage: and 100 parts of the Apple potatoe in various experiments, afford me from 18 to 20 parts of pure starch. From five pounds of the variety of the potatoe called Captain hart, Mr. Skrimshire, jun, obtained $12 \mathrm{oz}$. of starch, from the same quantity of the Rough red potatoe $10 \frac{\mathrm{I}}{2} \mathrm{oz}$., from the Moulton white $11 \frac{3}{4}$, from the Yorkshire kidney $10 \frac{3}{4}$ oz., from Hundred eyes 9 oz., from Purple red $8 \frac{x}{2}$, from $O x$ roble $8 \frac{1}{4}$. The other soluble substances in the potatoe are albumen and mucilage. 
From the analysis of Einhoff it appears that 7680 parts of potatoes afford

Of starch - - - - - - 1153

- Fibrous matter analogous to starch $\quad 540$

- Albumen - - - - - - - 107

- Mucilage in the state of a saturated solution - - - - - $\}$

2112

So that a fourth part of the weight of the potatoe at least may be considered as nutritive matter.

The turnip, carrot, and parsnip, afford principally saccharine, mucilaginous, and extractive matter. I obtained from 1000 parts of common turnips seven parts of mucilage, 34 of saccharine matter, and nearly one part of albumen. 1000 parts of carrots furnished 9.5 parts of sugar, three parts of mucilage, and one-half of extract; 1000 parts of parsnip afforded 90 parts of saccharine matter, and nine parts of mucilage. The Walcheren or white carrot, gave in 1000 parts, 98 parts of sugar, two parts of mucilage, and one of extract.

Fruits, in the organization of their soft parts, approach to the nature of bulbs. They contain a certain quantity of nourishment laid up in their cells for the use of the embryon plant; mucilage, sugar, starch, are found in many of them often combined with vegetable acids. Most of the fruit trees common in Britain have been naturalized on account of the saccharine matter they contain, which, united 
to the vegetable acids and mucilage, renders them at once arreeable to the taste and nutritive.

The value of fruits for the manufacture of fermented liquors may be judged of from the specific gravity of their expressed juices. The best cyder and perry are made from those apples and pears that afford the densest juices; and a comparison between different fruits may be made with tolerable accuracy by plunging them together into a saturated solution of salt, or a strong solution of sugar: those that sink deepest will afford the richest juice.

Starch or coagulated mucilage forms the greatest part of the seeds and grains used for food; and they are generally combined with gluten, oil, or albuminous matter. In corn, with gluten, in peas and beans, with albuminous matter; and in rape-seed, hemp-seed, linseed, and the kernels of most nuts, with oils.

I found 100 parts of good full grained wheat sown in autumn to afford

Of starch - - - 77

- Gluten - - - - 19

100 parts of wheat sown in spring,

Of starch - - - 70

-Gluten - - - 24

100 parts of Barbary wheat,

Of starch - - - 74

- Gluten - - . - 23

100 parts of Sicilian wheat,

Of starch _ - - 75

- Gluten - - $\leq 21$ 
I have examined different specimens of North American wheat, all of them have contained rather more gluten than the British. In general the wheat of warm climates abounds more in gluten, and in insoluble parts; and it is of greater specific gravity, harder, and more difficult to grind.

The wheat of the south of Europe, in consequence of the larger quantity of gluten it contains, is peculiarly fitted for making macaroni, and other preparations of flower in which a glutinous quality is considered as an excellence.

In some experiments made on barley, I obtained from 100 parts of full and fair Norfolk barley,

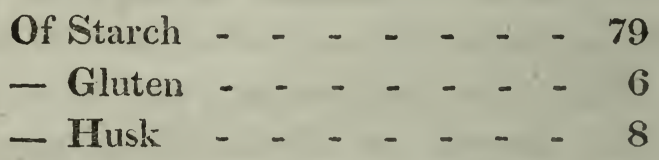

The remaining seven parts saccharine matter. The sugar in barley is probably the chief cause why it is more proper for malting than any other species of grain.

Einhoff has published a minute analysis of barley meal. He found in 3840 parts,

Of volatile matter - $\quad-\quad-360$

- Albumen - - - - - 44

- Saccharine matter - - 200

- Mucilage - - - - - 176

- I'hosphate of lime, with some

$$
\text { albumen - - - } 9
$$


Of Gluten - - - - - 135

- Husk, with some gluten and starch - - - 260

- Starch not quite free from gluten - - - - 2580

- Loss - - - - - - 78

Rye afforded to Einhoff, in 3840 parts; 2520 meal, 930 husk, and 390 moisture; and the same quantity of meal analyzed gave,

$$
\begin{aligned}
& \text { Of Starch - - - - } 2345 \\
& \text { - Albumen - - - - } 126 \\
& \text { - Mucilage - - - } 426 \\
& \text { - Saccharine matter - } 126 \\
& \text { - Gluten not dried - - } 364
\end{aligned}
$$

Remainder husk and loss.

I obtained from 1000 parts of rye, grown in Suffolk, 61 parts of starch, and five parts of gluten.

100 parts of oats, from Sussex, afforded me 59 parts of starch, six of gluten, and two of saccharine matter.

1000 parts of peas, grown in Norfolk, afforded me 501 parts of starch, 22 parts of saccharine matter, 35 parts of albuminous matter, and 16 parts of extract, which became insoluble during evaporation of the saccharine fluid. 
From 3840 parts of marsh beans (Vicia faba), Einhoff obtained,

Of Starch - - - - - - 1312

- Albumen - - - - - - 31

- other matters which may be conceived nutritive; such as gummy, starchy, fibrous matter analogous to animal matter)

The same quantity of kidney beans (Phaseolus vulyaris,) afforded,

Of matter analogous to starch - $\quad 1805$

- Albumen and matter approaching to animal matter in its nature - - -

- Mucilage - _ _ _ _ 799

From 3840 parts of lentiles he obtained $\mathbf{1 2 6 0}$ parts of starch, and 1433 of a matter analogous to animal matter.

The matter analogous to animal matter is described by Einhoff; as a glutinous substance insoluble in water; soluble in alcohol when dry, having the appearance of glue; probably a peculiar modification of gluten.

From 16 parts of hemp-seeds Bucholz obtained three parts of oil, three and a half parts of albu- 
men, about one and three quarters of saccharine and gummy matter. The insoluble husks and coats of the seeds weighed six and one-eighth parts.

The different parts of flowers contain different substances : the pollen, or impregnating dust of the date, has been found by Fourcroy and Vauquelin to contain a matter analogous to gluten, and a soluble extract abounding in malic acid. Link found in the pollen of the hazel-tree, much tannin and gluten.

Saccharine matter is found in the nectarium of flowers, or the receptacles within the corolla, and by tempting the larger insects into the flowers, it renders the work of impregnation more secure; for the pollen is often by their means applied to the stigma; and this is particularly the case when the male and female organs are in different flowers or different plants.

It has been stated that the fragrance of flowers depends upon the volatile oils they contain; and these oils, by their constant evaporation, surround the flower with a kind of odorous atmosphere; which, at the same time that it entices larger insects, may probably preserve the parts of fructification from the ravages of smaller ones. Volatile oils, or odorous substances, seem particularly destrictive to these minute insects and animalcules which feed on the substance of vegetables; thousands of aphides may be usually seen in the stalk and leaves of the rose; but none of them are ever 
observed on the flower. Camphor is used to preserve the collections of naturalists. The woods that contain aromatic oils are remarked for their indestructibility; and for their exemption from the attacks of insects: this is particularly the case with the cedar, rose-wood, and cypress. The gates of Constantinople, which were made of this last wood, stood entire from the time of Constantine, their founder, to that of Pope Eugene IV. a period of 1100 years.

The petals of many flowers afford saccharine and mucilaginous matter. The white lily yields mucilage abundantly: and the orange lily a mixture of mucilage and sugar; the petals of the convolvulus afford sugar, mucilage, and albuminous matter.

The chemical nature of the colouring matters of flowers has not as yet been subject to any very accurate observation. These colouring matters, in general, are very transient, particularly the blues and reds; alkalies change the colours of most flowers to green, and acids to red. . An imitation of the colouring matter may be made by digesting solutions of gall-nuts with chalk: a green fluid is obtained, which becomes red by the action of an acid; and has its green colour restored by means of alkalies.

The yellow colouring matters of flowers are the most permanent; the carthamus contains a red and a yellow colouring matter; the yellow colouring 


\section{7}

matter is easily dissolved by water, and from the red, rouge is prepared by a process which is kept secret.

The same substances as exist in the solid parts of plants are found in their fluids, with the exception of woody fibre. Fixed and volatile oils containing resin or camphor, or analogous substances in solution exist in the cylindrical tubes belonging to a number of plants. Different species of Euphorbia emit a milky juice, which when exposed to air deposit a substance analogous to starch, and another similar to gluten.

Opium, gum elastic, gamboge, the poisons of the Upas Antiar and Tieute, and other substances that exude from plants, may be considered as peculiar juices belonging to appropriate vessels.

The sap of plants, in general, is very compound in its nature; and contains most saccharine, mucilaginous, and albuminous matter in the alburnum; and most tannin and extract in the bark. The cambium, which is the mucilaginous fluid found in trees between the wood and the bark, and which is essential to the formation of new parts, seems to be derived from these two kinds of sap; and probably is a combination of the mucilaginous and albumin. ous matter of one, with the astringent matter of the other, in a state fitted to become organized by the separation of its watery parts.

The alburnous saps of some trees have been chemically examined by Vauquelin. He found in

\section{$\mathbf{x} 2$}


those of the elm, beech, yoke elm, hornbeam and birch, extractive and mucilaginous matter, acetic acid combined with potassa or lime. The solid matter afforded by their evaporation yielded an ammoniacal smell, probably owing to albumen: the sap of the birch afforded saccharine matter.

Deyeux in the sap of the vine and the yoke elm has detected a matter analogous to the curd of milk. I found a substance similar to albumen in the sap of the walnut-tree.

I found the juice which exudes from the vessels of the marshmallow when cut, to be a solution of mucilage.

The fluids contained in the sap vessels of wheat and barley, afforded in some experiments which I made on them, mucilage, sugar, and a matter which coagulated by heat; which last was most abundant in wheat.

The following table contains a statement of the quantity of soluble or nutritive matters contained in varieties of the different substances that have been mentioned, and of some others which are used as articles of food, either for man or cattle. The analyses are my own; and were conducted with a view to a knowledge of the general nature and quantity of the products, and not of their intimate chemical composition. The soluble matters afforded by the grasses, except that from the fiorin in winter, were obtained by Mr. Sinclair, garilener to the Duke of Bedford, from given weights of the 


\title{
149
}

\begin{abstract}
grasses cut when the seeds were ripe; they were sent to me by his Grace's desire for chemical examination; and form part of the results of an important and extensive series of experiments on grasses, made by direction of the Duke, at Woburn Abbey, the full details of which I shall hereafter bave the pleasure of stating.
\end{abstract}


Table of the Quantities of soluble or nutritivo Matters afforded by 1000 Parts of different vegetable Substances.

\begin{tabular}{|c|c|c|c|c|c|}
\hline Vegetables or vegretable Sabstance. & $\begin{array}{l}\text { Whoie quan- } \\
\text { tity of solu- } \\
\text { ble or numri- } \\
\text { tive matter. }\end{array}$ & $\begin{array}{c}\text { Nucilage or } \\
\text { Starclb. }\end{array}$ & $\begin{array}{l}\text { Saccharine } \\
\text { matter or } \\
\text { Sugar. }\end{array}$ & $\begin{array}{l}\text { Gluten or } \\
\text { Albumen. }\end{array}$ & $\begin{array}{l}\text { Extract, or } \\
\text { matter ren- } \\
\text { dered inso- } \\
\text { luble during } \\
\text { evapora- } \\
\text { tion. }\end{array}$ \\
\hline Middlesex wheat, average & & & & & \\
\hline crop $\ldots . . . \ldots \ldots \ldots$ & 955 & 765 & - & 190 & \\
\hline Spring wheat ........... & 940 & 700 & - & 240 & \\
\hline Mildewed wheat of 1806 & 210 & 178 & - & 32 & \\
\hline Blighted wheat of 1804 & 650 & 520 & - & 130 & \\
\hline Thick-skinned Sicilian & & & & & \\
\hline wheat of $1810, \ldots \ldots \ldots$ & 955 & 725 & - & 230 & \\
\hline Thin-skinned Sicilian & & & & & \\
\hline wheat of $1810 \ldots \ldots$ & 961 & 722 & - & 239 & \\
\hline Wheat from Poland & 950 & 750 & - & 200 & \\
\hline North American wheat .. & 955 & 730 & - & 225 & \\
\hline Norfolk barley ........... & 920 & 790 & 70 & 60 & \\
\hline Oats from Scotland ...... & 743 & 641 & 15 & 87 & \\
\hline Rye from Yorkshire .... & 792 & 645 & 38 & 109 & \\
\hline Common bean........ & 570 & 426 & - & 103 & 41 \\
\hline Dry peas .................. & 574 & 501 & 22 & 35 & 16 \\
\hline Potatoes ....... & $\left\{\begin{array}{l}\text { from } 250 \\
\text { to } \approx 00 .\end{array}\right.$ & $\left\{\begin{array}{l}\text { from } 200 \\
\text { to } 155 .\end{array}\right.$ & $\left\{\begin{array}{l}\text { from } 20 \\
\text { to } 15 .\end{array}\right.$ & $\left\{\begin{array}{l}\text { from } 40 \\
\text { to } 30 .\end{array}\right.$ & \\
\hline Linseed cake ......... & 151 & 123 & $\cdot 11$ & 17 & \\
\hline Red beet ................ & 148 & 14 & 121 & 14 & \\
\hline White beet ............. & 136 & 13 & 119 & 4 & \\
\hline Parsnip ............... & 99 & 9 & 90 & & \\
\hline Carrots ............... & 98 & 3 & 95 & & \\
\hline Common turnips .... & 42 & 7 & 34 & 1 & \\
\hline Swedish turnips...... & 64 & 9 & 51 & 2 & 2 \\
\hline Cabbage $\quad . . \ldots \ldots \ldots \ldots$ & 73 & 41 & 24 & 8 & \\
\hline Broad-leaved clover .... & 39 & 31 & 3 & 2 & 3 \\
\hline Long-rooted clover ...... & 39 & 30 & 4 & 3 & 2 \\
\hline White clover ............ & 32 & 29 & 1 & 3 & 5 \\
\hline Sainfoin $\ldots . . . \ldots \ldots \ldots$ & 39 & 28 & 2 & 3 & 6 \\
\hline Lucerne............ & 23 & 18 & 1 & - & 4 \\
\hline Meadow fox-tail grass & 33 & 24 & 3 & - & 6 \\
\hline Perengial rye grass .... & 39 & 26 & 4 & - & 5 \\
\hline Fertile meadow grass .... & 78 & 65 & 6 & - & 7 \\
\hline Roughish meadow grass.. & 39 & 29 & 5 & - & 6 \\
\hline Crested dog's-tail grass .. & 35 & 28 & 3 & - & 4 \\
\hline Spiked fescue grass ...... & 19 & 15 & 2 & 一 & 2 \\
\hline Sweet-scented soft grass & 82 & 72 & 4 & - & 6 \\
\hline Sweet-scented vernal grass & 50 & 43 & 4 & - & 3 \\
\hline Fiorin $\ldots \ldots \ldots \ldots \ldots$ & 54 & 46 & 5 & 1 & 2 \\
\hline Fiorin cut in winter...... & 76 & 64 & 8 & 1 & 3 \\
\hline
\end{tabular}




\section{1}

All these substances were, submitted to experiment green, and in their natural states. It is probable that the excellence of the different articles as food will be found to be in a great measure propor. tional to the quantities of soluble or nutritive matters they afford; but still these quantities cannot be regarded as absolutely denoting their value. Albuminous or glutinous matters have the characters of animal substances; sugar is more nourishing, and extractive matter less nourishing, than any other principles composed of carbon, hydrogene, and oxygene. Certain combinations likewise of these substances may be more nutritive than others.

I have been informed by Sir Joseph Banks, that the Derbyshire miners in winter, prefer oat cakes to wheaten bread; finding that this kind of nourishment enables them to support their strength and perform their labour better. In summer, they say oat cake heats them, and they then consume the finest wheaten bread they can procure. Even the skin of the kernel of oats probably has a nourishing power, and is rendered partly soluble in the stomach with the starch and gluten. In most countries of Europe, except Britain, and in Arabia, horses are fed with barley mixed with chopped straw; and the chopped straw. seems to act the same part as the husk of the oat. In the mill $14 \mathrm{lbs}$, of good wheat yield on an average 13lbs. of flour; the same quantity of barley $12 \mathrm{lbs}$, and of oats only 8lbs.

In the south of Europe, hard or thin-skioned 
wheat is in higher estimation, than soft or thickskinned wheat: the reason of which is obvious, from the larger quantity of gluten and nutritive matter it contains. I have made an analysis of only one specimen of thin-skinned wheat, so that other specimens may possibly contain more nutritive matter than that in the Table: the Barbary and Sicilian wheats, before referred to, were thickskinned wheats. In England the difficulty of grinding thin-skinned wheat is an objection; but this difficulty is easily overcome by moistening the corn *.

* For the following note on the subject I am indebted to the kindness of the Right Hon. Sir Joseph Banks, Bart. K. B.

Information received from John Jeffery, Esq. His Majesty's Consul General at Lisbon, in Answer to Queries transmitted to him, from the Comm. of P. C. for Trade, dated Jan. 12, 1812.

To grind hard corn with the mill-stones used in England, the wheat must be well screened, then sprinkled with water at the miller's discretion, and laid in heaps and frequently turned and thoroughly mixed, which will soften the husk so as to make it separate from the flour in grinding, and of course give the flour a brighter colour; otherwise the flinty quality of the wheat, and the thinness of the skin will prevent its separation, and will render the flour unfit for making into bread.

I am informed by a miller of considerable experience, and who works his mills entirely with the stones from England or Ireland, that he frequently prepares the hard Barbary corn by immersing it in water in close wicker baskets, and spreading it thinly on a floor to dry; much depends on the judgment 
and skill of the miller in preparing the corn for the mill according to its relative quality. I beg to observe, that it is not from this previous process of wetting the corn that the weight in the flour of hard corn is increased; but from its natural quality it imbibes considerably more water in making it into bread. The mill-stenes must not be cut too deep, but the furrows very fine, and picked in the usual way. The mills should work with less velocity in grinding hard corn than with soft, and set to work at first with soft corn, till the mill ceases to work well; then put on the hard corn. Hard wheat always sells at a higher price in the market than soft wheat, on an average of ten to fifteen per cent.; as it produces more flour in proportion, and less bran than the soft corn.

Flour made from hard wheat is more esteemed than what is made from soft corn; and both sorts are applied to every purpose.

The flour of hard wheat is in general superior to that made f rom soft; and there is no difference in the process of making them into bread; but the flour from hard wheat will imbibe and retain more water in making into bread; and will consequently produce more weight of bread: it is the practice here, and which I am persuaded it would be advisable to adopt in England, to make bread with flour of hard and soft wheat, which by being mixed, will make the bread mucl better. 


\section{LECTURE IV.}

On Soils: their constituent Parts. On the Analy. sis of Soils. Of the Uses of the Soil. Of the Rocks and Strata found beneath Soils. Of the Improvement of Soil.

No subjects are of more importance to the farmer than the nature and improvement of soils; and no parts of the doctrines of agriculture are more capable of being illustrated by chemical enquiries.

Soils are extremely diversified in appearance and quality; yet as it was stated in the Introductory Lecture, they consist of different proportions of the same elements; which are in various states of chemical combination, or mechanical mixture.

The substances which constitute soils have been already mentioned. They are certain compounds of the earths, silica, lime, alumina, magnesia, and of the oxides of iron and manganesum; and animal and vegetable matters in a decomposing state, and saline, acid or alkaline combinations.

In all chemical experiments on the composition of soils connected with agriculture, the constituent parts obtained are compounds; and they act as 
compounds in nature: it is in this state, therefore, that I shall describe their characteristic properties.

1. Silica, or the earth of flints, in its pure and crystallized form, is the substance known by the name of rock crystal, or Cornish diamond. As it is procured by chemists, it appears in the form of a white impalpable powder. It is not soluble in the common acids, but dissolves by heat in fixed alkaline lixivia. It is an incombustible substance, for it is saturated with oxygene. I have proved it to be a compound of oxygene, and the peculiar combustible body which I have named silicum; and from the experiments of Berzelius, it is probable that it contains nearly equal weights of these two elements.

2. These sensible properties of lime are well known. It exists in soils usually united to carbonic acid; which is easily disengaged from it by the attraction of the common acids. It is sometimes found combined with the phosphoric and sulphuric acids. Its chemical properties and agencies in its pure state will be described in the Lecture on manures obtained from the mineral kingdom. It is soluble in nitric and muriatic acids, and forms a substance with sulphuric acid, difficult of solution, called gypsum. It is not soluble in alkaline solutions. It consists of one proportion 40 of the peculiar metallic substance, which I have named calcium; and one proportion 15 of oxygene. 
3. Alumina exists in a pure and crystallized state in the white sapphire, and united to a little oxide of iron and silica in the other oriental gems. In the state in which it is procured by chemists, it appears as a white powder, soluble in acids and fixed alkaline liquors. From my experiments, it appears that alumina consists of one proportion 33 of aluminum, and one 15 of oxygene.

4. Magnesia exists in a pure crystallized state, constituting a mineral like talc found in North America. In its common form it is the magnesia usta, or calcined magnesia of druggists. It generally exists in soils combined with carbonic acid. It is soluble in all the mineral acids; but not in alkaline lixivia. It is distinguished from the other earths found in soils by its ready solubility in solutions of alkaline carbonates, saturated with carbonic acid. It appears to consist of 38 magnesium and 15 oxygene.

5. There are two well known oxides of iron, the black and the brown. The black is the substance that flies off when red hot iron is hammered. The brown oxide may be formed by keeping the black oxide red hot, for a long time in contact with air. The first seems to consist of one proportion of iron 103 , and two of oxygene 30 ; and the second of one proportion of iron 103, and three proportions of oxygene 45 . The oxides of iron sometimes exist in soils combined with carbonic acid. They are easily distinguished from other substances by their 


\section{7}

giving when dissolved in acids a black colour to solution of galls, and a bright blue precipitate to solution of prussiate of potassa and iron.

6. The oxide of manganesum is the substance commonly called manganese, and used in bleaching. It appears to be composed of one proportion of manganesum 113, and three of oxygene 45 . It is distinguished from the other substances found in soils, by its property of decomposing muriatic acid, and converting it into chlorine.

Vegetable and animal matters are known by their sensible qualities, and by their property of being decomposed by heat. Their characters may be learnt from the details in the last Lecture.

8. The saline compounds found in soils, are common salt, sulphate of magnesia, sometimes sulphate of iron, nitrates of lime aná of magnesia, sulphate of potassa, and carbonates of potassa and soda. To describe their characters minutely will be unnecessary; the tests, for most of them have been noticed p. 114.

The silica in soils is usually combined with alumina and oxide of iron, or with alumina, lime, magnesia and oxide of iron, forming gravel and sand of different degrees of fineness. The carbonate of lime is usually in an impalpable form: but sometimes in the state of calcareous sand. The magnesia, if not combined in the gravel and sand of soil, is in a fine powder united to carbonic acid. The impalpable part of the soil, which is usually 
called clay or loam, consists of silica, alumind, lime, and magnesia; and is, in fact, usually of the same composition as the hard sand, but more finely divided. The vegetable, or animal matters, (and the first is by far the most common in soils) exist in different states of decomposition. They are sometimes fibrous, sometimes entirely broken down and mixed with the soil.

To form a just idea of soils, it is necessary to conceive different rocks decomposed, or ground into parts and powder of different degrees of fineness; some of their soluble parts dissolred by water, and that water adhering to the mass, and the whole mixed with larger or smaller quantities of the remains of vegetables and animals, in different stages of decay.

It will be necessary to describe the processes by which all the varieties of soils may be analysed. I shall be minute in these particulars, and, I fear, tedious; but the philosophical farmer will, I trust, feel the propriety of full details on this subject.

The instruments required for the analysis of soils are few, and but little expensive. They are a balance capable of containing a quarter of a pound of common soil, and capable of turning when loaded, with a grain; a set of weights from a quarter of a pound troy to a grain; a wire sieve, sufficiently coarse to admit a mustard seed through its apertures; an Argand lamp and stand; some glass bottles; Hessian crucibles; porcelain, or queen's ware evaporating basins; a Wedgewood pestle and mor- 
tar; some filtres made of half a sheet of blotting paper, folded so as to contain a pint of liquid, and greased at the edges; a bone knife, and an apparatus for collecting and measuring aeriform fluids.

The chemical substances or reagents required for separating the constituent parts of the soil, have, for the most part, been mentioned before: they are muriatic acid (spirit of salt), sulphuric acid, pure volatile alkali dissolved in water, solution of prussiate of potash and iron, succinate of ammonia, soap lye, or solution of potassa, solutions of carbonate of ammonia, of muriate of ammonia, of neutral carbonate of potash, and nitrate of ammoniac.

In cases when the general nature of the soil of a field is to be ascertained, specimens of it should be aken from different places, two or three inches below the surface, and examined as to the similarity of their properties. It-sometimes happens, that upon plains the whole of the upper stratum of the land is of the same kind, and in this case, one analysis will be sufficient; but in vallies, and near the beds of rivers, there are very great differences, and it now and then occurs that one part of a field is calcareous, and another part siliceous; and in this case, and in analogous cases, the portions different from each other should be separately submitted to experiment.

Soils when collected, if they cannot be immedi- 
ately examined, should be preserved in phials quite filled with them, and closed with ground glass stoppers.

The quantity of soil most convenient for a perfect analysis, is from two to four hundred grains. It should be collected in dry weather, and exposed to the atmosphere till it becomes dry to the touch.

The specific gravity of a soil, or the relation of its weight to that of water, may be ascertained by introducing into a phial, which will contain a known quantity of water, equal volumes of water and of soil, and this may be easily done by pouring in water till it is half full, and then adding the soil till the fluid rises to the mouth; the difference between the weight of the soil and that of the water, will give the result. Thus if the bottle contains four hundred grains of water, and gains two hundred grains when half filled with water and half with soil, the specific gravity of the soil will be 2 , that is, it will be twice as heavy as water, and if it gained one hundred and sixty-five grains, its speeific gravity would be 1825, water being 1000 .

It is of importance, that the specific gravity of a soil should be known, as it affords an indication of the quantity of animal and vegetable matter it contains; these substances being always most abundant in the lighter soils.

The other physical properties of soils should likewise be examined before the analysis is made, as they denote, to a certain extent, their composition, 
and serve as guides in directing the experiments. Thus siliceous soils are generally rough to the touch, and scratch glass when rubbed upon it; ferruginous soils are of a red or yellow colour; and calcareous soils are soft.

1. Soils, though as dry as they can be made by continued exposure to air, in all cases still contain a considerable quantity of water, which adheres with great obstinacy to the earths and animal and regetable matter, and can only be driven off from them by a considerable degree of heat. The first process of analysis is, to free the given weight of soil from as much of this water as possible, without in other respects, affecting its composition; and this may be done by heating it for ten or twelve minutes over an Argand's lamp, in a basin of porcelain, to a temperature equal to 300 Fahrenheit; and if a thermometer is not used, the proper degree may be easily ascertained, by keeping a piece of wood in contact with the bottom of the dish; as long as the colour of the wood remains unaltered, the heat is not too high; but when the wood begins to be charred, the process must be stopped. A small quantity of water will perhaps remain in the soil even after this operation, but it always affords useful comparative results; and if a higher temperature were employed, the vegetable or animal matter would undergo decomposition, and in consequence the experiment be wholly unsatisfactory.

The loss of weight in the procoss should be care- 
fully noted, and when in four hundred grains of soil it reaches as high as 51), the soil may be considered as in the greatest degree absorbent, and retentive of water, and will generally be found to contain much vegetable or animal matter, or a large proportion of aluminous earth. When the loss is only from 20 to 10 , the land may be considered as only slightly absorhent and retentive, and siliceous earth probably forms the greatest part of it.

2. None of the loose stones, gravel, or large vegetable fibres should be divided from the pure soil till after the water is drawn off; for these bodies are themselves often highly absorbent and retentive, and in consequence influence the fertility of the land. The next process, however, after that of heating, should be their separation, which may be easily accomplished by the sieve, after the soil has been gently bruised in a mortar. The weights of the vegetable fibres or' wood, and of the gravel and stones should be separately noted down, and the nature of the last ascertained; if calcareous, they will effervesce with acids; if siliceous, they will be sufficiently hard to scratch glass; and if of the common aluminous class of stones, they will be soft, easily cut with a knife, and incapable of effervescing with acids.

3. The greater number of soils, besides gravel and stones, contain larger or smaller proportions of sand of different degrees of fineness; and it is a necessary operation, the next in the process of analysis, to detach them from the parts in a state of 
more minute division, such as clay, loam, marle, vegetable and animal matter, and the matter soluble in water. This may be effected in a way sufficiently accurate, by boiling the soil in three or four times its weight of water; and when the texture of the soil is broken down, and the water cool; by agitating the parts together, and then suffering them to rest. In this case, the coarse sand will generally separate in a minute, and the finer in two or three minutes, whilst the highly divided earthy, animal, or vegetable matter will remain in a state of mechanical suspension for a much longer time; so that by pouring the water from the bottom of the vessel, after one, two, or three minutes, the sand will be principally scparated from the other substances, which, with the water containing them, must be poured into a filtre, and after the water has passed through, collected, dried, and weighed. The sand must likewise be weighed, and the respective quantities noted down. The water of lixiviation must be preserved, as it will be found to contain the saline and soluble animal or vegetable matters, if any exist in the soil.

4. By the process of washing and filtration, the soil is separated into two portions, the most important of which is generally the finely divided matter. A minute analysis of the sand is seldom or mever necessary, and its nature may be detected in the same manner as that of the stones or gravel. It is 
always either siliceous sand, or calcareous sand, or a mixture of both. If it consist wholly of carbonate of lime, it will be rapidly soluble in muriatic acid, with effervescence; but if it consist partly of this substance, and partly of siliceous matter, the respective quantities may be ascertained by weighing the residuum after the action of the acid, which must be applied till the mixture has acquired a sour taste, and has ceased to effervesce. This residuum is the siliceous part: it must be washed, dried, and heated strongly in a crucible; the difference between the weight of it and the weight of the whole, indicates the proportion of calcareous sand.

5. The finely divided matter of the soil is usually very compound in its nature; it sometimes contains all the four primitive earths of soils, as well as animal and vegetable matter; and to ascertain the proportions of these with tolerable accuracy, is the most difficult part of the subject.

The first process to be performed, in this part of the analysis, is the exposure of the fine matter of the soil to the action of muriatic acid. This substance should be poured upon the earthy matter in an evaporating basin, in a quantity equal to twice the weight of the earthy matter; but diluted with double its volume of water. The mixture should be often stirred, and suffered to remain for an hour, or an hour and a half, before it is examined. 
If any carbonate of lime or of magnesia exist in the soil, they will have been dissolved in this time by the acid, which sometimes takes up likewise a little oxide of iron; but very seldom any alumina.

The fluid should be passed through a filtre; the solid matter collected; washed with rain water, dried at a moderate heat, and weighed. Its loss will denote the quantity of solid matter taken up. The washings must be added to the solution, which if not sour to the taste, must be made so by the ad. dition of fresh acid, when a little solution of prussiate of potassa and iron must be mixed with the whole. If a blue precipitate occurs, it denotes the presence of oxide of iron, and the solution of the prussiate must be dropped in till no farther effect is. produced. 'To ascertain its quantity, it must be collected in the same manner as other solid precipitates, and heated red; the result is oxide of iron, which may be mixed with a little oxide of man. ganesum.

Into the fluid freed from oxide of iron, a solu. tion of neutralized carbonate of potash must be poured till all effervescence ceases in it, and till its taste and smell indicate a considerable excess of alkaline salt.

The precipitate that falls down is carbonate of lime; it must be collected on the filtre, and dried at a heat below that of redness.

The remaining fluid must be boiled for a quarter 
of an hour, when the magriesia, if any exist, will be precipitated from it, combined with carbonic acid, and its quantity is to be ascertained in the same manner as that of the carbonate of lime.

If any minute proportion of alumina should, from peculiar circumstances, be dissolved by the acid, it will be found in the precipitate with the carbonate of lime, and it may be separated from it by boiling it for a ferw minutes with soap lye, sufficient to cover the solid matter; this substance dissolves alumina, without acting upon carbonate of lime.

Should the finely divided soil be sufficiently calcareous to effervesce very strongly with acids, a very simple method may be adopted for ascertaining the quantity of carbonate of lime and one sufficiently accurate in all common cases.

Carbonate of lime, in all its states, contains a determinate proportion of carbonic acid, $i$. e. nearly 43 per cent. so that when the quantity of this elastic fluid, given out by any soil during the solution of its calcareous matter in an acid is known, either in weight or measure, the quantity of carbonate of lime may be easily discovered.

When the process by diminution of weight is employed, two parts of the acid and one part of the matter of the soil must be weighed in two separate bottles, and very slowly mixed together till the effervescence ceases; the difference between their weight before and after the experiment, denotes the quantity of carbonic acid lost; for every 


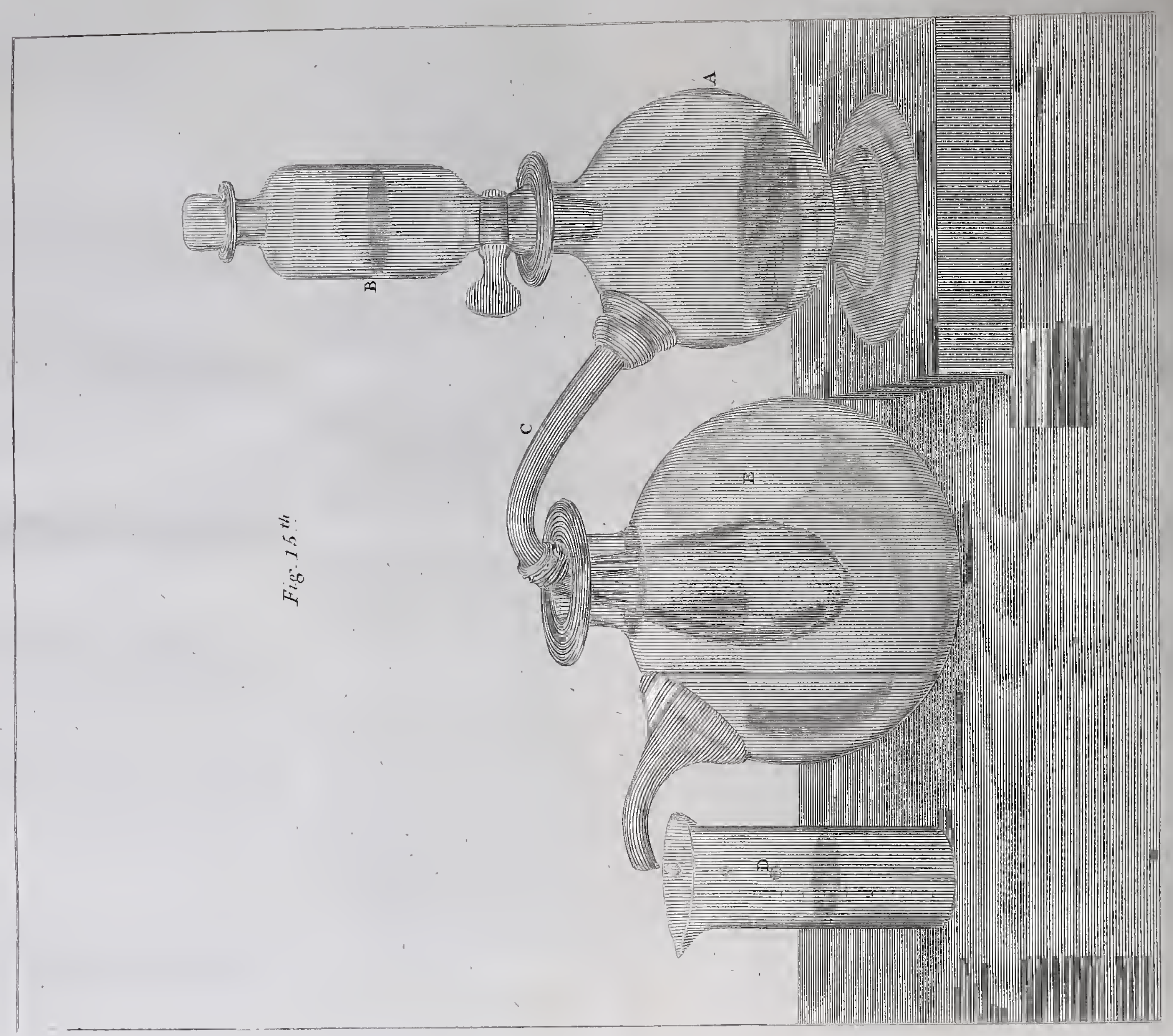


four grains and a quarter of which, ten grains of carbonate of lime must be estimated.

The best method of collecting the carbonic acid, so as to discover its volume, is by a peculiar pneumatic apparatus *, in which its bulk may be measured by the quantity of water it displaces.

6. After the calcareous parts of the suil has been acted upon by muriatic acid, the next process is to ascertain the quantity of finely divided insoluble animal and vegetable matter that it contains.

This may be done with sufficient precision, by strongly igniting it in a crucible over a common fire till no blackness remains in the mass. It should

* Fig. 15. A. B, C, D, represent the different parts of this apparatus. A. Represents the bottle for receiving the soil. B. The bottle containing the acid, furnished with a stop-cock. C. The tube connected with a flaccid bladder. D. The graduated measure. E. The bottle for containing the bladder. When this instrument is used, a given quantity of soil is introduced into A. B is filled with muriatic acid diluted with an equal quantity of water; and the stop-cock being closed, is connected with the upper orifice of $\mathrm{A}$, which is ground to receive it. The tube $\mathrm{D}$ is introduced into the lower orifice of $\mathrm{A}$, and the bladder connected with it placed in its flaccid state into $\mathrm{E}$, which is filled with water. The graduated measure is placed under the tube of $\mathbf{E}$. When the stop-cock of $\mathbf{B}$ is turned, the acid flows into $A$, and acts upon the soil ; the elastic fluid generated passes through $\mathrm{C}$ into the bladder, and displaces a quantity of water in $\mathbf{E}$ equal to it in bulk, and this water flows through the tube into the graduated measure : and gives by its volume the indication of the proportion of carbonic acid disengaged from the soil; for every ounce measure of which two grains of carbonate of lime may be estimated. 
be often stirred with a metallic rod, so as to expose new surfaces continually to the air; the loss of weight that it undergoes denotes the quantity of the sulistance that it contains destructible by fire and air.

It is not possible, without very refined and difficult experiments, to ascertain whether this substance is wholly animal or vegetable matter, or a mixture of both. When the smell emitted during the incineration is similar to that of burnt feathers, it is a certain indication of some substance either animal or analogous to animal matter; and a copious blue flame at the time of ignition, almost always denotes a considerable proportion of vegetable matter. In cases when it is necessary that the experiment should be very quickly performed, the destruction of the decomposable substances may be assisted by the agency of nitrate of ammoniac, which at the time of ignition may be thrown gradually upon the heated mass in the quantity of twenty grains for every hundred of residual soil. It accelerates the dissipation of the animal anci vegetable matter, which it causes to be converted into elastic fluids; and it is itself at the same time decomposed and lost.

7. The substances remaining after the destruction of the vegetable and animal matter, are generally minute particles of earthy matter, containing: asually alumina and silica, with combined oxide of iron or of manganesum. 
To separate these from each other, the solid matter should be boiled for two or three hours with sulphuric acid, diluted with four times its weight of water; the quantity of the acid should be regulated by the quantity of solid residuum to be acted on, allowing for every hundred grains, 'two drachms or one hundred and twenty grains of acid.

The substance remaining after the action of the acid, may be considered as siliceous; and it must be separated and its weight ascertained, after washing and drying in the usual manner.

The alumina and the oxide of iron and manganesum, if any exist, are all dissolved by the sulphuric acid; they may be separated by succinate of ammonia, added to excess; which throws down the oxide of iron, and by soap lye, which will dissolve the alumina, but not the oxide of manganesum: the weights of the oxides ascertained after they have been heated to redness will denote their quantities.

Should any magnesia and lime have escaped solution in the muriatic acid, they will be found in the sulphuric acid; this, however, is rarely the case; but the process for detecting them, and ascertaining their quantities, is the same in both instances.

The method of analysis by sulphuric acid, is sufficiently precise for all usual experiments; but if very great accuracy be an object, dry carbonate of potassa must be employed as the agent, and the 
residuum of the incineration (6) must be heated red for a half hour, with four times its weight of this substance, in a crucible of silver, or of well baked porcelain. The mass obtained must be dissolved in muriatic acid, and the solution evaporated till it is nearly solid; distilled water must then be added, by which the oxide of iron and all the earths, except silica, will be dissolved in combination as muriates. The silica, after the usual process of lixiviation, must be heated red; the other substances may be separated in the same manner as from the muriatic and sulphuric solutions.

This process is the one usually employed by chemical philosopers for the analysis of stones.

8. If any saline matter, or soluble vegetable or animal matter is suspected in the soil, it will be found in the water of lixiviation used for separating the sand.

This water must be evaporater to dryness in a proper dish, at a heat below its boiling point.

If the soid matter obtained is of a brown colour and inflammable, it may be considered as partly vegetable extract. If its smell, when exposed to heat, be like that of burnt feathers, it contains animal or albuminous matter; if it be white, crystalline, and not destructible by heat, it may be considered as principally saline matter; the nature of which may be known by the tests described page 114.

9. Should sulphate or phosphate of lime be sus- 
pected in the entire soil, the detection of them requires a particular process upon it. A given weight of it, for instance, four hundred grains, must be heated red for half an hour in a crucible, mixed with one-third of powdered charcoal. The mixture must be boiled for a quarter of an hour, in a half pint of water, and the fluid collected through the filtre, and exposed for some days to the atmosphere in an open vessel. If any notable quantity of sulphate of lime (gypsum) existed in the soil, a white precipitate will gradually form in the fluid, and the weight of it will indicate the proportion.

Phosphate of lime, if any exist, may be separated from the soil after the process for gypsum. Muriatic acid must be digested upon the soil, in quantity more than sufficient to saturate the soluble earths; the solution must be evaporated, and water poured upon the solid matter. This fluid will dissolve the compounds of earths with the muriatic acid, and leave the phosphate of lime untouched.

It would not fall within the limits assigned to this Lecture, to detail any processes for the detection of substances which may be accidentally mixed with the matters of soils. Other earths and metallic oxides are now and then found in them, hut in quantities too minute to bear any relation to fertility or barrenness, and the search for them would make the analysis much more complicated without rendering it more useful. 
10. When the examination of a soil is completed, . the products should be numerically arranged, and their quantities added together, and if they nearly equal the original quantity of soil, the analysis may be considered as accurate. It must, however, be noticed, that when phosphate or sulphate of lime are discovered by the independent process just described, (9,) a correction must be made for the general process, by subtracting a sum equal to their weight from the quantity of carbonate of lime, obtained by precipitation from the muriatic acid.

In arranging the products, the form should be in the order of the experiments by which they were procured.

Thus, I obtained from 400 grains of a good siliceous sandy soil from a hop garden near Tunbridge, Kent,

\begin{tabular}{lr} 
Of water of absorption $\quad-\quad$ & Grains \\
\hline
\end{tabular}

Of loose stones and gravel principally siliceous $\quad 53$

Of undecompounded vegetable fibres - $\quad \mathbf{1 4}$

Of fine siliceous sand - _ $\quad-\quad \quad \quad-\quad 212$

of minutely divided matter separated by agitation and filtration, and consisting of 、

Carbonate of lime $\quad-\quad \quad-\quad-19$

Carbonate of magnesia - $\quad-\quad-3$

Matter destructible by heat, principally vegetable - $\quad-\quad-\mathbf{1 5}$

Carried over 37298 
Graing.

Brought over $\quad 37298$

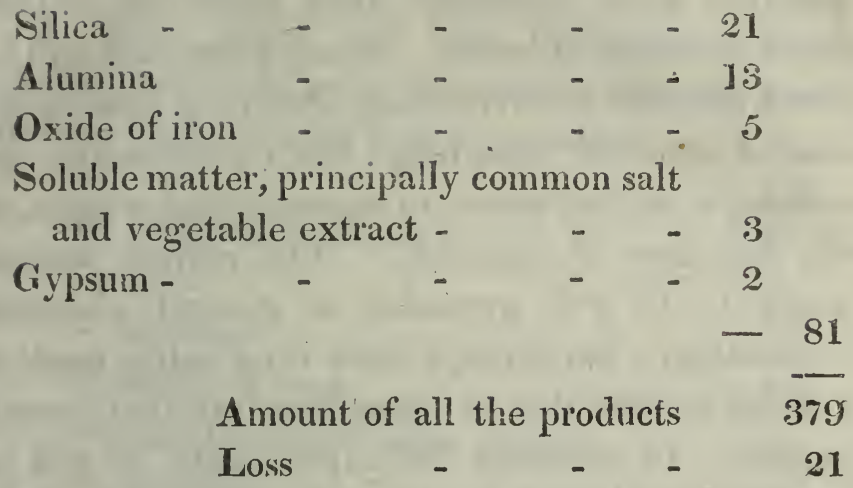

The loss in this analysis is not more than usually occurs, and it depends upon the impossibiliy of collecting the whole quantities of the different precipitates ; and upon the presence of more moisture than is accounted for in the water of absorption, and which is lost in the different processes.

When the experimenter is become acquainted with the use of the different instruments, the properties of the reagents, and the relations between the external and chemical qualities of soils, he will seldom find it necessary to perform, in any one case, all the processes that have been described. When his soil, for instance, contains no notable proportion of calcareous matter, the action of the muriatic acid (7) may be omitted. In examining peat soils, he will principally have to attend to the operation by fire and air (8); and in the analysis of chalks and loams, he will often be able to omit the experiment by sulphuric acid (9). 
In the first trials that are made by persons unacquainted with chemistry, they must not expect much precision of result. Many difficulties will be met with: but in overcoming them, the most useful kind of practical knowledge will be obtained; and nothing is so instructive in experimental science, as the detection of mistakes. The correct analyst ought to be well grounded in general chemical information; but perhaps there is no better mode of gaining it, than that of attempting original investigations. In pursuing his experiments, he will be continually obliged to learn the properties of the substances he is employing or acting upon; and his theoretical ideas will be more valuable in being connected with practical operations, and acquired for the purpose of discovery.

Plants being possessed of no locomotive powers, can grow only in places where they are supplied with food; and the soil is necessary to their existence, both as affording them nourishment, and enabling them to fix themselves in such a manner as to obey those mechanical laws hy which their radicles are kept below the surface, and their leaves exposed to the free atmosphere. As the systems of roots, branches and leaves are very different in different vegetables, so they flourish most in different soils, the plants that have bulbous roots require a looser and a lighter soil than such as have fibrous roots; and the plants possessing only short fibrous 
radicles demand a firmer soil than such as have tap roots, or extensive lateral roots.

A good turnip soil from Holkham, Norfolk, afforded me eight parts out of nine siliceous sand; and the finely divided matter consisted

\begin{tabular}{|c|c|c|c|c|c|}
\hline Of carbonat & of 1 & me & - & - & - \\
\hline - silica & - & - & - & & - \\
\hline - alumina & - & - & - & - & - \\
\hline - oxide of & iron & - & - & - & - \\
\hline - vegetabl & and & i & & & - \\
\hline - moisture & - & - & - & - & - \\
\hline
\end{tabular}

I found the soil taken from a field at Sheffieldplace in Sussex, remarkable for producing flourishing oaks, to consist of six parts of sand, and one part of clay and finely divided matter. And one hundred parts of the entire soil submitted to analysis, produced

Parts.

Silica - - - - - - - 54

Alumina - - - - - - - 28

Carbonate of lime - _ - - 3

Oxide of iron - - - - - 5

Decomposing vegetable matter - - 4

Moisture and loss - _ _ - - 3

An excellent wheat soil from the neighbourhood of West Drayton, Middlesex, gave three parts in 
five of siliceous sand; and the finely divided matter consisted of

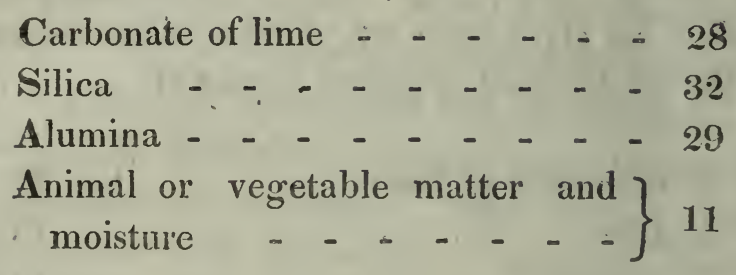

Of these soils the last was by far the most, and the first the least, coherent in texture. In all cases the constituent parts of the soil which give tenacity and coherence are the finely divided matters; and they possess the power of giving those qualities in the highest degree when they contain much alumina. A small quantity of finely divided matter is sufficient to fit a soil for the production of turnips and barley; and I have scen a tolerable crop of turnips on a soil containing 11 parts out of 12 sand. A much greater proportion of sand, however, always produces absolute sterility. The soil of Bagshot heath, which is entirely devoid of vegetable covering, contains less than $\frac{1}{20}$ of finely divided matter. 400 parts of it, which had been heated red, afforded me 380 parts of coarse siliceous sand; 9 parts of fine siliceous sand, and 11 parts of impalpable matter, which was a mixture of ferruginous clay, with carbonate of lime. Vegetable or animal matters, when finely divided, not only give cohe- 
rence, but likewise softness and penetrability; but neither they nor any other part of the soil must be in too great proportion; and a soil is unproductive if it consist entirely of impalpable matters.

Pure alumina or silica, pure carbonate of lime, or carbonate of magnesia, are incapable of supporting healthy vegetation.

No soil is fertile that contains as much as 19 parts out of 20 of any of the constituents that have been mentioned.

It will be asked, are the pure earths in the soil merely active as mechanical or indirect chemical agents, or do they actually afford food to the plant? This is an important question; and not difficult of solution.

The earths consist, as I have before stated, of metals united to oxygene; and these mietals have not been decomposed; there is consequently no reason to suppose that the earths are convertible into the elements of organized compounds, into carbon, hydrogene, and azote.

Plants have been made to grow in given quantities of earth. They consume very small portions only; and what is lost may be accounted for by the quantities found in their ashes; that is to say, it has not been converted into any new products.

The carbonic acid united to lime or magnesia, if any stronger acid happens to be formed in the soil during the fermentation of vegetable matter which. will disengage it from the earths, may be decom- 
posed : but the earths themselves cannot be supposed convertible into other substances, by any process taking place in the soil.

In all cases the ashes of plants contain some of the earths of the soil in which they grow ; but these earths, as may be seen from the table of the ashes afforded by different plants given in the last Lecture, never equal more than $\frac{1}{50}$ of the weight of the plant consumed.

If they be considered as necessary to the vegetable, it is as giving hardness and firmness to its organization. Thus, it has been mentioned that wheat, oats, and many of the hollow grasses, have an epidermis principally of siliceous earth ; the use of which seems to be to strengthen them, and defend them from the attacks of insects and parasitical plants.

Many soils are popularly distinguished as cold; and the distinction, though at first view it may appear to be founded on prejudice, is really just.

Some soils are much more heated by the rays of the sun, all other circumstances being equal, than others; and soils brought to the same degree of heat cool in different times, i. e. some cool much faster than others.

This property has been very little attended to in a philosophical point of view; yet it is of the highest importance in agriculture. In general, soils that consist principally of a stiff white clay are difficultly heated; and being usually very moist, 
they retain their heat only for a short time. Chalks are similar in one respect, that they are difficultly heated; but being drier they retain their heat longer, less being consumed in causing the evaporation of their moisture.

A black soil, containing much soft vegetable matter, is most heated by the sun and air ; and the coloured soils, and the soils containing much carbonaceous matter, or ferruginous matter, exposed under equal circumstances to sun, acquire a much higher temperature than pale-coloured soils.

When soils are perfectly dry, those that most readily become heated by the solar rays likewise cool most rapidly; but $I$ have ascertained by experiment, that the darkest coloured dry soil (that which contains abundance of animal or vegetable matter; substances which most facilitate the diminution of temperature,) when heated to the same degree, provided it be within the common limits of the effect of solar heat, will cool more slowly than a wet pale soil, entirely composed of earthy matter.

I found that a rich black mould, which contained nearly $\frac{x}{4}$ of vegetable matter, had its temperature increased in an hour from $65^{\circ}$ to $88^{\circ}$ by exposure to sunshine; whilst a chalk soil was heated only to $69^{\circ}$ under the same circumstances. But the mould removed into the share, where the temperature was $62^{\circ}$, lost, in half an hour, $15^{\circ}$; whereas the chalk, under the same circumstances, had lost onily $4^{\circ}$.

$\Lambda$ brown fertile soil, and a cold barren clay were 
each artificially heated to $88^{\circ}$, having been previously dried: they were then exposed in a temperature of $57^{\circ}$; in half an hour the dark soil was found to have lost $9^{\circ}$ of heat; the clay had lost only $6^{\circ}$. An equal portion of the clay containing moisture, after being heated to $88^{\circ}$, was exposed in a temperature of $55^{\circ}$; in less than a quarter of an hour it was found to have gained the temperature of the room. The soils in all these experiments were placed in small tin plate trays two inches square, and half an inch in depth; and the temperature ascertained by a delicate thermometer.

Nothing can be more evident, than that the genial heat of the soil, particularly in spring, must be of the highest importance to the rising plant. And when the leaves are fully developed, the ground is shaded; and any injurious influence, which in the summer might be expected from too great a heat, entirely prevented: so that the temperature of the surface, when bare and exposed to the rays of the sun, affords at least one indication of the degrees of its fertility; and the thermometer may be sometimes a useful instrument to the purchaser or improver of lands.

The moisture in the soil influences its temperature; and the manner in which it is distributed through, or combined with, the earthy materials, is of great importance in relation to the nutriment of the plant. If water is too strongly attracted by the earths, it will not be absorbed by the roots of the 
plants : if it is in too great quantity, or too loosely united to them, it tends to injure or destroy the fibrous parts of the roots.

There are two states in which water seems to exist in the earths, and in animal and vegetable substances: in the first state it is united by chemical, in the other by cohesive, attraction.

If pure solution of ammonia or potassa be poured into a solution of alum, alumina falls down combined with water; and the powder dried by exposure to air will afford more than half its weight of water by distillation; in this instance the water is united by chemical attraction. The moisture which wood, or muscular fibre, or gum, that have been heated to $212^{\circ}$, afford by distillation at a red heat, is likewise water, the elements of which were united in the substance by chemical combination.

When pipe-clay dried at the temperature of the atmosphere is brought in contact with water, the fluid is rapidly absorbed; this is owing to cohesive attraction. Soils in general, vegetable, and animal substances, that have been dried at a heat below that of boiling water, increase in weight by exposure to air, owing to their absorbing water existing in the state of vapour in the air, in consequence of cohesive attraction.

The water chemically combined amongst the elements of soils, unless in the case of the decomposition of animal or vegetable substances, cannot be 
absorbed by the roots of plants; but that adhering to the parts of the soil is in constant use in vegetation. Indeed there are few mixtures of the earths found in soils, that contain any chemically combined water; water is expelled from the earths by most substances that combine with them. Thus, if a combination of lime and water be exposed to carbonic acid, the carbonic acid takes the place of water; and compounds of alumina and silica, or other compounds of the earths, do not chemically unite with water: and soils, as it has been stated, are formed either by earthy. carbonates, or compounds of the pure earths and metallic oxides.

When saline substances exist in soils, they may be united to water both chemically and mechanically; but they are always in too small a quantity to influence materially the relations of the soil to water.

The power of the soil to absorb water by cohesive attraction, depends in great measure upon the state of division of its parts ; the more divided they. are, the greater is their absorbent power. The different constituent parts of soils likewise appear to act, even by cohesive attraction, with different degrees of energy. Thus vegetable substances seem to be more absorbent than animal substances; animal substances more so than compounds of alumina and silica; and compounds of alumina and silica more absurbent than carbonates: of lime and magnesia: 


\section{3}

these differences may, however, possibly depend upon the differences in their state of division, and upon the surface exposed.

The power of soils to absorb water from air, is much connected with fertility. When this power is great, the plant is supplied with moisture in dry seasons; and the effect of evaporation in the day is counteracted by the absorption of aqueons vapour from the atmosphere, by the interior parts of the soil during the day, and by both the exterior and interior during night.

The stiff clays approaching to pipe-clays in their nature, which take up the greatest quantity of water when it is poured upon them in a fluid form, are not the soils which absorb most moisture from the atmosphere in dry weather. 'They cake, and present only a small surface to the air ; and the vegetation on them is generally burnt up almost as readily as on sands.

The soils that are most efficient in supplying the plant with water by atmospheric absorption, are those in which there is a due mixture of sand, finely divided clay, and carbonate of lime, with some animal or vegetable matter; and which are so loose and light as to be freely permeable to the atmosphere. With respect to this quality, carbonate of lime and animal and vegetable matter are of great use in soils : they give absorbent power to the soil without giving it likewise tenacity: sand, which 
also destroys tenacity, on the contrary, gives little absorbent power.

I have compared the absorbent powers of many soils with respect to atmospheric moisture, and I have always found it greatest in the most fertile soils; so that it affords one method of judging of the productiveness of land.

1000 parts of a celebrated soil from Ormiston, in East Lothian, which contained more than half its weight of finely divided matter, of which 11 parts were carbonate of lime, and nine parts vegetable matter, when dried at $212^{\circ}$, gained in an hour by exposure to air saturated with moisture, at temperature $62^{\circ}, 18$ grains.

1000 parts of a very fer'tile soil from the banks of the river Parret, in Somersetshire, under the same circumstances, gained 16 grains.

1000 parts of a soil from Mersea, in Essex, worth 45 shiilings an acre, gained 1.3 grains.

1000 grains of a fine sand from Essex, worth 28 shillings an acre, gained 11 grains.

1000 of a cuarse sand worth 15 shillings an acre, gained only eight grains.

1000 of the soil of Bagshot-heath gained only three grains.

Water, and the decomposing animal and vegetable matter existing in the soil, constitute the true nourishment of plants; and as the earthy parts of the soil are useful in retaining water, so as 
to supply it in the proper proportions to the roots of the regetables, so they are likewise efficacious in producing the proper distribution of the animal or vegetable matter; when equally mixed with it they prevent it from decomposing too rapidly; and by their means the soluble parts are supplied in proper proportions.

Besides this agency, which may be considered as mechanical, there is another agency between soils and organizable matters, which may be regarded as chemical in its nature. The earths, and even the earthy carbonates, have a certain degree of chenical attraction for many of the principles of vegetable and animal substances. This is easily exemplifier in the instance of alumina and oil ; if an acid solution of alumina be mixed with a solution of soap, which consists of oily matter and potassa; the oil and the alumina will unite and form a white powder, which will sink to the bottom of the fluid.

The extract from decomposing vegetable matter when boiled with pipe-clay or chalk, forms a combination by which the vegetable matter is rendered more difficult of decomposition and of solution. Pure silica and siliceous sands have little action of this kind; and the soils which contain the most alumina and carbonate of lime, are these which act with the greatest chemical energy in preserving manures. Such soils merit the appellation which is commonly given to them of rich soils; for the 
vegetable nourishment is long preserved in them, unless taken up by the organs of plants. Siliceous sands, on the contrary, deserve the term hungry, which is commonly applied to them; for the vegetable and animal matters they contain not being attracted by the earthy constituent parts of the soil, are more liable to be decomposed by the action of the atmosphere, or carried off from them by water.

In most of the black and brown rich vegetable moulds, the earths seem to be in combination with a peculiar extractive matter, afforded during the decomposition of vegetables : this is slowly taken up, or attracted from the earths by water, and appears to constitute a prime cause of the fertility of the soil.

The standard of fertility of soils for different plants must vary with the climate; and must be particularly influenced by the quantity of rain.

The power of soils to absorb moisture ought to be much greater in warm or dry counties, than in cold and moist ones; and the quantity of clay, or vegetable or animal matter they contain greater. Soils also on declivities ought to be more absorbent than in plains or in the bottom of vallies. Their productiveness likewise is influenced by the nature of the subsoil or the stratum on which they rest.

When soils are immediately situated upon a bed of rock or stone, they are much sooner rendered dry by evaporation, than where the subsoil is of 


\section{7}

clay or marle; and a prime cause of the great fertility of the land in the moist climate of Ireland, is the proximity of the rocky strata to the soil.

A clayey subsoil will sometimes be of material advantage to a sandy soil; and in this case it will retain moisture in such a manner as to be capable. of supplying that lost by the earth above, in consequence of evaporation, or the consumption of it by plants.

A sandy, or gravelly subsoil, often corrects the imperfections of too great a degree of absorbent power in the true soil.

In calcareous countries, where the surface is a species of marle, the soil is often found only a few. inches above the limestone; and its fertility is not impaired by the proximity of the rock; though in a less absorbent soil; this situation would occasion barrenness; and the sandstone and limestone hills in Derbyshire and North Wales, may be easily distinguished at a distance in summer by the different tints of the vegetation. The grass on the sandstone hills usually appears brown and burnt up; that on the limestone hills, flourishing and green.

In devoting the different parts of an estate to the necessary crops, it is perfectly evident from what has been said, that no general principle can be laid down, except when all the circumstances of the nature, composition, and situation of the soil and subsoil are known.

The methods of cultivation likewise must be 
different for different soils. The same practice which will be excellent in one case may be destructive in another.

Deep ploughing may be a very profitable practice in a rich thick soil; and in a fertile shallow soil, situated upon cold clay or sandy subsoil, it may be extremely prejudicial.

In a moist climate where the quantity of rain that falls annually equals from 40 to 60 inches, as in Lancashire, Cornwall, and some parts of Ireland, a siliceous sandy soil is much more productive than in dry districts; and in such situations, wheat and beans will require a less coherent and absorbent soil than in drier situations; and plants having bulbous roots, will flourish in a soil containing as much as 14 parts out of 15 of sand.

Even the exhausting powers of crops will be influenced by like circumstances. In cases where plants cannot absorb sufficient moisture, they must take up more manure. And in Ireland, Cornwall, and the western Highlands of Scotland, corn will exhaust less than in dry inland situations. Oats, particularly in dry climates, are impoverishing in a much higher degree than in moist ones.

Soils appear to have been originally produced in conserpence of the decomposition of rocks and strata. It often happens that soils are found in an unaltered state upon the rocks from which they were derived. It is easy to form an idea of the manner in which rocks are converted into soils, by referring 
to the instance of soft granite, or porcelain granite. This substance consists of three ingredients, quartz, feldspar, and mica. The quartz is almost pure siliceous earth, in a crystalline form. 'The feldspar and mica are very compounded substances; both contain silica, alumina, and oxide of iron; in the feldspar there is usually lime and potassa; in the mica, lime and magnesia.

When a granitic rock of this kind has been long exposed to the influence of air and water, the lime and the potassa contained in its constituent parts are acted upon by water or carbonic acid; and the oxide of iron, which is almost always in its least oxided state, tends to combine with more oxygene; the consequence is, that the feldspar decomposes, and likewise the mica; but the first the most rapidly. The feldspar, which is as it were the cement of the stone, forms a fine clay: the mica partially decomposed mixes with it as sand; and the undecomposed quartz appears as gravel, or sand of different degrees of fineness.

As soon as the smallest layer of earth is formed on the surface of a rock, the seeds of lichens, mosses, and other imperfect vegetables which are constantly floating in the atmosphere, and which have made it their resting place, begin to vegetate; their death, decomposition, and decay, afford a certain quantity of organizable matter, which mixes with the earthy materials of the rock; in this improved soil more perfect plants are capable of sub- 
sisting; these in their turn absorb nourishment from water and the atmosphere; and after perishing, afford new materials to those already provided : the decomposition of the rock still continues; and at length by such slow and gradual processes, a soil is formed in which even forest trees can fix their roots, and which is fitted to reward the labours of the cultivator.

In instances where successive generations of vegetables have grown upon a soil, unless part of their produce has been carried off by man, or consumed by animals, the vegetable matter increases in such a proportion, that the soil approaches to a peat in its nature; and if in a situation where it can receive water from a higher district, it becomes spongy, and permeated with that fluid, and is gradually rendered incapable of supporting the nobler classes of vegetables.

Many peat-mosses seem to have been formed by the destruction of forests, in consequence of the imprudent use of the hatchet by the early cultivators of the country in which they exist: when the trees are felled in the out-skirts of a wood, those in the interior exposed to the influence of the winds; and having been accustomed to shelter, become unhealthy, and die in their new situation ; and their leaves and branches gradually decomposing, produce a stratum of vegetable matter. In many of the great bogs in Ireland and Scotland, the larger trees that are found in the out-skirts of them, bear 
the marks of having been felled. In the interior few entire trees are found; and the cause is, probably, that they fell by gradual decay; and that the fermentation and decomposition of the vegetable matter was most rapid where it was in the greatest quantity.

Lakes and pools of water are sometimes filled up by the accumulation of the remains of aquatic plants; and in this case a sort of spurious peat is formed. The fermentation in these cases, however, seems to be of a different kind. Much more gaseous matter is evolved; and the neighbourhood of morasses in which aquatic vegetables decompose, is usually aguish and unhealthy; whilst that of the true peat, or peat formed on soils originally dry, is always salubrious.

The earthy matter of peats is uniformly analogous to that of the stratum on which they repose; the plants which have formed them must have derived the earths that they contained from this stratum. Thus in Wiltshire and Berkshire, where the stratum below the peat is chalk, calcareous earth abounds in the ashes, and very little alumina and silica. They likewise contain much oxide of iron and gypsum, both of which may be derived from the decomposition of the pyrites, so abundant in chalk.

Different specimens of peat that $\mathbf{I}$ have burnt from the granitic and schistose soils of different parts of these islands, have always given ashes 
principally siliceous and aluminous; and a specimen of peat from the county of Antrim, gave ashes which afforded very nearly the same constituents as the great basaltic stratum of the county.

Poor and hungry soils, such as are produced from the decomposition of granitic and sandstone rocks, remain very often for ages with only a thin covering of vegetation. SToils from the decomposition of limestone, chalks, and basalts, are often clothed by nature with the perennial grasses; and afford, when ploughed up, a rich bed of vegetation for every species of cultivated plant.

Rocks and strata from which soils have been derived, and those which compose the more interior solid parts of the globe, are arranged in a certain order; and as it often happens that strata very different in their nature are associated together, and that the strata immediately beneath the soil contain materials which may be of use for improving it, a general view of the nature and position of rocks and strata in nature, will not, I trust, be unacceptable to the scientific farmer.

Rocks are generally divided by geologists into two grand divisions, distinguished by the names of primary and secondary.

The primary rocks are composed of pure crystalline matter, and contain no fragments of other rocks.

The secondary rocks, or strata, consist only partly of crystalline matter; contain fragments of other rocks or strata; often abound in the remains of ve- 


\section{3}

getables and marine animals; and sometimes contain the remains of land animals.

The primary rocks are generally arranged in large masses, or in layer's vertical, or more or less inclined to the horizon.

The secondary rocks are usually disposed in strata or layers, parallel, or nearly parallel to the horizon.

The number of primary rocks which are commonly observed in nature are eight.

First, granite, which, as has been mentioned, is composed of quartz, feldspar, and mica; when these bodies are arranged in regular layers in the rock, it is called gneis.

Second, micaceous schistus, which is composed of quartz and mica arranged in layers, which are usually curvilineal.

Third, sienite, which consists of the substance called hornblende and feldspar.

Fourth, serpentine, which is constituted by feldspar and a body named resplendent hornblende; and their separate crystals are often so small as to give the stone a uniform appearance: this rock abounds in veins of a substance called steatite, or soap rock.

Fifth, porphyry, which consists of crystals of feldspar, embedded in the same material, but usually of a different colour.

Sixth, granular marble, which consists entirely of crystals of carbonate of lime; and which, when its 
colour is white, and texture fine, is the substance used by statuaries.

Seventh, chlorite schist, which consists of chlorite, a green or gray substance somewhat analogous to mica and feldspar.

Eight, quartzose rock, which is composed of quartz in a granular form, sometimes united to small quantities of the crystalline elements, which have been mentioned as belonging to the other rocks.

The secondary rocks are more numerous than the primary; but twelve varieties include all that are usually found in these islands.

First, grauwacke, which consists of fragments of quartz, or chlorite schist, embedded in a cement, principally composed of feldspar.

Second, siliceous sandstone, which is composed of fine quartz or sand, united by a siliceous cement.

Third, limestone, consisting of carbonate of lime, more compact in its texture than in the granular marble; and often abounding in marine exuvia.

Fourth, aluminous schist, or shale, consisting of the decomposed materials of different rocks cemented by a small quantity of ferruginous or siliceous matter; and often containing the impressions of vegetables.

Fifth, calcareous sandstone, which is calcareous sand, cemented by calcareous matter.

Sixth, iron stone, formed of nearly the same 
materials as aluminous schist, or shale ; but containing a much larger quantity of oxide of iron.

Seventh, basalt or whinstone, which consists of feldspar and hornblende, with materials derived from the decomposition of the primary rocks; the crystals are generally so small as to give the rock a homogeneous appearance; and it is often disposed in very regular columns, having usually five or six sides.

Eighth, bituminous or common coal.

Niuth, gypsum, the substance so well known by that name, which consists of sulphate of lime; and often contains sand.

Tenth, rock salt.

Eleventh, chalk, which usually abounds in remains of marine animals, and contains horizontal layers of flints.

Twelfth plum-pudding stone, consisting of pebbles cemented by a ferruginous or siliceous cement.

To describe more particularly the constituent parts of the different rocks and strata will be unnecessary; at any time, incleed, details on this subject are useless, unless the specimens are examined by the eye; and a close inspection and comparison of the different species, will, in a short time, enable the inost comnion observer to distinguish them.

The highest mountains in these islands, and indeed in the whole of the old continent, are constituted by granite; and this rock has likewise been 
found at the greatest depths to which the industry of man has as yet been able to penetrate; micaceous schist is often found immediately upon granite; serpentine or marble upon micaceous schist: but the order in which the primary rocks are grouped together is various. Marble and serpentine are usually found uppermost; but granite, though it seems to form the foundation of the rocky strata of the globe, is yet sometimes discovered above micaceous schist.

The secondary rocks are always incumbent on the primary; the lowest of them is usually grauwacke: upon this, limestone or sandstoné is often found; coal generally occurs between sandstone or shale; basalt often exists above sandstone and limestone; rock salt almost always occurs associated with red sandstone and gypsum. Coal, basalt, sandstone and limcsione, are often arranged in different alternate layers, of no considerable thickness, so as to form a great extent of country. In a depth of less than 500 yards, 80 of these different alternate strata have been counted.

The veins which afford metallic substances, are fissures more or less vertical, filled with a material different from the rock in which they exist. This material is almost always crystalline; and usually consists of calcareous spar, fluor spar, quartz, or heavy spar, either separate or together. The metallic substances are generally dispersed through, or confusedly mixed with these crystalline bodies. 


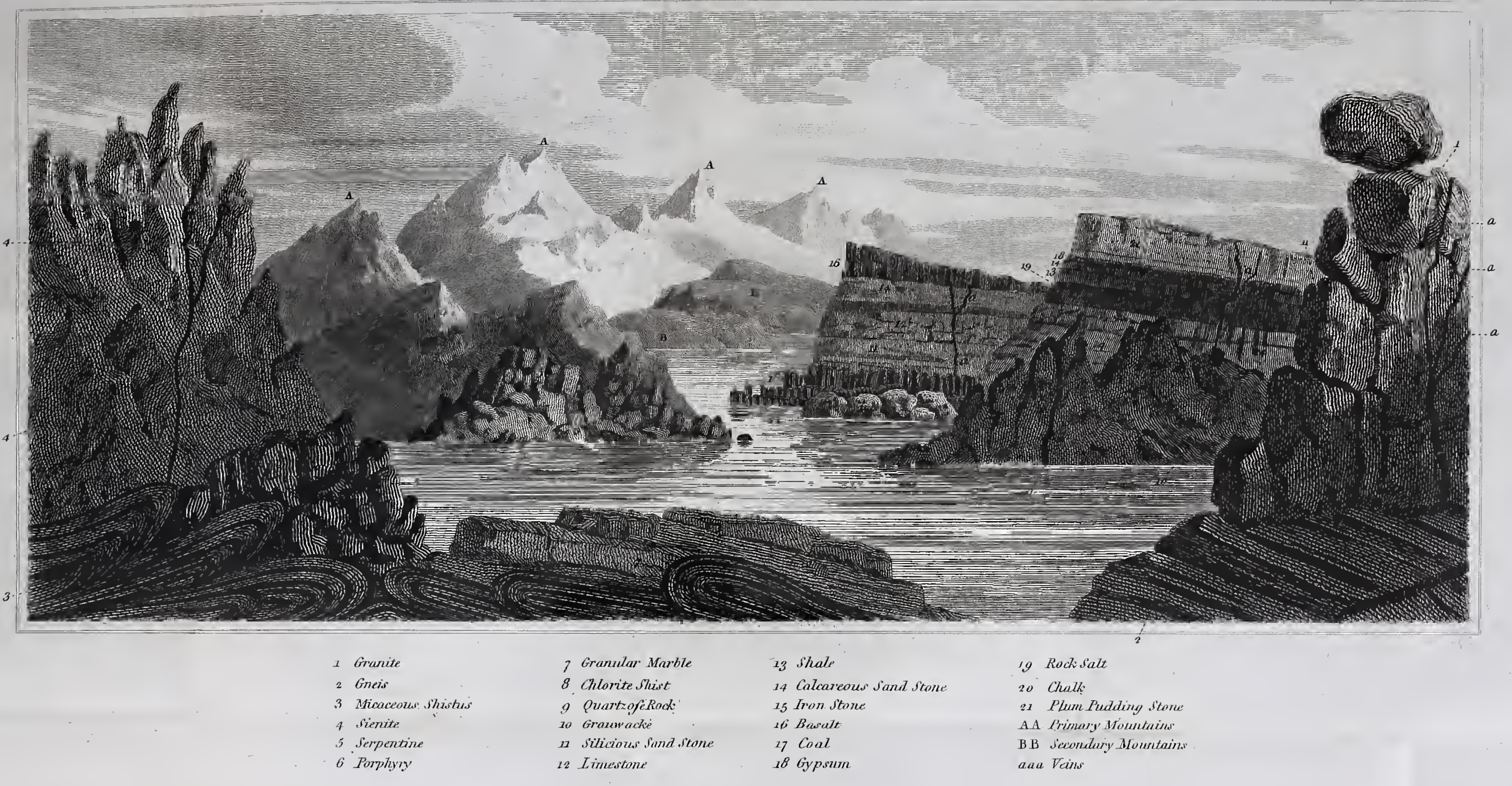

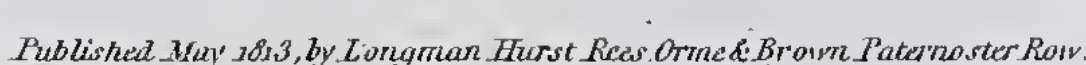




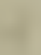

,
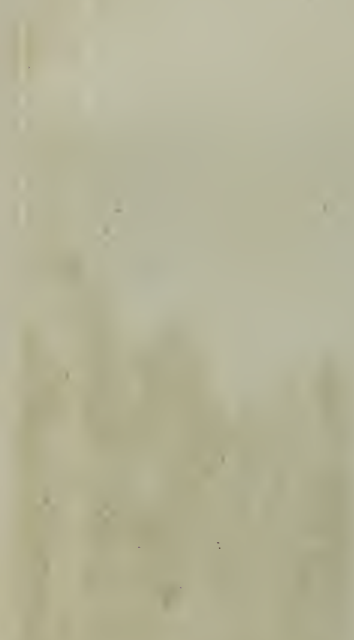

$=$
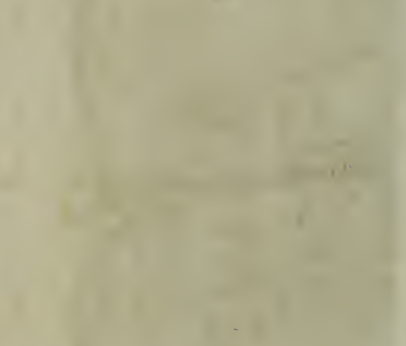

1
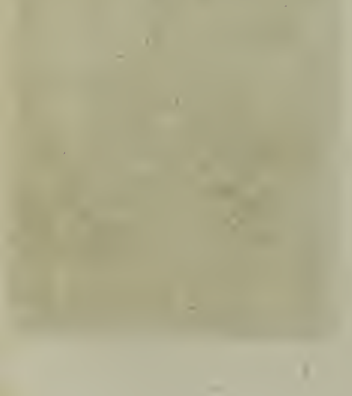

f

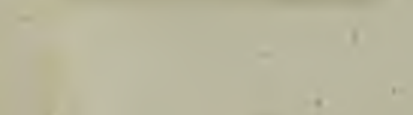


The veins in hard granite seldom afford much useful metal; but in the veins in soft granite, and in gneis, tin, copper, and lead are found. Copper and iron are the only metals usually found in the veins in serpentine. Micaceous schist, sienite, and granular marble, are seldom metalliferous rocks. Lead, tin, copper, iron, and many other metals are found in the veins in chlorite schist. Grauwacke, when it contains few fragments and exisț in large masses, is often a metalliferous rock. The precious Inetals, likewise iron, lead, and antimony, are found in it; and sometimes it contains veins or masses of stone coal, or coal fiee from bitumen. Limestone is the great metalliferous rock of the secondary family; and lead and copper are the metals most usually found in it. No metallic veins have ever been found in shale, chalk, or calcareous sandstone; and they are very rare in basalt and siliceous sandstone*.

In cases where veins in rocks are exposed to the atmosphere, indications of the metals they contain may be often gained from their superficial appearance. Whenever fluor spar is found in a vein, there is always sirong reason to suspect that it is associated with metallic subtances. A brown powder at the surface of a vein always indicates iron, and often tin; a pale yellow powder lead; and a

* Fig. 16, will give a general idea of the appearance and arrangement of rocks and veins. 
green colour in a vein denotes the presence of copper.

It may not be improper to give a general description of the geological constitution of Great Britain and Ireland. Granite forms the great ridge of hills extending from Land's Lind through Dartmoor into Devonshire. The highest rocky strata in Somersetshire are grauwacke and limestone. The Malvern hills are composed of granite, sienite, and porphyry. The highest mountains in Wales are chlorite schist, or grauwacke. Granite occurs at Mount Sorrel in Leicestershire. The great range of the mountains in Cumberland and Westmorland, are porphyry, chlorite, schist, and grauwacke; but granite is found at their western boundary. Throughout Scotland the most elevated rocks are granite, sienite, and micaceous schistus. No true secondary formations are found in South Britain, west of Dartmoor; and no basalt south of the Severn. The chalk district extends from the western part of Dorsetshire, to the eastern coast of Norfolk. The coal formations abound in the district between Glamorganshire and Derbyshire; and likewise in the secondary strata of Yorkshire, Durham, Westmorland, and Northumberland. Serpentine is found only in three places in Great Britain; near Cape Lizard in Cornwall, Portsoy in Aberdeenshire, and in Ayrshire. Black and grey granular marble is found near Padstow in Cornwall; and other coloured primary marbles exist in the neighbourhood of 
Plymouth. Coloured primary marbles are abundant - in Scotland; and white granular marble is found in the Isle of Sky, in Assynt, and on the banks of Loch Shin in Sutherland: the principal coal formations in Scotland are in Dumbartonshire, Ayrshire, Fifeshire, and on the banks of the Brora in Sutherland. Secondary limestone and sandstone are found in most of the low countries north of the Mendip hills.

In Ireland there are five great associations of primary mountains; the mountains of Morne in the county of Down; the mountains of Donegal ; those of Mayo and Galway, those of Wicklow, and those of Kerry. The rocks composing the four first of these mountain chains are principally granite, gneis, sienite, micaceous schist, and porphyry. The mountains of Kerry are chiefly constituted by granular quartz, and chlorite schist. Coloured marble is found near Killarney; and white marble on the western coast of Donegal.

Limestone and sandstone are the common secondary rocks found south of Dublin. In Sligo, Roscommon, and Leitrim, limestone, sandstone, shale, iron stone, and bituminous coal are found. The secondary hills in these counties are of considerable elevation; and many of them have basaltic summits. The northern coast of Ireland is principally basalt; this rock commonly reposes upon a white limestone, containing layers of flint, and the same fossils as chalk; but it is considerably harder than that rock. There are some instances, in this dis- 
trict, in which columnar basalt is found above sandstone and shale, alternating with coal. The stone coal of Ireland is principally found in Kilkenny, associated with limestone and grauwacke.

It is evident from what has been said concerning the production of soils from rocks, that there must be at least as many varieties of soils as there are species of rocks exposed at the surface of the earth; in fact there are many more. Independent of the changes produced by.cultivation and the exertions of human labour, the materials of strata have been mixed together and transported from place to place by various great alterations that have taken place in the system of our globe, and by the constant operation of water.

To attempt to class soils with scientific accuracy, would be a vain labour; the distinctions adopted by farmers are sufficient for the purposes of agriculture; particularly if some degree of precision be adopted in the application of terms. The term sandy, for instance, should never be applied to any soil that does not contain at least seven-eighths of sand; sandy soils that effervesce with acids should be distinguished by the name of calcareous sandy soil, to distinguish them from those that are siliceous. The term clayey soil should not be applied to any land which contains less than one-sixth. of impalpable earthy matter, not considerably effervescing with acids; the word loam should be limited to soils, containing at least one-third of impalpable earthy matter, copiously effer vescing with acids. A 
soil to be considered as peaty, ought to contain at least one half of vegetable matter.

In cases where the earthy part of a soil evidently consists of the decomposed matter of one particular rock, a name derived from the rock may with propriety be applied to it. Thus, if a fine red earth be found immediately above decomposing basalt, it may be denominated basaltic soil. If fragments of quartz and mica be found abundant in the materials of the soil, which is often the case, it may be denominated granitic soil ; and the same principles may be applied to other like instances.

In general, the soils, the materials of which are the most various and heterogeneous, are those called alluvial, or which have been formed from the depositions of rivers; many of them are extremely fertile. I have examined some productive alluvial soils, which have been very different in their composition. The soil which has been mentioned page 18.1, as very productive, from the banks of the river Parret in Somersetshire, afforded me eight parts of fincly divided earthy matter, and one part of siliceous sand; and an analysis of the finely divided matter gave the following results.

360 parts of carbonate of lime,

2.5 _- alumina.

20 - silica.

8 - oxide of iron.

19 - regetable, animal, and saline matter. 
A rich soil from the neighbourhood of the Avon, in the valley of Evesham in Worcestershire, afforded me three-fifths of fine sand, and two-fifths of impalpable matter; the impalpable matter consisted of

35 Alumina.

41 Silica.

14 Carbonate of lime.

3 Oxide of iron.

7 Vegetable, animal, and saline matter.

A specimen of good soil from Tiviot-dale, afforded five-sixths of fine siliceous sand, and one-sixth of impalpable matter; which consisted of

41 Alumina.

42 Silica.

4 Carbonate of lime.

5 Oxide of iron.

8 Vegetable, animal, and saline matter.

A soil yielding excellent pasture from the valley of the Avon, near Salisbury, afforded one-eleventh of coarse siliceous sand; and the finely divided matter consisted of

\section{Alumina.}

14 Silica.

63 Carbonate of lime.

2 Oxide of iron.

14 Vegetable, animal, and saline matter. 
In all these instances the fertility seems to depend upon the state of division, and mixture of the earthy materials and the vegetable and animal matter ; and may be easily explained on the principles which $I$ have endeavoured to elucidate in the preceding part of this Lecture.

In ascertaining the composition of sterile soils with a view to their improvement, any particular ingredient which is the cause of their unproductiveness, should be particularly attended to ; if possible, they should be compared with fertile soils in the same neighbourhood, and in similar situations, as the difference of the composition may, in many cases, indicate the most proper methods of improvement. If on washing a sterile soil it is found to contain the salts of iron, or any acid matter, it may be ameliorated by the application of quick lime. A soil of good apparent texture from Lincolnshire, was put into my hands by Sir Joseph Banks as remarkable for sterility : on examining it, I found that it contained sulphate of iron; and I offered the obvious remedy of top dressing with lime, which converts the sulphate into a manure. If there be an excess of calcareous matter in the soil, it may be improved by the application of sand, or clay. Soils too abundant in sand are benefited by the use of clay, or marle, or vegetable matter. A field belonging to Sir Robert Vaughan at Nannau, Merionethshire, the soil of which was a light sand, was much burnt up in the summer of 1805 ; I recom- 
mended to that gentleman the application of peat as a top dressing. 'The experiment was attended with immediate good effects; and Sir Robert last year informed me, that the benefit was permanent. A deficiency of vegetable or animal matter must be supplied by manure. An excess of vegetable matter is to be removed by burning, or to be remedied by the application of earthy materials. The improvement of peats, or bogs, or marsh lands, must be preceded by draining; stamnant water being injurious to all the nutritive classes of plants. Soft black peats, when drained, are often made productive by the mere application of sand or clay as a top dressing. When peats are acid, or contain ferruginous salts, calcareous matter is absolutely necessary in bringing them into cultivation. When they abound in the branches and roots of trees, or when their surface entirely consists of living vegetables, the wood or the vegetables must either be carried off, or be destroyed by burning. In the last case their ashes afford earthy ingredients, fitted to improve the texture of the peat.

The best natural soils are those of which the materials have been derived from diferent strata; which have been minutely divided by air and water, and are intimately blended together: and in improving soils artificially, the farmer cannot do better than imitate the processes of nature.

The materials necessary for the purpose are seldom far distant: coarse sand is often found 


\section{5}

immediately on chalk; and beds of sand and gravel are common below clay. The labour of improving the texture or constitution of the soil, is repaid by a great permanent advantage; less manure is required, and its fertility insured: and capital laid out in this way secures for ever, the productiveness, and consequently the value of the land. 


\section{LECTURE V.}

On the Nature and Constitution of the Atmosplere; and its Influence on Vegetables. Of the Germination of Seeds. Of the Functions of Plants in their different Stages of Growth; with a general View of the Progress of Vegetation.

THE constitution of the atmosphere has been already generally referred to in the preceding Lectures. Water, carbonic acid gas, oxygene, and azote, have been mentioned as the principal substances composing it; but more minute enquiries respecting their nature and agencies are necessary to afford correct views of the uses of the atmosphere in vegetation.

On these enquiries I now propose to enter; the pursuit of them, I hope, will offer some objects of practical use in farming; and present some philosophical illustrations of the manner in which plants are nourished; their organs unfolded, and their functions developed.

If some of the salt called muriate of lime that has been just heated red be exposed to the air, even in the driest and coldest weather, it will increase in 
weight and become moist; and in a certain time will be converted into a fluid. If put into a retort and heated, it will yield pure water; will gradually recover its pristine state; and, if heated red, its former weight : so that it is evident, that the water united to it was derived from the air. And that it existed in the air in an invisible and elastic form, is proved by the circumstance, that if a given quantity of air be exposed to the salt, its volume and weight will diminish, provided the experiment be correctly made.

The quantity of water which exists in air, as rapour, varies with the temperature. In proportion as the weather is hotter, the quantity is greater. At $50^{\circ}$ of Fahrenheit air contains about one-fiftieth of its volume of vapour; and as the specific gravity of vapour is to that of air nearly as 10 to 15 , this is about one-seventy-fifth of its weight.

At $100^{\circ}$, supposing that there is a free communication with water, it contains about one-fourteenth parts in volume, or one-twenty-first in weight. It is the condensation of vapour by diminution of the temperature of the atmosphere, which is probably the principal cause of the formation of clouds, and of the deposition of dew, mist, snow, or hail,

The power of different substances to absorb aqueous vapour from the atmosphere by cohesive attraction was discussed in the last Lecture. The leaves of living plants appear to act upon the vapour likewise in its elastic form, and to absorb it. 
Some vegetables increase in weight from this cause, when suspended in the atmosphere and unconnected with the soil; such are the house-leek, and different species of the aloe. In very intense heats, and when the soil is dry, the life of plants seems to be preserved by the absorbent power of their leaves: and it is a beautiful circumstance in the economy of nature, that aqueous vapour: is most abundant in the atmosphere when it is most needed for the purposes of life; and that when other sources of its supply are cut off, this is most copious.

The compound nature of water has been referred to. It may be proper to mention the experimental proofs of its decomposition into, and composition from, oxygene and hydrogene.

If the metal called potassium be exposed in a glass tube to a small quantity of water, it will act upon it with great violence; elastic fluid will be disengaged, which will be found to be hydrogene; and the same effects will be produced upon the potassium, as if it had absorbed a small quantity of oxygene; and the hydrogene disengaged, and the oxygene added to the potassium are in weight as two to 15; and if two in volume of hydrogene, and one in volume of oxygene, which have the weights of two and 15, be introduced into a close vessel, and an electrical spark passed through them, they will inflame and condense into 17 parts of pure water.

It is evident from the statements given in the 
third Lecture, that water forms by far the greatest. part of the sap of plants; and that this substance, or its elements, enters largely into the constitution of their organs and solid productions.

Water is absolutely necessary to the economy of vegetation in its elastic and fluid state; and it is not devoid of use even in its solid form. Snow and ice are bad conductors of heat; and when the ground is covered with snow, or the surface of the soil or of water is frozen, the roots or bulbs of the plants beneath are protected by the congealed water from the influence of the atmosphere, the temperature of which in northern winters is usually very much below the freezing point; and this water becomes the first nourishment of the plant in early spring. The expansion of water during its congelation, at which time its volume increases onetwelfth, and its contraction of bulk during a thaw, tend to pulverise the soil; to separate its parts from each other, and to make it more permeable to the influence of the air.

If a solution of lime in water be exposed to the air, a pellicle will speedily form upon it, and a solid matter will gradually fall to the bottom of the water, and in a certain time the water will become tasteless; this is owing to the combination of the lime, which was dissolved in the water, with carbonic acid gas which existed in the atmosphere, as may be proved by collecting the film and the solid matter, and igniting them strongly in a little tube of 
platina or iron; they will give off carbonic acid gas, and will become quicklime, which added to the same water, will again bring it to the state of lime water.

The quantity of carbonic acid gas in the atmosphere is very. small. It is not easy to determine it with precision, and it must differ in different situations; but where there is a free circulation of air, it is probably never more than one-five hundredth, nor less than one-eight hundredth of the volume of air. Carhonic acid gas is nearly one-third heavier than the other elastic parts of the atmosphere in their mixed state: hence at first view it might be supposed that it would be most abundant in the lower regions of the atmosphere; but unless it has been immediately produced at the surface of the earth in some chemical process, this does not seem to be the case: elastic fluids of different specific gravities have a tendency to equable mixture by a species of attraction, and the different parts of the atmosphere are constantly agitated and blended together by winds or other causes. De Saussure found lime water precipitated on Mlount Blanc, the highest point of land in Europe; and carbonic acid gas has been always found, apparently in due proportion, in the air brought down from great heights in the atmosphere by aërostatic adven surers.

The experimental proofs of the composition of carbonic acid gas are very simple. If $\mathbf{1 3}$ grains of 
well burnt charcoal be inflamed by a burning-glass in 100 cubical inches of oxygene gas, the charcoal will entirely disappear: and provided the experiment be correctly made, all the oxygene except a few cubical inches, will be found converted into carbonic acid; and what is very remarkable, the rolume of the gas is not changed. On this last circumstance it is easy to found a correct estimation of the quantity of pure charcoal and oxygene in carbonic acid gas: the weight of 100 cubical inches of oxygene gas is to that of 100 cubical inches of oxygene gas, as 47 to 34 : so that 47 parts in weight of carbonic acid gas, must be composed of 34 parts of oxygene and 13 of charcoal, which correspond with the numbers given in the second Lecture.

Carbonic acid is easily decomposed by heating potassium in it; the metal combines with the oxygene, and the charcoal is deposited in the form of a black powder.

'The principal consumption of the carbonic acid in the atmosphere, seems to be in affording nourishment to plants; and some of them appear to be supplied with carbon chiefly from this source.

Carbonic acid gas is formed during fermentation, combustion, putrefaction, respiration, and a number of operations taking place upon the surface of the earth; and there is no other process known in nature by which it can be destroyed hut by vegetation. 
After a given portion of air has been deprived of aqueous vapour and carbonic acid gas, it appears little altered in its properties; it supports combustion and animal life. There are many modes of separating its principal constituents, oxygene and azote, from each other. A simple one is by burning phospliorus in a confined volume of air: this absorbs the oxygene and leaves the azote; and 100 parts in volume of air, in which phosphorus has been burnt, yield 79 parts of azote; and by mixing. this azote with 21 parts of fresh oxygene gas artificially procured, a substance having the original characters of air is produced. 'l'o procure pure oxygene from air, quicksilver may be kept heated in it, at about $600^{\circ}$, till it becomes a red powder; this powrler, when ignited, will be restored to the state of quicksilver by giving oft oxygene.

Oxygene is necessary to some functions of regetables; but its great importance in nature is in its relation to the economy of animals. It is absolutely necessary to their life. Atmospheric air taken into the lungs of animals, or passed in solution in water through the gills of fishes, loses oxygene; and for the oxygene lost, about an equal volume of carbonic acid appears.

The effects of azote in regetation are not distinctly known. As it is found in some of the products of vegetation, it may be absorbed by certain plants from the atmosphere. It prevents the ac. 


\section{3}

tion of oxygene from being too energetic, and serves as a medium in which the more essential parts of the air act; nor is this circumstance uncon. formable to the analogy of nature; for the elements most abundant on the solid surface of the globe, are not those which are the most essential to the existence of the living beings belonging to it.

The action of the atmosphere on plants differs at different periods of their growth, and varies with the various stages of the development and decay of their organs; some general idea of its influence may have been gained from circumstances already mentioned: I shall now refer to it more particularly, and endeavour to connect it with a general view of the progress of regetation.

If a healthy seed be moistened and exposed to air at a temperature not below $45^{\circ}$, it soon germinates; it shonts forth a plume which rises upwards, and a radicle which descends.

If the air be confined, it is found that in the process of germination the oxygene, or a part of it is absorbed. The azote remains unaltered; no carbonic acid is taken away from the air, on the contrary, some is added.

Seeds are incapahle of germinating, except when oxygene is present. In the exhausted receiver of the air-pump, in pure azote, in pure carbonic acid, when moistened they swell, but do not vegetate; and if kept in these gasses, lose their living powers, and undergo putrefaction. 
If a seed be examined before germination, it will be found more or less insipid, at least not sweet; but after germination it is always sweet. Its coagulated mucilage, or starch, is converted into sugar in the process; a substance difficult of solution is changed into one easily soluble; and the sugar carried through the cells or vessels of the cotyledons, is the nourishment of the infant plant. It is easy to understand the nature of the change, by referring to the facts mentioned in the third Lecture; and the production of carbonic acid renders probable the idea, that the principal chemical difference between sugar and inucilage depends upon a slight difference in the proportions of their carbon.

The absorption of oxygene by the seed in germination, has been compared to its absorption in producing the evolution of fœtal life in the egg; but this analogy is only remote. All animals, from the most to the least perfect classes, require a supply of oxygene*. From the moment the heart

* The impregnated eggs of insects, and even fishes, do not produce young ones, unless they are supplied with air, that is, unless the fetus can respire. I have found that the eggs of moths did not produce larva when confined in pure carbonic acid; and when they were exposed in common air, the oxygene partly disappeared, and carbonic acid was formed. The fish in the egg or spawn, gains its oxygene from the air dissolved in water; and those fislses that spawn in spring and summer in still 


\section{5}

begins to pulsate till it ceases to beat, the aeration of the blood is constant, and the function of respiration invariable; carbonic acid is given off in the process, but the chemical change produced in the blood is unknown; nor is there any reason to suppose the formation of any substance similar to sugar. In the production of a plant from a seed, some reservoir of nourishment is needed before the root can supply sap; and this reservoir is the cotyledon in which it is stored up in an insoluble form, and protected if necessary during the winter, and rendered soluble by agents which are constantly present on the surface. The change of starch into sugar, connected with the absorption of oxyggene, may be rather compared to a process of fermentation than to that of respiration; it is a change effected upon unorganized matter, and can be artifi-

water, such as the pike, carp, perch, and bream, deposit their eggs upon subaquatic vegetables, the leaves of which, in performing their healthy functions, supply oxygene to the water. The fish that spawn in winter, such as the saimon and trout, seek spots where there is a constant supply of fresh water, as near the sources of streams as possible, and in the most rapid currents, where all stagnation is prevented, and where the water is saturated with air, to which it has been exposed during its deposition from clouds. It is the instinct leading these fish to seek a supply of air for their eggs which carries them from seas, or lakes into the mountain country; which induces them to move against the stream, and to endeavour to overleap weirs, milldaps, and calaracts. 
cially imitated; and in most of the chemical changes that occur when vegetable compounds are exposed to air, oxygene is absorbed, and carbonic acid formed or evolved.

It is evident, that in all cases of tillage the seeds should be sown so as to be fully exposed to the influence of the air. Aud one cause of the unproductiveness of cold clayey adhesive soils is, that the seed is coated with matter impermeable to air.

In sandy soils the earth is alivays sufficiently penetrable by the atmosphere; but in clayey soils there can scarcely be too great a mechanical division of parts in the process of tillage. Any seed not fully supplied with air, always produces a weak. and diseased plant.

The process of malting, which has been already referred to, is merely a process in which germination is artificially produced; and in which the starch of the cotyledon is changed into sugar; which sugar is afterwards, by fermentation, converted into spirit.

It is very evident from the chemical principles of germination, that the process of malting should be carried on no farther than to produce the sprouting of the radicle, and should be checked as soon as this has made its distinct appearance. If it is pushed to such a degree as to occasion the perfect development of the radicle and the plume, a consi- 
derable quantity of saccharine matter will have been consumed in producing their expansion, and there will be less spirit formed in fermentation, or produced in distillation.

As this circumstance is of some importance, I made in October 1806, an experiment relating to it. I ascertained by the action of alcohol, the relative proportions of saccharine matter in two equal quantities of the same barley; in one of which the germination had proceeded so far as to occasion protrusion of the radicle to nearly a quarter of an inch beyond the grain in most of the specimens, and in the other of which it had been checked before the radicle was a line in length; the quantity of sugar afforded by the last was to that in the first nearly as six to five.

The saccharine matter in the cotyledons at the time of their change into seed-leaves, renders them exceedingly liable to the attacks of insects: this principle is at once a nourishment of plants and animals, and the greatest ravages are committed upon crops in this first stage of their growth.

The tuinip fly, an insect of the colyoptera genus, fixes itself upon the seed-leaves of the turnip at the time that they are beginning to perform their functions: and when the rough leaves of the plume are thrown forth, it is incapable of injuring the plant to any extent. 
Several methods have been proposed for destroying the turrip fly, or for preventing it from injuring the crop. It has been proposed to sow radishseed with the turnip-seed, on the idea that the insect is fonder of the seed-leaves of the radish than those of the turnip; it is said that this plan has not been successful, and that the fly feeds indiscriminately on both.

There are several chemical menstrua which render the process of germination much more rapid, when the seeds have been steeped in them. As in these cases the seed-leaves are quickly produced, and more speedily perform their functions, I proposed it as a subject of experiment to examine whether such menstrua might not be useful in raising the turnip more speedily to that state in which it would be secure from the fly; but the result proved that the practice was inadmissible; for seeds so treated, though they germinated much quicker, did not produce healthy plants, and often died soon after sprouting.

I steeped radish seeds in September 1807, for twelve hours, in a solution of chlorine, and similar seeds in very diluted nitric acid, in very diluted sulphuric acid, in weak solution of oxysulphate of iron, and some in common water. The seeds in solutions of chlorine and oxysulphate of iron, threw out the germ in two days; those in nitric acid in three days, in sulphuric acid in five, and those in 
water in seven days. But in the cases of premature germination, though the plume was very vigorous for a short time, yet it became at the end of a fortnight weak and sickly; and at that period less vigorous in its growth than the spronts which had been naturally developed, so that there can be scarcely any useful application of these experiments. Too rapid growth and premature decay. seem invariably connected in organized structures; and it is only by following the slow operations of natural causes, that we are capable of making improvements.

There is a number of chemical substances which are very offensive and even deadly to insects, which do not injure, and some of which even assist vegetation. Several of these mixtures have been tried with various success; a mixture of sulphur and lime, which is very destructive to slugs, does not prevent the ravages of the fly on the young turnip crop. His Grace the Duke of Bedford, at my suggestion, was so good as to order the experiment to be tried on a considerable scale at Woburn farm : the mixture of lime and sulphur was strewed over one part of a field sown with turnips; nothing was applied to the other part, but both were attacked nearly in the same manner by the fly.

Mixtures of soot and quicklime, and urine and quicklime, will probably be more efficacious. The volatile alkali given off by these mixtures is offen- 
sive to insects; and they afford nourishment to the plant. Mr. 'T. A. Knight * informs me, that he has tried the method by ammoniacal fumes with success; but more extensive trials are necessary to

* Mr. Knight has been so good as to furnislı me with the following note on this subject.

" The experiment which I tried the year before last, and last year, to preserve turnips from the fy, has not been sufficiently often repeated to enable me to speak with any degree of decision; and last year all my turnips succeerled perfectly well. In consequence of your suggestion, when I had the pleasure to meet you some years ago at Holkham, that lime slacked with urine might possibly be found to kill, or drive off, the insects from a turnip crop, I tried that preparation in mixture with three parts of soot, which was put into a small barrel, with gimblet holes round it, to permit a certain quantity of the composition, about four bushels to an acre, to pass out, and to fall into the drills with the turnip secưs. Whether it was by affording highly stimulating food to the plant, or giving some flavour which the flies did not like, I cannot tell ; but in the year 1811, the adjoining rows wcre eaten away, and those to which the composition was applied, as above described, were scarcely at all touched. It is my intention in future to drill my crop in, first, with the composition on the top of the ridge; and then to sow at least a pound of seed, broad-cast, over the whole ground. The expense of this will be very trifling, not more than 2s. per acre; and the horse-hoe will instantly sweep away all the supernumeraries between the rows, should those escape the flies, to which however they will be chiefly attracted; because it will aiways be found that those insects prefer turnips growing in poor, to those in rich ground. One advantage seems to be the acceleration given to the growth of the plants, 
establish its general efficacy. It may, however, be safely adopted, for if it should fail in destroying the fly, it will at least be an useful manure to the. land.

After the roots and leaves of the infant plant are formed, the cells and tubes throughout its structure become filled with fluid, which is usually supplied from the soil, and the function of nourishment is performed by the action of its organs upon the external elements. The constituent parts of the air are subservient to this process; but, as it might be expected, they act differently under different circumstances.

When a growing plant, the roots of which are supplied with a proper nourishment, is exposed in the presence of solar light to a given quantity of atmospherical air, containing its due proportion of carbonic acid, the carbonic acid after a certain time is destroyed, and a certain quantity of oxygene is

by the highly stimulative effects of the food they instantly receive as soon as their growth commences, and long before their radicles have reached the dung. The directions above given apply only to turnips sowed upon ridges, with the manure immediately under them; and I am quite certain, that in all soils turnips should be thus cultivated. The close vicinity of the manure, and the consequent short time required to carry the food into the leaf, and return the organizable matter to the roots, are, in my hypothesis, points of vast importance; and the results in practice are correspondent." 
found in its place. If new quantities of carbonic acid gas be supplied, the same result occurs; so that carbon is added to plants from the air by the process of vegetation in sunshine; and oxygene is added to the atmosphere.

This circumstance is proved by a number of experiments made by Drs. Priestley, Ingenhousz and Woodhouse, and M. T. de Saussure; many of which I have repeated with similar results. The absorption of carbonic acid gas, and the production of oxygene are performed by the leaf; and leaves recently separated from the tree effect the change, when confined in portions of air containing carbonic acid; and absorb carbonic acid and produce oxygene, even when immersed in water holding carbonic acid in solution.

The carbonic acid is probably absorbed by the fluids in the cells of the green or parenchymatous part of the leaf; and it is from this part that oxygene gas is produced during the presence of light. M. Sennebier found that the leaf, from which the epidermis was stripped off, continued to produce oxygene when placed in water, containing carbonic acid gas, and the globules of air rose from the denuded parenchyma; and it is shewn both from the experiments of Sennebier and Woodhouse, that the leaves most abundant in parenchymatous parts produce most oxygene in water impregnated with carbonic acid. 
Some few plants* will vegetate in an artificial atmosphere, consisting principally of carbonic acid, and many will grow for some time in air, containing from one-half to one-third; but they are not so healthy as when supplied with smaller quantities of this elastic substance.

Plants exposed to light have been found to produce oxygene gas in an elastic medium and in water, containing no carbonic acid gas; but in quantities much smaller than when carbonic acid gas was present.

In the dark no oxygene gas is produced by plants, whatever be the elastic medium to which they are exposed; and no carbonic acid absorbed. In most cases, on the contrary, oxygene gas, if it he present, is absorbed, and carbonic acid gas is produced.

In the changes that take place in the composition of the organized parts, it is probable that saccharine compounds are principally formed during the absence of light; gum, woody fibre, oils, and resins during its presence; and the evolution of carbonic acid gas, or its formation during the night, may be necessary to give greater solubility to certain compounds in the plant. I once suspected that all the carbonic acid gas produced by plants in the night, or in shade, might be owing to the decay of some

* I found the Arenaria tenuifolia to produce oxygene in carbonic acid, which was nearly pure. 
part of the leaf, or epidermis ; but the recent experiments of Mr. D. Ellis are opposed to this idea; and I found that a perfectly healthy plant of celery, placed in a given portion of air for a few hours only, occasioned a production of carbonic acid gas, and an absorption of oxygene.

Some persons have supposed that plants exposed in the free atmosphere to the vicissitudes of sunshine and shade, light and darkness, consume more oxygene than they produce, and that their permanent agency upon air is similar to that of animals; and this opinion is espoused by the writer on the subject I have just quoted, in his ingenious researches on vegetation. But all experiments brought forwards in favour of this idea, and particularly his experiments, have been made under circumstances unfavourable to accuracy of result. The plants have been confined and supplied with food in an unnatural manner; and the influence of light upon them has been very much diminished by the nature of the media through which it passed. Plants confined in limited portions of atmospheric air soon become diseased; their leaves decay, and by their decomposition they rapidly destroy the oxygene of the air. In some of the early experiments of Dr. Priestley before he was acquainted with the agency of light upon leaves, air that had supported combustion and respiration, was found purified by the growth of plants when they were 
exposed in it for successive days and nights; and his experiments are the more unexceptionable, as the plants, in many of them, grew in their natural states; and shoots, or branches from them, only were introduced through water into the confined atmosphere.

I have made some few researches on this subject, and I shall describe their results. On the 12 th of July, 1800, I placed a turf four inches square, clothed with grass, principally meadow fox-tail, and white clover, in a porcelain dish, standing in a shallow tray filled with water; I then covered it with a jar of flint glass, containing 380 cubical inches of common air in its natural state. It was exposed in a garden, so as to be liable to the same changes with respect to light as in the common air. On the 20th of July the results were examined. There was an increase of the volume of the gas, amounting to fifteen cubical inches; but the temperature had changed from $64^{\circ}$ to $71^{\circ}$; and the pressure of the atmosphere, which on the 12 th had been equal to the support of 30.1 inches of mercury, was now equal to that of 30.2. Some of the leaves of the white clover, and of the fox-tail were yellow, and the whole appearance of the grass less bealthy than when it was first introduced. A cubical inch of the gas, agitated in lime-water, gave a slight turbidness to the water; and the absorption was not quite one-one hundred and fiftieth of its volume. 100 parts of the residual gas exposed to a solution 
of green sulphate of iron, impregnated with nitrous gas, a substance which rapidly absorbs oxygene from air, occasioned a diminution to 80 parts. 100 parts of the air of the garden occasioned a diminution to 79 parts.

If the results of this experiment be calculated upon it, it will appear that the air had been slightly deteriorated by the action of the grasses. But the weather was unusually cloudy during the progress of the experiment; the plants had not been supplied in a natural manner with carbonic acid gas; and the quantity formed during the night, and by the action of the faded leaves, must have been partly dissolved by the water; and that this was actually the case, I proved by pouring limewater into the water, when an immediate precipitation was occasioned. The increase of azote $\mathbf{I} \mathrm{am}$ inclined to attribute to common air disengaged from the water.

'T'he following experiment I consider as conducted under circumstances more analogous to those existing in nature. A turf four inches square, from an irrigated meadow, clothed with common meadow grass, meadow fox-tail grass, and vernal meadow grass, was placed in a porcelain dish, which swam on the surface of water impregnated with carbonic acid gas. A vessel of thin flint glass, of the capacity of 230 cubical inches, having a funnel furnished with a stop-cock inserted in the top, was made to cover the grass; and the apparatus was 
-

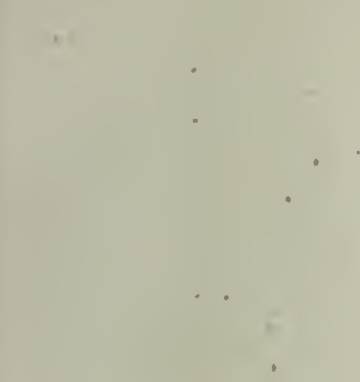

-

14

4

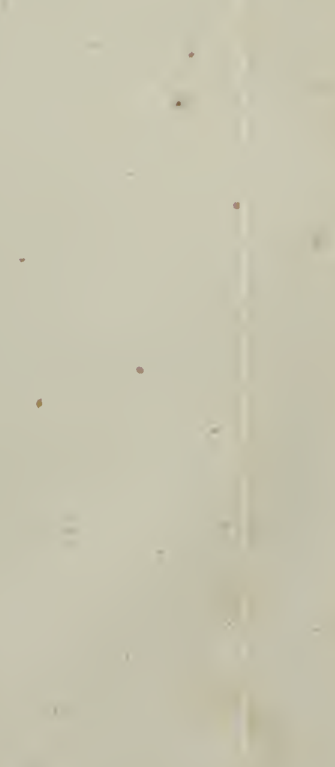




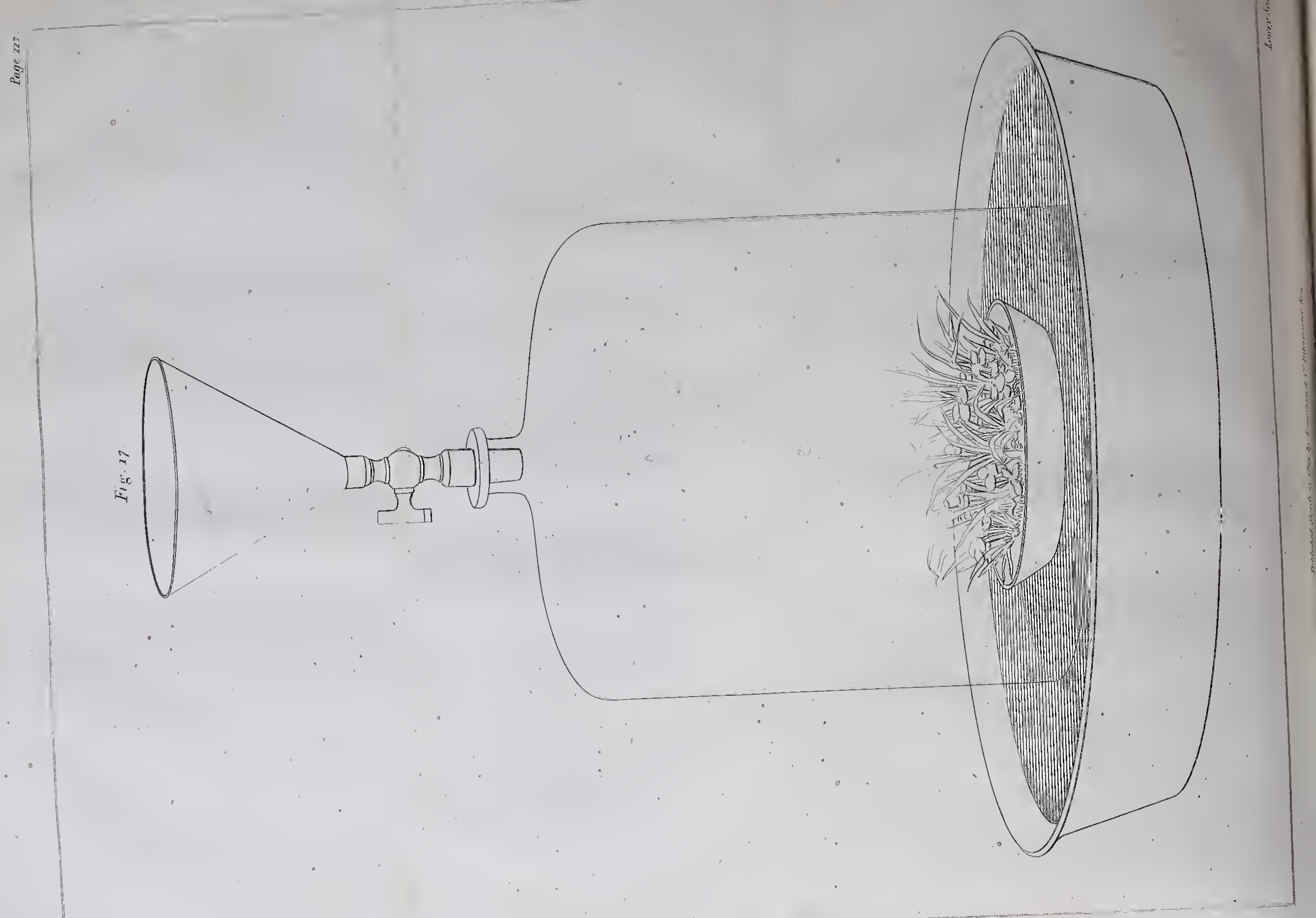


exposed in an open place; a small quantity of water was daily supplied to the grass by means of the stop-cock** Every day likewise a certain quantity of water was removed by a siphon, and water saturated with carbonic acid gas supplied in its place; so that it may be presumed, that a small quantity of carbonic acid gas was constantly present in the receiver. On the 7th of July, 1807, the first day of the experiment, the weather was cloudy in the morning, but fine in the afternoon; the thermometer at 67 , the barometer 30.2 : towards the evening of this day a slight increase of the gas was perceived, the next three days were bright; but in the morning of the 11th the sky was clouded; a consirlerable increase of the volume of the gas was now obscrved: the 12th was clondy, with gleams of sunshine; there was still an increase, but less than in the bright days; the 13 th was bright. About nine o'clock A. M. on the 14 th the receiver was quite full; and considering the original quantity in the jal, it must have been increased by at lcast 30 cubical inches of elastic fluid: at times during this day globules of gas escaped. At ten on the morning of the $15 \mathrm{th}$, I examined a portion of the gas; it contained less than one-fiftieth of carbonic acid gas: 100 parts of it exposed to the impregnated solution left only 75 parts; so that

* See Fig. 17. 
the air was four per cent. purer than the air of the atmosphere.

I shall detail another similar experiment made with equally decisive results. A shoot from a vine, having three healthy leaves belonging to it, attached to its parent tree, was bent so as to be placed under the receiver which had been used in the last experiment; the water confining the common air was kept in the same manner impregnated with carbonic acid gas: the experiment was carried on from August 6th, till August 14th, 1807; during this time, though the weather had been generally clouded, and there had been some rain, the volume of elastic fluid continued to increase. Its quality was examined on the morning of the 15 th ; it contained one-forty-second of carbonic acid gas, and 100 parts of it afforded 23.5 of oxygene gas.

These facts confirm the popular opinion, that when the leaves of vegetables perform their healthy functions, they tend to purify the atmosphere in the common variations of weather, and changes from light to darkness.

In germination, and at the time of the decay of the leaf, oxygene must be absorbed; but when it is considered how large a part of the surface of the earth is clothed with perennial grasses, and that half of the globe is always exposed to the solar light, it appears by far the most probable opinion, that more oxygene is produced than consumed dur- 
ing the process of vegetation; and that it is this circumstance which is the principal cause of the uniformity of the constitution of the atmosphere.

Animals produce no oxygene gas during the exercise of any of their functions and they are constantly consuming it; but the extent of the animal, compared to that of the vegetable, kingdom is very small; and the quantity of carbonic acid gas produced in respiration, and in various processes of combustion and fermentation, bears a proportion extremely minute to the whole volume of the atmosphere: if every plant during the progress of its life makes a very small addition of oxygene to the air, and occasions a very small consumption of carbonic acid, the effect may be conceived aderquate to the wants of nature.

It may occur as an objection to these views, that if the leaves of plants purify the atmosphere, towards the end of autumn, and through the winter, and early spring, the air in our climates must become impure, the oxygene in it diminish, and the carbonic acid gas increase, which is not the case; but there is a very satisfactory answer to this objection. The different parts of the atmosphere are constantly mixed together by winds, which when they are strong, move at the rate of from 60 to 100 miles in an hour. In our winter, the south-west gales convey air, which has been purified by the vast forests and savannas of South America, and which, passing over the ocean, arrives in an uncon- 
taminated state. The storms and tempests which often occur at the beginning. and towards the middle of our winter, and which generally blow from the same quarter of the globe, have a salutary influence. By constant agitation and motion, the equilibrium of the constituent parts of the atmosphere is preserved; it is fitted fo: the purposes of life; and those events, which the superstitious formerly referred to the wrath of heaven, or the agency of evil spirits, and in which they saw only disorder and confusion, are demonstrated by science, to be ministrations of divine intelligence, and connected with the order and harmony of our system.

I have reasoned, in a former part of this Lecture, against the close analogy which some persons have assumed between the absorption of oxygene and the formation of carbonic acirl gas in germination, and in the respiration of the foetus. Similar arguments will apply against the pursuit of this analogy, between the functions of the leaves of the adult plant, and those of the lungs of the adult animal. Plants grow vigorously only when supplied with light; and most species die if deprived of it. It caunot be supposed that the production of oxygene from the leaf, which is known to be connected with its natural colocir, is the exertion of a diseased function, or that it can acquire carbon in the daytime, when it is in most vigorous growth, when the sap is rising, when all its powers of obtaining nou- 
rishment are exerted; merely for the purpose of giving it off again in the night, when its leaves are closed, when the motion of the sap is imperfect, and when it is in a state approaching to that of quiescence. Many plants that grow upon rocks, or soils, containing no carbonic matter, can only be supposed to acquire their charcoal from the carbonic acid gas in the atmosphere; and the leaf may be considered at the same time as an organ of absorption, and an organ in which the sap may undergo different chemical changes.

When pure water only is absoiber by the roots of plants, the fluid, in passing into the leaves, will probably have greater power to absorb carbonic acid from the atmosphere. When the water is saturated with carbonic acid gas, some of this substance, even in the sunshine, may be given off by the leaves; but a part of it likewise will be always decomposed, which has been proved by the experiments of M. Sennebier.

When the fluid taken up by the roots of plants contains much carbonaceous matter, it is probable that plants may give off carbonic acid from their leaves, even in the sunshine. In short, the function of the leaf must vary according to the composition of the sap passing through it; and according to the nature of the products which are formed from it. When sugar is to be produced, as in early spring at the time of the development of buds and flowers, it is probable that less oxygene will be 
given off, than at the time of the ripening of the seed, when starch, or gums, or oils, are formed; and the process of ripening the seed usually takes place when the agency of the solar light is most intense. When the acid juices of fruits become saccharine in the natural process of vegetation, more oxygene, there is every reason to believe, must be given off, or newly combined, than at other times; for, as it was shewn in the Third Lecture, all the vegetable acids contain more oxygene than sugar. It appears probable, that in some cases, in which oily and resinous bodies are formed in vegetation, water may be decomposed; its oxygene set free, and its hydrogene absorbed.

I have already mentioned, that some plants produce oxygene in pure water; Dr. Ingenhouz found this to be the case with species of the confervæ, I have tried the leaves of many plants, particularly those that produce volatile oils. When such leaves are exposed in water saturated with oxygene gas, oxygene is given off in the solar light; but the quantity is very small and always limited; nor have I been able to ascertain with certainty, whether the vegetative powers of the leaf were concerned in the operation, though it seems probable. I obtained a considerable quantity of oxygene in an experiment made fifteen years ago, in which vine leaves were exposed to pure water; but on repeating the tial often since, the quantities have always been very much smailer; I am ignorant 


\section{3}

whether this difference is owing to the peculiar state of the leaves, or to some confervæ which might have adhered to the vessel, or to other sources of fallacy.

The most important and most common products of vegetables, mucilage, starch, sugar, and woody fibre, are composed of water, or the elements of water in their due proportion, and charcoal; and these, or some of them, exist in all plants; and the decomposition of carbonic acid, and the combination of water in vegetable structures, are processes which must occur almost universally.

When glutenous and albuminous substances exist in plants, the azote they contain may be suspected to be derived from the atmosphere: but no experiments have been made which prove this; they might easily be instituted upon mushrooms and funguses.

In cases in which buds are formed, or shoots thrown forth from roots, oxygene appears to be uniformly absorbed, as in the germination of seeds. I exposed a small potatoe moistened with common water to 24 cubical inches of atmospherical air, at a temperature of $59^{\circ}$. It began to throw forth a shoot on the third day; when it was a half an inch long I examined the air; nearly a cubical inch of oxygene was absorbed, and about three-fourths of a cubical inch of carbonic acid formed. The juices in the shoot separated from the potatoe, had a 
sweet taste; and the absorption of oxygene, and the production of carbonic acid, were probably connected with the conversion of a portion of starch into sugar. When potatoes that have been frozen are thawed, they become sweet; probably oxygene is absorbed in this process; if so, the change may be prevented by thawing them out of the contact of air; under water, for instance, that has been recently boiled.

In the tillering of corn, that is, the production of new staiks round the original plume, there is every reason to believe that oxygene must be absorised; for the stalk at which the tillering takes place, always contains sugar, and the shonts arise from a part deprived of light. The drill hushandry favours this process; for loose earth is thrown by hoeing round the stalks; they are preserved from light, and yet supplied with oxygene. I have counted from forty to one hundred and twenty stalks produced from a grain of wheat, in a moderately good crop of drilled wheat. And we are informed by Sir Kenelm Digby, in 1660, that there was in the possession of the Fathers of the Christian Doctrine at Paris, a plant of barley, which they, at that time, kept by them as a curiosity, and which consisted of 249 stalks springing from one root, or grain; and in which they counted above 18,000 grains, or seeds of barley.

The great increase which takes place in the 
transplantation of wheat, depends upon the circumstance, that each layer thrown out in tillering may be removed, and treated as a distinct plant. In the Philosophical 'Transactions, Vol. LVIII, p. 203, the following statement may be found: Mr. C. Miller, of Cambridge, sowed some wheat on the $2 \mathrm{~d}$ of June, 1766; and on the 8th of August, a plant was taken and separated into 18 parts, and replanted; these plants were again,taken up, and divided in the months of September and October, and planted separately to stand the winter, which division produced 67 plants. They were again taken up in March and April, and produced 500 plants: the number of ears thus formed from one grain of wheat was 21,109, which gave three pecks and three quarters of corn that weighed 47libs. 7ozs.; and that were estimated at 576,810 grains.

It is evident from the statements just given, that the change which takes place in the juices of the leaf by the action of the solar light, must tend to increase the proportion of inflammable matter to their other constituent parts. And the leaves of the plants that grow in darkness, or in shady places, are uniformly pale; their juices are watery and saccharine, and they do not afford oils or resinous substances. I shall detail an experiment on this subject.

I took an equal weight, 400 grains, of the leaves of two plants of endive, one bright green, which 
had grown fully exposed to light, and the other almosi white, which had been secluded from light by being covered with a box; after being both acted upon for some time by boiling water, in the state of pulp, the undissolved matter was dried, and exposed to the action of warm alcohol. The matter from the green leaves gave it a tinge of olive; that from the pale leaves did not alter its colour. Scarcely any solid matter was produced by evaporation of the alcohol that had been digested on the pale leaves: whereas by the evaporation of that from the green leaves, a considerable residuum was obtained; five grains of which were separated from the vessel in which the evaporation was carried on; they bumt with flame, and appeared partly matter analogous to resin. 53 grains of woody fibre were obtained from the green leaves, and only 31 from the pale leaves.

It has been mentioned in the Third Lecture, that the sap probably, in common cases, descends from the leaves into the bark; the bark is usually so loose in its texture, that the atmosphere may possibly act upon it in the cortical layers; but the changes taking place in the leaves, appear sufficient to explain the difference between the products obtained from the bark and from the alburnum; the first of which contains more carbonaceous matter than the last.

When the similarity of the elements of different vegetable products is considered, according to the views given in the third Lecture, it is easy to con- 


\section{7}

ceive how the different organized parts may be formed from the same sap, according to the manner in which it is acted on by heat, light, and air. By the abstraction of oxygene, the different inflammable products, fixed and volatile oils, resins, camphor, woody fibre, \&c. may be produced from saccharine or mucilaginous fluids; and by the abstraction of carbon and hydrogene, starch, sugar, the different vegetable acids and substances soluble in water, may be formed from highly combustible and insoluble substances. Even the limpid volatile oils which convey the fragrance of the flower, consist of different proportions of the same essential elements, as the dense woody fibre; and both are formed by different changes in the same organs, from the same materials, and at the same time.

M. Vanquelin has lately attempted to estimate the chemical changes taking place in vegetation, by analysing some of the organized parts of the horse-chesnut in their different stages of growth. He found in the buds collected, March 7, 1812, tanning principle, and albuminous matter capable of being obtained separately, but when obtained, combining with each other. In the scales surrounding the buds, he found the tanning principle, a little saccharine matter, resin, and a fixed oil. In the leaves fully developed, he discovered the same principles as in the buds; and in addition, a peculiar green resinous matter. The petals of the flower yielded a yellowish resin, saccharine matter, albu- 
minous matter, and a little wax: the stamina afforded sugar, resin, and tannin.

The young chestnuts examined immediately after their formation, afforded a large quantity of a matter which appeared to be a combination of albuminous matter and tannin. All the parts of the plant afforded saline combinations of the acetic and phosphoric acids.

M. Vauquelin could not obtain a sufficient quantity of the sap of the horse-chestnut for examination; a circumstance much to be regretted; and he has not stated the relative quantities of the different substances in the buds, leaves, flowers, and seeds. It is probable, however, from his unfinished details, that the quantity of resinous matter is increased in the leaf, and that the white fibrous pulp of the chestnut is formed by the mutual action of albuminous and astringent matter, which probably are supplied by different cells or vessels. I have already mentioned * that the cambium, from which the new parts in the trunk and branches appear to be formed, probably owes its powers of consolidation to the mixture of two different kinds of sap; one of which flows upwards from the roots; and other of which probably descends from the leaves. I attempted, in May 1804, at the time the cambium was forming in the oak, to ascertain the nature of the action of the sap of the alburnum upon the 
juices of the bark. By perforating the alburnum in a young oak, and applying an exhausting syringe to the aperture, I easily drew out a small quantity of sap. I could not, however, in the same way obtain sap from the bark. I was obliged to recur to the solution of its principles in water, by infusing a small quantity of fiesh bark in warm water; the liquid obtained in this way was highly coloured and astringent; and produced an immediate precipitate in the alburnous sap, the taste of which was sweetish, and slightly astringent, and which was colourless.

The increase of trees and plants must depend upon the quantity of sap which passes into their organs; upon the quality of this sap; and on its modification by the principles of the atmosphere. Water, as it is the vehicle of the nourishment of the plant, is the substance principally given off by the leaves. Dr. Males found, that a sunflower, in one day of twelve hours, transpired by its leares one pound fourteen ounces of water, all of which must have been imbibed by its roots.

The powers which cause the ascent of the sap have been slightly touched upon in the Second and Third Lectures. The roots imbibe fluids from the soil by capillary attraction; but this power alone is insufficient to account for the rapid elevation of the sap into the leaves. This is fully proved by the following fact detailed by Dr. Hales, Vol. I. of the 
Vegetable Statics, page 114. A vine branch of four or five years old was cut through, and a glass tube carefully attached to it ; this tube was bent as a siphon, and filled with quicksilver; so that the force of the ascending sap could be measured by its effect in elevating the quicksilver. In a few days it was found, that the sap had been propelled forwards with so much force, as to raise the quicksilver to 38 inches, which is a force considerably superior to that of the usual pressure of the atmosphere. Capillary attraction can only be exerted by the surfaces of small-vessels, and can never raise a fluid into tubes above the vessels themselves.

I referred in the beginning of the Third Lecture to Mr. Knight's opinion, that the contractions and expansions of the silver grain in the alburnum, are the most efficient cause of the ascent of the fluids contained in its pores and vessels. The views of this excellent physiologist are rendered extremely probable by the facts he has brought forwards in support of them. Mr. Knight found that a very small increase of temperature was sufficient to cause the fibres of the silver grain to separate from each other, and that a very slight diminution of heat produced their contraction. The sap rises most vigorously in spring and autumn, at the time the temperature is variable; and if it be supposed, that in expanding and contracting, the elastic fibres of the silver grain exercise a pressure upon the cells and tubes containing the fluid absorbed by the ca- 
pillary attraction of the roots, this fluid must constantly move upwards towards the points where a supply is needed.

The experiments of Montgolfier, the celebrated inventor of the balloon, have shewn that water may be raised almost to an indefinite height by a very small force, provided its pressure be taken off by continued divisions in the column of fluid. This principle, there is great reason to suppose, must operate in assisting the ascent of the sap in the cells and vessels of plants which have no rectilineal communication, and which every where oppose obstacles to the perpendicular pressure of the sap.

'The changes taking place in the leaves and buds, and the degree of their power of transpiration, must be intimately connected likewise with the motion of the sap upwards. This is shewn by several experiments of Dr. Hales.

A branch from an apple-tree was separated and introduced into water, and connected with a mercurial gage. When the leaves were upon it, it raised the mercury by the force of the ascending juices to four inches; but a similar branch, from which the leaves were removed, scarcely raised it a quarter of an inch.

Those trees, likewise, whose leaves are soft and of a spongy texture, and porous at their upper surfaces, displayed by far the greatest powers with regard to the elevation of the sap.

The same accurate philosopher whom I have 
just quoted, found that the pear, quince, cherry, walnut, peach, gooseberry, water-elder, and sycamore, which have all soft and unvarnished leaves, raised the mercury under favourable circumstances from three to six inches. Whereas the elm, oak, chestnut, hazel, sallow, and ash, which have firmer and more glossy leaves, raised the mercury only from one to two inches. And the evergreens and trees bearing varnished leaves, scarcely at all affected it; particularly the laurel and the lauristinus.

It will be proper to mention the facts which shew, that in many cases fluids descend through the bark; they are not of the same unequivocal nature as those which demonstrate the ascent of the *ap through the alburnum; yet many of them are satisfactory.

M. Baisse placed branches of different trees in an infusion of madder, and kept them there for a long time. He found in all cases, that the wood became red before the bark; and that the bark began to receive no tinge till the whole of the wood was coloured, and till the leaves were affected; and that the colouring matter first appeared above, in the bark immediately in contact with the leaves.

Similar experiments were made by M. Bonnet, and with analogous results, though not so perfectly distinct as those of $\mathbf{M}$. Baisse.

Du Hamel found, that in different species of the pine and other trees, when strips of bark were re- 


\section{3}

moved, the upper part of the wound only emitted fluid, whilst the lower part remained dry.

This may likewise be observed in the summer in fruit-trees, when the bark is wounded, the alburnum remaining untouched.

I have mentioned in the Third Lecture, that when new bark is formed to supply the place of a ring that has been stripped off, it first makes its appearance upon the upper edge of the wound, and spreads slowly downwards; and no new matter appears from below rising upwards, if the experiment has been carefully performed. I say carefully performed; because, if any of the interior coltical layer be suffered to remain communicating with the upper edge, new bark covered with epidermis will form below this, and appear as if protruded upon the naked alburnum, and formed within the wound; and such a circumstance would give rise to erroneons conclusions.

In the summer of 1804, I examined some elms at Kensincrton. The bark of many of them had been very much injured, and, in some cases, more than a square foot had been stripped off. In most of the wounds the formation of the new cortical layers was from above, and gradually extending downwards round the aperture; but in two instances there had been very distinctly a formation of bark towards the lower edge. I was, at first, very much surprised at this appearance, so contradictory to the general opinion; but, on passing the point of a 
pen-knife along the surface of the alburnum, from below upwards, I found that a part of the cortical layer, which was of the colour of the alburnum, had remained communicating with the upper edge of the wound, and that the new bark' had 'formed from this layer. I have had no opportunity of looking at the trees lately;"but I doubt not that the phænomenon may still be observed; for "some years must elapse before the new formations will be complete.

' In accounting for the experiment of M. Palisot de Beauvois, mentioned in the Third Lecture, is may be supposed that the cortical fluid flowed down the alburnum upon the insulated hark, and thus occasioned its increase; or it may be conceived that the bark itself contained sufficient cortical fluid at the time of its separation to form new parts by its action upon the alburnous fluid.

The motion of the sap through the bark seems principally to depend upon gravitation. When the watery particles have been considerably dissipated by the transpiring functions of the leaves, and the mucilaginous, inflammable, and astringent constituents, increased by the agency of heat, light, and air, the continued impulse upwards from the alburnum, forces the remaining inspissated fluid into the cortical vessels, which receive no other supply. In these, from it's weight, its natural tendency must be to descend; and the rapidity of the descent must depend upon the general consumption of the fluids of the hark in the living processes of vegetation; 
for there is every reason to believe, that no fluid passes into the soil through the roots; and it is impossible to conceive a free lateral communication between the absorbent vessels of the alburnum in the roots, and the transporting or carrying vessels of the bark; for if such a communication existed, there is no reason why the sap should not rise through the bark as well as through the alburnum; for the same physical powers would then operate upon both.

Some authors have supposed that the sap rises in the alburnum, and descends through the bark in consequence of a power similar to that which produces the circulation of the blood in animals; a force analogous to the muscular force in the sides of the vessels.

Dr. Thomson, in his System of Chemistry, has stated a fact which he considers as demonstrating the irritability of living vegetable systems. When a stalk of spurge (Euphorbia peplis) is separated by two incisions from its leaves and roots, the milky fluid flows through both sections. Now, says the ingenious author, it is impossible that this could happen without the living action of the vessels, for they cannot have been more than full; and their diameter is so small, that if it were to continue unaltered, the capillary attraction would be more than sufficient to contain their contents, and, consequently, not a drop would flow out. Since, there- 
fore, the liquid escapes, it must be driven out by a force different from a common physical force.

To this reasoning it may be answered, that the sides of all the vessels are soft, and capable of collapsing by gravitation, as veins do in animal systems long after they have lost all their vitality; which is an effect totally different from vital or irritable action ; and the phænomenon may be compared to that of puncturing a vessel of elastic gum filled with fluid, both above and below; the fluid will make its way through the apertures, though in much larger quantity from the lowest, which I have found is likewise the case with the spurge.

Dr. Barton has stated, that plants grow more vigorously in water in which a little camphor has been infused. This has been brought forward as a fact in favour of the irritability of the vegetable tubular system. It is said, that camphor can only be conceived to act as a stimulus, by increasing the living power's of the vessels, and causing them to contract with more energy. But this kind of speculation is rery unsatisfactory. Camphor, we know, has a disagreeable pungent taste, and powerful smell; but physicians are far from being agreed whether it is a stimulant or sedative, even in its operation upon the human body. We should have no right whatever, even supposing the irritability of vegetables proved, to conclude, that because camphor assisted the growth of plants, it acted on their living powers; and it is not right to 
infer the existence of a property proved in no other way, from the operation of uncertain qualities.

That camphor may assist the growth of plants it is easy to conceive; and why should we not consider its efficacy as similar to the efficacy of saccharine and mucilaginous matter, and particularly of oils, to which it is nearly allied in composition; and which afford food to the plant, and not stimulus; which are materials of assimilation, and not of excitement?

The arguments in favour of a contraction similar to muscular action have not then much weight; and besides, there are direct facts which render the opinion highly improbable.

When a single branch of a vine or other tree is introduced in winter into a hot-house, the trunk and the other branches remaining exposed to the cold atmosphere, the sap will soon begin to move towards the buds in the heated branch; these buds will gradually unfold themselves, and begin to transpire; and at length open into leaves. Now if any peculiar contractions of the sap vessels or cells were necessary for the ascent of the sap in the vessels, it is not possible that the application of heat to a single branch should occasion irritable action to take place in a trunk many feet removed from it, or in roots fixed in the cold soil : but allowing that the energy of heat raises the fluid merely by diminishing its gravity, increasing the facility of capillary action, and by producing an expansion of the 
fibres of the silver grain, the phænomenon is in perfect unison with the views advanced in the preceding part of this Lecture.

The ilex, or evergreen oak, preserves its leaves through the winter, even when grafted upon the common oak; and in consequence of the operation of the leaves, there is a certain motion of the sap from the oak towards the ilex, which, as in the last case, seems to be inconsistent with the theory of irritable action.

It is impossible to peruse any considerable part of the Vegetable Statics of Hales, without receiving a deep impression of the dependence of the motion of the sap upon common physical agencies. In the same tree this sagacious person observed, that in a cold cloudy morning when no sap ascended, a sudden change was produced by a gleam of sunshine, of half an hour; and a vigorous motion of the fluid. The alteration of the wind from south to the north immediately checked the effect. On the coming on of a cold afternoon after a hot day, the sap that had been rising began to fall. A warm shower and a sleet storm produced opposite efiects.

Many of his observations likewise shew, that the different powers which act on the adult tree, produce different effects at different seasons.

Thus, in the early spring, before the buds expand, the variations of the temperature, and changes of the state of the atmosphere with regard to moisture and dryness, exert their great effects upon the expan- 
sions and contractions of the vessels; and then the tree is in what is called by gardeners its bleeding. season.

When the leaves are fully expanded, the great determination of the sap is to these new organs. And hence a tree which emits sap copiously from a wound whilst the buds are opening, will no longer. emit it in summer when the leaves are perfect; but in the variable weather, towards the end of autumn, when the leaves are falling, it will again possess the power of bleeding in a very slight degree in the warmest days; but at no other times.

In all these circumstances there is nothing analogous to the irritable action of animal systems,

In animal systems the heart and arteries are in constant pulsation. Their functions are unceasingly. performed in all climates, and in all seasons; in winter, as well as in spring; upon the arctic snows, and under the tropical suns. They neither cease in the periodical nocturnal sleep, common to most animals; nor in the long sleep of winter, peculiar to a few species. The power is connected with animation, is limited to beings possessing the means of voluntary locomotion; it co-exists with the first appearance of vitality; it disappears only with the last spark of life.

Vegetables may be truly said to be living systems, in this sense, that they possess the means of converting the elements of common matter into organized 
structures, both by assimilation and reproduction; but we must not suffer ourselves to be deluded by the very extensive application of the word life, to conceive, in the life of plants, any power similar to that producing the life of animals. In calling forth the vegetable functions, conmon physical agents alone seem to operate; bnt in the animal system these agenis are made stbservient to a superior principle. To give the argument in plainer language, there are few philosophers who would be inclined to assert the existence of any thing above common matter, any thing immaterial in the vegetable œconomy. Such a doctrine is worthy only of a poetic form. The imagination may easily give Dryads to our trees, and Sylphs to our flowers; but neither Dryads nor Sylphs can be arlmitted in vegetable physiolo$\mathrm{gy}$; and for reasons nearly as strong, irritability and animation ought to be excluded.

As the operation of the different physical agents upon the sap ressels of plants ceases, and the fluid becomes quiescent, the materials dissolved in it by heat, are deposited upon the sides of the tubes now considerably diminished in their diameter; and in consequence of this deposition, a nutritive matter is provided for the first wants of the plant in early spring, to assist the opening of the buds, and their expansion, when the motion from the want of leaves is as yet feeble.

This beautiful principle in the vegetable œcono- 
my was first pointed ont by $\mathbf{D r}$. Darwin; and $\mathbf{M r}$. Knight has given a number of experimental elucidations of it.

Mr. Knight made numerous incisions into the alburnmm of the sycamore and the birch, at different heights; and in examining the sap that flowed from them, he found it more sweet and mucilagirous in proportion as the aperture from which it flowed was elevated; which he could ascribe to no other cause than to its having dissolved sugar and mucilage, which had been stored up through the winter.

He examined the alburnum in different poles of oak in the same forest; of which some had been felled in winter, and others in summer; and he always found most soluble matter in the wood felled in winter, and its specific gravity was likewise greater.

In all perennial trees this circumstance takes place; and likewise in grasses and shrubs. The joints of the perennial grasses contain more saccharine and mucilaginous matter in winter than at any other season; and this is the reason why the fiorin or Agrostis alba, which abounds in these joints, affords so useful a winter food.

'The roots of shrubs contain the largest quantity of nourishing matter in the depth of winter; and the bulb in all plants possessing it, is the receptacle in which nourishment is hoarded up during winter.

In annual plants the sap seems to be fully exhausted of all its nutritive matter by the product. 
of flowers and seeds, and no system exists by which it can be preserved.

When perennial grasses are cropped very close by feeding cattle late in autumn, it has been often observed by farmers, that they never rise vigorously in the spring; and this is owing to the removal of that part of the stalk which would have afforded them concrete sap, their first nourishment.

Ship builders prefer for their purposes that kind of oak timber afforded by trees that have had their bark stripped off in spring, and which have been cut in the autumn or winter following. The reason of the superiority of this timber is, that the concrete sap is expended in the spring in the sprouting of the leaf; and the circulation being destroyed, it is not formed anew; and the wood having its pores free from saccharine matter, is less liable to undergo fermentation from the action of moisture and air.

In perennial trees a new alburnum, and consequently a new system of vessels, is annually produced, and the nutriment for the next year deposited in them; so that the new buds, like the plume of the seed, are supplied with a reservoir of matter essential to their first development.

The old alburnum is gradually converted into heart-wood, and being constantly pressed upon by the expansive force of the new fibres, becomes harder, denser, and at length loses altogether its vascular structure; and in a certain time obeys the common laws of dead matter, decays, decomposes, 
and is converted into aeriform and carbonic elements; into those principles from which it was originally. formed.

The decay of the heart-wood seems to constitute the great limit to the age and size of trees. And in young branches from old trees, it is much more liable to decompose than in similar branches from seedlings. This is likewise the case with grafts. The graft is only nourished by the sap of the tree to which it is transferred; its properties are not changed by it: the leaves, blossoms, and fruits are of the same kind as if it had vegetated upon its parent stock. The only advantage to be gained in this way, is the affording to a graft from an old tree a more plentiful and healthy food than it could have procured in its natural state; it is rendered for a time more vigorous, and produces fairer blossoms and richer fruits. But it partakes not merely of the obvious properties, but likewise of the infirmities and dispositions to old age and decay, of the tree whence it sprung.

This seems to be distinctly shewn by the observations and experiments of Mr. Knight. He has; in a number of instances, transferred the young scions and healthy shoots from old esteemed fruitbearing trees to young seedlings. 'They flourished for two or three years; but they soon became diseased and sickly like their parent trees.

It is from this cause that so many of the apples formerly celebrated for their taste and their uses in 
the manufacture of cider are gradually deteriorating, and many will soon disappear. The gold'n pippin, the red streak, and the moil, so excellent in the beginning of the last century, are now in the extremest stage of their decay; and however carefully they are ingrafted, they merely tend to multiply a sickly and exhausted variety.

'The trees possessing the firmest and the least porous heart-wood are the longest in duration.

In general, the quantity of charcoal afforded by woods, offers a tolerably accurate indication of their durability: those most abuncant in charcoal and earthy matter are most permanent; and those that contain the largest proportion of gaseous elements are the most destructible.

Amongst our own trees, the chesnut and the oak are pre-eminent as to durability; and the chestnut affords rather more carbonaceous matter than the oak.

In old Gothic buildings these woods have been sometimes mistaken one for the other; but they may be easily known by this circumstance, that the pores in the alburnum of the oak are much larger and more thickly set, and are easily distinguished; whilst the pores in the chestnut require glasses to be seen distinctly.

In consequence of the slow decay of the heartwood of the oak and chestnut, these trees under favourable circumstances attain an age which cannot be much short of 1000 years. 
The beech, the ash, and the sycamore, most likely never live half as long. The duration of the apple tree is not, probably, much more than 200 years; but the pear tree, according to Mr. Knight, lives through double this period; most of our best apples are supposed to have been introduced into Britain by a fruiterer of Henry the Eighth, and they are now in aistate of old age.

The oak and chestnut decay much sooner in a moist situation, than in a dry and sandy soil; and their timber is less firm. The sap ressels in such cases are more expanded, though less nourishing matter is carried into them; and the general texture of the formations of wood necessarily less firm. Such wood splits more easily, and is more liable to be affected by variations in the state of the atmosphere.

The same trees, in general, are much longer lived in the northern than in the southern climates. The reason seems to be, that all fermentation and decomposition are checked by cold; and at very low temperatures both animal and vegetable matters altogether resist putrefaction: and in the northern winter, not only vegetable life, but likewise vegetable decay must be at a stand.

The antiputrescent quality of cold climates is fully illustrated in the instances of the rhinoceros and mammoth lately found in Siberia, entire beneath the frozen soil, in which they must probably have existed from the time of the deluge. I exa. 
mined a part of the skin of the mammoth sent to this country, on which there was some coarse hair; it had all the chemical characters of recently dried skin.

Trees that grow in situations much exposed to winds, have harder and firmer wood than such as are considerably sheltered. The dense sap is determined, by the agitation of the smaller branches, to the trunk and large branches: where the new alburnum formed is consequently thick and firm. Such trees abound in the crooked limbs fitted for forming knee-timber, which is necessary for joining the decks and the sides of ships. The gales in elevated situations gradually act, so as to give the tree the form best calculated to resist their effects. And the mountain oak rises robust and sturdy; fixed firmly in the soil, and able to oppose the full force of the tempest.

The decay of the best varieties of fruit-bearing trees which have been distributed through the country by grafts, is a circumstance of great importance. There is no mode of preserving them; and no resource, except that of raising new varieties by seeds.

Where a species has been ameliorated by culture, the seeds it affords, other circumstances being similar, produce more vigorous and perfect plants; and in this way the great improvements in the productions of our fields and gardens seem to have been occasioned. 
Wheat in its indigenous state, as a natural production of the soil, appears to have been a very small grass: and the case is still more remarkable with the apple and the plum. The crab seems to have been the parent of all our apples. And two fruits can scarcely be conceived more different in colour, size, and appearance than the wild plum and the rich magnum bonum.

The seeds of plants exalted by cultivation always furnish large and improved varieties; but the fla- vour, and even the colour of the fruit seems to be a matter of accident. Thus a hundred seeds of the golden pippin will all produce fine large-leaved apple trees, bearing fruit of a considerable size; but the tastes and colours of the apples from each will be different, and none will be the same in kind as those of the pippin itself. Some will be sweet, some sour, some bitter, some mawkish, some aromatic; some yellow, some green, some red, and some streaked. All the apples will, however, be much more perfect than those from the seeds of a crab, which produce trees all of the same kind, and all bearing sour and diminutive fruit.

The power of the horticulturist extends only to the multiplying excellent varieties by grafting. They cannot be rendered permanent; and the good fruits at present in our gardens, are the prociuce of a few seedlings, selected probably from hundred of thousands; the results of great labour and industry, and multiplied experiments. 
The larger and thicker the leaves of a seedling, and the more expanded its blossoms, the more it is likely to produce a good variety of fruit. Shortleaved trees should never be selected; for these approach nearer to the original standard: whereas the other qualities indicate the influence of cultivation.

In the general selection of seeds, it would appear that those arising from the most highly cultivated varieties of plants, are such as give the most vigorous produce; but it is necessary from time to time to change, and as it were, to cross the breed.

By applying the pollen, or dust of the stamina, from one variety to the pistil of another of the same species, a new variety may be easily produced; and Mr. Knight's experiments seem to warrant the idea, that great advantages may be derived from this method of propagation.

Mr. Knight's large peas produced by crossing two varieties, are celebrated amongst horticulturists, and will, I hope, soon be cultivated by farmers.

I have seen several of his crossed apples, which promise to rival the best of those which are gradually dying away in the cider countries.

And his experiments on the crossing of wheat, which is very easily effected, merely by sowing the different kinds together, lead to a result which is of considerable importance. He says, in the Philosophical Transactions for 1799, " in the year's $\mathbf{1 7 9 5}$ and 1796, when almost the whole crop of corn in the island was blighted, the varieties obtained by 
crossing alone escaped, though sown in several soils, and in very different siuations."

The processes of gardening for increasing the number of fruit-bearing branches, and for improving the fruit upon particular branches, will all admit of elucidation from the principles that have been advanced in this Lecture.

By making trees espaliers, the force of gravity is particularly directed towards the lateral parts of the branches, and more sap determined towards the fruit buds; and hence they are more likely to bear when in a horizontal than when in a vertical position.

The twisting of a wire, or tying a threarl round a branch has been often recommended as a means of making it produce fruit. In this case the descent of the sap in the bark must be impeded above the ligature; and more nutritive matter consequently retained and applied to the expanding parts.

In engrafting, the vessels of the bark of the stock and the graft cannot so perfectly come in contact as the alburnous vessels, which are much more numerous, and equally distributed; hence the circulation downwards is probably impeded, and the tendency of the graft to evolve its fruit-bearing buds increased.

By lopping trees, more nourishment is supplied to the remaining parts; for the sap flows laterally as well as perpendicularly. The same reasons will 
apply to explain the increase of the size of fruits by diminishing the number upon a tree.

As plants are capable of amelioration by peculiar methods of cultivation, and of having the natural term of their duration extended; so, in conformity to the general law of change, they are rendered unhealchy by being exposed to peculiar unfavourable circumstances, and liable to premature old age and decay.

The plants of warm climates transported into cold ones, or of cold ones transported into warm ones, if not absolutely destroyed by the change of situation, are uniformly rendered unhealthy.

Few of the tropical plants, as is well known, can be raised in this country, except in hot houses. The vine during the whole of our summer may be said to be in a feeble state with regard to health; and its fruit, except in very extraordinary cases, always contains a superabundance of acid. The gigantic pine of the north, when transported into the equatorial climates, becomes a degenerated dwarf; and a great number of instances of the same kind might be brought forward.

Much has been written, and many very ingenious remarks have been made by different philosophers, upon what have been called the habits of plants. 'Thus, in transplantig 'a tree, it dies or becomes unhealthy, unless its position with respect to the sun is the same as before. The seeds brought from warm 
climates germinate here much more early in the season than the same species brought from cold climates. The apple tree from Siberia, where the short summer of three months immediately succeeds the long winter, in England, usually puts forth its blossoms in the first year of its transplantation, on the appearance of mild weather ; and is often destroyed by the late frosts of the spring.

It is not difficult to explain this principle so intimately connected with the healthy or diseased state of plants. The organization of the germ, whether in seeds or buds, must be different according as more or less heat, or alternations of heat and cold, have affected it during its formation; and the nature of its expansion must depend wholly on this organization. In a changeable climate the formations will have been interrupted, and in different successive layers. In an equable temperature they will have been uniform; and the operation of new and sudden causes will of course be severely felt.

The disposition of trees may, however, be changed gradually in many instances; and the operation of a new climate in this way be made supportable. The myrtle, a native of the south of Europe, inevitably dies if exposed in the early days of its growth to the frosts of our winter; but if kept in a greenhouse during the cold seasons for successive years, and gradually exposed to low temperatures, it will, in an advanced stage of growth, resist even a very severe cold. And in the south and west of England 
the myrtle flourishes, produces blossoms and seeds, in consequence of this process, as an unprotected standard tree; and the layers from such trees are much more hardy than the layer's from myrtles reared within door's.

The arbutus, probably originally from similar cultivation, has become the principal ornament of the lakes of the south of Ireland. It thrives even in bleak mountain situations; and there can be little doubt but that the offspring of this tree inured to a temperate climate might be easily spread in Britain.

The same principles that apply to the effects of heat and cold will likewise apply to the influence of moisture and dryness. The layers of a tree liabituated to a moist soil will die in a dry one : even though such a soil is more favourable to the general growth of the species. And, as was stated, page 190, trees that have been raised in the centre of woods, are sooner or later destroyed, if exposed in their adult state to blasts, in consequence of the felling of the surrounding timber.

Trees, in all cases, in which they are exposed in high and open situations to the sun, the winds, and the rain, as I just now noticed, become low and robust, exhibiting curved limbs, but never straight and graceful trunks. Shrubs and trees, on the contrary, which are too much sheltered, too much secluded from the sun and wind extend exceedingly in height; but present at the same time slender and feeble branches, their leaves are pale and sickly, and 
in extreme cases they do not bear fruit. The exclusion of light alone is sufficient to produce this species of disease, as would appear from the experiments of Bonnet. This ingenious physiologist sowed three seeds of the pea in the same kind of soil : one he suffered to remain exposed to the free air; the other he enclosed in a tube of glass; and the third in a tube of wood. The pea in the tube of glass sprouted, and grew in a manner scarcely at all different from that under usual circumstances; but the plant in the tube of wood, deprived of light, became white, and slender, and grew to a much greater height.

The plants growing in a soil incapable of supplying them with sufficient manure or dead organized matter, are generally very low; having brown or dark green leaves, and their woody fibre abounds in earth. Those vegetating in peaty soils, or in lands too copiously supplied with animal or vegetable matter, rapidly expand, produce large bright green leaves, abound in sap, and generally blossom prematurely.

Where a land is too rich for corn it is not an uncommon practice to cut down the first stalks, as by these means its exuberance is corrected, and it is less likely to fall before the grain is ripe; excess of poverty or of richness is almost equally fatal to the hopes of the farmer: and the true constitution of the soil for the best crop is that in which the earthy materials, the moisture and manure, are pro- 
perly associated; and in which the decomposable vegetable or animal matter does not exceed onefourth of the weight of the earthy constituents.

The canker, or erosion of the bark and wood, is a disease produced often in trees by a poverty of soil; and it is invariably connected with old age. The cause seems to be an excess of alkaline and earthy matter in the descending sap. I have often found carbonate of lime on the edges of the canker in apple trees; and ulmin, which contains fixed alkali, is abundant in the canker of the elm. The old age of a tree, in this respect, is faintly analogous to the old age of animals, in which the secretions of solid bony matter are always in excess, and the tendency to ossification great.

The common modes of attempting to cure the canker, are by cutting the edges of the bark, binding new bark upon it, or laying on a plaster of earth; but these methods, though they have been much extolled, probably do very little in producing a regeneration of the part. Perhaps the application of a weak acid to the canker might be of use ; or, where the tree is of great value, it may be watered occasionally with a very diluted acid. The alkaline and eart y nature of the morbid secretion warrants the trial; but circumstances that cannot be foreseen may occur to interfere with the success of the experiment.

Besides the diseases having their source in the constitution of the plant, or in the unfavourable ope- 
ration of external elements, there are many others perhaps more injurious, depending upon the operations and powers of other living beings ; and such are the most difficult to cure, and the inost destructive to the labours of the husbandman.

Parasitical plants of different species, which attach themselves to trees and shrubs, feed on their juices, destroy their heaith, and finally their life, abound in all climates; and are, perhaps, the most formidable of the enemies of the superior and cultivated vegetable species.

The mildew, which has often occasioned great havock in our wheat crops, and which was particularly destructive in 1804, is a species of fungus, so small as to require glasses to render its form distinct, and rapidly propagated by its seeds.

This has been shewn by various botanists; and the subject has received a full illustration from the enlightened and elaborate researches of the President of the Royal Society.

The fungus rapidly spreads from stalk to stalk, fixes itself in the cells connected with the common tubes, and carries away and consumes that nourishment which should have been appropriated to the grain.

No remedy has as yet been discovered for this disease; but as the fungus increases by the diffusion of its seeds, great care should be taken that no mildewed straw is carried in the manure used for corn; 
and in the early crop, if mildew is observed upon any of the stalks of corn, they should be carefully removed and treated as weeds.

The popular notion amongst farmers, that a barberry-tree in the neighbourhood of a field of wheat often produces the mildew, deserves examination. 'This tree is frequently covered with a fungus, which if it should be shewn to be capable of degenerating into the wheat fungus, would offer an easy explanation of the effect.

There is every reason to believe, from the researches of Sir Joseph Banks, that the smut in wheat is produced by a very small fungus which fixes on the grain: the products that it affords by analysis are similar to those afforded by the puff-ball; and it is difficult to conceive, that without the agency of some organized structure, so complete a change should be effected in the constitution of the grain.

'The mistletoe and the iry, the moss and the lichen, in fixing upon trees, uniformly injure their vegetative processes, though in very different degrees. They are supported from the lateral sap vessels, and deprive the branches above of a part of their nourishment.

The insect tribes are scarcely less injurious than the parasitical plants.

To enumerate all the animal destroyers and tyrants of the vegetable kingdom would be to give a catalogue of the greater number of the classes in zoolo- 


\section{7}

gy. Every species of plant, almost, is the peculiar resting place, or dominion of some insect tribe; and from the locust, the caterpillar, and snail, to the minute aphis, a wonderful variety of the inferior insects are nourished, and live by their ravages upon the vegetable world.

I have already referred to the insect which feeds on the seed-leaf of the turnip.

The Hessian fly, still more destructive to wheat, has in some seasons threatened the United States with a famine. And the French government is * at this time isstiing decrees with a view to occasion the destruction of the larvæ of the grasshopper.

In general, wet weather is most favourable to the propagation of mildew, funguses, rust, and the small parasitical vegetables; dry weather to the increase of the insect tribes. Nature, amidst all her changes, is continually directing her resources towards the production and multiplication of life; and in the wise and grand economy of the whole system, even the agents that appear injurious to the hopes, and destructive to the comforts of man, are in fact ultimately connected with a more exalted state of his powers and his condition. His industry is awakened, his activity kept alive, even by the defects of climates and season. By the accidents which interfere with his efforts, he is made to exert his talents,

* January, 1813. 


\section{8}

to look farther into futurity, and to consider the vegetable kingdom not as a secure and inalterable inheritance, spontaneously providing for his wants; but as a doubtful and insecure possession, to be preserved only by labour, and extended and perfected by ingenuity. 


\section{LECTURE VI.}

Of Manures of vegetable and animal Origin. Of the Manner in which they become the nourishment of the Plant. Of Fermentation and Putrefaction. Of the different Species of Manures of vegetable Origin; of the different Species of animal Origin. Ofmixed Manures. General Principles with respect to the Use and Application of such Manures.

THat certain vegetable and animal substances introduced into the soil accelerate vegetation and increase the produce of crops, is a fact known since the earliest period of agriculture; but the manner in which manures act, the best modes of applying them, their relative value and durability, are still subjects of discussion. In this Lecture I shall endeavour to lay down some settled principles on these objects; they are capable of being materially elucidated by the recent discoveries in chemistry; and I need not dwell on their great importance to farmers.

The pores in the fibres of the ronts of plants are so small, that it is with difficulty they can be discovered by the microscope ; it is not therefore probable, that solid substances can pass into them from 
the soil. I tried an experiment on this subject; some impalpable powdered charcoal procured by washing gunpowder, and dissipating the sulphur by heat, was placed in a phial containing pure water, in which a plant of peppermint was growing: the roots of the plant were pretty generally in contact with the charcoal. The experiment was made in the beginning of May, 1805; the growth of the plant was very vigorous during a fortnight, when it was taken out of the phial: the roots were cut through in different parts; but no carbonaceous matter could be discovered in them, nor were the smallest fibrils blackened by charcoal, though this must have been the case had the charcoal been absorbed in a solid form.

No substance is more necessary to plants than carbonaceous matter; and if this cannot be introduced into the organs of plants except in a state of solution, there is every reason to suppose that other substances less essential will be in the same case.

I found, by some experiments made in 1804, that plants introduced into strong fresh solutions of sugar, mucilage, tanning principle, jelly, and other substances died; but that plants lived in the same solutions after they had fermented. At that time, I supposed that fermentation was necessary to prepare the food of plants; but I have since found that the deleterious effect of the recent vegetable solutions was owing to their being too concentrated; in consequence of which the regetable organs were 
probably clogged with solid matter, and the transpiration by the leaves prevented. In the beginning of June, in the next year, I used solutions of the same substances, but so much diluted, that there was only about one-two hundredth part of solid vegetable or animal matter in the solutions. Plants of mint grew luxuriantly in all these solutions; but least so in that of the astringent matter. I watered some spots of grass in a garden with the different solutions separately, and a spot with common water: the grass watered with solutions of jelly, sugar, and mucilage, grew most vigorously; and that watered with the solution of the tanning: principle grew better than that watered with common water.

I endeavoured to ascertain whether soluble vegetable substances passed in an unchanged state into the roots of plants, by comparing the products of the analysis of the roots of some plants of mint which had grown, some in common water, some in a solution of sugar. One hundred and twenty grains of the roots of the mint which grew in the solution of sugar, afforded five grains of pale green extract, which had a sweetish taste, but which slightly coagulated by the action of alcohol. One hundred and twenty grains of the roots of the mint which had grown in common water yielded three grains and a half of extract, which was of a deep olive colour ; its taste was sweetish, but more astrin- 
gent than that of the other extract, and it coagulated more copiously with alcohol.

These results, though not quite decisive, favour the opinion that soluble matters pass unaltered into the roots of plants; and the idea is confirmed by the circumstance that the radical fibres of plants made to grow in infusions of madder are tinged red, and it may be considered as almost proved by the fact, that substances which are even poisonous to vegetables are absorbed by them. I introduced the roots of a primrose into a weak solution of oxide of iron in vinegar, and suffered it to remain in it till the leaves became yellow; the roots were then carefully washed in distilled water, bruised, and boiled in a small quantity of the same fluid: the decoction of them passed through a filtre was examined by the test of infusion of nut-galls; the decoction gained a strong tint of purple, which proves that solution of iron had been taken up by the vessels or pores in the roots.

Vegetable and animal substances deposited in the soil, as is shewn by universal experience, are consumed during the process of regetation; and they can only nourish the plant by affording solid matters capable of being dissolved by water, or gaseous substances capable of being absorbed by the fluids in the leaves of vegetables; but such parts of them as are rendered gaseous, and that pass into the atmosphere, must produce a comparatively small effect, for gasses soon become diffused through the 
mass of the surrounding air. The great object in the application of manure should be to make it afford as much soluble matter as possible to the roots of the plant; and that in a slow and gradual manner, so that it may be entirely consumed in forming its sap and organized parts.

Mucilaginous, gelatinous, saccharine, oily, and extractive fluids, and solution of carbonic acid in water, are substances that in their unchanged states contain almost all the principles necessary for the life of plants; but there are few cases in which they can be applied as manures in their pure forms; and vegetable manures, in general, contain a great excess of fibrous and insoluble matter, which must undergo chemical changes before they can become the food of plants.

It will be proper to take a scientific view of the nature of these changes; of the causes which occasion them, and which accelerate or retard them; and of the products they afford.

If any fresh vegretable matter which contains sugar, mucilage, starch, or other of the vegetable compounds soluble in water be moistened and exposed to air, at a temperature from $55^{\circ}$ to $80^{\circ}$, oxygene will soon be absorbed, and carbonic acid formed; heat will be produced, and elastic fluids principally carbonic acid, gaseous oxide of carbon, and hydro-carbonate will be evolved; a dark coloured liquid, of a slightly sour or bitter taste, will likewise be formed; and if the process be suffered 
to continue for a time sufficiently long, nothing solid will remain, except earthy and saline matter, coloured black by charcoal.

The dark-coloured fluid formed in the fermentation always contains acetic acid; and when albumen or gluten exists in the vegetable substance, it likewise contains volatile alkali.

In proportion as there is more gluten, albumen, or matters soluble in water in the vegetable substances exposed to fermentation, so in proportion, all other circumstances being equal, will the process be more rapid. Pure woody fibre alone undergoes a change very slowly; but its texture is broken down, and it is easily resolved into new elements, when mixed with substances more liable to change, containing more oxygene and hydrogene. Volatile and fixed oils, resins and wax, are more susceptible of change than woody fibre, when exposed to air and water; but much less liable than the other vegetable compounds; and even the most inflammable substances, by the absorption of oxygene, become gradually soluble in water.

Animal matters in general are more liable to decompose than vegetable substances; oxygene is absorbed, and carbonic acid and ammonia formed in the process of their putrefaction. They produce foetid compound elastic fluids, and likewise azote: they affora dark-coloured acid and oily fluids, and leave a residuum of salts and earths mixed with carbonaceous matter. 
The principal substances which constitute the different parts of animals, or which are found in their blood, their secretions, ur their excrements, are gelatine, fibrine, mucus, fatty, or oily matter, albumen, urea, uric acid, and different acid, saline, and earthy matters.

Of these gelatine is the substance which when combined with water forms jelly. It is very liable to putrefaction. According to M. M. Gay Lussac and Thenard, it is composed of

$$
\begin{aligned}
& 47.88 \text { of carbon. } \\
& 27.207 \text { - oxygene. } \\
& 7.914 \text { - hydrogene. } \\
& 16.998
\end{aligned}
$$

These proportions cannot be considered as definite, for they do not bear to each other the ratios of any simple multiples of the number representing the elements; the case seems to be the same with other animal compounds: and even in vegetable substances, in general, as appears from the statements given in the Third Lecture, the proportions are far from having the same simple relations as in the binary compounds capable of being made artificially, such as acids, alkalies, oxides, and in salts.

Fibrine constitutes the hasis of the muscular fibre of animals, and a similar substance may be obtained from recent fluid blood; by stirring it with a stick the fibrine will adhere to the stick. It is not soluble in water; but by the action of acids, as Mr. Hatchet has shewn, it becomes soluble, and analo- 
gous to gelatine. It is less disposed to putrefy than gelatine. According to M. M. Gay Lussac and Thenard, 100 parts of fibrine contain

$$
\begin{array}{rr}
\text { Of carbon . . } & 53.360^{\circ} \\
\text { oxygene . } & 19.685 \\
\text { hydrogene } & 7.021 \\
\text { azote . . . } & 19.934
\end{array}
$$

Mucus is very analogous to vegetahle gum in its characters; and as Dr. Bostock has stated, it may be obtained by evaporating saliva. No experiments have been made upon its analysis; but it is probably similar to gum in composition. It is capable of undergoing putrefaction, but less rapidly than fibrine.

Animal fat and oils have not been accurately analyzed; but there is great reason to suppose that their composition is analogous to that of similar substances from the vegetable kingdom.

Albumen has been already referred to, and its analysis stated in the Third Lecture.

Urea may be obtained by the evaporation of human urine, till it is of the consistence of a syrup; and the action of alcohol on the crystalline substance which forms when the evaporated matter cools. In this way a solution of urea in alcohol is procured; and the alcohol may be separaterl from the urea by heat. Urea is very soluble in water, and is precipitated from water by diluted nitric acid in the form of bright pearl-coloured crystals ; 
this property distinguishes it from all other animal substances.

According to Fourcroy and Vanquelin, 100 parts of urea when distilled yield

92.027 parts of carbonate of ammonia.

4.608 carburetted hydrogene gas.

3.225 of charcoal.

Urea, particularly when mixed with albumen or gelatine, readily undergoes putrefaction.

Uric acid, as has been shewn by Dr. Egan, may be obtained from human urine by pouring an acid into it; and it often falls down from urine in the form of brick-coloured crystals. It consists of carbon, hydrogene, oxygene, and azote: but their. proportions have not yet been determined. Uric acid is one of the animal substances least liable to undergo the process of putrefaction.

According to the different proportions of these principles in animal compounds, so are the changes they undergo different. When there is much saline or earthy matter mixed or combined with them, the progress of their decomposition is less rapid than when they are principally composed of fibrine, albumen, gelatine, or urea.

The ammonia given off from animal compounds in putrefaction may be conceived to be formed at the time of their decomposition by the combination of hydrogene and azote; except this matter, the other products of putrefaction are analogous to those afforded by the fermentation of vegetable sub- 
stances; and the soluble substances formed abound in the elements, which are the constituent parts of vegetables, in carbon, hydrogene, and oxygene.

Whenever manures consist principally of matter soluble in water, it is evident that their fermentation or putrefaction should be prevented as much as possible; and the only cases in which these processes can be useful, are when the manure consists principally of vegetable or animal fibre. The circumstances necessary for the putrefaction of animal substances are similar to those required for the fermentation of vegetable substances; a temperature above the freezing point, the presence of water, and the presence of oxygene, at least in the first stage of the process.

To prevent manures from decomposing, they should be preserved dry, defended from the contact of air, and kept as cool as possible.

Salt and alcohol appear to owe their powers of preserving animal and vegetable substances to their attraction for water, by which they prevent its decomposing action, and likewise to their excluding air. The use of ice in preserving animal substances is owing to its keeping their temperature low. The efficacy of M. Appert's method of preserving animal and vegetable substances, an account of which has been lately published, entirely depends upon the exclusion of air. This method is by filling a vessel of tin plate or glass with the meat or vegetables; soldering or cementing the top so as to 
render the vessel air tight; and then keeping it half immersed in a vessel of boiling water for a sufficient time to render the meat or vegetables proper for food. In this last process it is probable that the small quantity of oxygene remaining in the vessel is absorbed; for on opening a tinned iron canister which had been filled with raw beef and exposed to hot water the day before, I found that the minute quantity of elastic fluid which could be procured from it, was a mixture of carbonic acid gas and azote.

Where meat or vegetable food is to be preserved on a large scale, for the use of the navy or army for instance, I am inclined to believe, that by forcibly throwing a quantity of carbonic acid, hydrogene, or azote, into the vessel, by means of a compressing pump, similar to that used for making artificial Seltzer water, any change in the substance would be more effectually prevented. No elastic fluid in this case would have room to form by the decomposition of the meat; and the tightness and strength of the vessel would be proved by the process. No putrefaction or fermentation can go on without the generation of elastic fluid; and pressure would probably act with as much efficacy as cold in the preservation of animal or vegetable food.

As different manures contain different proportions of the elements necessary to vegetation, so they require a different treatment to enable them to produce their full effects in agriculture. I shall there- 
fore describe in detail the properties and nature of the manures in common use, and give some general views respecting the best modes of preserving and applying them.

All green succulent plants contain saccharine or mucilaginous matter, with woody fibre, and readily ferment. They cannot, therefore, if intended for manure, be used too soon after their death.

When green crops are to be employed for enriching a soil, they should be ploughed in, if it be possible, when in flower, or at the time the flower is beginning to appear, for it is at this period that they contain the largest quantity of easily soluble matter, and that their leaves are most active in forming nutritive matter. Green crops, pond weeds, the paring of hedges or ditches, or any kind of fresh vegetable matter, requires no preparation to fit them for manure. The decomposition slowly proceerds beneath the soil; the soluble matters are gradually dissolved, and the slight fermentation that goes on checked by the want of a free communication of air, tends to rencler the woody fibre soluble without occasioning the rapid dissipation of elastic matter.

When old pastures are broken up and made arable, not only has the soil been enriched by the death and slow decay of the plants which have left soluble matters in the soil; but the leaves and roots of the grasses living at the time and occtipying so large a part of the surface, afford saccharine, muci- 
laginous, and extractive matters, which become immediately the food of the crop, and the gradual decomposition affords a supply for successive years.

Rape cake, which is used with great success as a manure, contains a large quantity of mucilage, some albuminous matter, and a small quantity of oil. This manure should be used recent, and kept as dry as possible before it is applied. It forms an excellent dressing for turnip crops; and is most œconomically applied by being thrown into the soil at the same time with the seed. Whoever wishes to see this practice in its highest degree of perfection, should attend Mr. Coke's annual sheep-shearing at Holkham.

Malt dust consists chiefly of the infant radicle separated from the grain. I have never made any experiment upon this manure; but there is great reason to suppose it must contain saccharine matter, and this will account for its powerful effects. Like rape cake, it should be used as dry as possible, and its fermentation prevented.

Linseed cake is too valuable as a food for cattle to be much employed as a manure; the analysis of linseed was referred to in the Third Lecture. The water in which flax and hemp are steeped for the purpose of obtaining the pure vegetable fibre, has considerable fertilizing powers. It appears to contain a substance analogous to albumen, and likewise much vegetable extractive matter. It putre- 
fies very readily. A certain degree of fermentation is absolutely necessary to obtain the flax and hemp in a proper state; the water to which they have been exposed should therefore be used as a manure as soon as the vegetable fibre is removed from it.

Sea weeds, consisting of different species of fuci, algæ, and confervæ, are much used as a manure on the sea coasts of Britain and Ireland. By digesting the common fucus, which is the sea weed usually most abundant on the coast, in boiling water, I obtained from it one-eighth of a gelatinous substance which had characters similar to mucilage. A quantity distilled gave nearly four-fifths of its weight of water, but no ammonia; the water had an empyreumatic and slightly sour taste; the ashes contained sea salt, carbonate of soda, and carbonaceous matter. The gaseous matter afforded was small in quantity, principally carbonic acid and gaseous oxide of carbon, with a little hydro-carbonate. This manure is transient in its effects, and does not last for more than a single crop, which is easily accounted for from the large quantity of water, or the elements of water, it contains. It decays without producing heat when exposed to the atmosphere, and seems, as it were, to melt down and dissolve away. I have seen a large heap entirely destroyed in less than two years, nothing remaining but a little black fibrous matter.

I suffered some of the firmest part of a fucus to remain in a close jar, containing atmospheric air, for 
a fortnight: in this time it had become very much shrivelled; the sides of the jar were lined with dew. The air examined was found to have lost oxygen, and contained carbonic acid gas.

Sea weed is sometimes suffered to ferment before it is used; but this process seems wholly unnecessary, for there is no fibrous matter rendered soluble in the process, and a part of the manure is lost.

The best farmers in the west of England use it as fresh as it can be procured; and the practical results of this mode of applying it are exactly con. formable to the theory of its operation. The carbonic acid formed by its incipient fermentation must be partly dissolved by the water set free in the same process; and thus become capable of absorption by the roots of plants.

The effects of the sea weed, as manure, must principally depend upon this carbonic acid, and upon the soluble mucilage the weed contains; and I found that some fucus which had fermented so as to have lost about half its weight, afforded less than one-twelfth of mucilaginous matter; from which it may be fairly concluded that some of this substance is destroyed in fermentation.

Dry straw of wheat, oats, barley, beans, and peas, and spoiled hay, or any other similar kind of dry vegetable matter, is, in all cases, useful manure. In general, such substances are made to ferment before they are employed, though it may be 
doubted whether the practice should be indiscriminately adopted

From 400 grains of dry barley straw I obtained eight grains of matter soluble in water, which had a brown colour, and tasted like mucilage. From 400 grains of wheaten straw I obtained five grains of a similar substance.

There can be no doubt that the straw of different crops immediately ploughed into the ground affords nourishment to plants; but there is an objection to this method of using straw from the difficulty of burying long straw, and from its rendering the husbandry foul.

When straw is marle to ferment, it becomes a more manageable manure; but there is likewise, on the whole, a great loss of nutritive matter. More manure is perhaps supplied for a single crop; but the land is less improved than it would be, supposing the whole of the vegetable matter could be finely divided and mixed with the soil.

It is usual to carry straw that can be employed for no other purpose to the dunghill, to ferment, and decompose; but it is worth experiment, whether it may not be more œconomically applied when chopped small by a proper machine, and kept dry till it is ploughed in for the use of a crop. In this case, though it would decompose much more slowly, and produce less effect at first, yet its influence would be much more lasting.

Mere woody fibre seems to be the only vegetable 
matter that requires fermentation to render it nutritive to plants. Tanners spent bark is a substance of this kind. Mr. Young, in his excellent Essay on Manures, which gained him the Bedfordian medal of the Bath Agricultural Society, states, "that spent bark seemed rather to injure than assist vegetation;" which he attributes to the astringent matter that it contains. But, in fact, it is freed from all soluble substances, by the operation of water in the tan-pit; and if injurious to vegetation, the effect is probably owing to its agency upon water, or to its mechanical effects. It is a substance very absorbent and retentive of moisture, and yet not penetrable by the roots of plants.

Inert peaty matter is a substance of the same kind. It remains for years exposed to water and air without undergoing change, and in this state yields little or no nourishment to plants.

Woody fibre will not ferment unless some substances are mixed with it, which act the same part as the mucilage, sugar, and extractive or albuminous matters, with which it is usually associated in herhs and succulent vegetables. Lord Meadowbank has judiciously recommended a mixture of common farm-yard dung for the purpose of bringing peats into fermentation; any putrescible or fermentable substance will answer the end; and the more a substance heats, and the more readily it ferments, the better will it be fitted for the purpose.

Lord Meadowbank states, that one part of dung 
is sufficient to bring three or four parts of peat into a state in which it is fitted to be applied to land; but of course the quantity must vary according to the nature of the dung and of the peat. In cases in which some living vegetables are mixed with the peat, the fermentation will be more readily effected.

Tanners spent bark, shavings of wood and sawdust, will probably require as much dung to bring them into fermentation as the worst kind of peat.

Woody fibre may be likewise prepared so as to become a manure, by' the action of lime. 'This subject I shall discuss in the next Lecture, as it follows naturally another series of facts, relating to the effects of lime in the soil.

It is evident from the analysis of woody fibre by M. M. Gay Lussac and Thenard, (which shews that it consists principally of the elements of water and carbon, the carbon being in larger quantities than in the other vegetable compounds) that any process which tends to abstract carbonaceous matter from it, must bring it nearer in composition to the soluble principles; and this is done in fermentation by the absorption of oxygene and production of carbonic acid; and a similar effect, it will be shewn, is produced by lime.

Wood-ashes imperfectly formed, that is, woodashes containing much charcoal, are said to have been used with success as a manure. A part of their effects may be owing to the slow and gradual consumption of the charcoal, which seems capable, 
under other circumstances than those of actual combustion, of absorbing oxygene so as to become carbonic acid.

In April, 1803, I enclosed some well-burnt charcoal in a tube half filled with pure water, and half with common air; the tube was hermetically sealed. I opened the tube under pure water, in the spring of 1804 , at a time when the atmospheric temperature and pressure were nearly the same as at the commencement of the experiment. Some water rushed in; and on expelling a little air by heat from the tube, and analyzing it, it was found to contain only seven per cent. of oxygene. The water in the tube, when mixed with lime-water, produced a copious precipitate; so that carbonic acid had evidently been formed and dissolved by the water.

Manures from animal substances, in general, require no chemical preparation to fit them for the soil. The great object of the farmer is to blend them with the earthy constituents in a proper state of division, and to prevent their too rapid decomposition.

The entire parts of the muscles of land animals are not commonly used as manure, though there are many cases in which such an application might be easily made. Horses, dogs, sheep, deer, and other quadrupeds that have died accidentally, or of disease, after their skins are separated, are often suffered to remain exposed to the air, or immersed in water, till they are destroyed by birds or beasts of 
prey, or entirely decomposed; and in this case, most of their organized matter is lost for the land in which they lie, and a considerable portion of it employed in giving off noxious gasses to the atmosphere.

By covering dead animals with five or six times their bulk of soil, mixed with one part of lime, and suffering them to remain for a few months; their decomposition would impregnate the soil with soluble matters, so as to render it an excellent manure; and by mixing a little fresh quick lime with it at the time of its removal, the disagreeable effluvia would be in a great measure destroyed; and it might be applied in the same way as any other manure to crops.

Fish forms a powerful manure, in whatever state it is applied; but it cannot be ploughed in too fresh, though the quantity should be limited. Mr. Young records an experiment, in which herrings spread over a field, and ploughed in for wheat, produced so rank a crop, that it was entirely laid before harvest.

The refuse pilchards in Cornwall are used throughout the county as a manure, with excellent effects. They are usually mixed with sand or soil, and sometimes with sea weed, to prevent them from raising too luxuriant a crop. The effects are perceived for several years.

In the fens of Lincolnshire, Cambridgeshire, and Norfolk, the little fishes called sticklebacks, are 
caught in the shallow waters in such quantities, that they form a great article of manure in the land bordering on the fens.

It is easy to explain the operation of fish as a manure. The skin is principally gelatine; which from its slight state of cohesion, is readily soluble in water : fat or oil is always found in fishes, either under the skin or in some of the viscera; and their fibrous matter contains all the essential elements of vegetable substances.

Amongst oily substances, Blubber has been employed as a manure. It is most useful when mixed with clay, sand, or any common soil, so as to expose a. large surface to the air, the oxygene of which produces soluble matter from it. Lord Somerville used blubber with great success at his farm in Surrey. It was made into a heap with soil, and retained its powers of fertilizing for several successive years.

The carbon and hydrogene abounding in oily substances, fully account for their effects; and their durability is easily explained from the gradual manner in which they change by the action of air and water.

Bones are much used as a manure in the neighbourhood of London. After being broken, and boiled for grease, they are sold to the farmer. The more divided they are, the more powerful are their effects. The expense of grinding them in a mill 
would probably be repaid by the increase of their fertilizing powers; and in the state of powder they might be used in the drill husbandry, and delivered with the seed, in the same manner as rape cake.

Bone dust, and bone shavings, the refuse of the turning manufacture, may be advantageously employed in the same way.

The basis of bone is constituted by earthy salts, principally phosphate of lime, with some carbonate of lime and phosphate of magnesia ; the easily decomposable substances in bone are fat, gelatine, and cartilage, which seems of the same nature as coagulated albumen.

According to the analysis of Fourcroy and Vauquelin, ox bones are composed

Of decomposable animal matter - 51

- phosphate of lime - - - $\quad 37.7$

- carbonate of lime - - - - 10

- phosphate of magnesia - _ 1.3 
M. Merat Guillot has given the following estimate of the composition of the bones of different animals.

\begin{tabular}{|c|c|c|c|}
\hline & \multicolumn{2}{|c|}{ Phosphate of Carbonate of } \\
\hline & & Lime. & Lime. \\
\hline Bone of Calf & - & 54 & \\
\hline __ Horse & - & 67.5 & 1.25 \\
\hline _L Sheep & - & 70 & 5 \\
\hline ___ Elk & - & 90 & 1 \\
\hline - - Hog & - & 52 & 1 \\
\hline ___ Hare & - & 85 & 1 \\
\hline _ _ Pullet & & 72 & 1.5 \\
\hline _ Pike & - & 64 & 1 \\
\hline —- Carp & - & 45 & 5 \\
\hline Horses' teeth & - & 85.5 & 20.5 \\
\hline Ivory - & - & 64 & 1 \\
\hline
\end{tabular}

The remaining parts of the 100 must be considered as decomposable animal matter.

Horn is a still more powerful manure than bone, as it contains a larger quantity of decomposable animal matter. From 500 grains of ox horn, Mr. Hatchett obtained only 1.5 grains of earthy residuum, and not quite half of this was phosphate of lime. The shavings or turnings of horn form an excellent manure, though they are not sufficiently abundant to be in common use. The animal matter in them seems to be of the nature of coagulated albumen, and it is slowly rendered solu- . ble by the action of water. The earthy matter in horn, and still more that in bones, prevents the too rapid decomposition of the animal matter, and renders it very durable in its effects. 
Hair, woollen rags, and feathers are all analogous in composition, and principally consist of a substance similar to albumen, united to gelatine. This is shewn by the ingenious researches of $\mathrm{Mr}$. Hatchett. The theory of their operation is similar to that of bone and horn shavings.

The refuse of the different manufactures of skin and leather form very useful manures; such as the shavings of the currier, furriers' clippings, and the offals of the tan-yard, and of the glue-maker. The gelatine contained in every kind of skin is in a state fitted for its gradual solution or decomposition; and when buried in the soil, it lasts for a considerable time, and constantly affords a supply of nutritive matter to the plants in its neighbourhood.

Blood contains certain quantities of all the principles found in other animal substances, and is consequently a very good manure. It has been already stated that it contains fibrine; it likewise contains albumen: the red particles in it which have been supposed by many foreign chemists to be coloured by iron in a particular state of combination with oxygene and acid matter, Mr. Brande considers as formed of a peculiar animal substance, containing very listle iron.

The scum taken from the boilers of the sugar bakers, and which is used as manure, principally consists of bullock's blood, which has been employed for the purpose of separating the impurities of 
commion brown sugar, by means of the coagulation of its albuminous matter by the heat of the boiler.

The different species of corals, coralines, and sponges, must be considered as substances of animal origin. From the analysis of Mr. Hatchett, it appears that all these substances contain considerable quantities of a matter analogous to coagulated albumen; the sponges afford likewise gelatine.

According to Merat Guillot, white coral contains equal parts of animal matter and carbonate of lime: red coral 46.5 of animal matter, and 53.5 of carbonate of lime ; articulated coraline 51 of animal matter, and 49 of carbonate of lime.

These substances are, I believe, never used as manure in this country, except in cases when they are accidentally mixed with sea weed; but it is probable that the coralines might be advantageously employed, as they are found in considerable quantity on the rocks, and bottoms of the rocky pools on many parts of our coast, where the land gradually declines towards the sea; and they might be detached by hoes, and collected without much trouble.

Amongst excrementations, animal substances used as manures, urine is the one upon which the greatest number of chemical experiments have been made, and the nature of which is best understood.

The urine of the cow contains, according to the experiments of $\mathrm{Mr}$. Brande, 


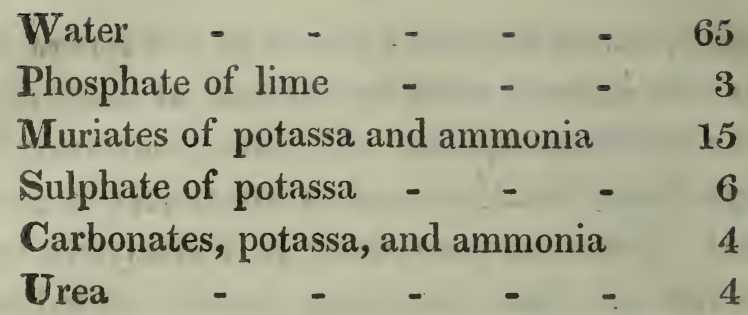

The urine of the horse, according to Fourcroy and Vauquelin, contains,

Of carbonate of lime - $\quad$ - 11

- carbonate of soda - $\quad 9$

- benzoate of soda - - - 24

- muriate of potassa - $\quad 9$

- urea - - - - - 7

- water and mucilage - $\quad-940$

In addition to these substances, Mr. Brande found in it phosphate of lime.

The urine of the ass, the camel, the rabbit, and domestic fowls have been submitted to different experiments, and their constitution have been found similar. In the urine of the rabbit, in addition to most of the ingredients above mentioned, Vauquelin detected gelatine; and the same chemist discovered uric acid in the urine of domestic fowls.

Human urine contains a greater variety of constituents than any other species examined.

Urea, uric acid, and another acid similar to it in nature called rosacic acid, acetic acid, albumen, gelatine, a resinous matter, and various salts are found in it. 
The human urine differs in composition according to the state of the body, and the nature of the food and drink made use of. In many cases of disease there is a much larger quantity of gelatine and albumen than usual in the urine; and in diabetes it contains sugar.

It is probable that the urine of the same animal must likewise differ according to the different nature of the food and drink used; and this will account for discordancies in some of the analyses that have been published on the subject.

Urine is very liable to change and to undergo the putrefactive process; and that of carnivorous animals more rapidly than that of graminivorous animals. In proportion as there is more gelatine and albumen in urine, so in proportion does it putrefy more quickly.

The species of urine that contain most albumen, gelatine, and urea, are the best as manures; and all urime contains the essential elements of vegetables in a state of solution.

During the putrefaction of urine the greatest part of the soluble animal matter that it contains is destroyed; it should consequently be used as fresh as possible; but if not mixed with solid matter, it should be diluted with water, as when pure it contains too large a quantity of animal 'matter' to form a proper. fluid nourishment for absorption by the roots of plants. 
Putrid urine abounds in ammoniacal salts; and though less active than fresh urine, is a very powerful manure.

According to a recent analysis published by Berzelius, 1000 parts of urine are composed of

$\begin{array}{lllllr}\text { Water - } & - & - & - & - & 933 \\ \text { Urea - } & - & - & - & - & 30.1 \\ \text { Uric acid } & - & - & - & - & 1\end{array}$

Muriate of ammonia, free lactic acid, lactate of ammonia and 17.14

The remainder different salts, phosphates, sulphates, and muriates.

Amongst excrementitious solid substances used as manures, one of the most powerful is the dung of birds that feed on animal food, particularly the dung of sea birds. The guano, which is used to a great extent in South America, and which is the manure that fertilizes the sterile plains of Peru, is a production of this kind. It exists abundantly, as we are informed by $\mathbf{M}$. Humboldt, on the small islands in the South Sea, at Chinche, Ilo, Iza, and Arica. 50 vessels are laden with it annually at Chinche, each of which carries from 1500 to 2000 cubical feet. It is used as a manure only in very small quantities; and particularly for crops of maize. I made some experiments on specimens of guano sent from South America to the Board of Agriculture in $\mathbf{1 8 0 5 .}$ It appeared as a fine brown powder; it blackened 
by heat, and gave off strong ammoniacal fumes; treated with nitric acid it afforded uric acid. In 1806 M. M. Fourcroy and Vauquelin published an elaborate analysis of guano. They state that it contains a fourth part of its weight of uric acid, partly saturated with ammonia, and partly with potassa; some phosphoric acid combined with the bases, and likewise with lime. Small quantities of sulphate and muriate of potassa, a little fatty matter, and some quartzose sand.

It is easy to explain its fertilizing properties : from its composition it might be supposed to be a very powerful manure. It requires water for the solution of its soluble matter to enable it to produce. its full beneficial effect on crops.

The dung of sea birds has, I believe, never been used as a manure in this country; but it is probable, that even the soil of the small islands on our coast much frequented by them, would fertilize. Some dung of sea birds brought from a rock on the coast of Merionethshire, produced a powerful but transient effect on grass. It was tried, at my request, by Sir Robert Vaughan at Nannau.

The rains in our climate must tend very much to injure this species of manure, where it is exposed to them, soon after its deposition; but it may probably be found in great perfection in caverns or clefts in rocks, haunted by cormorants and gulls. I examined some recent cormorant's dung which I found on a rock near Cape Lizard in Cornwall. It 
had not at all the appearance of the guano; was of a grayish white colour; had a very foetid smell like that of putrid aninal matter: when acted on by quick-lime it gave abundance of ammonia ; treated with nitric acid it yielded uric acid.

Night soil, it is well known, is a very powerful manure, and very liable to decompose. It differs in composition; but always abounds in substances composed of carbon, hydrogene, azote, and oxygene. From the analysis of Berzelius, it appears that a part of it is always soluble in water; and in whatever state it is used, whether recent or fermented, it supplies abundance of food to plants.

The disagreeable smell of night soil may be destroyed by mixing it with quicklime; and if exposed to the atmosphere in thin layers strewed over with quicklime in fine weather, it speedily dries, is easily pulverised, and in this state may be used in the same manner as rape cake, and delivered into the furrow with the seed.

The Chinese, who have more practical knowledge of the use and application of manures than any other people existing, mix their night soil with one-third of its weight of a fat marle, make it into cakes, and dry it by exposure to the sun. These cakes, we are informed by the French missionaries, have no disagreeable smell, and form a common. article of commerce of the empire.

The earth, by its absorbent powers, probably, prevents, to a certain extent, the action of moisture 
upon the dung, and likewise defends it from the effects of air.

After night soil, pigeons' dung comes next in order, as to fertilizing power. I digested 100 grains of pigeons' dung, in hot water for some hours, and obtained from it 23 grains of soluble matter; which afforded abundance of carbonate of ammonia by distillation; and left carbonaceous matter, saline matter principally common salt, and carbonate of lime as a residuum. Pigeons' dung when moist readily ferments, and after fermentation contains less soluble matter than before: from 100 parts of fermented pigeons' dung, I obtained only eight parts of soluble matter, which gave proportionally less carbonate of ammonia in distillation than recent pigeons' dung.

It is evident that this manure should be applied as new as possible; and when dry, it may be employed in the same manner as the other manures capable of being pulverised.

The soil in woods where great flocks of woodpigeons roost, is often highly impregnated with their dung, and it cannot be doubted, would form a valuable manure. I have found such soil yield ammonia when distilled with lime. In the winter likewise it usually contains abundance of vegetable matter, the remains of decayed leaves; and the dung tends to bring the vegetable matter into a state of solution.

The dung of domestic forls approaches very 
nearly in its nature to pigeons' dung. Uric acid has been found in it. It gives carbonate of ammonia by distillation, and immediately yields soluble matter to water. It is very liable to ferment.

The dung of fowls is employed in common with that of pigeons by tanners to bring on a slight degree of putrefaction in skins that are to be used for making soft leather; for this purpose the dung is diffused through water. In this state it rapidly undergoes putrefaction, and brings on a similar change in the skin. The excrements of dogs are employed by the tanner with similar effects. In all cases, the contents of the grainer, as the pit is called in which soft skins are prepared by dung, must form a very useful manure.

Rabbits' dung has never been analysed. It is used with great success as a manure by Mr. Fane, who finds it profitable to keep rabbits in such a manner as to preserve their dung. It is laid on as fresh as possible, and is found better the less it has fermented.

The dung of cattle, oxen and cows, has been chemically examined by M. M. Einhof and Thaer. They found that it contained matter soluble in water; and that it gave in fermentation nearly the same products as vegetable substances, absorbing oxygene and producing carbonic acid gas.

The recent dung of sheep, and of deer, afford, when long boiled in water, soluble matters, which equal from two to three per cent. of their weight. 


\section{1}

I have examined these soluble substances procured by solution and evaporation; they contain a very small quantity of matter analogous to animal mucus; and are principally composed of a bitter extract, soluble both in water and in alcohol. They give ammoniacal fumes by distillation; and appear to differ very little in composition.

I watered some blades of grass for several suc- , ' cessive days with a solution of these extracts; they evidently became greener in consequence, and grew more vigorously than grass in other respects, under the same circumstances.

The part of the dung of cattle, sheep, and deer, not soluble in water, appears to be mere woody fibre, and precisely analogous to the residuum of those vegetables that form their food after they have been deprived of all their soluble materials.

The dung of horses gives a brown fluid, which when evaporated, yields a bitter extract, which affords ammoniacal fumes more copiously than that from the dung of oxen.

If the pure dung of cattle is to be used as manure, like the other species of dung which have been mentioned, there seems no reason why it should be made to ferment except in the soil; or if suffered to ferment, it should be only in a very slight degree. The grass in the neighbourhood of recently voided dung, is always coarse and dark green; some persons have attributed this to a noxious quality in unfermenting dung ; but it seems 


\section{2}

to be rather the result of an excess of food furnished to the plants.

The question of the proper mode of the application of the dung of horses and cattle, however, properly talongs to the subject of composite manures, for it is usually mixed in the farm-yard with straw, offal, chaff, and various kind of litter; and itself contains a large proportion of fibrous vegetable matter.

A slight incipient fermentation is undoubtedly of use in the dunghill; for by means of it a disposition is brought on in the woody fibre to decay and dissolve, when it is carried to the land, or ploughed into the soil; and woody fibre is always in great excess in the refuse of the farm.

Too great a degree of fermentation is, however, very prejudicial to the composite manure in the dunghill; it is better that there should be no fermentation at all before the manure is used, than that it should be carried too far. This must be obvious from what has been already stated in this Lecture. The excess of fermentation tends to the destruction and dissipation of the most useful part of the manure; and the ultimate results of this process are like those of combustion.

It is a common practice amongst farmers to suffer the farm-yard dung to ferment till the fibrous texture of the vegetable matter is entirely broken down; and till the manure becomes perfectly cold, and so soft as to be easily cut by the spade. 
Independent of the general theoretical views unfarourable to this practice, founded upon the nature and composition of vegetable substances, there are many arguments and facts which shew that it is prejudicial to the interests of the farmer.

During the violent fermentation which is necessary for reducing farm-yard manure to the state in which it is called short muck, not only a large quantity of fluid, but likewise of gaseous matter, is lost; so much so, that the dung is reduced one half, or two-thirds in weight ; and the principal elastic matter disengaged, is carbonic acid with some ammonia; and both these, if retained by the moisture in the soil, as has been stated before, are capable of becoming an useful nourishment of plants.

In October, 1808, I filled a large retort capable of containing three pints of water, with some hot fermenting manure, consisting principally of the litter and dung of cattle; I adapted a small receiver to the retort, and connected the whole with a mercurial pneumatic apparatus, so as to collect the condensible and elastic fluids which might rise from the dung. The receiver soon became lined with dew, and drops began in a few hours to trickle down the sides of it. Elastic fluid likewise was generated; in three days thirty-five cubical inches had been formed, which, when analyzed, were found to contain twenty-one cubical inches of carbonic acid, the remainder was hydrocarbonate mixed with some azote, probably no more than existed in the com- 
mon air in the receiver. The fluid matter collected in the receiver at the same time amounted to nearly half an ounce. It had a saline taste, and a disagreeable smell, and contained some acetate and carbonate of ammonia.

Finding such products given off from fermenting litter, I introduced the beak of another retort filled with similar dung very hot at the time, in the soil amongst the roots of some grass in the border of a garden; in less than a week a very distinct effect was produced on the grass; upon the spot exposed to the influence of the matter disengaged in fermentation, it grew with much more luxuriance than the grass in any other part of the garden.

Besides the dissipation of gaseous matter when fermentation is pushed to the extreme, there is another disadvantage in the loss of heat, which, if excited in the soil, is useful in promoting the germination of the seed, and in assisting the plant in the first stage of its growth, when it is most feeble and most liable to disease: and the fermentation of manure in the soil must be particularly favourable to the wheat crop in preserving a genial temperature beneath the surface late in autumn, and during winter.

Again, it is a general principle in chemistry, that in all cases of decomposition, substances combine much more readily at the moment of their disengagement, than after they have been perfectly formed. And in fermentation beneath the soil the 
fuid matter produced is applied instantly, even whilst it is warm, to the organs of the plant, and consequently is more likely to be efficient, than in manure that has gone through the process; and of which all the principles have entered into new combinations.

In the writings of scientific agriculturists, a great mass of facts may be found in favour of the application of farm-yard dung in a recent state. Mr. Young, in the Essay on Manures, which I have already quoted, adduces a number of excellent authorities in support of the plan. Many, who doubted, have been lately convinced; and perhaps there is no subject of investigation in which there is such a union of theoretical and practical evidence. I have myself, within the last ten years, witnessed a number of distinct proofs on the subject. I shall content myself with quoting that which ought to have, and which I am sure will have, the greatest weight amongst agriculturists. Within the last seven years Mr. Coke has entirely given up the system formerly adopted on his farm, of applying fermented dung; and he informs me, that his crops have been since as good as they ever were, and that his manure goes nearly twice as far.

A great objection against slightly fermented dung is, that weeds spring up more luxuriantly where it is applied. If there are seeds carried out in the dung they certainly will germinate; but it is . 
seldom that this can be the case to any extent; and if the land is not cleansed of weeds, any kind of manure fermented or unfermented will occasion their rapid growth. If slightly fermented farmyard dung is used as a top dressing for pastures, the long straws and unfermented vegetable matter remaining on the surface should be removed as soon as the grass begins to rise vigorously, by raking, and carried back to the dunghill: in this case no manure will be lost, and the husbandry will be at once clean and oconomical.

In cases when farm-yard dung cannot be inmediately applied to crops, the destructive fermentation of it should be prevented as much as possible: the principles on which this may be effected have been already alluded to.

The surface should be defended as much as possible from the oxygene of the atmosphere; a compact marle, or a tenacious clay, offers the best protection against the air; and before the dung is covered over, or, as it were, sealed up, it should be dried as much as possible. If the dung is found at any time to heat strongly, it should be turned over, and cooled by exposure to air.

Watering dunghills is sometimes recommended for checking the progress of fermentation; but this practice is inconsistent with just chemical views. It may cool the dung for a short time; but moisture, as 1 have before stated, is a principal agent in all processes of decomposition. Dry fibrous matter 
will never ferment. Water is as necessary as air to the process; and to supply it to fermenting dung, is to supply an agent which will hasten its decay.

In all cases when dung is fermenting, there are simple tests by which the rapidity of the process, and consequently the injury done, may be discovered.

If a thermometer plunged into the dung does not rise to above 100 degrees of Fahrenheit, there is little danger of much aeriform matter flying off. If the temperature is higher, the dung should be immediately spread abroad.

When a piece of paper moistened in muriatic acid held over the steams arising from a dunghill gives dense fumes, it is a certain test that the decomposition is going too far, for this indicates that volatile alkali is disengaged.

When dung is to be preserved for any time, the situation in which it is kept is of importance. It should, if possible, be defended from the sun. To preserve it under sheds would be of great use ; or to make the site of a dunghill on the north side of a wall. The floor on which the dung is heaped, should, if possible, be paved with flat stones; and there should be a little inclination from each side towards the centre, in which there should be drains connected with a small well, furnished with a pump, by which any fluid matter may be collected for the use of the land. It too often happens that a dense mucilaginous and extractive fluid 
is suffered to drain away from the dunghill, so as to be entirely lost to the farm.

Sireet and road dung, and the sweepings of houses, may be all regarded as composite manures; the constitution of them is necessarily various, as they are derived from a number of different substances. These manures are usually applied in a proper manner, without bieng fermented.

Soot, which is principally formed from the combustion of pit-coal or coal, generally contains likewise substances derived from animal matters. This is a very powerful manure. It affords ammoniacal salts by distillation, and yields a brown extract to hot water, of a bitter taste. It likewise contains an empyreumatic oil. Its great basis is charcoal, in a state in which it is capable of being rendered soluble by the action of oxygene and water.

This manure is well fitted to be used in the dry state, thrown into the ground with the seed, and requires no preparation.

The doctrine of the proper application of manures from organised substances, offers an illustration of an important part of the æeconomy of nature, and of the happy order in which it is arranged.

The death and decay of animal substances tend to resolve organised forms into chemical constituents; and the pernicious effluvia disengaged in the process seem to point out the propriety of burying them in the soil, where they are fitted to become the food of vegetables. The fermentation and pu- 
trefaction of organised substances in the free atmosphere are noxious processes; beneath the surface of the ground they are salutary operations. In this case the food of plants is prepared where it can be used; and that which would offend the senses and injure the health, if exposed, is converted by gradual processes into forms of beauty and of usefulness; the foetid gas is rendered a constituent of the aroma of the flower, and what might be poison, becomes nourishment to animals and to man. 


\section{0}

\section{LECTURE VII.}

On Manures of mineral Origin, or fossile Manures; their Preparation, and the Manner in which they Act. Of Lime in its different States; Operation of Lime as a Manure and a Cement; different Combinations of Lime. Of Gypsum; Ideas respecting its Use. Of other Neutro-saline Compounds, employed as Manures. Of Alkalies and alkaline Salts; of Common Salt.

ThE whole tenor of the preceding Lectures shews, that a great variety of substances contributes to the growth of plants, and supplies the materials of their nourishment. The conversion of matter that has belonged to living structures intu organised forms, is a process that can be easily understood; but it is more difficult to follow those operations by which earthy and saline matters are consolidated in the fibre of plants, and by which they are made subservient to their functions. Some enquirers adopting that sublime generalization of the ancient philosophers, that matter is the same in essence, and that the different substances considered as elements by chemists, are merely different arrangements of the 
same indestructible particles, have endeavoured to prove, that all the varieties of the principles found in plants, may be formed from the substances in the atmosphere; and that vegetable life is a process in which bodies that the analytical philosopher is unable to change or to form, are constantly composed and decomposed. These opinions have not been advanced merely as hypotheses; attempts have been made to support them by experiments. M. Schrader and Mr. Bracomot, from a series of distinct investigations, have arrived at the same conclusions. 'They state that different seeds sown in fine sand. sulphur, and metallic oxides, and supplied only with atmospherical air and water, produced healthy plants, which by analysis yielded various earthy and saline matters, which either were not contained in the seeds, or the material in which they grew; or which were contained only in wuch smaller quantities in the seeds: and hence they conclude that they must have been formed from air or water, in consequence of the agencies of the living organs of the plant.

The researches of these two gentlemen were conducted with nuch ingenuity and address; but there were circumstances which interfored with their results, which they could not have known, as at the time their labours were published they had not been investigated.

I have found that common distilled water is far from being free from saline impregnations. In ana- 
lysing it by Voltaic electricity, I procured from it alkalies and earths; and many of the combinations of metals with chlorine are extremely volatile substances. When distilled water is supplied in an unlimited manner to plants, it may furnish to them a number of different substances, which though in quantities scarcely perceptible in the water, may accumulate in the plant, which probably perspires only absolutely pure water.

In 1801 I made an experiment on the growth of oats, supplied with a limited quantity of distilled water in a soil composed of pure carbonate of lime. The soil and the water were placed in a vessel of iron, which was included in a large jar, connected with the free atmosphere by a tube, so curved as to prevent the possibility of any dust, or fluid, or solid. matter from entering into the jar. My object was to ascertain whether any siliceous earth would be formed in the process of vegetation; but the oats grew very feebly, and began to be yellow before any flowers formed: the entire plants were burnt, and their ashes compared with those from an equal number of grains of oat. Less siliceous earth was given by the plants than by the grains; but their ashes yielded much more carbonate of lime. That there was less siliceous earth 1 attribute to the circumstance of the husk of the oat being thrown off in germination; and this is the part which most abounds in silica. Healthy green oats taken from a growing crop, in a field of which the soil was a 
fine sand, yielded siliceous earth in a much greater proportion than an equal weight of the corn artificially raised.

The general results of this experinient are very much opposed to the idea of the composition of the earths, by plants, from any of the elements found in the atmosphere, or in water; and there are other facts contradictory to the idea. Jacquin states that the ashes of glass wort (Salsola soda), when it grows in inland situations, afford the vegetable alkali; when it grows on the sea shore, where compounds which afford the fossile or marine alkali are more abundant," it yields that substance. Du Hamel found, that plants which usually girow on the sea shore, made small progress when planted in soils containing little common salt. The sunflower, when growing in lands containing no nitre, does not afford that substance; though when watered by a solution of nitre, it yields nitre abundantly. The tables of de Saussure, referred to in the Third Lecture, shew. that the ashes of plants are similar in constitution to the soils in which they have vegetated.

De Saussure made plants grow in solutions of different salts, and he ascertained, that in all cases, certain portions of the salts were absorbed by the plant, and found unaltered in their organs.

Even animals do not appear to possess the power of forming the alkaline and earthy substances. Dr. Fordyce found, that when canary birds, at the time 
they were laying eggs, were deprived of access to carbonate of lime, their eggrs bad soft shells; and if there is any process for which nature may be conceived most likely to supply resources of this kind, it is that connected with the reproduction of the species.

As the evidence on the subject now stands, it seems fair to conclude, that the different earths and saline substances found in the organs of plants, are supplied by the soils in which they grow ; and in no cases composed by new arrangements of the elements in air or water. What may be our ultimate view of the laws of chemistry, or how far our ideas of elementary principles may be simplified, it is impossible to say. We can only reason from facts. We cannot imitate the powers of composition belonging to vegetable structures; but at least we can understand them : and as far as our rescarches have gone, it appears, that in vegetation compound forms are uniformly produced from simpler ones; and the elements in the soil, the atmosphere, and the earth absorbed and made parts of beautiful and diversified structures.

The views which have been just developed lead to correct ideas of the operation of these manures which are not necessarily the result of decayed organised bodies, and which are not composed of different proportions of carbon, hydrogene, oxygene, and azote.-They must produce their effect, either 
by becoming a consitituent part of the plant, or by acting upon its more essential food, so as to render it more fitted for the purposes of vegetable life.

The only substances which can with propriety be called fossile manures, and which are found unmixed with the remains of any organised beings, are certain alkaline earths or alkalies, and their combinations.

The only alkaline carths which bave been hitherto applicd in this way, are line and magnesia. Potassa and soda, the two fixed alkalies, are both used in certain of their chemical compounds. I shall state in succession such facts as have come to my knowledge respecting each of these bodies in their applications to the purposes of agriculture; but I shall enlarge most upon the subject of lime; and if I should enter into some details which may be tedious and minute, I trust, my excuse will be found in the importance of the inquiry; and it is one which has been greatly elucidated by late discoveries.

The most common form in which lime is found on the surface of the earth, is in a state of combination with carbonic acid or fixed air. If a piece of limestone, or chalk, be thrown into a fluid acid, there will be an effervescence. This is owing to the escape of the carbonic acid gas. The lime becomes dissolved in the liquor.

When limestone is strongly heated, the carbonic acid gas is expelled, and then nothing remains but the pure alkaline earth; in this case there is a loss 
of weight; and if the fire has been very high, it approaches to one-half the weight of the stone; but in common cases, limestones, if well dried before burning, do not lose much more than from 35 to 40 per cent., or from seven to eight parts out of twenty.

I mentioned, in discussing the agencies of the atmosphere upon vegetables, in the beginning of the Fifth Lecture, that air always contains carbonic acid gas, and that lime is precipitated from water by this substance. When burnt lime is exposed to the atmosphere, in a certain time it becomes mild, and is the same substance as that precipitated from lime water; it is combined with carbonic acid gas. Quicklime, when first made, is caustic and burning to the tongue, render's vegetable blues green, and is soluble in water; but when combined with carbonic acid it loses all these properties, its solubility and its taste: it regains its power of effervescing, and becomes the same chemical substance as chalk, or limestone.

Very few limestones, or chalks, consist entirely of lime and carbonic acid. The statuary marbles, or certain of the rhomboidal spars, are almost the only pure species; and the different properties of limestones, both as manures and cements, depend upon the nature of the ingredients mixed in the limestone; for the true calcareous element, the carbonate of lime, is uniformly the same in nature, properties, and effects, and consists of one proportion of carbonic acid 41.4, and one of lime 55. 
When a limestone does not copiously effervesce in acids, and is sufficiently hard to scratch glass, it contains siliceous, and probably aluminous earth. When it is deep brown, or red, or strongly coloured of any of the shades of brown or yellow, it contains oxide of iron. When it is not sufficiently hard to scratch glass, but effervesces slowly, and makes the acid in which it effervesces milky, it contains magnesia. And when it is black, and emits a fotid smell if rubbed, it contains coaly or bituminous matter.

The analysis of limestones is not a difficult matter; and the proportions of their constituent parts may be easily ascertained, by the processes described in the Lecture on the Analysis of Soils; and usually with sufficient accuracy for all the purposes of the farmer, by the fifth process.

Before any opinion can be formed of the manner in which the different ingredients in limestones modify their properties, it will be necessary to consider the operation of the pure calcareous element as a manure, and as a cement.

Quicklime in its pure state, whether in powder, or dissolved in water, is injurious to plants.-I have in several instances killed grass by watering it with lime water.-But lime, in its state of combination. with carbonic acid, as is evident from the analyses given in the Fourth Lecture, is a useful ingredient in soils. Calcareous earth is found in the ashes of the greater number of plants; and exposed to the 
air, lime cannot long continue caustic, for the reasons that were just now assigned, but soon becomes united to carbonic acid.

When newly burnt lime is exposed to air, it soon falls into porvder; in this case it is called slacked lime; and the samic effect is immediately produced by throwing water upon it, when it heats violently, and the water disappears.

Slacked lime is merely a combination of lime, with about one-third of its weight of water; i. e fifty-five parts of lime absork seventeen parts of water; and in this case it is composed of a definite proportion of water, and is called by chemists hydrate of lime; and when hydrate of lime becomes carbonate of lime by long exposure to air, the water is expelled, and the carbonic acid gas takes its place.

When lime, whether freshly burnt or slacked, is mixed with any moist fibrous vegetable matter, there is a strong action between the lime and the vegetable matter, and they form a kind of compost together, of which a part is usually soluble in water.

By this kind of operation, lime renders matter which was before comparatively inert, nutritive; and as charcoal and oxygene abound in all vegetable matters, it becomes at the same time converted into carbonate of lime.

Mild lime, powdered limestone, marles, or chalks, have no action of this kind upon vegetable matter; 
1.y their action they prevent the too rapid decomposition of substances already dissolved; but they have no tendency to form soluble matters.

It is obvious from these circumstances, that the operation of quicklime, and marle or chalk, depends upon principles altogether different.-Quicklime, in being applied to land, tends to bring any, hard vegetable matter that it contains into a state of more rapid decomposition and solution, so as to render it a proper food for plants.-Chalk and marle, or carbonate of lime, will only improve the. texture of the soil, or its relation to absorption; $\mathbf{i}^{\prime}{ }_{i}$ acts merely as one of its earthy ingredients.--Quic' klime, when it becomes mild, operates in the $\mathrm{s}^{\prime}$. manner as chalk; but in the act of becoming mild, it prepares soluble out of insoluble matter.

It is upon this circumstance that the ' speration of lime in the preparation for wheat cror s depends; and its efficacy in fertilizing pents, and in bringing into a state of cultivation all soils abounding in hard roots or dry fibres, or inert ver setable matter.

The sulution of the question $r$, hether quicklime ought to be applied to a soil, depends upon the quantity of inert vegetable m'atter that it contains. The solution of the question ${ }_{4}$, whether marle, mild lime, or powdered limestc, ne, ought to be applied, depends upon the quantity of calcareous matter already in the soil. All s,oils are improved by mild. lime, and ultimately by quicklime, which do not effervesce with acids; and sands more than clays. 
When a soil deficient in calcareons matter contains much soluble vegetable manure, the application of quicklime should always be avoided, as it either tends to decompose the soluble matters by uniting to their carbon and oxygene so as to become mild lime, or it combines with the soluble matters, and forms compounds having less attrac. tion for water than the pure vegetable substance.

The case is the same with respect to most animal manuires; but the operation of the lime is different in different cases, and depends upon the nature of the animal matter. Lime forms a kind of insoluble s. ap with oily matters, and then gradually decompo. es them by separating from them oxygene and cark on. It combines likewise with the animal acids, and probably assists their decomposition by abstrac ing carbonaceous matter from them combined $w$ th oxygene; and consequently it must render the $\mathbf{m}$ less zutritive. It tends to diminish likewise the "utritive powers of albumen from the same causes; a nd always destroys, to a certain extent, the efficacy of animal manures, either by combining with certar $\mathrm{n}$ of their elements, or by giving to them new arrangु"ements. Lime should never be applied with animal manures, unless they are too rich, or for the purpose of preventing noxious effluvia, as in certain cases mentioned in the last Lecture. It is injurious when mixed with any common dung, and tends to rende:r the extractive matter insoluble. 
1 made an experiment on this subject : I mixed a quantity of brown soluble extract, which was procured from sheeps' dung with five times its weight of quicklime. I then moistened them with water; the mixture heated very much; it was suffered to remain for fourteen hours, and was then acted on by six or seven times its bulk of pure water: the water, after being passed through a filter, was evaporated to dryness; the solid matter obtained was scarcely coloured, and was lime mixed with a little saline matter.

In those cases in which fermentation is useful to produce nutriment from vegetable substances, lime is always efficacious. I mixed some moist tanner's spent bark with one-fifth of its weight of quicklime, and suffered them to remain together in a close vessel for three months; the lime had become coloured, and was effervescent: when water was boiled upon the mixture, it gained a tint of fawn colour, and by evaporation furnished a fawn-coloured powder, which must have consisted of lime united to vegetable matter, for it burnt when strongly heated, and left a residuum of mild lime.

The limestones containing alumina and silica are less fitted for the purposes of manure than pure limestones; but the lime formed from them has no noxious quality. Such stones are less efficacious, merely because they furnish a smaller quantity of quicklime.

I mentioned bituminous limestones. There is 
very seldom any considerable portion of coaly matter in these stones; never as much as five parts in 100 ; but such limestones make very good lime. The carbonaceous matter can do no injury to the land, and may, under certain circumstances, become a food of the plant, as is evident from what was stated in the last Lecture.

The subject of the application of the magnesian limestone is one of great interest.

It had been long known to farmers in the neighbourhood of Doncaster, that lime made from a certain limestone applied to the land, often injured the crops considerably, as I mentioned in the Introductory Lecture. Mr. Tennant, in making a series of experiments upon this peculiar calcareous substance, found that it contained magnesia; and on mixing some calcined magnesia with soil, in which he sowed different seeds, he found that they either died, or vegetated in a very imperfect manner, and the plants were never healthy. And with great justice and ingenuity he referred the bad effects of the peculiar limestone to the magnesian earth it contains.

In making some inquiries concerning this subject, I found that there were cases in which this magnesian limestone was used with good effect.

Amongst some specimens of limestone which Lord Somerville put into my hands; two marked as peculiarly good proved to be magnesian limestones. And lime made from the Breedon limestone is used 
in Leicestershire, where it is called hot lime; and I have been informed by farmer's in the neighbourhood of the quarry, that they employ it advantageously in small quantities, seldom more than 25 or 30 bushels to the acre. And that they find it may be used with good effect in larger quantities, upon rich land.

A minute chemical consideration of this question will lead to its solution.

Magnesia has a much weaker attraction for carbonic acid than lime, and will remain in the state of caustic or calcined magnesia for many months, though exposed to the air. And as long as any caustic lime remains, the magnesia cannot be combined with carbonic acid, for lime instantly attracts carbonic acid from magnesia.

When a magnesian linestone is burnt, the magnesia is deprived of carbonic acid much sooner than the lime; and if there is not much vegetable or animal matter in the soil to supply by its decomposition carbonic acid, the magnesia will remain for a long while in the caustic state; and in this state acts as a poison to certain vegetables. And that more magnesian lime may be used upon rich soils, seems to be owing to the circumstance, that the decomposition of the manure in them supplies carbonic acid. And magnesia in its mild state, $i . e$. fully combined with carbonic acid, seems to be always an useful constituent of soils. I have thrown carbonate of magnesia (procured by boiling the solu- 
tion of magnesia in super-carbonate of potassa) upon grass, and upon growing wheat and barley, so as to render the surface white; but the vegetation was not injured in the slightest degree. And one of the most fertile parts of Cornwall, the Lizard, is a district in which the soil contains mild magnesian earth.

The Lizard Downs bear a short and green grass, which feeds sheep producing excellent mutton; and the cultivated parts are amongst the best corn lands in the county.

That the theory which I have ventured to give of the operation of magnesian lime is not unfounded, is shewn by an experiment which I made expressly for the purpose of determining the true nature of the operation of this substance. I took four portions of the same soil: with one I mixed $\frac{r}{20}$ of its weight of caustic magnesia, with another I mixed the same quantity of magnesia and a proportion of a fat decomposing peat equal to one-fourth of the weight of the soil. One portion of soil remained in its natural state; and another was mixed with peat without magnesia. The mixtures were made in December 1806; and in April 1807, barley was sown in all of them. It grew very well in the pure soil, but better in the soil containing the magnesia and peat; and nearly as well in the soil containing peat alone: but in the soil containing the magnesia alone, it rose very feeble, and looked yellow and sickly. 
I repeated this experiment in the summer of $\mathbf{1 8 1 0}$ with similar results; and I found that the magnesia in the soil mixed with peat became strongly effervescent, whilst the portion in the unmixed soil gave carbonic acid in much smaller quantities. In the one case the magnesia had assisted in the formation of a manure, and had become mild; in the other case it had acted as a poison.

It is obvious, from what has been said, that lime from the magnesian limestone may be applied in large quantities to peats; and that where lands have been injured by the application of too large a quantity of magnesian lime, peat will be a proper and efficient remedy.

I mentioned that magnesian limestones effervesced little when plunged into an acid. A simple test of magnesia in a limestone is this circumstance, and its rendering diluted nitric acid, or aqua fortis milky.

From the analysis of Mr. 'Tennant, it appears that the magnesian limestones contain from

20.3 to 22.5 magnesia.

29.5 to 31.7 lime.

47.2 carbonic acid.

0.8 clay and oxide of iron.

Magnesian limestones are usually coloured brown or pale yellow. They are found in Somersetshire, Leicestershire, Derbyshire, Shropshire, Durham, and Yorkshire. I have never met with any in 
other counties in England; but they abound in many parts of Ireland, particularly near Belfast.

The use of lime as a cement is not a proper subject for extensive discussion in a course of Lectures on the chemistry of agriculture; yet as the theory of the operation of lime in this way is not fully stated in any elementary book that $I$ have perused, I shail say a very few words on the applications of this part of chemical knowledge.

There are two modes in which lime acts as a cement; in its combination with water, and in jts combination with carbonic acid.

The hydrate of lime has been already mentioned. When quick lime is rapidly made into a paste with water, it soon loses its softness, and the water and the lime form together a solid coherent mass, which consists, as has been stated before, of 17 parts of water to 55 parts of lime. When hydrate of lime whilst it is consolidating, is mixed with red oxide of iron, alumina, or silica, the mixture becomes harder and more coherent than when lime alone is used; and it appears that this is owing to a certain degree of chemical attraction between hydrate of lime and these bodies; and they render it less liable to decompose by the action of the carbonic acid in the air, and less soluble in water.

The basis of all cements that are used for works which are to be covered with water must be formed from hydrate of lime; and the lime made from im- 
pure limestones answers this purpose very well. Puzzolana is composed principally of silica, alumina, and oxide of iron; and it is used mixed with lime to form cements intended to be employed under water. Mr. Smeaton, in the construction of the Eddystone lighthouse, used a cement composed of equal parts by weight of slacked lime and puzzolana. Puzzolana is a decomposed lava. Tarras, which was formerly imported in consideralule quantities from Holland, is a mere decomposed basalt: two parts of slacked lime and one part of tarras forms the principal part of the mortar used in the great dykes of Holland. Substances which will answer all the ends of puzzolana and tarras are abundant in the British islands. An excellent red. tarras may be procured in any quantities from the Giants' Causeway, in the north of Ireland: and decomposing basalt is abundant in many parts of Scotland, and in the northern districts of England in which coal is found.

Parker's cement, and cements of the same kind made at the alum works of Lord Dundas and Lord Mulgrave, are mixtures of calcined ferruginous, silicious, and aluminous matter, with hydrate of lime.

The cements which act by combining with carbonic acid, or the common mortars, are made by mixing together slacked lime and sand. These mortars, at first solidify as hydrates, and are slowly converted into carbonate of lime.by the action of 
the carbonic acid of the air. Mr. Tennant found that a mortar of this kind in three years and a quarter had regained 63 per cent. of the quantity of carbonic acid gas which constitutes the definite proportion in carbonate of lime. The rubbish of mortar from houses owes its power to benefit lands principally to the carbonate of lime it contains, and the sand in it; and its state of cohesion renders it particularly fitted to improve clayey soils.

The hardness of the mortar in very old buildings depends upon the perfect conversion of all its parts into carbonate of lime. The purest limestones are the best adapted for making this kind of mortar; the magnesian limestones make excellent water cements, but act with too little energy upon carbonic acid gas to make good common mortar.

The Romans, according to Pliny, made their best mortar a year before it was used; so that it was partially combined with carbonic acid gas before it was employed.

In burning lime there are some particular precautions required for the different kinds of limestones. In general, one bushel of coal is sufficient to make four or five bushels of lime. The magnesian limestone requires less fuel than the common limestone. In all cases in which a limestone containing much aluminous or siliceous earth is burnt, great care should be taken to prevent the fire from becoming too intense; for such lime easily vitrifies, in consequence of the affinity of lime for silica and 
alumina. And as in some places there are no other limestones than such as contain other earths, it is important to attend to this circumstance. A moderately good lime may be made at a low red heat; but it will melt into a glass at a white heat. In limekilns for burning such lime, there should be always a damper.

In general, when limestones are not magnesian their purity will be indicated by their loss of weight in burning; the more they lose, the larger is the quantity of calcareous matter they contain. The magnesian limestones contain more carbonic acid than the common limestones; and I have found all of them lose more than half their weight by calcination.

Besides being used in the forms of lime and carbonate of lime, calcareous matter is applied for the purposes of agriculture in other combinations. One of these bodies is gypsum or sulphate of lime. This substance consists of sulphuric acid (the same body that exists combined with water in oil of vitriol) and lime; and when dry it is composed of 55 parts of lime and 75 parts of sulphuric acid. Common gypsum or selenite, such as that found at Shotover Hill, near Oxford, contains, besides sulphuric acid and lime, a considerable quantity of water; and its composition may be thus expressed:

Sulphuric acid one proportion $\mathbf{7 5}$

Lime one proportion - $\quad 55$

Water two proportions - $\mathbf{3 4}$ 
The nature of gypsum is easily demonstrated; if oil of vitriol be added to quicklime, there is a violent heat produced; when the mixture is ignited, water is given off, and gypsum alone is the result, if the acid has been used in sufficient quantity; and gypsum mixed with quicklime, if the quantity has been deficient. Gypsum, free from water, is sometimes found in nature, when it is called anhydrous selenite. It is distinguished from common gypsum by giving off no water when heated.

When gypsum, free from water, or deprived of water by heat, is made into a paste with water, it rapidly sets by combining with that fluid. Plaster of Paris is powdered dry gypsum, and its property as a cement, and in its use in making casts, depends upon its solidifying a certain quantity of water, and making with it a coherent mass. Gypsum is soluble in about 500 times its weight of cold water, and is more soluble in hot water; so that when water has been boiled in contact with gypsum, crystals of this substance are deposited as the water cools. Gypsum is easily distinguished by its properties of affording precipitates to solutions of oxalates and of barytic salts.

Great difference of opinion has prevailed amongst agricnlturists with respect to the uses of gypsum. It has been advantageously used in Kent, and various testimonies in favour of its efficacy have been laid before the Board of Agriculture by Mr. Smith. 
In America it is cmployer with signal success; but in most counties of Eugland it has failed, though tried in various ways, aad upon different crops.

Very discordant notions have been formed as to the mode of operation of gypsum. It has been suppos $\mathrm{d}$ by some persons to act by its power of attracting moisture from the air; but this agency must be comparatively insignificant. When combined with water, it retains that fluid too powerfully to yield it to the roots of the plant, and its adhesive attraction for moisture is inconsiderable; the small quantity in which it is used likewise is a circumstance hostile to this idea.

It las been said that gypsum assists the putrefaction of animal substances, and the decomposition of manure. I have tried some experiments on this subject which are contradictory to the notion. I mixed some minced veal with about one-one hundredth part of its weight of gypsum, and exposed some veal without gypsum under the same circumstances; there was no difference in the time in which they began to putrefy, and the process seemed to me most rapid in the case in which there was no gypsum present. I made other similar mixtures, employing in some cases larger, and in some cases smaller quantities of gypsum; and I used pigeons' dung in one instance instead of flesh, and with precisely simular results. It certainly in no case increased the rapidity of putrefaction.

Though it is not generally known, yet a series of 
experiments has been carried on for a great length of time in this country upon the operation of gypsum as a manure. The Berkshire and the Wiltshire peat-ashes contain a considerable portion of this substance. In the Newbury peat-ashes I have found from one-fourth to one-third of gypsum; and a larger quantity in some peat-ashes from the neighbourhood of Stockbridge: the other constituents of these ashes are calcareous, aluminous, and siliceous earth, with variable quantities of sulphate of potassa, a little common salt, and sometimes oxide of iron. The red ashes contain most of this last substance.

These peat-ashes are used as a top dressing for cultivated grasses, particularly sainfoin and clover. In examining the ashes of sainfoin, clover, and rye grass, I found that they afforded considerable quantities of gypsum; and this substance, probably, is intimately combined as a necessary part of their woody fibre. If this be allowed, it is easy to explain the reason why it operates in such small quantities ; for the whole of a clover crop, or sainfoin crop, on an acre, according to my estimation, would afford by incineration only three or four bushels of gypsum. In examining the soil in a field near Newbury, which was taken from below a foot-path near the gate, where gypsum could not have been artificially furnished, I could not detect any of this substance in it; and at the very time I collected the soil, the peat-ashes were applied to the 
clover in the field. The reason why gypsum is not generally efficacious, is probably because most cultivated soils contain it in sufficient quantities for the use of the grasses. In the common course of cultivation, gypsum is furnished in the manure; for it is contained in stable dung, and in the dung of all cattle fed on grass; and $1 ;$ is not taken up in corn crops, or crops of peas and beans, and in very small quantities in turnip crops; but where lands are exclusively devoted to pasturage and hay, it will be continually consumed. I have examined four different soils cultivated by a series of common courses of crops, for gypsum. One was a light sand from Norfolk; another a clay, bearing a good wheat, from Middlesex; the third a sand, from Sussex; the fourth a clay, from Essex. I found gypsum in all of them; and in the Middlesex soil it amounted nearly to one per cent. Lord Dundas in. forms me, that having tried gypsum without any benefit on two of his estates in Yorkshire, he was induced to have the soil examined for gypsum, according to the process described in the Fourth Lecture, and this substance was found in both the suils.

Should these statements be confirmed by future inquiries, a practical inference of some value may be derived from them. It is possible that lands which have ceased to bear good crops of clover, or artificial grasses, may be restored by being manured with gypsum. I have mentioned that this 
substance is found in Oxfordshire; it is likewise abundant in many other parts of England; in Gloucestershire, Somersetshire, Derbyshire, Yorkshire, \&c. and requires only pulverization for its preparation.

Some very interesting documents upon the use of sulphate of iron or green vitriol, which is a salt produced from peat in Bedfordshire, have been laid before the Boaiel by Dr. Pearson; and I have witnessed the fertilizing effects of a ferruginous water used for irrigating a grass meadow made by the Duke of Manchester at Priestley Bog, near Woburn, an account of the produce of which has been published by the Board of Agriculture. I. have no doubt that the peat salt and the vitriolic water acted chiefly by producing gypsum.

The soils on which both are efficacious are calcareous; and sulphate of iron is decomposed by the carbonate of lime in such soils. The sulphate of iron consists of sulphuric acid and oxide of iron, and is an acid and a very soluble salt; when a solution of it is mixed with carbonate of lime, the sulphuric acid quits the oxide of iron to unite to the lime, and the compounds produced are insipid and comparatively insoluble.

I collected some of the deposition from the ferruginous water on the soil in Priestley meadow. I found it consisted of gypsum, carbonate of iron, and insoluble sulphate of iron. The principal grasses in Priestley meadow are, meadow fox-tail, cock's-foot, 


\section{5}

meadow fescue, fiorin, and sweet-scented vernal grass. I have examined the ashes of three of these grasses, meadow fox-tail, cock's-foot, and fiorin. They contained a considerable proportion of gypsum.

Vitriolic impregnations in soils where there is no calcareous matter, as in a soil from Lincolnshire, to which I referred in the Fourth Lecture, are injurious; but it is probably in consequence of their supplying an excess of ferruginous matter to the sap. Oxide of iron in small quantities forms an useful part of soils : and, as is evident from the details in the Third Lecture, it is found in the ashes of plants, and probably is hurtful only in its acid combinations.

I have just mentioned certain peats, the ashes of which afford gypsum; but it must not be inferred from this that all peats agree with them. I have examined various peat-ashes from Scotland, Ireland, Wales, and the northern and western parts of England, which contained no quantity that could be useful; and these ashes abounded in siliceous, aluminous earths, and oxide of iron.

Lord Charleville found in some peat-ashes from Ireland sulphate of potassa, i. e. the sulphuric acid combined with potassa.

Vitriolic matter is usually formed in peats; and if the soil or substratum is calcarecus, the ultimate result is the production of gypsum. In general, when a recent peat-ash emits a strong smell re- 
sembling that of rotten eggs when acted upon by vinegar, it will furnish gypsum.

Phosphate of lime is a combination of phosphoric acid and lime, one proportion of each. It is a compound insoluble in pure water, but soluble in water containing any acid matter. It forms the greatest part of calcined bones. It exists in most excrementitious substances, and is found both in the straw and grain of wheat, barley, oats, and rye, and likewise in beans, peas, and tares. It exists in some places in these islands native, but only in very small quantities. Phosphate of lime is generally conveyed to the land in the compositon of other manure, and it is probably necessary to corn crops and other white crops.

Bone ashes ground to powder will probably be found useful on arable lands containing much vegetable matter, and may perhaps enable soft peats to produce wheat; but the powdered bone in an uncalcined state is much to be preferred in all cases when it can be procured.

The saline compounds of magnesia will require very little discussion as to their uses as manures. The most important relations of this subject to agriculture have been considered in the former part of this Lecture, when the application of the magnesian limestone was examined. In combination with sulphuric acid magnesia forms a soluble salt. This substance, it is stated by some inquirers, has been found of use as a manure; but it is not found 
in nature in sufficient abundance, nor is it capable of being made artificially sufficiently cheap to be of useful application in the common course of husbandry.

Wood ashes consist principally of the vegetable alkali united to carbonic acid; and as this alkali is found in almost all plants, it is not difficult to conceive that it may form an essential part of their organs. The general tendency of the alkalies is to give solubility to vegetable matters; and in this way they may render carbonaceous and other substances capable of being taken up by the tubes in the radicle fibres of plants. The regetable alkali likewise has a strong attraction for water, and even in small quantities may tend to give a due degree of moisture to the soil, or to other manures; though this operation from the small quantities used, or existing in the soil, can be only of a secondary kind.

The mineral alkali, or soda, is found in the ashes of sea-weed, and may be procured by certain chemical agencies from common salt. Common salt consists of the metal named sodium, combined with chlorine; and pure soda consists of the same metal united to oxygene. When water is present, which can afford oxygene to the sodium, soda may be obtained in several modes from salt.

The same reasoning will apply to the operation of the pure mineral alkali, or the carbonated alkali, as to that of the vegetable alkali; and when common salt acts as a manure; it is probably by entering 
into the composition of the plant in the same manner as gypsum, phosphate of lime, and the alkalies. Sir John Pringle has stated, that salt in small quantities assists the decomposition of animal and vegetable matter. 'This circumstance may render' it useful in certain soils. Common salt likewise is offensive to insects.- That in small quantities it is sometimes a useful manu'e, I believe it fully proved; and it is probable that its efficacy depends upon many combined causes.

Some persons have argued against the employment of salt ; becanse when used in large quantities, it either does no good, or renders the ground sterile; but this is a very ui,fair mode of reasoning. 'That salt in large quantities rendered land barren, was known long before any records of agricultural science existed. We read in the scriptures, that Abimelech took the city of schechem, " and beat down the city, and sowed it with salt;" that the soil might be for ever unfruitful. Virgil reprohates a salt soil; and Pliny, hough he recommends giving salt to cattle, yet affirms, that when strewed over land it renders it barren. But these are not argunents agaiust a proper applicatiou of it. Refuse salt in Cornwall, which, however, likewise contairs some of the oil and exuviæ of fish, has long been known as an admirable manure. And the Cheshire farmers contend for the benefit of the peculiar produce of their country.

It is not unlikely, that the same causes influence 
the effects of salt, as those which act in modifying the operation of gypsum. Most lands in this island, particularly those near the sea, probably contain a sufficient quantity of salt for all the purposes of vegetation; and in such cases the supply of it to the . soil will not only be useless, but may be injurious. In great storms the spray of the sea has been carried more than 50 miles from the shore; so that from this source salt must be often supplied to the soil. I have found salt in all the sandstone rocks that I have examined, and it must exist in the soil derived from these rocks. It is a constituent likewise of almost every kind of animal and vegetable manure.

Besides these compounds of the alkaline earths and alkalies, many others have been recommended for the purposes of increasing vegetation; such are nitre, or the nitrous acid combined with potassa. Sir Kenelm Digby states, that he made barley grow very luxuriantly by watering it with a very weak solution of nitre; but he is too speculative a writer to awaken confidence in his results. This substance consists of one proportion of azote, six of oxygene, and one of potassium; and it is not unlikely that it may furnish azote to form albumen, or gluten, in those plants that contain them; but the nitrous salts are too valuable for other purposes to be used as manures.

Dr. Home states, that sulphate of potassa, which, as $\mathbf{I}$ just now mentioned, is found in the ashes of 
some peats, is a useful manure. But Mr. Naismith* questions his results; and quotes experiments hostile to his opinion, and, as he conceives, unfavourable to the efficacy of any species of saline manure.

Much of the discordance of the evidence relating to the efficacy of saline substances depends upon the circumstance of their having been used in different proportions, and in general, in quantities much too large.

I made a number of experiments in May and June, 1807, on the effects of different saline substances on barley and on grass growing in the same garden, the soil of which was a light sand, of which 100 parts were composed of 60 parts of siliceous sand, and 24 parts finely divided matter, consisting of seven parts carbonate of lime, 12 parts alumina and silica, less than one part saline matter, principally common salt, with a trace of gypsum and sulphate of magnesia: the remaining 16 parts were vegetable matter.

The solutions of the saline substances were used twice a week, in the quantity of two ounces, on spots of wass and corn, sufficiently remote from each other to prevent any interference of results. The substances tried were super-carbonate, sulphate, acetate, nitrate, and muriate of potassa; sulphate of soda, sulphate, nitrate, muriate, and carbonate of ammonia. I found, that in all cases when the

* Elements of Agriculture, p. 78. 
quantity of the salt equalled one-thirtieth part of the weight of the water, the effects were injurious; but least so in the instances of the carbonate, sulphate, and muriate of ammonia. When the quantities of the salts were one-three hundredth part of the solution the effects were different. The plants watered with the solutions of the sulphates grew just in the same manner as similar plants watered with rain water. Those acted on by the solution of nitre, acetate, and super-carbonate of potassa, and muriate of ammonia, grew rather better. Those treated with the solution of carbonate of ammonia grew most luxuriantly of all. This last result is what might be expected, for carbonate of ammonia consists of carbon, hydrogene, azote, and oxygene. There was, however, another result which I had not anticipated; the plants watered with solution of nitrate of ammonia did not grow better than those watered with rain water. The solution reddened litmus paper; and probably the free acid exerted a prejudicial effect, and interfered with the result.

Soot doubtless owes part of its efficacy to the ammoniacal salts it contains. The liquor produced by the distillation of coal contains carbonate and acetate of ammonia, and is said to be a very good manure.

In 1808, I found the growth of wheat in a field at Roehampton assisted by a very weak solution of acetate of ammonia. 


\section{2}

Soapers' waste has been recommended as a manure, and it has been supposed that its efficacy depended upon the different saline matters it contains; but their quantity is very minute indeed, and its principal ingredients are mild lime and quicklime. In the soapers' waste from the best manufactories, there is scarcely a trace of alkali. Lime moistened with sea water affords more of this substance, and is said to have been used in some cases with more benefit than common lime.

It is unnecessary to discuss to any greater extent the effects of saline substances on vegetation; except the ammoniacal compounds, or the compounds containing nitric, acetic, and carbonic acid; none of them can afford by their decomposition any of the common principles of vegetation, carbon, hydrogene, and oxygene.

The alkaline sulphates and the earthy muriates are so seldom found in plants, or are found in such minute quantities, that it can never be an object to apply them to the soil. It was stated in the beginning of this Lecture, that the earthy' and alkaline substances seem never to be formed in vegetation; and there is every reason, likewise, to believe, that they are never decomposed ; for after being absorbed they are found in their ashes.

The metallic bases of them cannot exist in contact with aqueous fluids; and these metallic bases, like other metals, have not as yet been resolved into any other forms of matter by artificial pro- 


\section{3}

cesses; they combine readily with other elements; but they remain undestructible, and can be traced undiminished in quantity, through their diversified combinations. 


\section{LECTURE VIII.}

On the Improvement of Lands by Burning; chemical Principles of this Operation. On Irrigation and its Effects. On fallowing; its Disadvantayes and Uses. On the convertible Husbandry founded on regular Rotations of different Crops. On Pasture; Views connected with its Application. On various Agricultural Objects connected with Chemistry. Conclusion.

THE improvement of sterile lands by burning, was known to the Romans. It is mentioned by Virgil in the first book of the Georgics: "Sæpe etiam steriles incendere profuit agros." It is a practice still much in use in many parts of these Islands; the theory of its operation has occasioned much discussion, both amongst scientific men and farmers. It rests entirely upon chemical doctrines; and I trust I shall be able to offer you satisfactory elucidations on the subject.

The basis of all common soils, as I stated in the Fourth Lecture, are mixtures of the primitive earths and oxide of iron; and these earths have a certain degree of attraction for each other. To regard this 
attraction in its proper point of view, it is only necessary to consider the composition of any common siliceous stone. Feldspar, for instance, contains siliceous, aluminous, calcareous earths, fixed alkali, and oxide of iron, which exist in one compound, in consequence of their chemical attractions for each other. Let this stone be ground into impalpable powder, it then becomes a substance like clay: if the powder be heated very strongly it fuses, and on cooling forms a coherent mass similar to the original stone; the parts separated by mechanical division adhere again in consequence of chemical attraction. If the powder is heated less strongly the particles only superficially combine with each other, and form a gritty mass, which, when broken into pieces, has the characters of sand.

If the power of the powdered feldspar to absorb water from the atmosphere before, and after the application of the heat, be compared, it is found much less in the last case.

The same effect takes place when the powder of other siliceous or aluminous stones is made the subject of experiment.

I found that two equal portions of basalt ground into impalpable powder, of which one had been strongly ignited, and the other exposed only to a temperature equal to that of boiling water, gained very different weights in the same time when exposed to air. In four hours the one had gained 
only two grains, whilst the other had gained seven grains.

When clay or tenacious soils are burnt, the effect is of the same kind; they are brought nearer to a state analogous to that of sands.

In the manufacture of bricks the general principle is well ihistrated; if a piece of "ly y brick earth be applied to the tungue it will adhere to it very strongly, in consequence of its power to absorb watér; but after it has been burnt there will be scarcely a sensible adhesiun.

The process of burning renders the soil less com- . pact, less tenaci us and retentive of moisture; and when properly appled, may convert a matter that was stiff, damp, and in consequence cold, into one powdery, dry, and warm; and much more proper - as a bed for vegetable life.

The great objection made by speculative chemists to paring and burning, is, that it destroys vegetable and animal matter, or the manure in the soil; but in cases in which the texture of its earthy ingredients is permanently improved, there is more than a compensation for this temporary disadvantage. And in some soils where there is an excess of inert vegetable matter, the destruction of it inust be beneficial; and the carbonaceous matter renaining in the ashes may be more useful to the crop than the vegetable fibre, from which it was produced.

- I have examined by a chemical analysis three spe- 
cimens of ashes from different lands that had undergrone paring and burning. The first was a quantity sent to the Board by Mr. Boys of Bellhanger, in Kent, whose treatise on paring and burning has been published. They were from a chalk soil, and 200 grains contained

80 Carbonate of lime.

11 Gypsum.

9 Charcoal.

15 Oxide of iron.

3 Saline matter.

Sulphate of potash.

Muriate of magnesia, with a minute quantity of vegetable alkali.

The remainder alumina and silica.

Mr. Boys estimates that 2660 bushels are the common produce of an acre of ground, which, according to his calculation would give $172900 \mathrm{lbs}$. containing

$\begin{array}{lcc}\text { Carbonate of lime } & 69160 \mathrm{lbs} \\ \text { Gypsum - } & - & 9509.5 \\ \text { Oxide of iron } & - & 12967.5 \\ \text { Saline matter } & - & 2593.5 \\ \text { Charcoal - } & - & 7780.5\end{array}$

In this instance there was undoubtedly a very considerable quantity of matter capable of being . active as manure produced in the operation of burning. The charcoal was very finely divided; and exposed on a large surface on the field, must have been gradually converted into carbonic acia. And 
sypsum and oxide of iron, as I mentioned in the last Lecture, seem to produce the very best effects when applied to lands containing an excess of carbonate of lime.

The second specimen was from a soil near Coleorton, in Leicestershire, containing only four per cent. of carbonate of lime, and consisting of threefourths light siliceous sand, and about one-fourth clay. This had been turf before burning, and 100 parts of the ashes gave

6 parts charcoal.

3 Muriate of soda and sulphate of potash, with a trace of vegetable alkali.

9 Oxide of iron.

And the remainder the earths.

In this instance, as in the other, finely divided charcoal was found; the solubility of which would be increased by the presence of the alkali.

The third instance was, that of a stiff clay, from Mount's Bay, Cornwall. This land had been brought into cultivation from a heath by burning about ten years before; but having been neglected, furze was springing up in different parts of it, which gave rise to the second paring and burning. 100 parts of the ashes contained

8 parts of charcoal.

2 of saline matter, principally common salt, with a little vegetable alkali.

7 Oxide of iron.

2 Carbonate of lime.

Remainder alumina and silica. 
Here the quantity of charcoal was greater than in the other instances. The salt, I suspect, was owing to the vicinity of the sea, it being but two miles off. In this land there was certainly an excess of dead vegetable fibre, as well as unprofitable living vegetable matter; and $I$ have since heard, that a great improvement took place.

Many obscure causes have been referred to for the purpose of explaining the effects of paring and burning; but I believe they may be referred entirely to the diminution of the coherence and tenacity of clays, and to the destruction of inert, and useless vegetable matter, and its conversion into a manure.

Dr. Darwin, in his Phytologia, has supposed, that clay during torrefaction, may absorb some nutritive principles from the atmosphere that afterwards may be supplied to plants; but the earths are pure metallic oxides, saturated with oxygene; and the tendency of burning is to expel any other volatile principles that they may contain in combination. If the oxide of iron in soils is not saturated with oxygene, torrefaction tends to produce its further union with this principle; and hence in burning, the colour of clays changes to red. The oxide of iron containing its full proportion of oygene has less attraction for acids than the other oxide, and is consequently less likely to be dissolved by any fluid acids in the soil; and it appears in this state to act in the same manner as the earths. A very 
ingenious author, whom I quoted at the end of the last Lecture, supposes that the oxide of iron when combined with carbonic acid is poisonous to plants; and that one use of torrefaction is to expel the carbonic acid from it; but the carbonate of iron is not soluble in water, and is a very inert substance; and I have raised a luxuriant crop of cresses in a soil composerl of one-fifth carbonate of iron, and fourfifths carbonate of lime. Carbonate of iron abounds in some of the most fertile soils in England, particularly the red hop soil. And there is no theoretical ground for supposing, that carbonic acid, which is an essential food of plants, should in any of its combinations be poisonous to them ; and it is known that lime and magnesia are both noxious to vegetation, unless combined with this principle.

All soils that contain too much dead vegetable fibre, and which consequently lose from one-third to one-half of their weight by incineration, and all such as contain their earthly constituents in an impalpable state of division, i. e. the stiff clays and marles, are improved by burning; but in coarse sands, or rich soils containing a just mixture of the earths; and in all cases in which the texture is already sufficiently loose, or the organisable matter sufficiently soluble, the process of torrefaction cannot be useful.

All poor siliceous sands must be injured by it; and here practice is found to accord with theory. Mr. Young, in his Essay on Manures, states, " that 
he found burning injure sand;" and the operation is uever performed by good agriculturists upon siliceous sandy soils, after they have once been bronght into cultivation.

An intelligent farmer in Mount's Bay told me, that he had pared and burned a small field several years ago, which he had not been able to bring again into good condition. I examined the spot, the grass was very poor and scanty, and the soil an arid siliceous sand.

Irrigation or watering land, is a practice, which at first view appears the reverse of torrefaction; and in general, in nature the operation of water is to bring earthy substances into an extreme state of division. But in the artificial watering of meadows, the beneficial effects depend upon many different causes, some chemical, some mechanical.

Water is absolutely essential to vegetation; and when land has heen covered by water in the winter, or in the beginning of spring, the moisture that has penetrated deep into the soil, and even the subsoil, becomes a source of nourishment to the roots of the plant in the summer, and prevents those bad effects that often happen in lands in their natural state, from a long continuance of dry weather.

When the water used in irrigation has flowed over a calcareous country, it is generally found impregrated with carbonate of lime; and in this state it tends, in many instances, to ameliorate the soil. 
Common river water also generally contains a certain portion of organisable matter, which is much greater after rains, than at other times; and which exists in the largest quantity when the stream rises in a cultivated country.

Even in cases when the water used for flooding is pure, and free from animal or vegetable substances, it acts by causing the more equable diffusion of nutritive matter existing in the land; and in very cold seasons it preserves the tender roots and leaves of the grass from being affected by frost.

Water is of greater specific gravity at $42^{\circ}$ Fahrenheit, than at $32^{\circ}$, the freezing point; and hence in a meadow irrigated in winter, the water immediately in contact with the grass is rarely below $40^{\circ}$, a degree of temperature not at all prejudicial to the living organs of plants.

In 1804, in the month of March, I examined the temperature in a water meadow near Hungerford, in Berkshire, by a very delicate thermometer. 'The temperature of the air at seven in the morning was $29^{\circ}$. The water was frozen above the grass. The temperature of the soil below the water in which the roots of the grass were fixed, was $43^{\circ}$.

In general those waters which breed the best fish are the best fitted for watering meadows; but most of the benefits of irrigation may be derived from any kind of water. It is, however, a general principle, that waters containing ferruginous impregnations, though possessed of fertilizing effects, when 
applied to a calcareous soil, are injurious on soils that do not effervesce with acids; and that calcareous waters which are known by the earthy deposit they afford when boiled, are of most use on siliceous soils, or other soils containing no remarkable quantity of carbonate of lime.

The most important processes for improving land, are those which have been already discussed, and that are founded upon the circumstance of removing certain constituents from the soil, or adding others or changing their nature; but there is an operation of very ancient practice still much employed, in which the soil is exposed to the air, and submitted to processes which are purely mechanical, namely, fallowing.

The benefits arising from fallows have been much over-rated. A summer fallow, or a clean fallow, may be sometimes necessary in lands overgrown with weeds, particularly if they are sands which cannot be pared and burnt with advantage; but is certainly unprofitable as part of a general system in hushandry.

It has been supposed by some writers, that certain principles necessary to fertility are derived from the atmosphere, which are exhatisted by a succession of crops, and that these are again supplied during the repose of the land, and the exposure of the pulverized soil to the infiuence of the air; but this in truth is not the case. The earths commonly found in soils cannot be combined with 
more oxygene; none of them unite to azote; and such of them as are capable of attracting carbonic acid, are always saturated with it in those soils on which the practice of fallowing is adopted. The vague ancient opinion of the use of nitre, and of nitrous salts in vegetation, seems to have been one of the principal speculative reasons for the defence of summer fallows. Nitrous salts are produced during the exposure of soils containing vegetable and animal remains, and in greatest abundance in hot weather; but it is probably by the combination of azote from these remains with oxygene in the atmosphere that the acid is formed; and at the expense of an element, which otherwise would have formed ammonia; the compounds of which, as is evident from what was stated in the last Lecture, are much more efficacious than the nitrous compounds in assisting vegetation.

When weeds are buried in the soil, by their gradual decomposition they furmish a certain quantity of soluble matter; but it may be doubted whether there is as much useful manure in the land at the end of a clean fallow, as at the time the vegetables clothing the surface were first ploughed in. Carbonic acid gas is formed during the whole time by the action of the vegetable matter upon the oxygene of the air, and the greater part of it is lost to the soil in which it was formed, and dissipated in the atmosphere. 
The action of the sun upon the surface of the soil tends to disengage the gaseous and the volatile fluid matters that it contains; and heat increases the rapidity of fermentation: and in the suminer fallow, nourishment is rapidly produced, at a time when no vegetables are present capable of absöro: ing it.

Land, when it is not employed in preparing food for animals, should be applied to the purpose of the preparation of mantire for plants; and this is effected by means of green crops, in consequence of the absorption of carbonaceous matter in the carbonic acid of the atmosphere. In a summer's fallow a period is always lost in which vegetables may be raised, either as food for animals, or as nourishment for the next crop'; and the texture of the soil is not so much improved by its exposure as in winter, when the expansive powers of ice, the gradual dissolution of snows, and the alternations from wet to dry, tend to pulverize it, and to mix its different parts together.

In the drill husbandry the land is preserved clean by the extirpation of the wreds by hand, and by raising the crops in rows, which renders the destruction of the weeds much more easy. Manure is supplied either by the green crops themselves, or from the dung of the cattle fed upon them; and the plants having large systems of leaves, are made to alterwate with' those bearing' grain.

$$
\text { A. A. } 2
$$


It is a great advantage in the convertible system of cultivation, that the whole of the manure is employcd; and that those parts of it which are not fitted for one crop, remain as nourishment for another. Thus, in Mr. Coke's course of crops, the turnip is the first in the order of succession; and this crop is manured with recent dung, which immediately affords sufficient soluble matter for its nourishment; and the heat produced in fermentation assists the germination of the seed and the growth of the plant. After turnips, barley with grass seeds is sown; and the land having been little exhausted by the turnip crop, affords the soluble parts of the decomposing manure to the grain. The grasses, rye grass, and clover remain, which derive a small part only of their organized matter from the soil, and probably consume the gypsum in the manure which would be useless to other crops: these plants likewise by their large systems of leaves, absorb a considerable quantity of nourishment from the atmosphere; and when ploughed in at the end of two years, the decay of their roots and leaves affords manure for the wheat crop; and at this period of the course, the woody fibre of the farm-yard manure which contains the phosphate of lime and the other difficultly soluble parts, is broken down: and as soon as the most exhausting crop is taken, recent manure is again applied.

Mr. Gregg, whose very enlightened system of cultivation has been published by the Board of 


\section{7}

Agriculture, and who has the merit of first adopting a plan similar to Mr. Coke's upon strong clays, suffers the ground after barley to remain at rest for two year's in grass; sows' peas and beans on the leys; ploughs in the pea or bean stubble for wheat; and in some instances, follows his wheat crops by a course of winter tares and winter barley, which is eat off in the spring, before the land is sower for turnips.

Peas and beans, in all instances, seem well adapted to prepare the ground for wheat; and in some rich lands, as in the alluvial soil of the Parret, mentioned in the Fourth Lecture, and at the foot of the South Downs in Sussex, they are raised in alternate crops for years together. Peas and beans contain, as appears from the analyses in the Third Lecture, a small quantity of a matter analogous to albumen; but it seems that the azote which forms a constituent part of this matter, is derived from the atmosphere. The dry bean leaf, when burnt, yields a smell approaching to that of decomposing animal matter; and in its decay in the soil, may furnish principles capable of becoming a part of the gluten in wheat.

Though the general composition of plants is very analogons, yet the specific difference in the products of many of them, and the facts stated in the last Lecture, prove that they must derive different materials from the soil; and though the vegetables having the smallest systems of leaves will propor- 
tionably most exhaust the soil of common nutritive matter, yet particular vegretables when their produce is carried off, will require peculiar principles to be supplied to the land in which they grow. Strawberies and potatoes at fipst produce luxuriantly in virgin mould, recently turned up from pasture; but in a few years they degenerate, and require a fresh soil; and the organization of these plants is such, as to be constantly producing the migration of their layers: thus the strawberry, by its long shoots, is constantly endeavouring to occupy a new soil; and the fibrous radicles of the potatoe produce bulbs at a considerable distance from the parent plant. Lands, in a course of years, often cease to afford good cultivated grasses; they became (as it is popularly said) tired of them; and. one of the probable reasons for this was stated in the last Lecture:

The most remarkable instance of the powers of vegetables to exhaust the soil of certain principles necessary to their growth is found in certain funguses. Mushrooms are said never to rise in two successive seasons on the same spot; and the production of the phænomena called fairy rings has been ascribed by $\mathrm{Dr}$. Wollaston to the power of the peculiar fungus which forms it, to exhaust the soil of the nutriment necessary for the growth of the species. The consequence is, that the ring: annually extends; for no seeds will grow where their parents grew. before them; and the interior 
part of the circle has been exhausted by preceding crops ; but where the fungus has died, nourishment is supplied for grass, which ustally rises within the circle, coarse, and of a dark green colour.

When cattle are fed upon land not benefited by their manure, the effect is always an exhaustion of the soil ; this is particularly the case where carrying horses are kept on estates; they consume the pasture during the night, and drop the greatest part of their manure during their labour in the daytime.

The exportation of grain from a country, unless some articles capable of becoming manure are introduced in compensation, must ultimately tend to exhaust the soil. Some of the spots, now desart sands in northern Africa, and Asia Minor, were anciently fertile. Sicily was the granary of Italy; and the quantity of corn carried off from it by the Romans, is probably a chief cause of its present sterility. In this island, our commercial system at present has the effect of affording substances, which in their use and decomposition nust enrich the land. Corn, sugar, tallow, oil, skins, furs, wine, silk, cotton, \&c. are imported, and fish are supplied from the sea. Amongst our numerous exports woollen, and linen, and leather goods, are almost the only substances which contain any nutritive materials derived from the soil.

In all courses of crops it is necessary that every part of the soil should be made as useful as possible 
to the different plants; but the depth of the furrow in ploughing must depend upon the nature of the soil, and of the subsoil. In rich clayey soils the furrow can scarcely be too deep; and even in sands, unless the subsoil contains some principles noxious to vegetables, the same practice should be adopted. When the roots are deep, they are less liable to be injured, either by excess of rain, or drought; the layers shoot forth their radicles into every part of the soil; and the space from which the nourishment is derived is more considerable, than when the seed is superficially inserted in the soil.

There has been much difference of opinion with respect to permanent pasture; but the advantages or disadvantages can only be reasoned upon according to the circumstances of situation and climate. Under the circumstances of irrigation, lands are extremely productive, with comparatively little labour; and in climates where great quantities of rain falls, the natural irrigation produces the same efferts as artificial. When hay is in great demand, as sometimes happens in the neighbourhood of the metropolis, where manure can be easily procured, the application of it to pasture is repaid for by the increase of crop; but top-dressing grass land with animal or vegetable manure, cannot be recommended as a general system. Dr. Coventry very justly observes, that there is a greater waste of the manure in this case, than when it is ploughed into the soil for seed crops. 


\section{1}

The loss by exposure to the air, and the sunshine, offer reasons in addition to those that have been already quoted in the Sixth Lecture, for the application of manure even in this case, in a state of incipient, and not completed fermentation.

Very little attention has been paid to the nature of the grasses best adapted for permanent pasture. The chief circumistance which gives value to a grass, is the quantity of nutritive matter that the whole crop will afford; but the time and duration of its produce are likewise points of great iniportance; and a grass that supplies green nutriment throughout the whole of the year, may be more valuable than a grass which yields its produce only in summer, though the whole quantity of food supplied by it should be much less.

The grasses that propagate themselves by layers, the different species of Agrostis, supply pasture throughout the year; and, as it has been mentioned on a former occasion, the concrete sap stored up in their joints, renders them a good food even in winter. I saw four square yards of fiorin grass cut in the end of January, this year, in a meadow exclusively appropriated to the cultivation of fiorin, by the Countess of Hardwicke, the soil of which is a damp stiff clay. They afforded 28 pounds of forder; of which 1000 parts afforded, 64 parts of nutritive matter, consisting nearly of one-sixth of sugar, and five-sixths of mucilage, with a little cxtractive matter. In another experiment, four 
square yards gave 27 pounds of grass. The quality of this grass is inferior to that of the fiorin referred to in the Table, in the latter part of the Third Lecture, which was cultivated by Sir Joseph Banks in Middlesex, in a much richer soil, and cut in December.

The fiorin grass, to be in perfection, requires a moist climate or a wet soil, and it grows luxuriantly in cold clays unfitted for other grasses. In light sands, and in dry situations, its produce is much inferior as to quantity and quality.

'The common grasses, properly so called, that afford most nutritive matter in early spring, are the vernal meadow grass, and meadow fox-tail grass; but their produce at the time of flowering and ripening the seed are inferior to that of a great number of other grasses ; their latter-math, is, however, abundant.

Tall fescue grass stands highest, according to the experiments of the Duke of Bedford, of any grass, properly so called, as to the quantity of nutritive matter afforded by the whole crop when cut at the time of flowering; and meadow cat's-tail grass affords most food when cut at the time the seed is ripe; the highest latter-math produce of the grasses examined in the Duke of Bedford's experiments is from the sea meadow grass.

Nature has provided in all permanent pastures a mixture of various grasses, the produce of which differs at different seasons. Where pastures are to 


\section{3}

be made artificially, such a mixture ought to be imitated; and, perhaps, pastures superior to the natural ones may be made by selicting due proportions of those species of grasses fitted for the soil, which afford respectively the greatest quantities of spring, summer, latter-math, and winter produce; a reference to the details in the Appendix will shew that such a plan of cultivation is very practicable.

In all lands, whether arable or pasture, weeds of every description should be rooted out before the seed is ripe; and if they are suffered to remain in hedge rows, they should be cut when in flower, or before, and made into heaps for manure; in this case they will furnish more nutritive matter in their decomposition; and their increase by the dispersion of seeds will be prevented. The farmer, who suffers weeds to remain till their ripe seeds are shed, and scattered by the winds, is not only hostile to his own interests, but is likewise an enemy to the public: a few thistles neglected will soon stock a farm; and by the light down which is attached to their seeds, they may be distributed over a whole country. Nature has provided such ample resources for the continuance of even the meanest vegetable tribes, that it is very difficult to ensure the destruction of such as are hostile to the agriculturist, even with every precaution. Seeds excluded from the air, will remain for years inactive in the 
soil,* and yet germinate under favourable circumstances; and the different plants, the seeds of which, like those of the thistle and dandelion, are furnished with beards or wings, may be brought from an immense distance. The fleabane of Canada has only lately been found in Europe; and Linnæus "supposes that it has been transported from America, by the very light downy plumes with which the seed is provided.

In feeding cattle with green food, there are many advantages in soiling, or supplying them with food, where their manure is preserved, out of the field; the plants are less injured when cut, than when torn or jagged by the teeth of the cattle, and no food is wasted by being trodden down. They are likewise obliged to feed without making selection; and in consequence the whole food is consumed: the attachment, or dislike to a particular kind of food exhibited by animals, offers no proof of its nutritive powers. Cattle at first refuse linseed cake,

* The appearance of seeds in places where their parent plants are not found may be easily accounted for from this circumstance and other circumstances. Many seeds are carried from island to island by currents in the sea, and are defended by their hard coats from the immediate action of the water. West Indian seeds (of this description) are often found on our coasts, and readily germinate; their long voyage having been barely sufficient to afford the cotyledon its due proportion of moisture. Other seeds are carried indigested in the stomach of birds, and 
one of the most nutritive substances on which they can be fed.*

When food artificially composed is to be given to

supplied with food at the moment of their deposition. The light sceds of the mosses and lichens probably float in every part of the atmosphere, and abound on the surface of the sea.

* For the following observations on the selection of different kinds of common food by sheep and cattle, I am obliged to Mr. George Sinclair.

" Lolium perenne, rye grass. Sheep eat this grass when it is in the early stage of its growth, in preference to most others; but after the seed approaches towards perfection, they leave it for almost any other kind. A field in the Park at Woburn was laid down in two equal parts, one part with rye grass and white clover, and the other part with cock's-foot and red clover: from the spring till midsummer the sheep kept almost constantly on the rye grass; but after that time they left it, and adhered with equal constancy to the cock's-foot during the remainder of the season.

Dactylis glomerata, cock's-foot. Oxen, horses, and sheep, eat this grass readily. The oxen continue to eat the straws and flowers, from the time of flowering till the time of perfecting the seed; this was exemplified in a striking manner in the field before alluded to. The oxen generally kept to the cock's-foot and red clover, and the sheep to the rye-grass and white clover. In the experiments published in the Amœnitates Academicæ, by the pupils of Linneus, it is asserted that this grass is rejected by oxen; the above fact, however, is in contradiction of it.

Alopecurus pratensis, meadow fox-tail. Sheep and horses seem to have a greater relish for this grass than oxen. It delights in a soil of intermediate quality as to moisture or dryness, and is very productive. In the water-meadow at Priestley, it consti- 
cattle, it should be brought as nearly as possible to the state of natural food. Thus, when sugar is given to them, some dry fibrous matter should be

tutes a considerable part of the produce of that excellent mea dow. It there keeps invariably possession of the top of the ridges, extending generally about six feet from each side of the watercourse; the space below that, to where the ridge ends, is stocked with cock's-foot, the rough stalked meadow grass, Festuca pratensis, Festuca duriuscula, Agrostis stolonifera, Agrostis palustris, and sweet-scented vernal grass, with a sinall admixture of some other kinds.

Phleum pratense, meadow cat's-tail. This grass is eaten without reserve. by oxen, sheep, and horses. Dr. Pulteney says, that it is disliked by sheep; but in pasfures where it abounds, it does not appear to be rejected by these animals; but eaten in common with such others as are growing with it. Hares are remarkably fond of it. The Plleum nodosum, Phleum alpinum, $\boldsymbol{P}$ oa fertilis, and $\boldsymbol{P}$ oa compressa, were left untouched, although they were closely adjoining to it. It seems to attain the greatest perfection in a rich deep loam.

Agrostis stolonifera, fiorin. In the Experiments detailed in the Amoenitates Academicx, it is said, that horses, sheep, and oxen, eat this grass readily. On the Duke of Bedford's farm at Mauldell, fiorin hay was placed in the racks before horses in small distinct quantities; alternately with common hay; but no decided preference for either was manifested by the horses in this trial. But that cows and horses prefer it to liay, when in a green state, seems fully proved by Dr. Richardson, in his several publications on Fiorin ; and of its productive powers in England (which has been doubted by some); there are satisfactory proofs. Lady Hardwicke has given an account of a trial of this grass, wherein twenty-three milch cows, and one young horse, besides a 
mixed with it, such as chopped straw, or dry withered grass, in order that the functions of the stomach and bowels may be performed in a natural

number of pigs, were kept a fortnight on the produce of one acre.

Poa trivialis, rough-stalked meadow. Oxen, horses, and sheep, eat this grass with avidity. Hares also eat it; but they give a decided preference to the smooth-stalked meadow-grass, to which it is, in many respects, nearly allied.

Poa pratensis, smooth-stalked meadow grass. Oxen and horses are observed to eat this grass in common with others; but sheep rather prefer the hard fescue, and sheeps' fescue, which affect a similar soil. This species exhausts the soil in a greater degree than almost any other species of grass; the roots being numerous, and powerfully creeping, become in two or three years completely matted together; the produce diminishes as this takes place. It grows common in some meadows, dry banks, and even on walls.

Cynosurus cristatus, crested dog's-tail grass. The South Down sheep, and deer, appear to be remarkably fond of this grass : in some parts of Woburu Park this grass forms the principal part of the herbage on which these animals chiefly browse; while another part of the Park, that contains the Agrostis capillaris, Agrostis pumilis, Festuca ovina, Festuca duriuscula, and Festuca cambrica, is seldom touched by them; but the Welch breed of sheep almost constantly browse upon these, and neg. lect the Cynosurus cristatus, Lolium perenne, and Poa trivialis.

Agrostis vulgaris (capillaris, Linn.), fine bent; commou bent. This is a very common grass on all poor dry sandy soils. It is not palatable to cattle, as they never eat it readily, if any other. kinds be within their reach. The Welch sheep, however, prefer it, as I before observed; and it is singular, that those 
manner. The principle is the same as that of the practice alluded to in the Third Lecture, of giving chopped straw with barley.

sheep being bred in the park, when some of the best grasses are equally within their reach, should still prefer those grasses which naturally grow on the Welch mountains; it seems to argue that such a preference is the effect of some other cause, than that of labit.

Festuca ovina, sheeps' fescue. All kinds of cattle relish this grass; but it appears from the trial that has been made with it on clayey soils, that it continues but a short time in possession of such, being soon overpowered by the most luxuriant kinds. On dry shallow soils that are incapable of producing the larger sorts, this should form the principal crop, or rather the whole; for it is seldom or ever, in its natural state, found intimately mixed with others; but by itself.

F'estuca durinscula, hard fescue grass. This is certainly one of the best of the dwarf soris of grasses. It is grateful to all kinds of cattle; hares are very fond of it : they cropped it close to the roots, and neglected the Festuca ovina, and Festuca rubra, which were contiguous to it. It is present in most good meadows and pastures.

Festuca pratensis, meadow fescue. This grass is seldom absent from rich meadows and pastures; it is observed to be highly grateful to oxen, sheep, and horses, particularly the former. It appears to grow most luxuriantly when combined with the hard fescue, and Poa trivialis.

Avena eliator, tall oat-grass. This is a very productive grass, frequent in meadows and pastures, but is disliked by cattle, particularly by horses; this, perfectly, agrees with the small portion of nutritive matter which it affords. It seems to thrive best on a strong tenacious clay.

Avena flavescens, yellow oat-grass. This grass seems partial to dry soils, and meadows, and appears to be eaten by sheep 


\section{9}

In washing sheep, the use of water containing carbonate of lime should be avoided; for this substance decomposes the yolk of the wool, which is an animal soap, the natural defence of the wool;

and oxen, equally with the meadow barley, crested dog's tail and sweet-scented vernal grasses, which naturally grow in company with it. It nearly doubles the quantity of its produce by the application of calcareous manure.

Holcus lanatus, meadow soft grass. This is a very common grass, and grows on all soils, from the richest to the poorest. It affords an abundance of seed, which is light, and easily dispersed by the wind. It appears to be generally disliked by all sorts of cattle. The produce is not so great as a view of it in fields would indicate; but being left almost entirely untouched by cattle, it appears as the most productive part of the herbage. The hay which is made of it, from the number of downy hairs which cover the surface of the leaves, is soft and spongy, and disliked by cattle in general.

Anthoxanthum odoratum, sweet-scented vernal grass. Horses, oxen; and sheep, eat this grass; though in pastures where it is combined with the mearlow fux-tail, and white clover, cock'sfoot, rough-stalked meadow, it is left untouched, from which it would scem unpalatible to cattle. Mr. Grant, of Leighton, laid down one half a fiel of a considerable extent with this grass, combined with white clover. The other half of the firld with fox-tail and red clover. The sheep won!d not touch the sweet-scented vernal, but kept consrantly upon the fox-tail. The writer of this, saw the field when the grasses were in the highest state of perfection; and harcily any thing could be more satisfactory. Equal quantities of the seeds of white clover, were sown with each of the grasses; but from the dwarf nature , of the sweet-scented vernal grass, the clover mixed with. it had attained to greater luxuriunce, than that mixed with the meadow foxtail." 
and wool often washed in calcareous water, becomes rough and more brittle. The finest wool, such as that of the Spanish and Saxon sheep, is most abundant in yolk. M. Vauquelin has analysed several different species of yolk, and has found the principal part of all of them a soap, with a basis of potassa, (i. e. a compound of oily matter and potassa), with a little oily matter in excess. He has found in them, likewise, a notable quantity of acetate of potassa, and minute quantities of carbonate of potassa and muriate of potassa, and a peculiar odorous animal matter.

M. Vauquelin states, that he found some specimens of wool lose as much as 45 per cent. in being deprived of their yolk; and the smallest loss in his experiments was 35 per cent.

The yolk is most useful to the wool on the back of the sheep in cold and wet seasons; probably the application of a little soap of potassa, with excess of grease to the sheep brought from warmer climates in our winter, that is, increasing their yolk artificially, might be useful in cases where the fineness of the wool is of great importance. A mixture of this kind is more conformable to nature, than that ingeniously adopted by Mr. Bakewell; but at the time his labours commenced, the chemical nature of the yolk was unknown. 
I have now exhausted all the subjects of discussion, which my experience or information has been able to supply on the connexion of chemistry with agriculture.

I venture to hope, that some of the views brought forward, may contribute to the improvement of the most important and useful of the arts.

I trust that the enquiry will be pursued by others; and that in proportion as chemical philosophy advances towards perfection, it will afford new aids to agriculture.

There are sufficient motives connected both with pleasure and profit, to encourage ingenious men to pursue this new path of investigation. Science cannot long be despised by any persons as the mere speculation of theorists; but must soon be considered by all ranks of men in its true point of view, as the refinement of common sense, guided by experience, gradually substituting sound and rational principles, for vague popular prejudices.

The soil offers inexhaustible resources, which, when properly appreciated and employed, must increase our wealth, our population, and our physical strength.

We possess advantages in the use of machinery, and the division of labour, belonging to no other 
nation. And the same energy of character, the same extent of resources which have always distinguished the people of the British Islands, and made thern excel in arms, commerce, letters, and philosophy, apply with the happiest effect to the improvement of the cultivation of the earth. Nothing is impossible to labour, aided by ingenuity. The true objects of the agriculturist are likewise those of the patriot. Men value most what they have gained with effort; a just confidence in their own. powers results from success; they love their country better; because they have seen it improved by their own talents and industry; and they indentify with their interests, the existence of those institutions which have afforded them security, independence, and the multiplied enjoyments of civilized life. 


\section{APPENDIX.}

AN

\section{ACCOUNT OF THE RESULTS}

OF

EXPERIMENTS ON THE PRODUCE AND NUTRITIVE

QUALITIES OF DIFFERENT GRASSES,

AND OTHER PLANTS,

USED AS THE FOOD OF ANIMALS.

INSTITUTED BY

JOHN, DUKE OF BEDFORD. 


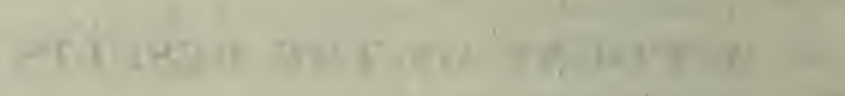

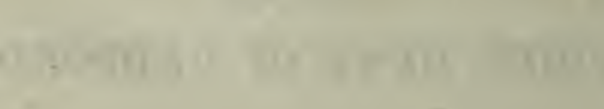




\section{INTRODUCTION}

\section{BYTHE EDITOR,}

OF the 215 proper grasses which are capable of being cultivated in this climate two only have been employed to any extent for making artificial pastures, rye grass and cock's-foot grass; and their application for this purpose seems to have been rather the result of accident, than of any proofs of their superiority over other grasses.

A knowledge of the comparative merits and value of all the different species and varieties of grasses cannot fail to be of the highest importance in practical agriculture. The hope of obtaining this knowledge was the motive that induced the Duke of Bedford to institute this series of experiments.

Spots of ground, each containing four square feet, in the garden at Woburn Abbey, were enclosed by boards in such a manner that there was no lateral communication between the earth included by the boards, and that of the garden. The soil was removed in these enclosures, and new. 
soils supplied; or mixture of soils were made in them, to furnish as far as possible to the different grasses those soils which seem most favourable to their growth; a few varicties being adopted for the purpose of ascertaining the effect of different soils on the same plant.

The grasses were either planted or sown, and their produce cut and collected and dried, at the proper seasons, in summer and autumn, by Mr. Sinclair, his Grace's gardener. For the purpose of determining as far as possible the nutritive powers of the different species, equal weights of the dry grasses or vegetable substances were acted upon by hot water till all their soluble parts were dissolved; the solution was then evaporated to diyness by a gentle heat in a proper stove, and the matter obtained carefuliy woigled. This part of the process was liken ise courlucted with much address and inteliigence by Mir. Sinclair, by whom all the following details and calculations are furnished.

'The iry extracts supposed to contain the nutritive matter of the grasses, were sent to me for chemical examination. The composition of some of them is stated in the table, page 150 ; I shall offer a few chemical observations on others at the end of this Appendix. It will be found from the general conclusions, that the mode of determining the nutritive power of the grasses, by the quantity of matter they contain soluisle in water, is sufficiently accurate for all the purposes of agricultural investigation. 


\section{7}

BOOKS QUOTED IN THE FOLLOWING PAGES.

Curt. Lond.-Flora Londinensis. By William Curtis, 2 vols. London 1798, fol.

Fl. Dan.-Flora Danica, or Icones Plantarum sponte nascentium in Regnis Daniæ et Norvegiæ, editæ a Ge. Æder. Hafuix 1761, fol.

Engl. Bot._English Botany, by J. E. Suith, M. D; the Figures by J. Sowerby, London 1790, 8 vo.

W. B.--Botanical Arrangewents. By Dr. Withering. London 1801,4 vol.

Huds.-Hudsoni Flora Anglica, 1778. vol. ii.

Host. G. A.-Nic. 'Thomæ Host Icones et Descriptiones Graminum Austriacorum, vol, i.-iii. Vindobonæ, 1801, fol.

Hort. Kew.-Hortus Kewensis. By W. J. Aiton, vol, i. London 1810. 
Details of Experiments on Grasses. By GEORGE SINCLAIr, Gardener to his Grace the Duke of BedFord, and Corresponding Member of the Horticultural Society of Edinburgh.

I. Anthoxanthum odoratum. Engl. Bot. 647.-Curt. Lond. Sweet-scented vernal grass. Nat. of Britain.

At the time of flowering, the produce from the space of an acre equal to ,000091827364 of a brown sandy loam with manure, is

Grass 11 oz. 8 dr.* The produce per acre - - $125235 \quad 0=7827 \quad 2 \quad 0$ $80 \mathrm{dr}$. of grass weigh when dry - - $-21 \frac{x}{2} \mathrm{dr}$. $336560=2103 \quad 8 \quad 0$ The produce of the space, ditto - $-49.1 \frac{8}{10}$

The weight lost by the produce of one acre in drying $572310 \quad 0$ $64 \mathrm{dr}$. of grass afford of nutritive matter $1 \mathrm{dr}$.

The produce of the space, ditto - $\quad-2.3 \frac{5}{10}$

oz. or lbs. per acre

At the time the seed is ripe the produce is

Grass, $9 \mathrm{oz}$. The produce

per acre - $\quad-98010 \quad 0=612510 \quad 0$

* The weight is avoirdupoise; lbs. pounds, oz. ounces, dr. drachms. The weights not named are, quarters of drachms, and fractions of quarters of drachms; thus $7.1 \frac{1}{4}$ means 7 drachms 1 quarter of a drachm and $\frac{x}{4}$ of a quartes. 
oz. or lbs. per acre

$80 \mathrm{dr}$. of grass weigh

when dry - $-24 \mathrm{dr}$.

The produce of the space, ditto - - 43 $\left.\frac{\mathrm{r}}{16}\right\}$

The weight lost by the produce of one acre in drying

$64 \mathrm{dr}$. of grass afford of nutritive matter $3.1 \mathrm{dr}$. The produce of the space, ditto - $-7.1 \frac{1}{4}$

The weight of nutritive matter which is lost by taking the crop at the time the grass is in fiower, exceeding half of its value $\quad \begin{array}{lll}188 & 12 \quad 4\end{array}$

The proportional value which the grass at the time of flowering bears to that at the time the seed is ripe, is as 4 to 13.

The latter-math produce is

Grass, $10 \mathrm{oz}$. The produce

$$
\text { per acre - - } \quad 108900 \quad 0=6806 \quad 4 \quad 0
$$

$64 \mathrm{dr}$. of grass afford nutri-

tive matter, $2.1 \mathrm{dr}$. $\quad 3828 \quad 8=299 \quad 4 \quad 8$

The proportional value which the grass of the lattermath bears to that, at the time the seed is ripe, is nearly as 9 to 13.

The smallness of the produce of this grass renders it improper for the purpose of hay; but its early growth, and the superior quantity of nutritive matter which the latter-math affords, compared with the quantity afforded by the grass at the time of flowering, causes it to rank high as a pasture grass, on such soils as are well fitted for its growth; such are peat-bogs, and lands that are deep and moist. 
1I. Holcus odoralus. Host. G. A. Growing.in woods. Sweet-scented soft grass. Nat. of Germany. Flo. Ger.-H. borealis. Growing in moist meadows.

At the time of flowering, the produce from a rich sandy loam is

oz. or lbs. per acre

Grass, 14 oz. The produce

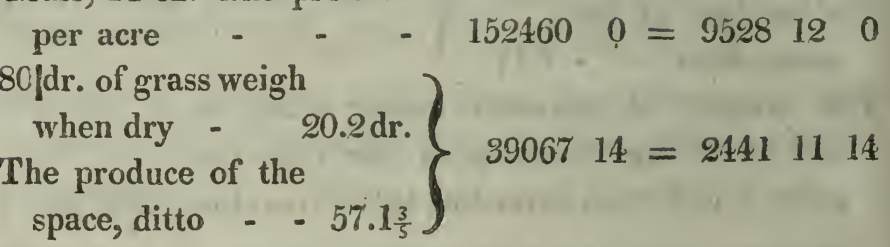

The weight lost by the produce of one acre in drying $7087 \quad 0 \quad 2$

$64 \mathrm{dr}$. of grass afford of nutritive matter $4.1 \mathrm{dr}$.

The produce of the space, ditto $\quad-14.3 \frac{\mathrm{J}}{2}$

$1012413=61015 \quad 5$

At the time the seed is ripe the produce is

Grass, 40 oz. The produce per acre $\quad-\quad-435600 \quad 0=27225 \quad 0 \quad 0$

$64 \mathrm{dr}$. of grass weigh

when dry - $28 \mathrm{dr}$.

The produce of the space, ditto - $-224 \mathrm{dr}$.)

The weight lost by the produce of one acre in drying $17690 \quad 4 \quad 0$ $64 \mathrm{dr}$. of grass afford nutritive matter - $5.1 \mathrm{dr}$. The proauce of the space, ditto - 52.2dr.

$3573213=2233 \quad 413$ 
'The weight of nutritive matter which is lost

by taking the crop at the time the grass is in flower, being more than half of its value

- 1600810 ,

The proportional value which the grass at the time of flowering bears to that at the time the seed is ripe is as 17 to 21.

The produce of latter-math is

Grass, $25 \mathrm{oz}$. The pro-

oz. or lbs. peracre

duce per acre - $\quad-272250 \quad 0=1701510 \quad 0$ $64 \mathrm{dr}$. of grass afford

of nutritive matter $4.1 \mathrm{dr} . \quad 18079 \quad 1=112915 \quad 1$

The grass of the latter-math crop, and of the crop at the time of flowering, taking the whole quantity, and their relative proportions of nutritive matter, are in value nearly as 6 to 10 ; the value of the grass at the time the seed is ripe, exceeds that of the latter-math, in proportion as 21 to 17 .

Though this is one of the earliest of the flowering grasses, it is tender, and the produce in the spring is inconsiderable. If however, the quantity of nutritive matter which it affords, be compared with that of any of those species which flower nearly at the same time, it will be found greatly superior. It serds forth but a smail number of flower stalks, which are of a slender'structure compared to the size of the leaves. This will account in a great measure for the equal quantities of nutritive matter afforded by the grass at the time of flowering, and the lattermath. 
III. Cynosurus cceruleus. Engl. Bot. 1613. Host. G A. 2. t. 98.

Blue more-grass. Nat of Britain. Sesleria cærulea.

At the time the seed is ripe the produce from a light sandy soil is

Grass, $10 \mathrm{oz}$. The produce

$$
\text { oz. or lbs. per acre }
$$

$64 \mathrm{dr}$. of grass afford of nu-

tritive matter $3.3 \mathrm{dr}$.

$108900 \quad 0=6806 \quad \& \quad 0$

The produce of this grass is greater than its appearance would denote; the leaves seldom attain to more than four or five inches in length, and the flower stalks seldom arise to more. Its growth is not rapid after being cropped, nor does it seem to withstand the effects of frost, which if it happen to be severe and early in the spring, checks it so much as to prevent it from flowering for that season; otherwise the quantity of nutritive matter which the grass affords (for the straws are very inconsiderable, ) would rank it as a valuable grass for permanent pasture.

IV. Alopecurus pratensis. Curt. Lònd. Alo. myosuroides. Meadow fox-tail-grass. Nat. of Britain. Eng. Bot. S48.

At the time of flowering, the produce from the clayey loam is

Grass, 30 oz. The produce per acre - - $326700 \quad 0=20418120$ $80 \mathrm{dr}$. of grass weigh when dry $24 \mathrm{dr}$. The produce of the space, ditto 
oz. or lbs. per acre

The weight lost by the produce of one acre in drying 1429320 $6 \mathrm{dr}$. of grass afford of nutritive matter $1.2 \mathrm{dr}$. The produce of the space, ditto $11.1 \mathrm{dr}$.

- 1429320

The produce from a sandy loam is

Grass, $12 \mathrm{oz} .8 \mathrm{dr}$. The produce per acre $1361250=8507130$ $\mathrm{SO} \mathrm{dr}$. of grass weigh when

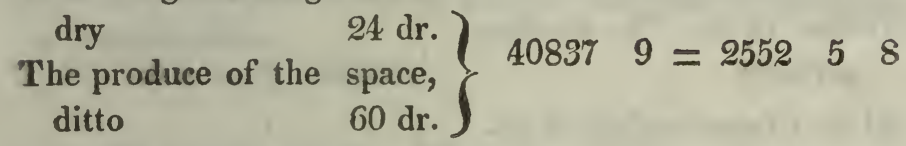
$60 \mathrm{dr}$. of grass afford of nutritive matter $1 \mathrm{dr}$. The produce of the space, ditto $3.0 \frac{\pi}{2}$

$212615=1321415$

At the time the seed is ripe, the produce from the clayey loam is

Grass, $19 \mathrm{oz}$. The produce per acre - $\quad-206910 \quad 0=1293114 \quad 0$ $80 \mathrm{dr}$. of grass weigh when $\left.\begin{array}{cc}\begin{array}{c}\text { dry } \\ \text { The produce of the space, } \\ \text { ditto }\end{array} \\ 136.3 \frac{\mathrm{I}}{5}\end{array}\right\} \begin{array}{lll}5819 & 52 & 2\end{array}$

The weight lost by the produce of one acre in drying - $\quad$ - $\quad 7111 \quad 814$ $64 \mathrm{dr}$. of grass afford of nutritive matter $2.1 \mathrm{~d}$. The produce of the space, ditto 
The weight of nutritive oz. or lbs. per acre matter which is lost by leaving the crop till the seed be ripe. beirg one twenty-fifth part of its value

The proportional value which the grass, at the time of flowering, bears to that at the time the seed is ripe, is as 6 to 9 .

The latter-math produce, from the clayey loam is Grass, 12 oz. The produce per acre - - $1306800=816780$

$64 \mathrm{dr}$. of grass afford of nutritive matter $2 \mathrm{dr}$.
The produce of the space,
ditto

The proportional value which the whole of the latter-math crop bears to that at the time the seed is ripe, is as 5 to 9 , and to that at the time of flowering, proportionably - as 13 to 24 .

The above statement clearly shews that there is nearly three-fourths of produce greater from a clayey luam than from a sandy soil, and the grass from the latier is comparatively of less value, in proportion as 4 to 6 . The straws produced by tiie sandy soil are deficient in number, and in every respect less than those from the clayey loam; which will account for the unequal quantities of nutritive matter afforded by them; but the proportional value in which the grass of the latter-math exceeds that of the crop at the time of flowering, is as 4 to 3 : a difference which appears extraordinary, when the quantity of 
flower-stalks which are in the grass at the time of flowering is considered. In the Anthoxanthum odoratum the proportional difference between the grass of these crops is still greater, nearly as 4 to 9 ; in the $P$ or pratensis they are equal; but in all the latter flowering grasses experio mented upon, the flowering straws of which resemble those of the Alopecurus pratensis or Anthoxanthum odoratum, the greater proportional value is always on the contrary found in the grass of the flowering crop. Whatever the cause may be, it is evident that the loss sustained by taking the crops of these grasses at the time of flowering is considerable.

V. Alopecurus alpinus. Engl. Bot. 1126.

Alpine fox-tail grass. Nat. of Scotland.

At the time of flowering, the produce from a sandy loam with a small portion of manure, is

oz. or lbs. peracre

Grass, $8 \mathrm{oz}$. The produce

per acre - - $\quad 87120 \quad 0=5445 \quad 5 \quad 0$

$60 \mathrm{dr}$. of grass weigh when

The produce of the $16 \mathrm{dr}$.

space, ditto - $34_{\frac{2}{16}}$

The weight lost by the pro-

duce of one acre in drying

$64 \mathrm{dr}$. of grass afferd of nu-

$t$ ritive matter $1 \mathrm{dr}$.

The produce of the

space, ditto - $2 \mathrm{dr}$.

$232320=1452 \quad 0 \quad 0$

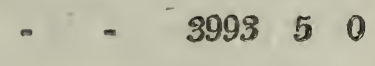

$13614=8514$ 
VI. Poa alpina. Engl. Bot. 1003. Flo. Dan. 107. Alpine meadow grass. Nat. of Scotland.

At the time of flowering, the produce from a light sandy loam, is

Grass, 8 oz. The produce

oz. or lbs. per acre

per acre - $\quad-\quad 87120 \quad 0=5445 \quad 0 \quad 0$

$64 \mathrm{dr}$. of grass afford of

nutritive matter - $1.2 \mathrm{dr} . \quad 204114=127914$

VII. Avena pubescens. Engl. Bot. 1640. Host. G. A. 2, t. 50.

Downy oat grass. Nat. of Britain.

- At the time of flowering, the produce from a rich sandy soil, is

Grass, $23 \mathrm{oz}$. The produce

per acre - - $250470 \quad 0=15654 \quad 6 \quad 0$

$80 \mathrm{dr}$. of grass weigh when

$\left.\begin{array}{l}\text { dry }-30 \mathrm{dr} . \\ \text { The produce of the }\end{array}\right\} 93926 \quad 0=5870 \quad 6 \quad 4$ space, ditto - $138 \mathrm{dr}$.

The weight lost by the produce of one acre in drying - - $\quad$ - 97831512 $64 \mathrm{dr}$. of grass afford of nutritive matter $1.2 \mathrm{dr}$. The produce of the space, ditto $\quad 8.2 \frac{2}{16}$

$58700=36614 \quad 6$

At the time the seed is ripe, the produce is

Grass, $10 \mathrm{oz}$. The produce

per acre $\quad-\quad 108900 \quad 0=680640$ 
oz. or lbs. per acre

$80 \mathrm{dr}$. of grass weigh when

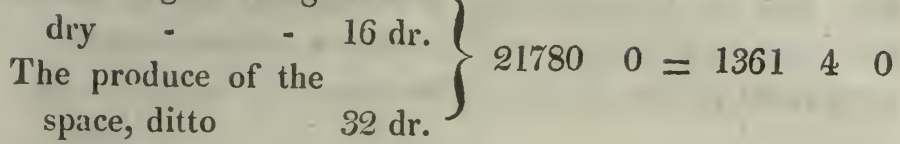

The weight lost by the pro-

duce of one acre in drying

- $\quad-544500$

$64 \mathrm{dr}$. of grass afford of nu-

tritive matter

$2 \mathrm{dr}$.

The produce of the space, ditto - $5 \mathrm{dr}$.

The weight of nutritive matter which is lost

by leaving the crop till the seed be ripe,

being more than half of its value - -

$154 \quad 6 \quad 3$

The proportional value which the grass, at the time of flowering, bears to that at the time the seed is ripe, is as 6 to 8.

The produce of latter-math is

Grass, $10 \mathrm{oz}$. The produce

per acre - $\quad-108900 \quad 0=6806 \quad 4 \quad 0$

$64 \mathrm{dr}$. of grass afford of nu- -

tritive matter - $2 \mathrm{dr} . \quad 34032=212110$.

The proportional value which the grass, at the time of flowering, bears to that of the latter-math, is as 6 to 8 . The grass of the seed-crop, and that of the latter-math, are of equal value.

The downy hairs which cover the surface of the leaves of this grass, when growing on poor light soils, almost entirely disappear when it is cultivated on a richer soil. It possesses several good qualities which recommend it to particular notice; it is hardy, early, and more productive than many others which affect similar soils and situations. Its growth, after being cropped, is tolerably rapid,

C $\mathbf{C} 2$ 
although it does not attain to a great length if left grow: ing; like the $\boldsymbol{P}$ oa pratensis, it sends forth flower stalks but 'once in a season, and it appears well calculated for permanent pasture on rich light soils.

VIII. Poa pratensis. Curt. Lond. Engl. Bot. 1073. Smooth stalked meadow grass. Nat. of Britain.

At the time of flowering, the produce from a mixture of bog-earth and clay, is

Grass, $15 \mathrm{oz}$. The produce

oz. or lbs. per acre

$$
\text { per acre - } \quad-163350 \quad 0=1020960
$$

$80 \mathrm{dr}$. of grass weigh when

dry - $\quad 22.2 \mathrm{dr}$. The produce of the space, ditto - $67.2 \mathrm{dr}$.

$$
45942 \quad 3=2871 \quad 6 \quad 3
$$

The weight lost by the produce of one acre in drying $64 \mathrm{dr}$. of grass afford of nutritive matter $1.3 \mathrm{dr}$.

The produce of the space, ditto $\quad 6.2 \frac{\pi}{16}$

$44669=27929$

At the time the seed is ripe, the produce is

Grass, $12.8 \mathrm{oz}$. The produce

peracre - - $1361250=8507130$ $80 \mathrm{dr}$. of grass weigh when dry $32 \mathrm{dr}$. The produce of the space, ditto - $80 \mathrm{dr}$.

$54450=340320$

The weight lost by the produce of one acre in drying $\quad$ - 5104110 
oz. or lbs. per acre

$64 \mathrm{dr}$. of grass afford of nutritive matter $1.2 \mathrm{dr}$.

The produce of the space, ditto - - $-4.2 \frac{3}{16}$

$31906=19960$

The weight of nutritive matter which is lost by

leaving the crop till the seed be ripe, being nearly one fourth of its value

$7912 \cdot 9$

The produce of latter-math is

Grass, $6 \mathrm{oz}$. The produce

per acre - - $65340 \quad 0=408312 \quad 0$

$64 \mathrm{dr}$. of grass afford of nutritive

matter $\quad 1.3 \mathrm{dr} .178610 \quad 11110 \quad 0$

The proportional value in which the grass of the lattermath exceeds that of the flowering crop, is as 6 to 7 . The grass of the seed crop and that of the latter-math are of equal value.

This grass is therefore of least value at the time the seed is ripe; a loss of more than one-fourth of the value of the whole crop is sustained if it is not cut till that period : the straws are then dry, and the root leaves in a sickly decaying state; those of the latter-math, on the contrary, are luxuriant and healthy. This species sends forth flower-stalks but once in a season, and these being the most valuable part of the plant for the purpose of hay; it will, from this circumstance, and the superior value of the grass of the latter-math, compared to that of the seed crop, appear well adapted for permanent pasture.

IX. Poa ccerulea.---Var. Poa pratensis. Engl. Bot. 1004. Poa subcærulea.

Short blueish meadow grass. Nat. of Britain. $H_{\text {? }}$

Kew. 1-155. Poa humilis. 
At the time of flowering, the produce from a soil of the like nature as the preceding, is

$$
\text { oz. or lbs. per acre }
$$

Grass, $11 \mathrm{oz}$. The produce per acre

$$
119700=748614 \quad 0
$$

$64 \mathrm{dr}$. of grass afford of nutritive matter - $2 \mathrm{dr}$. The produce of the space, ditto - $5.2 \mathrm{dr}$. $80 \mathrm{dr}$. of grass weigh when

$$
\text { dry - } \quad-24 \mathrm{dr} \text {. }
$$

The produce of the space, ditto - $52.3 \frac{3}{16}$

The weight lost by the produce of one acre in drying $\quad$ - $\quad$ - $524013 \quad 0$

If the produce of this variety be compared with that of the preceding one, it will be found less; nor does it seem to possess any superior excellence. The superior nutritive power does not make up for the deficiency of produce by $80 \mathrm{lbs}$. of nutritive matter per acre.

X. Festuca hordiformis. Poa hordiformis. H. Cant. Barley-like fescue grass. Nat. of Hungary.

At the time of flowering, the produce from a sandy soil, with manure, is

Grass, $20 \mathrm{oz}$. The produce

$$
\text { oz. or lbs. per acre }
$$

$$
\text { per acre - - } 217800 \quad 0=1361280
$$

80 dr. of grass weigh

when dry - $24 \mathrm{dr}$.

The produce of the space, ditto - $96 \mathrm{dr}$.

$$
65340 \quad 0=4083120
$$

The weight lost by the produce of one acre in drying 


\section{APPENDIX.}

$64 \mathrm{dr}$. of grass afford

oz. or lbs. per acre

$\left.\begin{array}{c}\text { of nutritive matter } 2.1 \mathrm{dr} \\ \text { The produce of the } \\ \text { space, ditto - } 11.1 \mathrm{dr} .\end{array}\right\} \quad 7657 \quad 0=\begin{array}{lll}478 & 9 & 0\end{array}$

This is rather an early grass, though later than any of the preceding species; its foliage is very fine, resembling the $\boldsymbol{F}$. duriuscula, to which it seems nearly allied, differing only in the length of the awns, and the glaucous colour of the whole plant. The considerable produce it affords, and the nutritive powers it appears to possess, joined to its early growth, are qualities which strongly recommend it to further trial.

XI. Poa trivialis. Curt. Lond. Engl. Bot. 107\% Host. G. A. 2. t. 62.

Roughish meadow grass. Nat. of Britain.

At the time of flowering, the produce from a light brown loam, with manure, is

Grass, $11 \mathrm{oz}$. The produce

$$
\text { per acre - - } 119790 \quad 0=748614 \quad 0
$$

$80 \mathrm{dr}$. of grass weigh

whendry - $24 \mathrm{dr}$.

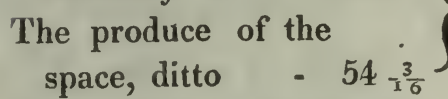

$359370=2246 \quad 1 \quad 0$

The weight lost by the pro-

duce of one acre in drying $\quad$ - $\quad 524013 \quad 0$

$64 \mathrm{dr}$. of grass afford

of nutritive matter $2 \mathrm{dr}$.

The produce of the

$37437=233157$ space, ditto - $5.2 \mathrm{dr}$. 
oz. or Ibs. per acre

At the time the seed is ripe,

the produce is

Grass, 11.8 oz. The pro-

duce per acre $\quad-\quad 1252350=7827 \quad 30$

80 dr. of grass weigh

when dry
The produce of the
space, ditto $-82.3 \frac{3}{\mathrm{~T} 6}$

The weight lost by the pro-

duce of one acre in drying

64 dr.-of grass afford

of nutritive matter $2.3 \mathrm{dr}$.

The produce of the

space, ditto - $7.3 \frac{3}{5}$.

The weight of nutritive matter which is lost

by taking the crop at the time of flower-

ing, exceeding one-fourth of its value - $102 \quad 512$

The proportional value in which the grass of the seed crop exceeds that at the time of flowering is as 8 to 11 .

The produce of latter-math is

Grass, 7 oz. The produce

per acre - - $\quad 76250 \quad 0=476460$

$64 \mathrm{dr}$. of grass afford of nu-

tritive mitter $y \mathrm{dr}$.

$35734=22354$

The proportional value by which the grass of the lattermath exceeds that of the flowering crop is as 8 to 12, and that of tie seed crop as 11 to 12 .

Here then is a satisfactory proof of the superior value of the crop at the cime the seed is ripe, and of the consequent loss sustained by taking it when in flower; the produce of each crop being nearly equal. The deficiency 
of hay in the flowering crop, in proportion to that of the seed crop, is very striking. Its superior pindice, the highly nutritive powers which the grass seems to possess, and the season in which it arrives at perfection, are merits whicl distinguish it as one of the most valua le of those grasses, which afiect moist rich suils, and sheltered situations; but on dry exposed situations it is altogether inconsiderable; it yearly diminishes, and ultimately dies off, not unfrequently in the space of four or five years.

XII. Festuca glauca. Curtis.

Glaucous fescue grass. Nat. of Britain.

Grass, $14 \mathrm{oz}$. The produce

oz. or lbs. per acre

$$
\text { per acre - } \quad 152460 \quad 0=9528120
$$

$80 \mathrm{dr}$. of grass weigh

when dry $32 \mathrm{dr}$.
The produce of the
space, ditto $-89.2 \frac{\frac{1}{16}: \frac{2}{3^{2}}}{}$

The weight lost by the pro-

duce of one acre in drying

$609840=381180$

$64 \mathrm{dr}$. of grass afford

of nutritive matter $1.2 \mathrm{dr}$.

The produce of the space, ditto $\quad 5.1 \mathrm{dr}$.

At the time of flowering

the produce is

Grass, $14 \mathrm{oz}$. The produce

per acre - - $152460 \quad 0=9528120$

$80 \mathrm{dr}$. of grass weigh

when dry - $32 \mathrm{dr}$.

The produce of the

space, ditto $\quad-89.2 \frac{2}{5}$.

$25734=223 \quad 5 \quad 4$ 
oz. or lbs. peracre

The weight lost by the produce of one acre in drying $\quad$ - $\quad 5717 \quad 4 \quad 0$ 64 di. of grass afford of nutritive matter $3 \mathrm{dr}$. 'The produce of the space, ditto $-10.2 \mathrm{dr}$.

$$
71469=446109
$$

The weight of nutritive matter which is lost

by leaving the crop till the seed be ripe,

being half of the value of the crop - $223 \quad 5 \quad 5$

The proportional value by which the grass, at the time of flowering exceeds that at the time the seed is ripe, is as 6 to 12.

The proportional difference in the value of the flowering and seed crops of this grass is directly the reverse of that of the preceding species, and affords another strong proof of the value of the straws in grass which is intended for hay. The straws, at the time of flowering, are of a very succulent nature; but from that period till the seed be perfected, they gradually become dry and wiry. Nor does the root leaves sensibly increase in number or in size, but a total suspension of increase appears in every part of the plant, the ronts and seed vessels excepted. The straws of the Poa triviculis are, on the contrary, at the time of flowering, weak and tender; but as they advance towards the period of ripening the seed, they become firm. and succulent; after that period, however, they rapidly dry up and appear little better than a mere dead substance. 
XIII. Festuca glabra. Wither. B.2. P. 154.

Smooth fescue grass. Nat. of Scotland.

At the time of flowering, the produce from a clayey loam with manure is

Grass, 21 oz. The produce
per acre
- 228690
$0=14293 \quad 0 \quad 0$

$80 \mathrm{dr}$. of grass weigh

$\left.\begin{array}{c}\text { when dry }-32 \mathrm{dr} . \\ \begin{array}{c}\text { The produce of the } \\ \text { space, ditto }-134.1_{\frac{2}{1} 6.2} \cdot 5\end{array}\end{array}\right\} 91476 \quad 0=5717 \quad 4 \quad 0$

The weight lost by the pro-

$\begin{array}{lllll}\text { duce of one acre in drying } & - & 8576 & 14 & 0\end{array}$

$64 \mathrm{dr}$. of grass afford

of nutritive matter $2 \mathrm{~d}$.

The produce of the space, ditto $10.2 \mathrm{dr}$.

$71460=44610 \quad 0$

At the time the seed is ripe the produce is

Grass, $14 \mathrm{oz}$. The produce

peracre - $\quad-152460 \quad 0=9521120$

$80 \mathrm{dr}$. of grass weigh when dry - $32 \mathrm{dr}$.

The produce of the space, ditto - $89.2 \frac{2}{5}$

The weight lost by the produce of one acre in drying $\quad \begin{array}{llll}5717 & 4 & 0\end{array}$

$64 \mathrm{dr}$. of grass afford of nutritive matter $1.1 \mathrm{dr}$. The produce of the space, ditto $\quad-\quad 4.1 \frac{8}{16}$ $297711=186 \quad 111$ 
The weight of nutritive matter which is lost

Ibs. per acre

by leaving the crop till the seed be ripe,

exceeding half of its value $\quad-\quad \begin{array}{llll}260 & 9 & 0\end{array}$

The proportional value which the grass at the time the seed is ripe, bears to that of the crop at the time of flowering, is as 5 to 8 .

oz. or lbs. per acre.

The produce of latter-math is

Grass, 9 oz. The produce

$$
\text { peracre - } \quad 98010 \quad 0=612510 \quad 0
$$

$64 \mathrm{dr}$. of grass afford

of nutritive matter $2 \mathrm{gr}$.

The produce of the

space, ditto $\quad-1.0 \frac{1}{2} \mathrm{dr}$.

$76511=47130$

The proportional value which the grass of the lattermath bears to that of the crop at the time of flowering, is as 2 to 8 , and to that of the crop, at the time the seed is ripe, is as 2 to 5 .

The general appearance of this grass is very similar to that of the Festuca duriuscula: it is, however, specifically different, and inferior in many respects, which will be manifest on comparing their several produce with each other; but if it be compared with some others, now under general cultivation, the result is much in its favour, the soil which it affects being duly attended to. The Anthoxanthum odoratum being taken as an example, it appears that

lbs. per acre

Festuca glabra, affords of nutritive matter

From the crop at the time of flowering 446.$\}$

At the time the seed is ripe, ditto - 186. 
Anthoxanthum odoralum,

At the time of flowering, ditto 122. $\}$ ibs. per acre.

At the time the seed is ripe, ditto 311.$\} \quad-433$.

The weight of nutritive matter, which is afforded

by the produce of one acre of the Festuca gla-

bra exceeding that of the Anthoxanthum odoratum, in proportion nearly as 6 to $9 . \quad-\quad 199$.

XIV. Festuca rubra. Wither. B. 2.P. 153.

Purple fescue grass. Nat. of Britain.

At the time of flowering, the produce from a light sandy soil, is

Grass, $15 \mathrm{oz}$. The produce

oz. or lbs. per acre

$$
\text { per acre - - } 163350 \quad 0=10209 \quad 6 \quad 0
$$

$80 \mathrm{dr}$. of grass weigh

when dry - $34 \mathrm{dr}$.

The produce of the

space, ditto - $102 \mathrm{dr}$.

The weight lost by the produce of one acre in

drying

$5692312=355711 \quad 0$

$64 \mathrm{dr}$. of grass afford of nutritive matter $1.2 \mathrm{dr}$.

The produce of the

$3828 \quad 8=239 \quad 4 \quad 8$

space, ditto $22_{\frac{2}{16}} \mathrm{dr}$.

6651110

At the time the seed is ripe the produce is

Grass, 16 oz. The produce

per acre

174240

$0=10890$

00.

$80 \mathrm{dr}$. of grass weigh

when dry - $36 \mathrm{dr}$.

The produce of the

$784080=490080$

space, ditto $115 \frac{3}{\frac{1}{6}} \mathrm{dr}$.

The weight lost by the produce of one acre in

drying

598980 
$64 \mathrm{dr}$. of grass afford of nutritive matter The produce of the space, ditto - $8 \mathrm{dr}$.

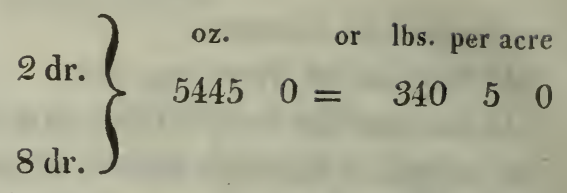

The weight of nutritive matter which is lost

by taking the crop when the grass is in

flower, being nearly one-third part of its

value

$-$

10108

The proportional value which the grass, at the time of flowering, bears to that at the time the seed is ripe, is as 6 to 8.

This species is smaller in every respect than the preceding. The leaves are seldom more than from three to four inches in length; it affects a soil similar to that favourable to the growth of the Festuca ovina, for which it would be a profitable substitute, as will clearly appear on a comparison of their produce with each other.

The produce of latter-math is

Grass, $5 \mathrm{oz}$. The produce

$$
\text { per acre } \quad 54450 \quad 0=340320
$$

$64 \mathrm{dr}$. of grass afford of

nutritive matter - $1.2 \mathrm{dr} . \quad 1276 \quad 2=\quad 7912 \quad 0$

The proportional value which the grass of the latter-math bears to that at the time the seed is ripe is as 6 to 8 , and is of equal value with the grass at the time of flowering.

XV. Festuca ovina. Engl. Bot. 585. Wither. B.2.P. 152. Sheep's fescue grass. Nat. of Britain.

At the time the seed is ripe the produce is

Grass, $8 \mathrm{oz}$. The produce

$$
\text { per acre - - } 87120 \quad 0=544500
$$

$64 \mathrm{dr}$. of grass afford

of nutrilive matter $1.2 \mathrm{dr}$.

The produce of the space, ditto . $3 \mathrm{dr}$. 


\section{APPENDIX.}

The produce of latter-math is

Grass, $5 \mathrm{oz}$. The produce

oz. or lbs. per acre

per acre - $\quad 544500=340320$

$64 \mathrm{dr}$. of grass afford of

nutritive matter $-1.1 \mathrm{dr} .10637=6677$

The dry weight of this species was not ascertained, because the smallness of the produce renders it entirely unfit for hay. If the nutritive powers of this species be compared with those of the preceding, the inferiority will appear thus :

Festuca ovina, (as above) affords of nutritive matter

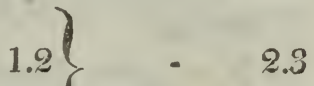

Ditto

ditto

$1.1)$

Festuca Rubra ditto ditto

Ditto

ditto ditto

The comparative degree of nourishment which the grass of the Festuca rubra affords, exceeds therefore that afforded by the $F$. ovina, in proportion as 11 to 14 .

From the trial that is here detailed, it does not seem to possess the nutritive powers generally ascribed to it; it has the advantage of a fine foliage, and may, therefore, very probably be better adapted to the masticating organs of sheep, than the larger grasses, whose nutritive powers are shewn to be greater: hence on situations where it naturally grows, and as pasture for sheep, it may be inferior to few others. It possesses natural characters very distinct from $F$. rubra. 
XVI. Briza media. Engl. Bot. 340. Host. G. A. 2. t. 29. Common quaking-grass. Nat. of Britain.

At the time of flowering, the produce from a rich brown loam, is

Grass, $14 \mathrm{oz}$. The produce

oz. or lbs. per acre

$$
\text { per acre - } \quad 152460 \quad 0=952812 \quad 0
$$

$80 \mathrm{dr}$. of grass weigh

when dry $\quad 26 \mathrm{dr}$.

The produce of the

space, ditto $72.2 \frac{3}{16} \mathrm{dr}$.

$49549 \quad 8=3096 \quad 13 \quad 8$

The weight lost by the produce of one acre in

drying - - - 6431148

$64 \mathrm{dr}$. of grass afford of nutritive matter $2.3 \mathrm{dr}$.

The produce of the space, ditto $\left.\quad-9.2 \frac{2}{16}\right\}$

$$
65510=409 \quad 7 \quad 0
$$

At the time the seed is ripe the produce is

Grass, $14 \mathrm{oz}$. The produce

per acre - $\quad 152460 \quad 0=952812 \quad 0$

$80 \mathrm{dr}$. of grass weigh

when dry - $28 \mathrm{dr}$.

The produce of the

space, ditto

$78.1 \frac{3}{5}\{$

$533620=3335 \quad 1 \quad 0$

The weight lost by the produce of one acre in

drying - - - $\quad$ - 6183110

$64 \mathrm{dr}$. of grass afford

of nutritive matter $3.1 \mathrm{dr}$.

The produce of the

space, ditto - $\left.11.1 \frac{x}{2}\right\}$

$77421=48314 \quad 1$

The weight of nutritive matter which is lost

by taking the crop at the time of flowering,

being nearly one-fourth part of its value $\begin{array}{lll}09 & 1 & 0\end{array}$ 
The proportional value which the grass at the time of flowering, bears to that at the time the seed is ripe, is as 11 to 13 .

The latter-math produce is

Grass, $12 \mathrm{oz}$. The produce

oz. or lbs. per acre

per acre - $\quad 130680 \quad 0=8167 \quad 8 \quad 0$

$64 \mathrm{dr}$. of grass afford of

nutritive matter - $2 \mathrm{dr} . \quad 408312=255312$

The proportional value in which the grass at the time of flowering, exceeds that of the latter-math, is as $\mathbf{8}$ to 11 ; and the latter-math stands to that at the time the seed is ripe in proportion as 8 to 13 .

The merits of this grass seem to demand notice; its nutritive powers are considerable, and its produce large when compared with others which affect a similar soil.

XVII. Dactylis glomerata. Engl. Bot. 535. Fl. Dan. 748. Round-headed cock's-foot grass. Nat. of Britain. Wither. B. 2 E. 149.

At the time of flowering, the produce from a rich sandy loam is

Grass, $41 \mathrm{oz}$. The produce

per acre - $\quad 446490 \quad 0=2790510 \quad 0$ $80 \mathrm{dr}$. of grass weigh when dry - $34 \mathrm{dr}$.

The produce of the $\} 189758 \quad 4=1185914$ space, ditto - $278 \frac{4}{5} \mathrm{dr}$.

The weight lost by the produce of one acre in drying 160451112 $64 \mathrm{dr}$. of grass afford of nutritive matter $2.2 \mathrm{dr}$. The produce of the $174240=10890$ space, ditto $\left.\quad 25.2 \frac{1}{3}\right\}$ 
At the time the seed is ripe the produce is

Grass, $39 \mathrm{oz}$. The produce

oz. or lbs. peracre
per acre
421710
$0=26544 \quad 6 \quad 0$
$80 \mathrm{dr}$. of grass weigh
when dry
The produce of the
space, ditto
$40 \mathrm{dr} .\{2123550=1397230$

The weight lost by the produce of one acre $\begin{array}{llll}13272 & 3 & 0\end{array}$ $64 \mathrm{dr}$. of grass afford of nutritive matter $3.2 \mathrm{dr}$.

The produce of the space, ditto . - $34.0 \frac{1}{2}$

The weight of nutritive matter which is gained by leaving the crop till the seed be ripe, being more than one-third part of its value, is

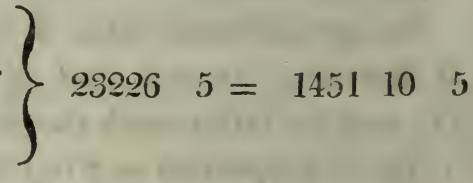

The proportional valuc which the grass at the time of flowering, bears to that at the time the seed is ripe, is as 5 to 7 , nearly.

The produce of latter math is

Grass, $17 \mathrm{oz}$. $8 \mathrm{dr}$. The pro-

duce per acre
64 dr. of grass afford of nutritive matter $\quad 1.2 \mathrm{dr} . \quad 44069=281109$

The proportional value which the grass of the lattermath bears to that at the time of flowering, is as 6 to 10 ; and to that at the time the seed is ripe, as 6 to 14 . $61 \mathrm{dr}$. of the straws at the time of flowering afford of nutritive matter $1.2 \mathrm{dr}$. The leayes or latter-math, and the straws simply, are therefore of equal proportional value; a circumstance which will point out this grass to be more valuable for permanent pasture than for hay. The above 
details prove, that a loss of nearly one-third of the value of the crop is sustained, if it is left tiil the period when the seed is ripe, though the proportional value of the grass at that time is greater, $i . e$. as 7 to 5 . The produce does not increase if the grass is left growing after the period of flowering, but uniformly decreases; and the loss of latter-math, which, (from the rapid growth of the foliage after the grass is cropped) is very considerable. These circumstances point out the necessity of keeping this grass closely cropped, either with the scythe or cattle, to reap the full benefit of its great merits.

XVIII. Bromus tectorum.- Host. G. A. 1, t. 15.

Nodding pannicled brome-grass. Nat. of Europe

Introduced 1776. H.K. 1. 168.

At the time of flowering, the produce from a light sandy soil, is

Grass, $11 \mathrm{oz}$. The produce

oz. or lbs. per acre

$$
\text { per acre - - } 119790 \quad 0=7486 \quad 14 \quad 0
$$

$S 0 \mathrm{dr}$. of grass weigh

when dry - $42 \mathrm{dr}$.

The produce of the space, ditto - $92.1 \frac{3}{5}$

The weight lost by the produce of one acre in

drying - - - - 355644

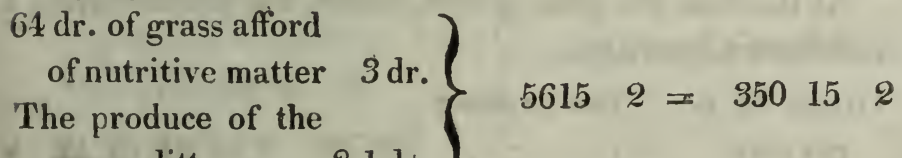
The produce of the space, ditto - $8.1 \mathrm{dr}$.

This species being strictly annual, affords no lattermath, which renders it comparatively of little value.

1) 12 
XIX. Festuca cambrica. Hudson. W. B. 2.P. 155.

Nat. of Britain.

At the time of flowering, the produce from a light sandy soil, is

Grass, 10 oz. The produce oz. or lbs. peracre per acre - - $108900 \quad 0=6806 \quad 4 \quad 0$ $80 \mathrm{dr}$. of grass weigh when dry - $34 \mathrm{dr}$.

The produce of the space, ditto - $68 \mathrm{dr}$.

$462828=2892108$ The weight lost by the produce of one acre in $\begin{array}{lllllll}\text { drying } & - & - & - & 3913 & 9 & 8\end{array}$ $64 \mathrm{dr}$. of grass afford of nutritive matter $2.1 \mathrm{dr}$. The produce of the space, ditto - $5.2 \frac{1}{2}$

$3828 \quad 8=239 \quad 4-8$

This species is nearly allied to the Festuca ovina, from which it differs little, except that it is larger in every respect. The produce, and the nutritive matter which it affords, will be found superior to those given by the $F$. ovina, if they are brought into comparison.

XX. Bromus diandrus. Curt. Lond. Engl. Bot. 1006. Nat. of Britain.

At the time the grass is ripe flower, the produce from 2 rich brown loam, is

Grass, 30 oż. The produce

$$
\text { peracre - - } 326700 \quad 0=2041812 \quad 0
$$

$80 \mathrm{dr}$. of grass weigh when dry - $34 \mathrm{dr}$.

The produce of the space, ditto - $204 \mathrm{dr}$. 
The weight lost by the produce of one acre in drying $\begin{array}{lll}11740 & 13 & 0\end{array}$

$64 \mathrm{dr}$. of grass afford of nutritive matter $3 \mathrm{dr}$.

The produce of the space, ditto - 22.2$\}$

$153141=95721$

This species, like the preceding, is strictly annual; the above is therefore the produce for one year, which, if compared with that of the least productive of the perennial grasses, will be found inferior, and it must consequently be regarded as unworthy of culture.

XXI. Poa angustifolia. With. 2. P. 142.

Narrow-leaved meadow grass. Nat. of Britain.

At the time of flowering, the produce from a brown loam, is

Grass, $27 \mathrm{oz}$. The produce

oz. or lbs. per acre

$$
\text { per acre - } \quad 294030 \quad 0=1837614 \quad 0
$$

$80 \mathrm{dr}$. of grass weigh

when dry - $34 \mathrm{dr}$.

The produce of the

$12496212=7810212$ space, ditto $183.2 \frac{2}{5}$

The weight lost by the produce of one acre in drying - $\quad-\quad$ - $\quad 1056611 \quad 4$

$64 \mathrm{dr}$. of grass afford of nutritive matter $5 \mathrm{dr}$.

The produce of the space, ditto - 33.3 )

$2288611=1430611$

At the time the seed is ripe, the produce is

Grass, 14 oz. The produce

per acre

$1524600=9598120$ 
80 dr. of grass weigh

when dry
The produce of the

$32 \mathrm{dr} .\left\{\begin{array}{cc}\text { oz. } & \text { or lbs. per acre } \\ 6098 \mathrm{2} \frac{2}{5}\end{array}\right\} \quad 0=381180$ space, ditto

The weight lost by the produce of one acre in

$$
\text { drying }
$$

57174.0

$64 \mathrm{dr}$. of grass afford

of nutritive matter $5.1 \mathrm{dr}$.

The produce of the space, ditto - $18.1 \frac{\mathrm{I}}{2}$

The weight of nutritive matter which is lost

by leaving the crop till the seed be ripe, exceeding one-third part of its value - $\quad 649 \quad 0 \quad 4$

In the early growth of the leaves of this species of Poa, there is a striking proof that early flowering in grasses is not always connected with the most abundant early produce of leaves. In this respect all the species which have already come under examination, are greatly inferior to that now spoken of. Before the middle of A pril the leaves attain to the length of more than twelve inches, and are soft and succulent; in May, however, when the flowerstalks make their appearance, it is subject to the disease termed rust, which affects the whole plant; the consequence of which is manifest in the great deficiency of produce in the crop at the time the seed is ripe, being onehalf less than at the time of the flowering of the grass. Though this disease begins in the straws, the leaves suffer most from its effects, being at the time the seed is ripe completely dried up: the straws, therefore, constitute the principal part of the crop for mowing, and they contain more nutritive malter in proportion than the leaves. This grass is evidently most valuable for permanent pasture, for which, in consequence of its superior, rapid, and early growtb, and the disease beginning at the straws, nature 
seems to have designed it. The grasses which approach nearest to this in respect of early produce of leaves, are the Pou ferlitis, Dactylis glomerata, Phleum pratense, Alopecurus pratensis, Avena cliator, and Bromus littoreus, all grasses of a coarser kind.

XXII. Azena eliator. Curis 191. Engl. Bot. 813.Holcus avenaceus. Tall oat-grass. Nat. of Britain.

At the time the seed is ripe, the produce is,

Grass, 24 oz. The produce oz. or lbs, per acre. per acre $\quad-\quad \quad-261360 \quad 6=16335 \quad 0 \quad 0$ SO dr. of grass weigh when dry - $28 \mathrm{dr}$. The produce of the space ditto - $134.1 \frac{3}{5}$

$9147514=5717314$

The weight lost by the produce of one acre in drying $1061712 \quad 2$

$64 \mathrm{dr}$. of grass aflord of nutritive matter $1 \mathrm{dr}$. The produce of the space, ditto - 6 dr.$$
408312=255 \quad 312
$$

The produce of latter-math is,

Grass, $20 \mathrm{oz}$. The protuce

$$
\text { peracre } \quad-\quad 2 \text { i7S00 } 0=1361280
$$

$64 \mathrm{dr}$. of grass afford of nutritive matter $1.1 \mathrm{dr} . \quad$ - $\quad 425314=2651314$

The weight of nutritive matter which is afforded by the crop of the latter.math, exceeding that afforded by the grass of the seed crop in proportion nearly as 26 to $25 \quad$ - $\quad \begin{array}{lll}10 & 9 & 2\end{array}$

This grass scnds forth flower straws during the whole season; the latter-math contaius nearly an equal number 
with the flowering crop. It is subject to the rust, but the disease does not makes its appearance till after the period of flowering; it affects the whole plant, and at the time the seed is ripe the leaves and straws are withered and dry. This accounts for the superior value of the latter-math over the seed crop, and points out the propriety of taking the crop when the grass is in flower.

XXIII. Poa eliator. Curtis, 50. Tall meadow grass. Nat. of Scotland.

At the time of flowering, the produce from a rich clayey loam is,

Grass, $18 \mathrm{oz}$. The produce

oz. or lbs. per acre.

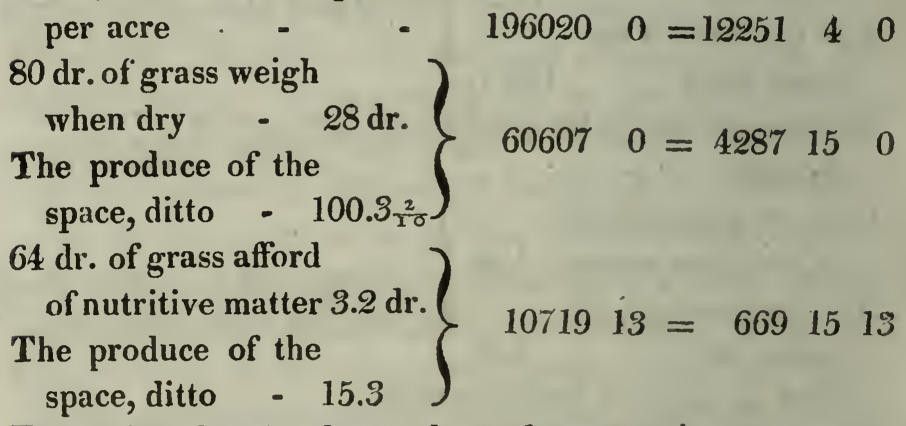

The weight lost by the produce of one acre in

drying - $\quad$ - $\quad$ - $\quad 3617153$

The botanical characters of this grass are almost the same as those of the Avena eliator, differing in the want of the awns only. It has the essential character of the Holci (Florets male, and hermaphrodite. Calyx husks twovalved with two florets) and since the Avena eliator is now referred to that genus this may with certainty be considered a variety of it. 
XXIV. Festuca duriuscula. Engl. Bot. 470. W. B.2.P. 153.

Hard fescue grass. Nat. of Britain.

At the time of flowering, the produce from a light sandy loam is,

oz. or lbs. per acre

Grass, $27 \mathrm{oz}$. The produce

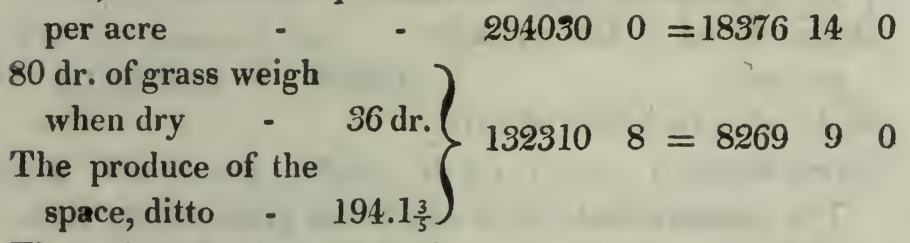

The weight lost by the produce of one acre

in drying - $\quad-\quad 10106 \quad 4 \quad 8$

$64 \mathrm{dr}$. of grass afford

$\left.\begin{array}{c}\text { of nutritive matter } 3.2 \mathrm{dr} . \\ \text { The produce of the }\end{array}\right\} 1607912=10041512$

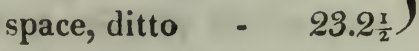

At the time the seed is ripe the produce is,

Grass, $28 \mathrm{oz}$. The produce

per acre - $\quad 304920 \quad 0=19075 \quad 8 \quad 0$

$80 \mathrm{dr}$. of grass weigh

when dry - $36 \mathrm{dr}$.

The produce of the

$137214 \quad 0=8575 \quad 14 \quad 0$

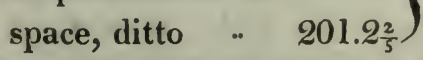

The weight lost by the produce of one acre in drying - $\quad$ - $\quad$ - $\quad 1048110 \quad 0$

$64 \mathrm{dr}$. of grass afford of nutritive matter $1.2 \mathrm{dr}$.

The produce of the space ditto - $10.2 \mathrm{dr}$.

$71469=446109$ 
lbs. per acre

The weight of nutritive matter which is lost

by learing the crop till the seed be ripe ex-

$\begin{array}{lllll}\text { ce ding one half of its value } \quad- & 558 \quad 5 & 3\end{array}$

The proportional value which the grass at the time the sced is ripe, bears to that at the time of flowering, is as 6 to 14 , nearly.

The produce of latter-math is,

Grass, $15 \mathrm{oz}$. The produce

$$
\text { per acre } \quad-\quad-163350 \quad 0=10209 \cdot 6 \quad 0
$$

$64 \mathrm{dr}$. of grass afiord of nutri-

tive matter - $\quad 1.1 \mathrm{dr} .31904=19964$

The proportional value which the grass of the lattermath bears to that at the time of flowering, is as 5 to 14 , and to that at the time the seed is ripe, 5 to 6 .

The above particulars will confirm the favourable opinion which was given of tisis grass when speaking of the Fesluca hordiformis, and $F$. glabra. Its produce in the spring is not very great, but of the finest quality, and at the time of flowering is considerable, If it be compared with those affecting similar soils such as Poa pratensis, Festuca ovina, \&rc. either considered as a grass for lay, or permanent pasture, it will be found of greater value.

XXV. Bromus erectus. Engl. Bot. 471. Host. G. A. Upright perennial brome grass. Nat. of Britain.

At the time of flowering, the produce from a rich sandy soil is,

Grass, $19 \mathrm{oz}$. The produce

$$
\text { per acre - } \quad \text { - } 206910 \quad 0=12931140
$$


$80 \mathrm{dr}$. of grass weigh

oz. or lbs. per acre when dry - $36 \mathrm{dr}$.

The produce of the space, ditto - $136.3_{\frac{1}{5}}^{\frac{1}{5}}$

The weight lost by the produce of one acre in drying 711288

$64 \mathrm{dr}$. of grass afford of nutritive matter $2.3 \mathrm{dr}$.

The produce of the space, ditto - 13.0

$93109 \quad 8=5819 \quad 5 \quad 8$

XXVI. Milium effusum. Curt. Lond. Engl. Bot. 1106. Common millet grass. Nat. of Britain.

At the time of flowering, the produce from a light sandy soil is,

Grass 11 oz. 8 dr. The pro-

duce per acre $\quad-\quad 196020 \quad 0=12951 \quad 4 \quad 0$ So dr. of grass weigh

when dry - $31 \mathrm{dr}$.

The produce of the

space, ditto - $111.2 \frac{2}{6}$

$889010=5551010$

$61 \mathrm{dr}$. of grass afford

of nutritive matter $1.3 \mathrm{dr}$. $(535914=3311514$

The produce of the

space, ditto - $7.3_{+}^{2}$

$7595712=4747 \quad 512$

This species in its natural state seems confined to woods as its place of growth; but the trial that is here mentioned, confirms the opinion that it will grow and thrive in open exposed situations. It is remarkable for the lightness of the produce, in proportion to its bulk. It produces foliage carly in the spring in considerable abundance; but its nutritive powers appear comparatively little. 
XXVII. Festuca pratensis. Engl. Bot. 1592. C. Lond. Meadow fescue grass. Nat. of Britain.

At the time of flowering, the produce from a bog soil, with coal ashes for manure, is,

oz. or lbs. per acre

Grass, $20 \mathrm{oz}$. The produce

$$
\text { per acre - - } 217800 \quad 0=13612 \quad 8 \quad 0
$$

$80 \mathrm{dr}$. of grass weigh

$\left.\begin{array}{l}\text { when dry }-38 \mathrm{dr} . \\ \text { The produce of the } \\ \text { space, ditto - } 152 \mathrm{dr} .\end{array}\right\} 1034558=6465150$

The weight lost by the produce of one acre

in drying - $\quad-\quad-\quad-\quad \begin{array}{llll}7146 & 9 & 0\end{array}$

$64 \mathrm{dr}$. of grass afford

of nutritive matter $4.2 \mathrm{dr}$. ?

The produce of the

space, ditto - $22.2 \mathrm{dr}$.

$$
153141=95721
$$

At the time the seed is ripe the produce is,

Grass, $28 \mathrm{oz}$. The produce

$$
\text { per acre - } \quad 304920 \quad 0=19057 \quad 8 \quad 0
$$

$80 \mathrm{dr}$. of grass weigh

when dry - $32 \mathrm{dr}$. ?

The produce of the

space, ditto - $179.0 \frac{4}{5}$

The weight lost by the produce of one acre

in drying

$11434 \quad 8 \quad 0$

$64 \mathrm{dr}$. of grass afford

of nutritive matter $1.2 \mathrm{dr}$.

The produce of the

space, ditto - $10.2 \mathrm{dr}$.

$71469=446109$

The weight of nutritive matter which is lost

by leaving the crop till the seed be ripe,

exceeding one half of its value

51078 
The value of the grass at the time the seed is ripe, is to that of the grass at the time of flowering, as 6 to 18 .

The loss which is sustained by leaving the crop of this grass till the seed be ripe is very great. That it loses more of its weight in drying at this stage of growth, than at the time of flowering, perfectly agrees with the deficiency of nutritive matter in the seed crop, in proportion to that in the flowering crop : the straws being succulent in the former, they constitute the greatest part of the weight; but in the latter they are comparatively withered and dry, consequently the leaves constitute the greatest part of the weight. It may be observed here, that there is a great difference between straws or leaves that have been dried after they were cut in a succulent state, and those which are dried (if I may so express it) by nature while growing. The former retain all their nutritive powers; but the latter, if completely dry, very little, if any.

XXVIII. Lolium perenne. Engl. Bot.315. Flo. Dan.747. Perennial rye-grass. Nat. of Britain.

At the time of flowering, the produce from a rich brown loam is,

Grass, 11 oz. $8 \mathrm{dr}$. The pro-

oz. or lbs. per acre

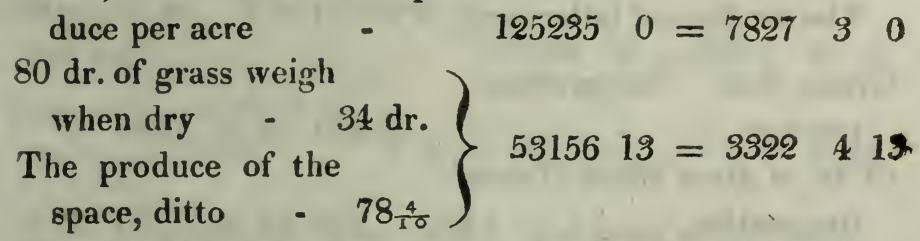

The weight lost by the produce of one acre

in drying - $\quad$ - $\quad$ - $449414 \mathrm{~s}$

$64 \mathrm{dr}$. of grass äfford

of nutritive matter $2.2 \mathrm{dr}$.

The produce of the

$489115=3051115$

space, ditto $\quad-7.0 \frac{3}{4}$ 
At the time the seed is ripe, the produce is,

Grass, 22 oz. The produce

oz. or lbs. per acre

per acre - $\quad 239580 \quad 0=14973120$

$80 \mathrm{dr}$. of grass weigh when

dry $-24 \mathrm{dr}$. ( $718740=4492 \quad 20$
$\left.\begin{array}{l}\text { The produce of the } \\ \text { space, ditto }-105.2 \frac{2}{5}\end{array}\right\}$

The weight lost by the pro-

duce of one acre in drying - $\quad$ - $1048110 \quad 0$

$64 \mathrm{dr}$. of grass afford of nutritive matter $2.3 \mathrm{dr}$.

The produce of the space, ditto - $\quad 15.0 \frac{2}{16}$

The weight of nutritive matter which is lost by

taking the crop at the time of flowering,

nearly one half of its value - $\quad 33788$

The proportional value which the grass at the time of flowering, bears to that at the time the seed is ripe, is as 10 to 11 .

The produce of latter-math is

Grass, $5 \mathrm{oz}$. The produce

- peracre - - $544500=340320$ $64 \mathrm{dr}$. of grass afford of nutri-
tive matter
$1 \mathrm{dr}$.
$85012=53212$

The proportional value which the grass of the latter-math bears to that at the time of flowering, is as 4 to 10 , and to that at the time the seed is ripe, as 4 to 11 . 
XXIX. Poa marilimea. Engl. Bot. 1140.

Sea meadow grass. Nat. of Britain.

$\Lambda t$ the time of flowering, the produce from a light brown loam, is

Grass, $15 \mathrm{oz}$. The produce

oz. or lbs. per acre per acre - - $196020 \quad 0=12251 \quad 4 \quad 0$ SO dr. of grass weigh when dry - $32 \mathrm{dr}$. The produce of the space, ditto - $115 \cdot \frac{x}{5}$

$784080=4900 \quad 0 \quad 0$

The weight lost by the produce of one acre in

$\begin{array}{lllll}\text { drying } & - & - & & \end{array}$ $64 \mathrm{dr}$. of grass afford of nutritive matter $\quad 4.2 \mathrm{dr}$. The produce of the space, ditto $20.1 \mathrm{dr}$.

$137820=86160$

The produce of latter-math is

Grass, 18 øz. The produce per acre $\quad-\quad 196020 \quad \theta=12251 \quad 4 \quad 0$ $61 \mathrm{dr}$. of grass afford of nutritive matter $\quad-1 \mathrm{dr} . \quad 306213=191631$

The proportional value which the grass of the lattermath bears to that at the time of flowering, is as 4 to 18 . 
XXX. Cynosurus cristatus. Engl. Bot. 316. Host. G. A. 2, t. 96.

Crested dog's-tail grass.

At the time of flowering, the produce from the brown loam, with manure, is

Grass, $9 \mathrm{oz}$. The produce

$$
\text { per acre - } \quad 0 \quad 0=6125 \quad 10 \quad 0
$$

$80 \mathrm{dr}$. of grass weigh

when dry $-24 \mathrm{dr}$. ?

The produce of the space, ditto - $43 \mathrm{dr}$.

oz. or lbs, per acre

The weight lost by the produce of one acre in

drying - $\quad-\quad$ - $\quad 4 \quad 4287150$

64 dr. of grass afford of nutritive matter $4.1 \mathrm{dr}$. ?

The produce of the

$65087=406137$ space, ditto $\quad-9.2 \frac{1}{16}$

At the time the seed is ripe, the produce is

Grass, $18 \mathrm{oz}$. 'The produce

$$
\text { per acre - } \quad-196020 \quad 0=12251 \quad 4 \quad 0
$$

$80 \mathrm{dr}$. of grass weigh when

dry $32 \mathrm{dr}$.

$\left.\begin{array}{c}\begin{array}{c}\text { The produce of the space, } \\ \text { ditto }\end{array} \\ 115.0 \frac{8}{10}\end{array}\right\} \begin{array}{lll}78408 & 0=4900 \quad 0 & 0\end{array}$

The weight lost by the produce of one acre in

drying - $\quad-\quad 4 \quad 7350 \quad 120$ 


\section{APPENDIX.}

oz. or lbs. per acre

$64 \mathrm{dr}$. of grass afford of nutritive matter $2.2 \mathrm{dr}$. ? The produce of the
space, ditto $-11.1 \mathrm{dr}$.

$$
76570=478 \quad 9 \quad 0
$$

The weight of nutritive matter which is lost

by taking the crop at the time of flowering,

$\begin{array}{llll}\text { exceeding one-sixth of its value } \quad-\quad 71 & 12 & 9\end{array}$

XXXI. Arena pratensis. Engl. Bot. 1204. Fl. Dan. 1083.

Meadow oat-grass. Nat. of Britain.

At the time of flowering, the produce from a rich sandy loam, is

Grass, $10 \mathrm{oz}$. The produce

per acre - - - $108900 \quad 0=6806 \quad \& 0$

$80 \mathrm{dr}$. of grass weigh

when dry - $22 \mathrm{dr}$. $\left.\begin{array}{c}\text { The produce of the } \\ \text { space, ditto }-44 \mathrm{dr} \text {. }\end{array}\right\} 299478=187111 \mathrm{\&}$

The weight lost by the produce of one acre in

drying - - - 493488

$64 \mathrm{dr}$. of grass afford

$\left.\begin{array}{l}\text { of nutritive matter } 2.1 \mathrm{dr} . \\ \text { he produce of the }\end{array}\right\} 3828 \quad 8=23948$ space, ditto - $5.2 \frac{1}{2}$

At the time the seed is ripe the produce is,

Grass $14 \mathrm{oz}$. The produce

per acre - $\quad 152460 \quad 0=9528 \quad 12 \quad 0$

E 
$80 \mathrm{dr}$. of grass weigh

oz. or lbs. per acre when dry

The produce of the space, ditto

$$
e_{67.0 \frac{4}{5}}^{24 d r .} 457380=2858100
$$

The weight lost by the produce of one acre in drying

$61 \mathrm{dr}$. of grass afford

of nutritive matter $1 \mathrm{dr}$.

The produce of the space, ditto - $3.2 \mathrm{dr}$.

The weight of nutritive matter which is lost

By leaving the crop till the seed be ripe,

exceeding one third part of its value $\quad-\quad \begin{array}{lll}90 & 6 & Q\end{array}$

The proportional value which the crops, at the time the seed is ripe, bear to that at the time of flowering, is as 4 to 9 .

XXXII. Bromus multiflorus. Engl. Bot. 1884. Host.

$$
\text { G.A. 1, t. } 11 .
$$

Many flowering brome-grass. Nat of Britain.

At the time of flowering, the produce from a clayey loam is

Grass, $33 \mathrm{oz}$. The produce

$$
\text { per acre - - } 359970 \quad 0=2246010 \quad 0
$$

$80 \mathrm{dr}$. of grass weigh

when dry $\quad-\quad 44 \mathrm{dr}$.

The produce of the

$197653 \quad 8=12353 \quad 5 \quad 8$ space, ditto - $290.0 \frac{2}{5}$

The weight lost by the produce of one acre in

drying - $\quad$ - $\quad 10107 \quad 4 \quad 8$ 
oz. or libs. peracre

$61 \mathrm{dr}$. of grass afford of nutritive matter

The produce of the space ditto 41.13

$2807512=17511112$

This species is annual, and no valuable properties have as yet been discovered in the seed. It is only noticed on account of its. being frequently found in poor grass lands, and sometimes in meadows. It appears from the above particulars to possess nutritive powers equal to some of the best perennial kinds, if taken when in flower; but if left till the seed be ripe (which, from its early growth, is frequently the case), the crop is comparatively of no value, the leaves and straws being then completely dry.

XXXIII. Festuca loliacea. Curt. Lond. Engl. Bot. 1821.

Spiked fescue grass. Nat. of Britain.

At the time of flowering, the produce from a brown rich loam, is

Grass, $24 \mathrm{oz}$. The produce

$$
\text { per acre } \quad 261360 \quad 0=16335 \quad 0 \quad 0
$$

$80 \mathrm{dr}$. of grass weigh when dry - $35 \mathrm{dr}$.

The produce of the space, ditto $168 \mathrm{dr}$. $1143450=7146 \quad 9,0$ The weight lost by the produce of one acre in drying $9188 \quad 7 \quad 0$ $64 \mathrm{dr}$. of grass afford of nutritive matter $3 \mathrm{dr}$. The produce of the space; ditto $-18 \mathrm{dr}$. 
At the time the seed is ripe, the produce is

oz. or lbs. per acre

Grass, $16 \mathrm{oz}$. The produce

$$
\text { per acre } \quad 174240 \quad 0=10890 \quad 0 \quad 0
$$

$80 \mathrm{dr}$. of grass weigh

when dry - $33 \mathrm{dr}$.

$\left.\begin{array}{l}\text { The produce of the } \\ \text { space, ditto }-105 \frac{3}{5} \mathrm{dr} \text {. }\end{array}\right\} 71874 \quad 0=449220$

The weight lost by the produce of one acre in

drying $\quad-\quad$ - $\quad$ - $\quad 639714 \quad 0$

$64 \mathrm{dr}$. of grass afford

of nutritive matter $3.1 \mathrm{dr}$.

The produce of the

space, ditto - $13 \mathrm{dr}$.

$$
88182=55320
$$

The latter-math produce is

Grass, 5 oz. The produce

per acre $\quad-\quad 514500=340320$

$64 \mathrm{dr}$. of grass afford of nutri-

tive matter - $1.1 \mathrm{dr} .10637=6677$

The weight of nutritive matter which is lost by

leaving the crop till the seed be ripe, exceed-

ing one fourth part of its value $\quad-\quad 212110$

The proportional value which the grass, at the time of Howering, bears to that at the time the seed is ripe, is as 12 to 13 ; and the value of the latter-math stands in proportion to that of the crop at the time of flowering, as 5 to 12 , and to that of the crop taken at the time the seed is ripe, as 5 to 13 .

This species of fescue greatly resembles the rye grass, in habit and place of growth: it has excellencies which make it greatly superior to that grass, for the purposes of either hay or permanent pasture. This species seems to 
improve in produce in proportion to its age, which is directly the reverse of the Lolium perenne.

XXXIV. Poa cristata. Host. G. A. 2, t. 75,-Aira Cristata. Engl. Bot. 648.

Crested meadow grass. Nat. of Britain.

At the time of flowering, the produce from a sandy loam is

Grass, 16 oz. The produce

oz. or lbs. per acre

$$
\text { per acre - } \quad \begin{array}{rlll}
174240 & 0=10890 & 0 & 0
\end{array}
$$

$80 \mathrm{dr}$. of grass weigh when dry - $36 \mathrm{dr}$.

The produce of the

$$
7848 \quad 0=4900 \quad 8 \quad 0
$$
space, ditto - $\left.115_{\frac{3}{16}}\right\}$

The weight lost by the produce of one acre in drying - $\quad-\quad 5 \quad 598980$ $64 \mathrm{dr}$. of grass afford of nutritive matter $2 \mathrm{dr}$. The produce of the space, ditto - $8 \mathrm{dr}$.

$$
54450=340 \quad 5 \quad 0
$$

The produce of this species, and the nutritive natter that it affords, are equal to those of the Festuca ovina at the time the seed is ripe: they equally delight in dry soils. The greater bulk of grass in proportion to the weight, with the comparative coarseness of the foliage, render the Poa cristata inferior to the Festuca ovinas 
XXXV. lestuca myurus. Engl. Bot. 1412. Host. G. 1. 2, t. 93.

Wall fescue grass. Nat. of Britain.

At the time of flowering, the produce from a light sandy soil is

Grass, $14 \mathrm{oz}$. The produce

oz. or lbs. per acre

per acre $\quad-\quad 152460 \quad 0=9528 \quad 12 \quad 0$

$80 \mathrm{dr}$. of grass weigh

when dry - $24 \mathrm{dr}$.

The produce of the

space, ditto - $\left.67 \frac{2}{10}\right\}$

The weight lost by the produce of one acre in

drying - $\quad-\quad \quad-\quad 667020$

$64 \mathrm{dr}$. of grass afford

of nutritive matter $1.2 \mathrm{dr}$.

The produce of the

space, ditto - $5.1 \mathrm{dr}$.

$35734=223 \quad 5 \quad 4$

This species is strictly annual; it is likewise subject to the rust; and the above being its whole produce for one year, it ranks as a very inferior grass.

XXXVI. Aira flexuosa. Engl. Bot. 1519. Host.

G. A. 2, t. 43.

Waved mountain hair-grass. Nat. of Britain.

At the time of flowering, the produce from a heath soil is

Grass, $12 \mathrm{oz}$. The produce

$$
\text { per acre - } 1306800=8167 \quad 8 \quad 0
$$

$80 \mathrm{dr}$. of grass weigh when dry - $31 \mathrm{dr}$.

The produce of the space, ditto - $74 \frac{2}{15}$ 
oz. or lbs. per acre

The weight lost by the produce of one acre in drying $\quad-\quad$ - $\quad-\quad 500298$

$64 \mathrm{dr}$. of grass afford $\left.\begin{array}{l}\begin{array}{l}\text { of nutritive matter } 1.2 \mathrm{dr} . \\ \text { The produce of the }\end{array}\end{array}\right\} 306213=191613$ space, ditto $-4.2 \mathrm{dr}$.

XXXVII. Hordeum bulbosum. Hort. Kew. 1, P. 179. Bulbous barley grass. Nat. of Italy and the Levant. Introduced 1770, by Mons. Richard.

At the time of flowering, the produce from a clayey loam with manure, is

Grass, $35 \mathrm{oz}$. The produce per acre - $\quad 3811500=23821 \quad 0 \quad 0$ $80 \mathrm{dr}$. of grass weigh when dry - $93 \mathrm{dr}$. The produce of the $\} 157224 \quad 0=9826 \quad 8 \quad 6$ space, ditto - $231 \mathrm{dr}$.)

The weight lost by the produce of one acre in drying

$13994 \quad 710$

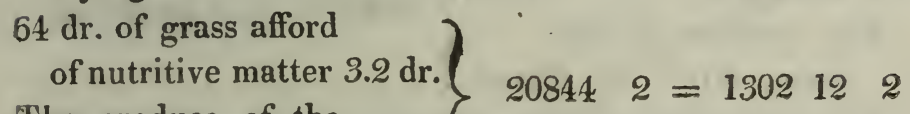
The produce of the pace, ditto $\quad-30.2 \frac{2}{4}$ 
XXXVIII. Festuca calamaria. Engl. Bot. 1005.

Reed-like fescue grass. Nat. of Britain.

At the time of flowering, the produce from a clayey loam is

Grass, $80 \mathrm{oz}$. The produce

oz. or lbs. peracre

$$
\text { per acre } \quad \text { - } \quad 871200 \quad 0=54450 \quad 0 \quad 0
$$

$80 \mathrm{dr}$. of grass weigh

when dry - $28 \mathrm{dr}$.

The produce of the $\} 304920 \quad 0=19057 \quad 8 \quad 0$ space, ditto - $448 \mathrm{dr}$.

The weight lost by the produce of one acre in

drying

$64 \mathrm{dr}$. of grass afford

of nutritive matter $4.2 \mathrm{dr}$.

The produce of the

space, ditto - $90 \mathrm{dr} .5$

3539280

At the time the seed is ripe, the produce is

Grass, 75 oz. The produce

$$
\begin{array}{llllll}
\text { per acre } & - & 816750 \quad 0=5104614 \quad 0
\end{array}
$$

$80 \mathrm{dr}$. of grass weigh when dry

The produce of the space, ditto - $283 \mathrm{dr}$.)

The weight lost by the produce of one acre in drying $19 \mathrm{dr} .\left\{\begin{array}{l}193978 \quad 2=1212310 \quad 0 \\ 0\end{array}\right.$ $64 \mathrm{dr}$. of grass afford of nutritive matter $3 \mathrm{dr}$. $382852=2392132$

The produce of the space, ditto -56.1 ) 
Ibs. per acre

The weight of nutritive matter which is lost

by leaving the crop till the seed be ripe,

being nearly one third part of its value 143511 \&

The proportional value which the grass at the time the seed is ripe, bears to that at the time of flowering, is as 12 to 18 .

This grass, as has already been remarked, produces a fine early foliage in the spring. The produce is very great, and its nutritive powers are considerable. It appears, from the above particulars, to be best adapted for hay. A very singular disease attacks, and sometimes nearly destroys the seed of this grass: the cause of this disease seems to be unknown; it is denominated Clavus, by some; it appears by the seed swelling to three times its usual size in length and thickness, and the want of the carcle. Dr. Willdenow describes two distinct species of it: 1st, the simple clavus, which is mealy and of a dark colour, without any smell or taste; 2nd, the malignant clavus, which is violet blue, or blackish, and internally too has a blueish colour, a fetid smell, and a sharp pungent taste. Bread made from grain affected with this last species, is of a blueish colour; when eaten, produces cramps and giddiness.

XXXIX. Bromus littoreus. Host. G. A. P. 7, t. 8.

Sea-side brome grass. Nat. of Germany, grows on the banks of the Danube and other rivers.

At the time of flowering, the produce from a clayey loam is

Grass, 61 oz. The produce

oz. or lbs. per acre per acre $664290 \quad 0=41518 \quad 2 \quad 0$ 
$\left.\begin{array}{l}80 \mathrm{dr} \text {. of grass weigh } \\ \text { when dry - } 41 \mathrm{dr} \text {. } \\ \text { The produce of the } \\ \text { space, ditto - } 500_{\frac{2}{1} \delta}\end{array}\right\} 34044810=21278010$ The weight lost by the produce of one acre in drying $64 \mathrm{dr}$. of grass afford
of nutritive matter $1.2 \mathrm{dr}$. The produce of the $155674=973 \quad 14$ space, ditto $-22.3 \frac{\pi}{2}$

At the time the seed is ripe, the produce is Grass, $56 \mathrm{oz}$. The produce per acre 609840

$20540 \quad 16$

$\mathrm{SO} \mathrm{dr}$. of grass weigh

when dry - $32 \mathrm{dr}$.

The produce of the $2439360=15246 \quad 0 \quad 0$ space, ditto - $358 \frac{x}{6}$

The weight lost by the produce of one acre in drying

$64 \mathrm{dr}$. of grass afford

$$
\left.\begin{array}{c}
\text { of nutritive matter } 3.2 \mathrm{dr} \text {. } \\
\text { The produce of the } \\
\text { space, ditto - } 196
\end{array}\right\}
$$
$\begin{array}{llll}22869 & 0 & 0\end{array}$ The weight of nutritive matter which is lost by taking the crop at the time of flowering, exceeding one half of its value $\quad-\quad \begin{array}{llll}1111 & 5 & 6\end{array}$ The proportional value which the grass at the time of flowering, bears to that at the time the seed is ripe, is as 6 to 14 .

This species greatly resembles the preceding in habit and manner of growth; but is inferior to it in value, which is evident from the deficiency of its produce, and 
of the nutritive matter afforded by it. The whole plant is likewise coarser and of greater bulk in proportion to its weight. The seed is affected with the same disease which destroys that of the former species.

XL. Festuca eliator. Engl. Bot. 1593. Host. G. A. 2, t. 79. Tall fescue grass. Nat. of Britain.

At the time of flowering, the produce from a black rich loam, is

Grass, $75 \mathrm{oz}$. The produce

oz. or lbs. peracre per acre - $\quad-816750 \quad 0=5104614 \quad 0$

$80 \mathrm{dr}$. of grass weigh when dry - $-28 \mathrm{dr}$.

The produce of the space, ditto $-420 \mathrm{dr}$.

$2858628=17866 \quad 6 \quad 8$

The weight which is lost by the produce of one acre in drying $\quad-\quad \begin{array}{lllll}- & - & 33180 & 7 & 8\end{array}$

- $64 \mathrm{dr}$. of grass afford of nutritive matter $5 \mathrm{dr}$.

The produce of the space, ditto $-93.3$

$63808 \quad 9=3988 \quad 0 \quad 9$

At the time the seed is ripe the produce is

Grass, $75 \mathrm{oz}$. The produce peracre - $\quad-816750 \quad 0=51046$ 4. 0 . $80 \mathrm{~d}$. of grass weigh when dry - $-28 \mathrm{dr}$. The produce of the space, ditto $-420 \mathrm{dr}$.

The weight lost by the produce of one acre in drying 
$64 \mathrm{dr}$. of grass afford of nutritive matter $3 \mathrm{dr}$.

The produce of the space, ditto oz. - or lbs. peracre The weight of nutritive matter which is lost

by leaving the crop till the seed be ripe, exceeding one-third part of its value $\quad \begin{array}{lll}1595 & 3 & 7\end{array}$

The proportional value which the grass at the time the seed is ripe, bears to that at the time of flowering, is as 12 to 20.

The produce of latter-math is

Grass, $23 \mathrm{oz}$. The produce

per acre $\quad-\quad-250470 \quad 0=15654 \quad 6 \quad 0$

$64 \mathrm{dr}$. of grass afford nutri-

tive matter $4 \mathrm{dr}$. - - $\quad 156546=97866$

The proportional value which the grass of the lattermath bears to that of the crop, is as 16 to 20 ; and to that at the time the seed is ripe, as 12 to 16 , inverse.

This species of fescue is closely allied to the Festuca pratensis, from which it differs in little, except that it is larger in every respect. The produce is nearly three times that of the $\boldsymbol{F}$.pratensis, and the nutritive powers of the grass are superior in direct proportion, as 6 to 8.

XIII. Nardus stricta. Engl. Bot. 290. Host. G. A.2, t. 4.

Upright mat-grass. Nat. of Britain.

At the time the seed is ripe, the produce is

Grass, $9 \mathrm{oz}$. The produce

$$
\text { per acre } \quad-\quad \quad-98010 \quad 0=612510 \quad 0
$$

$80 \mathrm{dr}$. of grass weigh

when dry $\quad-32 \mathrm{dr}$. space ditto - $\left.-57.2 \frac{2}{5}\right)$ 


\section{APPENDIX.}

oz. or lbs. per acre

The weight lost by the produce

of one acre in drying

$64 \mathrm{dr}$. of grass afford

of nutritive matter $2.1 \mathrm{dr}$.

The produce of the space, ditio - $\left.5.0^{\frac{x}{5}}\right\}$

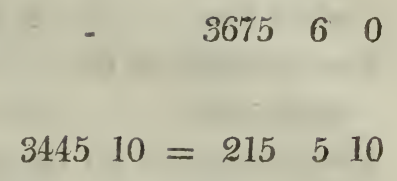

XLII. Triticum, Sp.

Wheat-grass.

At the time of flowering, the produce from a rich sandy loam is

Crrass, IS oz. The produce

$$
\text { per acre - } \quad-196020 \quad 0=12251 \text { \& } 0
$$

$80 \mathrm{dr}$. of grass weigh when dry - - $32 \mathrm{dr}$.

The produce of the space, ditto $\quad-115 \frac{\mathrm{T}}{5}$

The weight lost by the produce of one acre in drying - 7350120

$64 \mathrm{dr}$. of grass afford of nutritive matter $2.2 \mathrm{dr}$.

The produce of the space, ditto - $11.1 \mathrm{dr}$.

$78408 \quad 0=4900 \quad 8 \quad 0$

XLIII. Festuca fluitans. Curt. Lond. Engl. Bot 1520.

Poa fluitans.

Floating fescue grass. Nat. of Britain.

At the time of flowering, the produce from a strong tenacious clay, is

Grass, $20 \mathrm{oz}$. The produce

per acre $\quad-217800 \quad 0=13612 \quad 8 \quad 0$ 
(i2.

or Ibs. per acre

$80 \mathrm{dr}$. of grass weigh when dry

$-24 \mathrm{dr}$.

The produce of the space, ditto - $96 \mathrm{dr}$.

$65340 \quad 0=408312 \quad 0$

The weight lost by the produce of one acre in drying

$64 \mathrm{dr}$. of grass afford of nutritive matter $1.3 \mathrm{dr}$.

The produce of the space, ditto $-8.3 \mathrm{dr}$.

$.952812 \quad 0$

The above produce was taken from grass that had occupied the ground for four years, during which time it had increased every year; it therefore appears contrary to what some have supposed to be capable of being cultivated in perennial pastures.

XLIV. Holcus lanatus. Curt. Lond. Fl. Dan. 1181.

Meadow soft grass. Yorkshire grass. Nat. of Britain.

At the time of flowering, the produce from a strong clayey loam is

Grass, $28 \mathrm{oz}$. The produce

per acre $\quad 304920 \quad 0=19057 \quad 8 \quad 0$

$80 \mathrm{dr}$. of grass weigh

when drý - $26 \mathrm{dr}$.

The produce of the

space, ditto

$157.2 \frac{2}{5}$

The weight lost by the produce of one acre in drying - $\quad$ - $\quad-12395142$

$64 \mathrm{dr}$. of grass afford of nutritive matter $4 \mathrm{dr}$.

The produce of the space, ditto - $\quad-28 \mathrm{dr}$.

$190578=1191 \quad 18$ 
At the time the seed is ripe, the produce is

oz. or lbs. peracre

Grass, 28 oz. 'The produce

$$
\text { per acre - - } \quad 304920 \quad 0=19057 \& \quad 0
$$

$80 \mathrm{dr}$. of grass weigh

when dry - - $16 \mathrm{dr}$. $\left.\begin{array}{c}\text { The produce of the } \\ \text { space, ditto }-59.2 \frac{2}{5}\end{array}\right\} 609840=381180$

The weight lost by the produce of one acre

$$
\text { in drying - } \quad \text { - } \quad \ldots \quad 15246 \quad 0 \quad 0
$$

$6 \pm \mathrm{dr}$. of grass afford

$\left.\begin{array}{l}\text { of nutritive matter } 2.3 \mathrm{dr} . \\ \text { The produce of the } \\ \text { space, ditto - } 19.1 \mathrm{dr} \text {. }\end{array}\right\} 131020=818140$

The weight of nutritive matter which is lost

by leaving the crop till the seed be ripe,

exceeding one-third part of its value $\quad 372 \quad 3 \quad 8$

The proportional value which the grass at the time the seed is ripe, bears to that at the time of flowering; is as 11 to 12 .

XLV. Festuca dumetorum. Flo. Dan. 700.

Pubescent fescue grass. Nat. of Britain.

At the time of flowering, the produce from a black sandy loam, is

Grass, $16 \mathrm{oz}$. The produce

$$
\text { per acre - } \quad-\quad 174240 \quad 0=10890 \quad 0 \quad 0
$$

$80 \mathrm{dr}$. of grass weigh

when dry $40 \mathrm{dr}$.
he produce of the
space, ditto - $128 \mathrm{dr}$.

The weight lost by the pro-

duce of one acre in drying $\quad \begin{array}{rlll}5445 & 0 & 0\end{array}$ 
$61 \mathrm{dr}$. of grass afford

oz. or lbs. per acre
of nutritive matter
The produce of the
space, ditto - $4 \mathrm{dr}$.

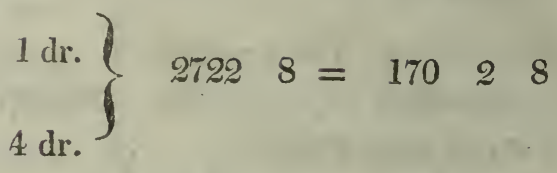

XLVI. Poa fertilis. Host. G. A.

Fertile meadow grass. Nat. of Germany.

At the time of flowering the produce from a clayey loam, is

Grass, $22 \mathrm{oz}$. The produce

per acre - $\quad 239580 \quad 0=14973120$

$80 \mathrm{dr}$. of grass weigh

when diy $\quad-42 \mathrm{dr}$.

The produce of the

space, ditto

$184 \frac{4}{5}$ dr.

The weight lost by the pro-

duce of one acre in ärying $\quad-711188$ $64 \mathrm{dr}$. of grass afford of nutritive matter $4.2 \mathrm{dr}$. The produce of the space, ditto - 24.3

$1257798=786138$

If the nutritive powers and produce of this species, be compared with any other of the same family, or such as resemble it in habit and the soil which it affects, a superiority will be found, which ranks this as one of the most valuable grasses; next to the $P$ oa angustifolia, it produces the greatest abundance of early folinge, of the best quality, which fully compensates for the comparative lateness of flowering.! 
XLVII. Arundo colorata. Hort. Kew. I. P. 174. Engl. Bot. 402. Phalaris arundinacea.

Striped-leaved reed grass. Nat. of Britain.

At the time of flowering, the produce from a black sandy loam is

Grass, 40 oz. The pro-

oz. or lbs. per acre

duce per acre $\quad-\quad-435600 \quad 0=27225 \quad 0 \quad 0$

$80 \mathrm{dr}$. of grass weigh

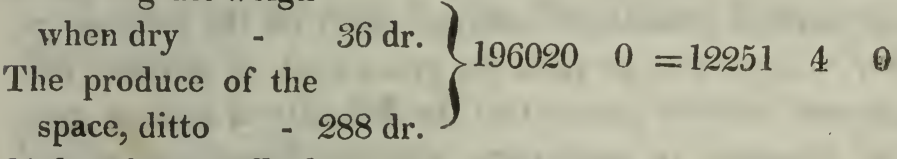

$61 \mathrm{dr}$. of grass afford

$\left.\begin{array}{c}\text { of nutritive matter } 4 \mathrm{dr} \text {. } \\ \text { The produce of the }\end{array}\right\} 27225 \quad 0=170190$

space, ditto $-40 \mathrm{dr}$.

The strong nutritive powers which this grass possesses recommend it to the notice of occupiers of strong clayey lands, which cannot be drained. Its produce is great, and the foliage will not be denominated coarse, if compared with those which afford a produce equal in quantity.

XLVIII. Trifolium pratense. W. Bot. 3, P. 137.

Broad-leaved cultivated clover. Nat. of Britain.

At the time the seed is ripe, the produce from a rich clayey loam, is

Grass 72 oz. The produce

oz. or lbs. per acre

$$
\text { per acre - - - } 784080 \quad 0=49005 \quad 0 \quad 0
$$

$80 \mathrm{dr}$. of grass weigh

when dry - $-20 \mathrm{dr}$.

The produce of the

space, ditto $\quad-288 \mathrm{dr}$.

$1960200=12251 \quad 0 \quad 0$ 
oz. or libs. per acre

The weight lost by the produce of one acre in drying $64 \mathrm{dr}$. of grass afford of nutritive matter 2.2

The produce of the space, ditto - $45 \mathrm{dr}$.

$$
306282=1914 \quad 42
$$

If the weight which is lost by the produce of this species of clover, in drying, be compared with that of many of the natural grasses, its inferior value for the purpose of hay, compared to its value for green food, or pasture, will appear; for it is certain that the difficulty of making good hay increases in proportion with the quantity of superfluous moisture which the grass may contain. Its value for green food, or pasture, may further be seen.by comparing its nutritive powers, with those manifested by other plants generally esteemed best for this purpose.

Trifolium pratense (as above) affords of nutritive matter

$-2.2 \mathrm{dr}$.

XLIX. Trifolium repens (white clover) from an equal quantity of grass $\quad-\quad-2.0 \mathrm{dr}$.

L. Ditto, variety, with brown leaves, ditto $\quad-2.2 \mathrm{dr}$. The grass of the $\boldsymbol{T}$. pratense, therefore, exceeds in value that of the $T$. repens, by a proportion as 8 to 10 ; but it is of equal proportional value with the brown variety.

LI. Burnet (Poterium sanguisorba) affords of nutritive matter $-2.2 \mathrm{dr}$.

LII. Bunias orientalis (a newly introduced plant), ditto $-2.2 \mathrm{dr}$. The proportional value of these two last, and of the 
T. pratense, and the brown-leaved variety of T.repens, are equal: they exceed the T.repens as 8 to 10 .

The comparative produce of these four last-mentioned species, per acre, has not been ascertained.

\section{Trifolium macrorhizum.}

Long-rooted clover. Nat. of Hungary.

At the time the seed is ripe, the produce from a rich clayey loam, is

Grass, $144 \mathrm{oz}$. The produce

oz. or lbs. peracre

$$
\text { per acre - } \quad-1568160 \quad 0=98010 \quad 0 \quad 0
$$

$80 \mathrm{dr}$. of grass weigh

when dry - $34 \mathrm{dr}$.

The produce of the

space, ditto

- $979 \frac{1}{5}$

The weight lost by the pro.

duce of one acre in drying - $\quad 5635512 \quad 0$

$64 \mathrm{dr}$. of grass afford

of nutritive matter $2.3 \mathrm{dr}$. $\{6738114=.4211 \quad 5 \quad 14$

The produce of the

space, ditto - $99 \mathrm{dr}$.

The root of this species of clover is biennial : it penetrates to a great depth in the ground, and is in consequence little affected by the extremes of wet or dry weather. It requires good shelter, and a deep soil. The produce, when compared to that of others that are allied to is in habit, and place of growth, proves greatly superior. The following particulars, some of which refer to results stated in the next two pages, will make this manifest:

$$
\text { F F } 2
$$


Ifis.

Trifolium pratcnse $\begin{cases}\text { Produces per acre, Grass } & 49005 \\ \text { Ditto, } & \text { Hay - } 12251\end{cases}$ Broad leaved clover Affords do. of nutritive matter 1914 Medicago sativa. (Produces per acre, Grass - 70785 Lucern. From a soil Ditto, Hay - 28314 of the like nature - (Aftords of nutritive matter 1659

Hedysarum onobry- Produces per acre, Grass - 8848 chis.

Saintfoin. Ditto, Hay - 3539

The wright of nutritive matter afforded by the produce of the $T$. macrorhizum, exceeding that of the T.pratense, in proportion, nearly as 7 to 152297 The proportional value of the grass of $T$. pratense to that of $\boldsymbol{T}$. macrorhizum, is 10 to 11 .

The weight of nutritive matter afforded by the $T$. macrortizum, exceeding that of the Medicago sativa, in proportion nearly as 13 to 33 . 2552 The proportional value of the grass is as 11 to 6 . The weight of nutritive matter which is afforded by the produce of the $T$. macrorhizum, exceeding that of the Hedysarum onobrychis in proportion nearly as 5 to $67 \quad-\quad$ - 3897

The proportional value of the grass, like that of the $T$. pratense, is as 11 to 10 .

The produce of each of the above-mentioned species was taken from a similar soil, and in the same situation, the conclusions must therefore be considered positive, with respect to such soils only. It is evident that more than twice the quantity of nutritive matter is afiorded by the produce of one acre of the $T$ : macrorlizum, than from the produce of an equal space covered by the $T$. pratense. Its short 
duration in the soil (for if sown early in the autumn, on a rich light soil, it is only an annual plant) renders it fit only for green food or hay; this in some measure lessens its value, when compared with the $T$. pratense. It possesses the essential property of affording abundance of good seed; and if the ground be kept clear of weeds, it sows itself, vegetates, and grows rapidly, without covering-in, or any operation whatever. For four years it has propagated itself in this manner, on the space of ground which it now occupies, and from which this statement of its comparative value is made. The produce of lucern in grass, comes nearer to this speeies in quantity, but is greatly deficient in nutritive matter, as much as 13 to 33 . The long continuance of lucern in the soil is therefore the only merit which it possesses above the two last-mentioned species; and when that is the object of the cultivator, it will of necessity have the preference.

The value of the grass of saintfoin is equal to that of the $T$. pratense; and proportionally less than that of the T'rifolium macrorhisum, as 10 to 11 . The quantity of grass is very small, and on soils of the nature above described, it is doubtless inferior. However, from the superior value of the grass, on dry hilly situations or chalky soils, it may in such situations possibly be their superior in every respect.

LIV. Medicago Sativa. Wither. B. 3, P. 643.

Lucern. Nat. of Britain.

At the time the seed is ripe, the produce from a rich clayey loam is

oz. or lbs. per acre

Grass, 104 oz. The produce

$$
\text { per acre - } 1132560 \quad 0=70785
$$


oz. or lbs. per acre

$80 \mathrm{dr}$. of grass weigh when dry - $32 \mathrm{dr}$.

The produce of the space, ditto $\quad-665.2 \frac{2}{5}$

$453024=28314 \quad 0 \quad 0$

The weight lost by the produce of one acre in drying $\quad$ - $\quad 42471 \quad 0 \quad 0$ $64 \mathrm{dr}$. of grass afford of nutritive matter $1.2 \mathrm{dr}$. The produce of the space, ditto - $39 \mathrm{dr}$.

$$
265446=7659 \quad 0 \quad 6
$$

LV. Hedysarum onobrychis. Wither. 3, P. 628. Saintfoin. Nat. of Britain.

At the time the seed is ripe, the produce from a rich clayey loam is

Grass, $13 \mathrm{oz}$. The produce

$$
\text { peracre } \quad-\quad 141570 \quad 0=8848 \quad 20
$$

$80 \mathrm{dr}$. of grass weigh

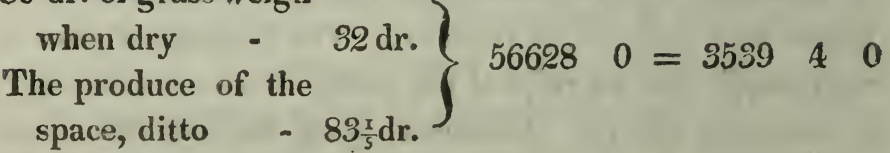
The weight lost by the produce of one acre in drying - 5308140. $64 \mathrm{dr}$. of grass afford of nutritive matter $2.2 \mathrm{dr}$. The produce of the space, ditto $-8.0 \frac{x}{2}$ 
LVI. Hordeum pratense. Engl. Bot. 409. Host. G. A. 1, t. 33.

Meadow barley-grass. Nat. of Britain.

At the time of flowering, the produce from a brown loam, with manure, is

Grass, 12 oz. The produce

oz. or lbs. per acre peracre - - $130680 \quad 0=8167 \quad 8 \quad 0$ $80 \mathrm{dr}$. of grass weigh when dry - $32 \mathrm{dr}$.

The produce of the space, ditto $67.1 \mathrm{dr}$

$522720=3267 \quad 0 \quad 0$

The weight lost by the produce of one acre in drying - - $4900 \quad 8 \quad 0$ $64 \mathrm{dr}$. of grass afford of nutritive matter $3.3 \mathrm{dr}$. The produce of the space, ditto $-11.1 \mathrm{dr}$.

$76570=478 \quad 9 \quad 0$

LVII. Poa compressa. Engl. Bot. 365.

Flat-stalked meadowgrass. Nat. of Britain.

At the time of flowering, the produce from a gravelly soil, with manure, is

Grass, 5 oz. The produce

$$
\text { per acre - - } 544500=340320
$$

$80 \mathrm{dr}$. of grass weigh

when dry $-34 \mathrm{dr}$.
$\left.\begin{array}{c}\text { The produce of the } \\ \text { space, ditto }-34 \mathrm{dr} .\end{array}\right\}$

The weight lost by the produce of one acre in drying 19561212 
oz. or lbs. per acre

$64 \mathrm{dr}$. of grass afford of nutritive matter $5 \mathrm{dr}$. The produce of the space, ditto $-6.1$

The specific characters of this species are much the same as those of the Poa fertilis, differing in the compressed figure of the straws, and creeping root only. If the produce was of magnitude, it would be one of the most valuable grasses; for it produces foliage early in the spring, and possesses strong nutritive powers.

LVIII. Poa aquatica. Curt. Lond, Engl. Bot. 1315. Reed Meadow-grass. Nat. of Britain.

At the time of flowering, the produce from a strong tenacious clay, is

Grass, $186 \mathrm{oz}$. The produce

oz. or lbs. per acre

$$
\text { per acre - } \quad 20225540=12659640
$$

$80 \mathrm{dr}$. of grass weigh

$\left.\begin{array}{c}\text { when dry } \\ \begin{array}{c}\text { The produce of the } \\ \text { space, ditto } 1785.2_{\frac{2}{16}}\end{array}\end{array}\right\} 1215324=75957120$

The weight lost by the pro-

duce of one acre in drying $\quad$ - $\quad 50638 \quad 8 \quad$ a

$64 \mathrm{dr}$. of grass afford

of nutritive matter $2.2 \mathrm{dr}$. $\{79122=4945210$

The produce of the

space, ditto

$116.1 \mathrm{dr}$. 


\section{APPENDIX.}

LIX. Aira aquatica. Curt. Lond. Engl. Bot. $155 \%$.

Water hair grass. Nat. of Britain.

At the time of flowering; the produce from water, is

Grass, 16 oz. The produce

oz. or lbs. per acre

$$
\text { per acre - } \quad-\quad 174240 \quad 0=10890 \quad 0 \quad 0
$$

$80 \mathrm{dr}$. of grass weigh

when dry $\quad-24 \mathrm{dr}$.

The produce of the space, ditto $\quad-76.3_{\frac{1}{16}}$

The weight lost by the produce of one acre in drying

$$
522720=3267 \quad 0 \quad 0
$$

$64 \mathrm{dr}$. of grass afford

The produce of the space, ditto - $9 \mathrm{dr}$.

LX. Bromus cristatus. Triticum cristatum, H. G. A. 2, t. 24.

Secale prostratum. Jacquin. Nat. of Germany.

At the time of flowering, the produce from a clayey loam, is

Grass, 13 oz. The produee

$$
\text { per acre - } \quad-141570 \quad 0=8848 \quad 0 \quad 0
$$

$80 \mathrm{dr}$. of grass weigh

when dry

32 dr. $56628 \quad 0=3530$ 4 0

The produce of the space, ditto $83.1 \mathrm{dr}$.

The weight lost by the produce of one acre in drying 
64 dr. of grass afford oz. or lbs. per acre of nutritive matter $2.2 \mathrm{dr}$. The produce of the space, ditto $\left.-8.0 \frac{2}{16}\right\}$

$$
55301=345100
$$

LXI. Elymus Sibiricus. Hort. K. 1, P. 176. Cult. 1758 , by Mr. P. Millar.

Siberian lyme grass. Nat. of Siberia.

At the time of flowering, the produce from a sandy loam, with manure, is

Grass, 24 oz. The produce

per acre $\quad-\quad$ - $\quad 261960 \quad 0=1633500$
$80 \mathrm{dr}$. of grass weigh when

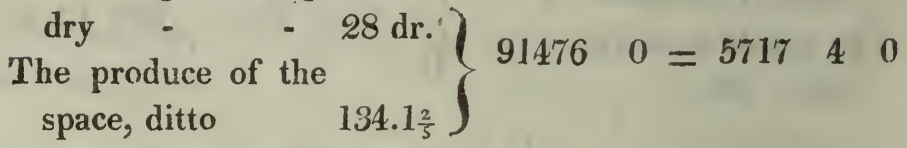

The weight lost by the produce of one acre in drying $64 \mathrm{dr}$. of grass afford of nutritive matter $2.1 \mathrm{dr}$. The produce of the space, ditto $-13.2 \mathrm{dr}$.

LXII. Aira" caspitosa." Host. G. A. 2. t. 42. Engl. Bot. 1557.

Turfy hair grass. Nat. of Britain.

At the time the seed is ripe, the produce from a strong tenacious clay is

Grass, 15 oz. The produce

$$
\text { sper acre - } \quad-163350 \quad 6=10209 \quad 6 \quad 0
$$


oz.

or liss. per acre

$80 \mathrm{dr}$. of grass weigh when dry - $26 \mathrm{dr}$.

The produce of the space, ditto - $\left.135 \frac{\mathrm{r}}{\mathrm{s}}\right\}$

$5308812=3318 \quad 012$

'The weight lost by the produce of one acre in

drying

$6891 \quad 5 \quad 4$

$64 \mathrm{dr}$. of grass afford of nutritive matter - $2 \mathrm{dr}$.

The produce of the space, ditto $7.2 \mathrm{dr}$.

LXIII. Hordeum murinum. Curt. Lond. Engl. Bot. 1971.

Wall barley grass. Way Bennet. Nat. of Britain.

At the time of flowering, the produce from a clayey loam, is

Grass, $18 \mathrm{oz}$. The produce

$$
\begin{array}{llllll}
\text { per acre } & - & 196020 & 0=12251 \quad 4 \quad 0
\end{array}
$$

$80 \mathrm{dr}$. of grass weigh

when dry $28 \mathrm{dr} .\{686070=4287150$ space, ditto

The weight lost by the produce of one acre in drying $\begin{array}{lll}7963 & 5 & 0\end{array}$

$64 \mathrm{dr}$. of grass afford

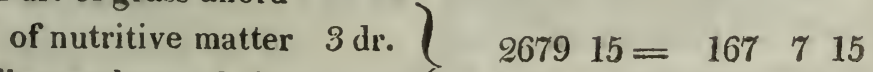
The produce of the space, ditto $\left.3.3_{1^{\frac{3}{6}}}\right\}$ 
LXIV. Avena flavescens. Curt. Lond. Engl. Bot. 952. Yellow oat-grass. Nat. of Britain.

At the time of llowering, the produce from a claycy loam, is

$$
\text { oz. or lbs. peracre }
$$

Grass, 12 oz. The produce

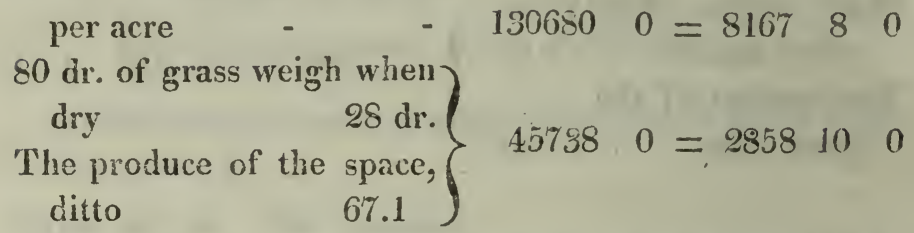

The weight lost by the pro-

$$
\text { duce of one acre in drying - } \quad-\quad 530814 \quad 0
$$

$64 \mathrm{dr}$. of grass afford of nutritive matter $3.3 \mathrm{dr}$. $\left.\begin{array}{r}\text { The produce of the space, } \\ \text { ditto } \\ 11.1 \mathrm{dr} .\end{array}\right\} \begin{array}{rrrr}7657 & 0=478 \quad 9 & 0\end{array}$

At the time the seed is ripe, the produce is

Grass, $18 \mathrm{oz}$. The produce

$$
\text { per acre } \quad-\quad 196020 \quad 0=12251 \quad 4 \quad 0
$$

$80 \mathrm{dr}$. of grass weigh when dry - $32 \mathrm{dr}$. $\left.\begin{array}{cc}\text { The produce of the space, } \\ 115.0 \frac{4}{5}\end{array}\right\} \quad 78408 \quad 0=\begin{array}{lll}3900 & 8 & 0\end{array}$

The weight lost by the produce of one acre in drying $64 \mathrm{dr}$. of grass afford of $\mathrm{nu}$ -

$$
\left.\begin{array}{c}
2.1 \mathrm{dr} . \\
\begin{array}{c}
\text { tritive matter produce of the space, } \\
10.0 \frac{\mathrm{l}}{2}
\end{array} \\
\text { ditto }
\end{array}\right\} 68915=43011
$$


The weight of nutritive matter which is lost if the crop be left till the seed be ripe, exceeding one-tenth part of its value - 471311

The proportional value which the grass, at the time the seed is ripe, bears to that at the time of flowering, is as 9 to 15 .

The produce of latter-math is

oz. or lbs. peracre

Grass, 6 oz. The produce

$$
\text { per acre - } \quad 65340 \quad 0=480312 \quad 0
$$

$64 \mathrm{dr}$. of grass afford of nu-

$$
\text { tritive matter } \quad 1.1 \mathrm{dr} . \quad 1276 \quad 2=79122
$$

The proportional value which the grass of the lattermath bears to that at the time of flowering, is as 5 to 15 ; and to that at the time the seed is ripe, as 5 to 9 .

This species is pretty generally cultivated in many parts of this kingdom ; and it appears from the above details to be a valuable grass, though inferior to many others.

1.XV. Bromus sterilis. Engl. Bot. 1030. Host. G. A. 1, t. 16.

Barren brome grass. Nat. of Britain.

At the time of flowering, the produce fiom a sandy soil, is

Grass, 44 oz. The produce

$$
\text { per acre - } \quad 479160 \quad 0=29947 \quad 8 \quad 0
$$

so dr. of grass weigh

when dry

The produce of the space, ditto . $396 \mathrm{dr}$.

The weight lost by the produce of one acre

in drying

$13102 \quad 0 \quad 8$ 
oz. or lbs. per acre

$64 \mathrm{dr}$. of grass afford of nutritive matter $\left.\begin{array}{l}\text { The produce of the space, } \\ 55 \mathrm{dr} .\end{array}\right\} \begin{array}{rl}37434 & 6=2339100\end{array}$

$64 \mathrm{dr}$. of the flowers afford of nutritive matter $2.2 \mathrm{dr}$. The nutritive powers of the straws and leaves are, therefore, more than twice as great as those of the flowers. This species, being strictly annual, is of comparatively little value. The above particulars shew that it has very considerable nutritive powers, more than its name would imply, if taken at the time of flowering; but if left till the seed be ripe, it is, like all other annuals, comparatively of no value.

LXVI. Holcus mollis. Curt. Lond. Wither. B.2. P. 134. Creeping soft grass. Nat. of Britain.

At the time of flowering, the produce from a sandy soil, is

Grass, $50 \mathrm{oz}$. The produce

$$
\text { per acre - } \quad-\quad 544500 \quad 0=31031 \quad 4 \quad 0
$$

$80 \mathrm{dr}$. of grass weigh

when dry - $32 \mathrm{dr}$.

The produce of the

space, ditto

$320 \mathrm{dr}$.

$217800 \quad 0=13612 \& \quad 0$

The weight lost by the produce of one acre

in drying $\quad$ - $\quad$ - 20418120

$64 \mathrm{dr}$. of grass afford

of nutritive matter $4.2 \mathrm{dr}$.

The produce of the

$382852^{\circ}=2392132$ space, ditto $56.1 \mathrm{dr}$. 
At the time the seed is ripe, the produce is

Grass, 31 oz. The produce

$$
\text { per acre - - } 337590 \quad 0=21099 \quad 6 \quad 0
$$

80 dr. of grass weigh

$\left.\begin{array}{ll}\text { when dry } & 32 \mathrm{dr} . \\ \text { spe produce of the ditto } & 198.1 \frac{3}{5}\end{array}\right\} 1350360=\$ 439126$

The weight lost by the produce of one acre in drying $1265910 \quad 0$

$64 \mathrm{dr}$. of grass afford of nutritive matter $3.2 \mathrm{dr}$.

The produce of the space, ditto $\left.27.0 \frac{2}{5}\right\}$

$1816115=11531315$

The weight of nutritive matter which is lost

by leaving the crop till the seed be ripe,

being nearly one half of its value $\quad-\quad \begin{array}{llll}1283 & 15 & 3\end{array}$ $64 \mathrm{dr}$. of the roots afford of nutritive matter $5.2 \mathrm{dr}$.

The proportional value which the grass at the time the seed is ripe, bears to that at the time of flowering, is as $\mathbf{1 4}$ to 18 .

The above details prove this grass to have merits which, if compared with those of other species, rank it with some of the best grasses. The small loss of weight which it sustains in drying might be expected from the nature of the substance of the grass; and the loss of weight at each period is equal. The grass affords the greatest quantity of nutritive matter wlien in flower, which makes it rank as one of those best adapted for hay. 
LXVII. Poa fertilis. Var. B. Host. G. A. The species. Fertile meadow grass. Variety 1. Nat. of Germany.

At the time of flowering, the produce from a brown sandy loam is

Grass, 23 oz. The produce

oz. or lbs. per acre

per acre $\quad$ - $\quad 250470 \quad 0=15654 \quad 6 \quad 0$

$80 \mathrm{dr}$. of grass weigh

when dry - $34 \mathrm{dr}$.

The produce of the

space, ditto - $156 \frac{2}{5}$

The weight lost by the produce of one acre

in drying

$106148 \quad 0=6653$ \& 0

$64 \mathrm{dr}$. of grass afford

of nutritive matter $3 \mathrm{dr}$. $1174012=7331212$

The produce of the

space, ditto - $17.1 \mathrm{dr}$.

At the time the seed is ripe, the produce is

Grass, $22 \mathrm{oz}$. The produce

$$
\begin{array}{llllll}
\text { per acre } & - & 239580 & 0 & =14973120
\end{array}
$$

$80 \mathrm{dr}$. of grass weigh

$\begin{array}{llll}\text { when dry } \quad 44 \mathrm{dr} . & (131769 \quad 0=8235 \quad 9 & 0\end{array}$

The produce of the space, ditto - $193.2 \mathrm{dr}$.

The weight lost by the produce of one acre $\begin{array}{lllllll}\text { in drying } & - & - & - & 6738 & 3 & 0\end{array}$

$64 \mathrm{dr}$. of grass afford of nutritive matter $5 \mathrm{dr}$.
he produce of the
space, ditto $-27.2 \mathrm{dr}$. 
oz. or lbs. per acre

The weight of nutritive matter which is lost

by taking the crop at the time of flowering,

exceeding one third part of its value, is $436 \quad 1 \quad 3$

The proportional value which the grass at the time of flowering, bears to that at the time the seed is ripe, is as 12 to 20.

The produce of latter-math is

Grass, $7 \mathrm{oz}$. The produce

$$
\text { per acre } \quad \text { - } \quad 76230 \quad 0=4764 \quad 6 \quad 0
$$

$64 \mathrm{dr}$. of grass afford

of nutritive matter $1.2 \mathrm{dr}$. $\} 178610=1111010$

The proportional value which the grass of the lattermath bears to that at the time of flowering, is as 6 to 12 ; and to that at the time the seed is ripe, as 6 to 20 .

LXVIII. Cynosurus erucaformis. Beckmannia erucæformis. Host. G. A. 3, t. 6.

Linear-spiked dog's-tail grass. Nat. of Germany.

At the time the seed is ripe, the produce is

Grass, 18 oz. The produce

$$
\text { per acre - } 196020 \quad 0=12251 \text { \& } 0
$$

$80 \mathrm{dr}$. of grass weigh

when dry - $36 \mathrm{dr}$.

The produce of the

space, ditto - 129.2 $\frac{2}{5}$

$882090=5513 \quad 10$

The weight lost by the produce of one acre

in drying - $\quad-\quad 673830$

$64 \mathrm{dr}$. of grass afford

$\left.\begin{array}{c}\text { of nutritive matter } 3.1 \mathrm{dr} . \\ \text { The produce of the }\end{array}\right\} 99542=62222$

space, ditto - $14.2 \frac{2}{4}$ 
LXIX. Phleum nodosum. W. B. 2, P. 118.

Bulbous stalked cat's-tail grass. Nat. of Britain.

At the time of flowering, the produce from a clayey loam is

Grass, $18 \mathrm{oz}$. The produce

oz. or lbs. per acre per acre - $\quad 196020 \quad 0=12251 \quad 4 \quad 0$

$80 \mathrm{dr}$. of grass weigh

$\begin{gathered}\text { when dry }-18 \mathrm{dr} . \\ \text { The produce of the }\end{gathered} 931098=581958$ space, ditto - 136 $\frac{4}{5}$

The weight lost by the produce of one acre

in drying - $\quad$ - $\quad$ - 6431148

$64 \mathrm{dr}$. of grass afford

of nutritive matter $2.2 \mathrm{dr}$.

The produce of the

$7657 \quad 0=478 \quad 9 \quad 0$ space, ditto - $11.1 \mathrm{dr}$.

This grass is inferior in many respects to the Phleum pratense. It is sparingly found in meadows. From the number of bulbs which grow out of the straws, a greater portion of nutritive matter might have been expected. This seems to prove, that these bulbs do not form so valuable a part of the plant as the joints, which are so conspicuous in the Phleum pratense, the nutritive powers of which exceed those of the $P$. nodosum, as 8 to 28 .

LXX. Phleum pratense. Wither. 2. P. 117. Meadow cat's-tail grass. Nat. of Britain.

At the time of flowering, the produce from a clayey loam is

Grass, $60 \mathrm{oz}$. The produce

per acre

$653400 \quad 0=40837 \quad 8 \cdot 0$ 
oz. or lbs. per acre

So dr. of grass weigh when dry - $34 \mathrm{dr}$. $\left\{\begin{array}{llll}277695 & 0=1735515 & 0\end{array}\right.$

The produce of the space, ditto - $408 \mathrm{dr}$.

'I'he weight lost by the produce of one acre in drying $\quad-\quad 2 \quad-\quad 2348190$

$64 \mathrm{dr}$. of grass afford

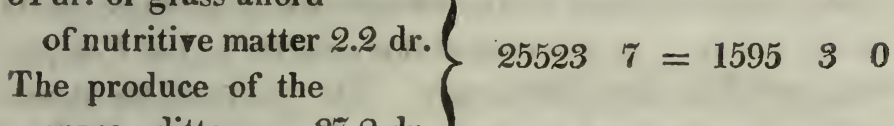
space, ditto - $37.2 \mathrm{dr}$. )

The weight of nutritive matter, which is lost by leaving the crop till the seed be ripe, exceeding one half of its value

At the time the seed is ripe, the produce is

Grass, $60 \mathrm{oz}$. The produce per acre - $\quad-653400 \quad 0=40837 \quad 8 \quad 0$

$80 \mathrm{dr}$. of grass weigh when

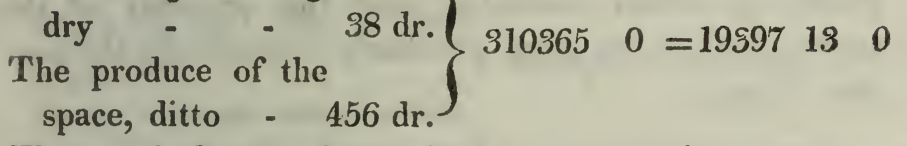

The weight lost by the produce of one acre in drying 21439110 $64 \mathrm{dr}$. of grass afford
of nutritive matter $5.3 \mathrm{dr}$.

The produce of the

$5870314=36681514$ space, ditto - $86.1 \mathrm{dr}$. )

The latter-math produce is

Grass, $14 \mathrm{oz}$. The produce per acre - - $152460 \quad 0=952812 \quad 0$

$64 \mathrm{dr}$. of grass afford of nu-

tritive matter $2 \mathrm{dr}$. - $47646=297126$ $64 \mathrm{dr}$. of the straws afford of nutritive matter $7 \mathrm{dr}$. The G G 2 
nutritive powers of the straws simply, therefore, exceed those of the leaves, in proportion as 28 to 8 ; and the grass at the time of flowering, to that at the time the seed is ripe, as 10 to 23 ; and the latter-math to the grass of the flowering crop, as 8 to 10 .

The comparative merits of this grass will appear, from the above particulars, to be very great; to which may be added the abundance of fine foliage that it produces early in the spring. In this respect it is inferior to the Poa fertilis, and Poa angustifolia only. The value of the straws at the time the seed is ripe, exceeds that of the grass at the time of flowering, as 28 to 10 ; a circumstance which increases its value above many others: for, by this property, its valuable early foliage may be cropped, to an advanced period of the season, without injury to the crop of hay, which, in other grasses which send forth their flowering straws early in the season, would cause a loss of nearly one half of the value of the crop, as is clearly proved by former examples; and this property of the straws, makes the plant peculiarly valuable for the purpose of hay.

LXXI. Phleum pratense. Var. minor. Wither. B. 2, 118. Var. 1.

Meadow cat's-tail grass. Var. Smaller. Nat. of Britain.

At the time of ripening the seed, the produce from a clayey loam, is

Grass, $40 \mathrm{oz}$. The produce

oz. or lbs. per acre

per acre $\quad$ - $\quad 435600 \quad 0=2722500$

$80 \mathrm{dr}$. of grass weigh

when dry - $34 \mathrm{dr}$.

The produce of the

$185130 \quad 0=11570 \quad 10 \quad 0$ space, ditto - $272 \mathrm{dr}$. 
oz. or lbs. per acre

The weight lost by the produce of one acre in drying - $\quad-\quad$ - $\quad-1565460$

$64 \mathrm{dr}$. of grass afford of nutritive matter - $2.3 \mathrm{dr}$.

The produce of the

$18173=1169133$ space, ditto - $272 \mathrm{dr}$.)

The latter-math produce is

Grass, $14 \mathrm{oz}$. The produce peracre $\quad 1524600=9528120$

$64 \mathrm{dr}$. of grass afford of nu-

tritive matter $1.2 \mathrm{dr}$. $\quad-\quad 35734=22354$

LXXII. Elymus arenarius. Engl. Bot. 1672.

Upright sea lyme grass. Nat. of Britain.

At the time the seed is ripe, the produce from a clayey loam, is

Grass, $64 \mathrm{oz}$. The produce

per acre $\quad-\quad 696960 \quad 0=43560 \quad 0 \quad 0$

$80 \mathrm{dr}$. of grass weigh when

$\left.\begin{array}{l}\text { dry } \\ \text { The produce of the } \\ \text { space, ditto } 576 \mathrm{dr} .\end{array}\right\} \begin{array}{llll}392040 & 0=24502 & 8 & 0\end{array}$

The weight lost by the produce of one acre in drying - $\quad$ - 1895780 $64 \mathrm{dr}$. of grass afford of nutritive matter $5 \mathrm{dr}$. $\left\{\begin{array}{l}544500=340320 \\ 20\end{array}\right.$ The produce of the space, ditto - $80 \mathrm{dr}$. 
LXXIII. Elymus geniculatus. Pendulous lyme grass. Engl. Bot. 1586.

Pendulous sea lyme grass. Nat. of England.

At the time of flowering, the produce from a sandy soil, is

Grass, $30 \mathrm{oz}$. The produce

oz. or Ibs. per acre per acre - $\quad 326700 \quad 0=20418 \quad 12 \quad 0$ $80 \mathrm{dr}$. of grass weigh when dry - $32 \mathrm{dr}$. The produce of the space, ditto - $192 \mathrm{dr}$.

$130680 \quad 0=8167 \quad 8 \quad 0$

The weight lost by the produce of one acre in drying $64 \mathrm{dr}$. of grass afford

of nutritive matter $3.1 \mathrm{dr}$. The produce of the space, ditto $\left.-24.1 \frac{\pi}{2}\right\}$

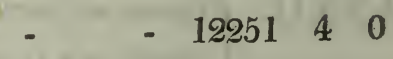

LXXIV. Bromus inermis. Host. G. A. 1, t. 9.

Awnless brome grass. Nat. of Germany. Introduced by Mr. Hunneman in 1794 .

At the time the seed is ripe, the produce from a black sandy soil, is

Grass, $18 \mathrm{oz}$. The produce

per acre - - $196020 \quad 0=12251 \quad 4 \quad 0$

$80 \mathrm{dr}$. of grass weigh when

$\left.\begin{array}{l}\text { dry }-\quad 35 \mathrm{dr} . \\ \begin{array}{c}\text { The produce of the } \\ \text { space, ditto }-126 \mathrm{dr} .\end{array}\end{array}\right\} 8575812=53591412$

The weight lost by the pro-

duce of one acre in drying - - 68915 


\section{APPENDIX.}

oz. or lbs. per acre

64 dr. of grass afford of nutritive matter - $4.1 \mathrm{dr}$.

The produce of the

$1301615=813815$ space, ditto - $19.0 \frac{3}{5}$

The produce of latter-math is

Grass, $13 \mathrm{oz}$. 'The produce

peracre - - $\quad 141570 \quad 0=8848 \quad 2 \quad 0$

$64 \mathrm{dr}$. of grass afford of nu-

tritive matter $1.1 \mathrm{dr} . \quad$ - $27650=172130$

LXXV. Agrostis vulgaris. Wither. Bot. 2, 132. Hud.

A. capilaris, Dr. Smith, A. arenaria.

Fine bent grass. Nat. of Britain.

At the time the seed is ripe, the produce from a sandy soil, is

Grass, $14 \mathrm{oz}$. The produce

per acre - $\quad-152460 \quad 0=9528120$

$80 \mathrm{dr}$. of grass weigh

when dry
The produce of the

$76230 \quad 0=4764 \quad 6 \quad 0$

space, ditto - $112 \mathrm{dr}$.

The weight lost by the pro-

duce of one acre in drying - $\quad 4764 \quad 6 \quad 0$ $64 \mathrm{dr}$. of grass afford

of nutritive matter $1.2 \frac{3}{16} \mathrm{dr}$.

The produce of the

space, ditto - $5.1_{\frac{\mathrm{T}}{\mathrm{T}}}$

$$
401915=251315
$$

This is one of the most common of the bents, likewise the earliest; in these respects it is superior to all others of the same family, but inferior to several of them in produce, and the quantity of nutritive matter it affords. As the species of this family are generally rejected by the 
cultivator, on account of the lateness of their flowering; and this circumstance, as has already been observed, does not always imply a proportional lateness of foliage, their comparative merits in this respect may be better seen, by bringing them into one view, as to the value of their early foliage.

The apparent difference of time.

Agrostis vulgaris

palustris

stolonifera

canina

stricte

nivea

littoralis

repens

mexicana

fascicularis
Middle of April

One week later

Two, ditto

Ditto, ditto

Ditto, ditto

Three weeks, ditto

Ditto,

Ditto,

Ditto,

Ditto, ditto

ditto

ditto

ditto
Their nutritive powers.

LXXVI. Agrostis palustris. Wither. Bot. 2, P. 129. Var. 2, alba. Engl. Bot. 1189. A. alba. Marsh bent grass.

At the time of flowering, the produce from a bog-earth, is

oz. or lbs. per acre

Grass, 15 oz. The produce per acre
- 163350
$6=10209 \quad 6 \quad 0$

$30 \mathrm{dr}$. of grass weigh

$\left.\begin{array}{c}\text { when dry } \\ \text { The produce of the } \\ \text { space, ditto }-108 \mathrm{dr} .\end{array}\right\} 735078=459438$

The weight lost by the produce of one acre in drying 
$64 \mathrm{dr}$. of grass afford

oz. or lbs. per acre $\left.\begin{array}{c}\text { of nutritive matter } 2.3 \mathrm{dr} . \\ \text { The produce of the }\end{array}\right\} 701815=4381015$ space, ditto - $10.1 \frac{\mathrm{x}}{4}$

At the time the seed is ripe the produce is

Grass, $20 \mathrm{oz}$. The produce

per acre - $\quad 217800 \quad 0=13612 \quad 8 \quad 0$

$80 \mathrm{dr}$. of grass weigh

when dry - $32 \mathrm{dr}$.

The produce of the space, ditto - $128 \mathrm{dr}$.

$87120 \quad 0=5445 \quad 0 \quad 0$

The weight lost by the pro-

duce of one acre in drying $\quad-\quad 8167 \quad 8 \quad 0$

$64 \mathrm{dr}$. of grass afford

$\left.\begin{array}{l}\text { of nutritive matter } 2.3 \mathrm{dr} . \\ \text { The produce of the }\end{array}\right\} 93589=584149$ space, ditto - $13.3 \mathrm{dr}$.

The weight of nutritive matter which is lost by taking the crop at the time of flowering, being one fourth part of its value $146 \quad 3 \quad 10$ The proportional value of grass, in each crop, is equal.

LXXVII. Panicum dactylon. Engl. Bot. 850. Host. G. A. 2, t. 18.

Creeping Panic grass. Nat. of Britain.

At the time of flowering, the produce from a sandy loam, with manure is

Grass, $46 \mathrm{oz}$. The produce

$$
\text { per acre - - - } 500940 \quad 0=3130812 \quad 0
$$

$80 \mathrm{dr}$. of grass weigh

when dry - $-36 \mathrm{dr}$.

The produce of the

$2251230=14088 \quad 150$

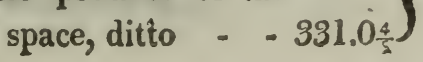


The weight lost by the pro-

duce of one acre in drying

oz. or lbs. per acre $64 \mathrm{dr}$. of grass afford of nutritive matter $2 \mathrm{dr}$. The produce of the space, ditto - $-23 \mathrm{dr}$.

LXXVIII. Agrostis stolonifera. Engl. Bot. 1532. Wither. Bot. 2, 181. (Fiorin, Dr. Richardson.)

Creeping bent. Nat. of Britain.

At the time of flowering, the produce from a bog soil, is

Grass, $26 \mathrm{oz}$. The pro-

duce per acre - $\quad 283140 \quad 0=17696 \quad 4 \quad 0$

$80 \mathrm{dr}$. of grass weigh when dry - $35 \mathrm{dr}$.

The produce of the space, ditto - $182 \mathrm{dr}$.

$12387312=7742 \quad 112$

The weight lost by the produce of one acre $\begin{array}{llll}9732 & 15 & 0\end{array}$ $64 \mathrm{dr}$. of grass afford of nutritive matter $3.2 \mathrm{dr} .\{154843=967123$ The produce of the space, ditto - $22.3 \mathrm{dr}$.

At the time the seed is ripe, the produce is Grass, $28 \mathrm{oz}$. The produce per acre - $\quad 304920 \quad 0=19057 \quad 8 \quad 0$ $80 \mathrm{dr}$. of grass weigh when dry - . $36 \mathrm{dr}$. The produce of the

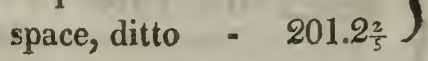
$1372140=857514 \quad 0$ 


\section{APPENDIX.}

oz. or lbs. per acre

The weight lost by the produce of one acre in drying

$64 \mathrm{dr}$. of grass afford of nutritive matter $3.2 \mathrm{dr}$.

The produce of the $166750=104235$ space, ditto - $24.2 \mathrm{dr}$.

The weight of nutritive matter which is lost by taking the crop at the time of flowering, being nearly one fourteenth of its value

LXXIX. Agrostis stolonifera. Var. angustifolia. Creeping bent, with narrow leaves. Nat. of Britain.

At the time the seed is ripe, the produce from a bog soil, is

Grass, 24 oz. The produce

oz. or lbs. peracre

$$
\text { per acre - } \quad 261360 \quad 0=16335 \quad 0 \quad 0
$$

$80 \mathrm{dr}$. of grass weigh

$\left.\begin{array}{c}\text { whendry }-36 \mathrm{dr} . \\ \text { The produce of the } \\ \text { space, ditto }-172.3 \frac{\mathrm{x}}{\mathrm{S}}\end{array}\right\} 1176120=7350120$

The weight lost by the pro-

duce of one acre in drying $\quad-\quad 8984 \quad 4 \quad 0$ $64 \mathrm{dr}$. of grass afford

of nutritive matter $3 \mathrm{dr}$. space, ditto - - $18 \mathrm{dr}$.

The weight of nutritive matter afforded by the produce of one acre of the Agrostis stolonifera, exceeding that of the variety in proportion, is 6 to 8 
The above details will assist the farmer in deciding on the comparative value of this grass. From a careful examination it will doubtless appear to possess merits well worthy of attention, though perhaps not so great as has been supposed, if the natural place of its growth and habits be impartially taken into the account. From the couchant nature of this grass, it is denominated couch-grass, by practical men, and from the length of time that it retains the vital power, after being taken out of the soil, is called squitch, quick, full of life, \&c.

LXXX. Agrostis canina. Engl. Bot. 1856.

Brown bent. Nat. of Britain.

At the time of flowering, the produce from a brown sandy loam, is

Grass, $9 \mathrm{oz}$. The produce

per acre $\quad-\quad \quad 98010 \quad 0=612510 \quad 0$

$80 \mathrm{dr}$. of grass weigh

when dry - $34 \mathrm{dr}$.

The produce of the

$$
\text { space, ditto } \quad-63 \frac{x}{5}
$$

oz. or lbs. peracre

The weight lost by the pro-

duce of one acre in drying $\quad-\quad 3437 \quad 5 \quad 0$

$64 \mathrm{dr}$. of grass afford

of nutritive matter $2.2 \mathrm{dr}$.

The produce of the

space, ditto - $5.21 \frac{x}{2}$

$43013 \quad 0=2688 \quad 5 \quad 0$

LXXXI. Agrostis canina. Var. muticæ.

A wnless brown bent. Nat. of Britain.

At the time the seed is ripe, the produce from a sandy soil is

Grass, 21 oz. The produce

per acre $\quad-\quad-2286900=1429320$ 
oz. or lbs. per acre

$80 \mathrm{dr}$. of grass weigh when dry

The produce of the - $24 \mathrm{dr}$. space, ditto $\left.\quad-100.3 \frac{\mathrm{r}}{\mathrm{s}}\right\}$

The weight lost by the produce of one acre in drying - $\quad-\quad-1000530$ $64 \mathrm{dr}$. of grass afford of nutritive matter $1.3 \mathrm{dr}$.

The produce of the $686070=4287150$ space, ditto - 9.0.3

The weight of nutritive matter which the produce of one acre of the awnless variety,. exceeds that of the last mentioned species 151811

LXXXI1. Agrostis stricta. Curt. A. rubra.

Upright bent grass. Nat. of Britain.

At the time the seed is ripe, the produce from a bog soil, is

Grass, 11 oz. The produce per acre - $\quad 119790 \quad 0=748614 \quad 0$ $80 \mathrm{dr}$. of grass weigh when dry - $29 \mathrm{dr}$. The produce of the space, ditto - $-63 \frac{4}{5} \mathrm{dr}$.

The weight lost by the produce of one acre in drying

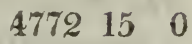
$64 \mathrm{dr}$. of grass afford of nutritive matter $1.2 \mathrm{dr}$. The produce of the $28079=17579$ space, ditto $\quad 4.0 \frac{5}{10}$ 
LXXXIII. Agrostis nivea.

Snowy bent grass. Nat. of Britain.

At the time the seed is ripe, the produce from a sandy soil, is

Grass, 7 oz. The produce

oz. or lbs. per acre per acre - - $\quad .762300=476460$ $08 \mathrm{dr}$. of grass weigh when dry - $22 \mathrm{dr}$. The produce of the space, ditto - $-30.3 \frac{x}{5}$

The weight lost by the produce of one acre in drying 345430 $64 \mathrm{dr}$. of grass afford of nutritive matter $2 \mathrm{dr}$. The produce of the space, ditto $-3 \frac{\mathrm{I}}{2} \mathrm{dr}$.

$209634=131030$ LXXXIV. Agrostis fascicularis. Huds. Var. canina. Curt. Tufted leaved bent. Nat. of Britain.

At the time of flowering, the produce from a light sandy soil, is

Grass 4 oz. The produce per acre $\quad-\quad-43560 \quad 0=2722 \quad 8 \quad 0$ $80 \mathrm{dr}$. of grass weigh when dry - - $\quad 20 \mathrm{dr}$.

The produce of the space, ditto - $-16 \mathrm{dr}$.

The weight lost by the produce of one acre in drying $64 \mathrm{dr}$. of grass afford of nutritive matter $2 \mathrm{dr}$. The produce of the $108900=680100$ space, ditto - $\quad-2 \mathrm{dr}$.

$2041 \quad 14 \quad 0$ $13614=8514$ 
LXXXV. Festuca pinnata. Bromus pinnatus. Engl. Bot. 730.

Spiked fescue. Nat. of Britain.

At the time the seed is ripe, the produce from a light sandy soil, with manure, is

Grass, $30 \mathrm{oz}$. The produce

oz. or lbs. per acre

$$
\text { per acre - - } 326700 \quad 0=2041812 \quad 0
$$

$80 \mathrm{dr}$. of grass weigh

when dry - $32 \mathrm{dr}$.

The produce of the $\} 1306800=3167 \& 0$ space, ditto - $192 \mathrm{dr}$.

'The weight lost by the produce of one acre

in drying - $\quad-\quad 4 \quad \begin{array}{lll}12251 & 4 & 0\end{array}$

$64 \mathrm{dr}$. of grass afford

of nutritive matter $1.1 \mathrm{dr}$.

The produce of the

space, ditto

$-9.1 \frac{2}{4}$

$638013=3981213$

LXXXVI. Panicum viride. Curt. Lond. Engl. Bot. 875.

Green panic grass. Nat. of Britain.

At the time the seed is ripe, the produce from a light sandy soil, is

Grass, 8 oz. The produce

per acre - - $87120 \quad 0=5445 \quad 0 \quad 0$

$80 \mathrm{dr}$. of grass weigh

when dry - $32 \mathrm{dr}$. $\left.\begin{array}{c}\begin{array}{c}\text { when dry }- \\ \text { The produce of the }\end{array} \\ \text { space, ditto - }-51 \frac{\mathrm{x}}{5}\end{array}\right\} 348480=217800$

The weight lost by the produce of one acre in drying 
$64 \mathrm{dr}$. of grass afford of nutritive matter $1.2 \mathrm{dr}$. The produce of the space, ditto $\quad-3 \mathrm{dr}$.

oz. or lbs. per acre $204114=127914$

LXXXVII. Panicum sanguinale. Curt. Lond. Engl. Bot. 849.

Blood coloured panic grass. Nat. of Britain.

At the time the seed is ripe the produce from a sandy soil, is

Grass, $10 \mathrm{oz}$. The produce peracre - $\quad 108900 \quad 0=6806 \quad 4 \quad 0$ $64 \mathrm{dr}$. of grass afford of nutritive matter $\quad-\quad 1.0_{\frac{1}{16}}^{2} \quad 1914 \quad=119104$

This and the preceding species are strictly annual, and from the results of this trial, their nutritive powers appear to be very inconsiderable. The seed of this species, Mr. Schreber describes (in Beschreibung der Graser) as the manna grass. In Poland, Lithuania, \&cc. it is collected in great abundance, when, after being thoroughly separated from the husks, it is fit for use. When boiled with milk, or wine, it forms an extremely palatable food, and is most commonly made use of whole, in the manner of sago, to which it is in general preferred. 
LXXXVIII. Agrostis lobata. Curtis, lobata et arenaria. Lobed bent grass.

At the time of flowering, the produce from a sandy soil, is

Grass, 10 oz. The produce

oz. or lbs. per acre per acre - $\quad 108900 \quad 0=6806 \quad 4 \quad 0$

$80 \mathrm{dr}$. of grass weigh . when dry - $40 \mathrm{dr}$. $\left.\begin{array}{c}\text { The produce of the } \\ \text { space, ditto }-80 \mathrm{dr} .\end{array}\right\} \begin{array}{lll}5450 & 0=340320\end{array}$

The weight lost by the produce of one acre in drying - - $\quad-\quad 340320$ $64 \mathrm{dr}$. of grass afford of nutritive matter $3 \mathrm{dr}$.

The produce of the space, ditto $\quad-7.2 \mathrm{dr}$.

LXXXIX. Agrostis repens. Whither. Bot. A. nigra. Creeping rooted bent, black bent. 'Nat. of Britain.

At the time of flowering, the produce from a clayey loam, is

Grass, 9 oz. 'The produce per acre - - $98010 \quad 0=612510 \quad 0$ $80 \mathrm{dr}$. of grass weigh
when dry -
- $35 \mathrm{dr}$. $\left.\begin{array}{c}\text { The produce of the } \\ \text { space, ditto - } 63 \mathrm{dr} .\end{array}\right\} 428796=2679156$

The weight lost by the produce of one acre in drying 
oz. or lbs. per acre

$64 \mathrm{dr}$. of grass afford of nutritive matter $3 \mathrm{dr}$. The produce of the - space, ditto - $6.3 \mathrm{dr}$.

$$
45943=28723
$$

XC. Agrostis Mexicana. Hort. Kew. 1. P. 150.

Mexican bent grass. Nat. of S. America. Introduced, 1780, by M. G. Alexander.

At the time of flowering the produce from a black sandy soil, is

Grass, 28 oz. The produce

$$
\text { per acre } \quad-\quad 304920 \quad 0=19057 \quad 8 \quad 0
$$

$80 \mathrm{dr}$. of grass weigh

when dry - $28 \mathrm{dr}$.

The produce of the space, ditto - $\left.156.3 \frac{\mathrm{r}}{\mathrm{s}} \mathrm{dr}.\right)$

$1067220=667020$

The weight lost by the produce of one acre in
drying
$12387 \quad 6 \quad 0$

$64 \mathrm{dr}$. of grass afford of nutritive matter $2 \mathrm{dr}$. The produce of the space, ditto - $14 \mathrm{dr}$. .

$$
952812=595812
$$

XCI. Stipa pennata. Eng. Bot. 1356.

Long-awned feather grass. Nat. of Britain.

At the time of flowering, the produce from a heath soil, is,

Grass, 14 oz. The produce

$$
\text { per acre - } \quad 152460 \quad 0=9528120
$$


oz. or lbs. per acre

$80 \mathrm{dr}$. of grass weigh when dry - $29 \mathrm{dr}$. The produce of the $5526612=3454212$ space, ditto - $81 \frac{1}{5} \mathrm{dr}$.

The weight lost by the produce of one acre in drying - - $\quad$ - $\quad$ - $\quad 60749$ $64 \mathrm{dr}$. of grass afford of nutritive matter $2.3 \mathrm{dr}$.

The produce of the $65510=40970$ space, ditto - $\left.9.2 \frac{1}{2}\right\}$

XCII. Triticum repens. Engl. Bot. 909.

Creeping rooted wheat grass. Nat. of Britain.

At the time of flowering, the produce from a light clayey loam, is

Grass, $18 \mathrm{oz}$. The produce

per acre - $\quad-196020 \quad 0=12251 \quad 4 \quad 0$

$80 \mathrm{dr}$. of grass weigh when dry - $32 \mathrm{dr}$.

The prorluce of the

$784080=49008 \quad 0$ space, ditto - $\left.115 \frac{1}{3}\right\}$

The weight lost by the produce of one acre in

drying - $\quad$ - $\quad$ - 7350120

$64 \mathrm{dr}$. of grass afford of nutritive matter $2 \mathrm{dr}$.

The produce of the $612510=3821310$ space, ditto - $9 \mathrm{dr}$.

$64 \mathrm{dr}$. of the roots, afford of nutritive matter $5.3 \mathrm{dr}$. The proportional value of the roots, is therefore to that of the grass, as 23 to 8. 
XCIII. Alopecurus agrestis. Engl. Bot.848. A. myosuroides.

Slender fox-tail grass. Nat. of Britain. Curt. Lond.

At the time of flowering, the produce from a light sandy loam, is

Grass, $12 \mathrm{oz}$. The produce

per acre - - $130680 \quad 0=8167 \quad 8 \quad 0$

$80 \mathrm{dr}$. of grass weigh . when dry - $31 \mathrm{dr}$.

The produce of the

oz. or lbs. per acre space, ditto $-74.1 \frac{3}{5} \mathrm{dr}$.

$64 \mathrm{dr}$. of grass afford of nutritive matter $1.3 \mathrm{dr}$.

The produce of the space, ditto - $5.1 \mathrm{dr}$.

$506388=3164 \quad 14 \quad 8$

$3573 \quad 4=223 \quad 5 \quad 4$

XCIV. Bromus asper. Engl. Bot. 1172. Curt. Lond. Bromus hirsutus. Huds. Bromus ramosus. B. sylvaticus, volger. B. altissimus. Hairy stalked brome grass. Nat. of Britain.

, At the time of flowering, the produce from a light sandy soil, is

Grass, 20 oz. The produce

$$
\text { per acre - } \quad 217800 \quad 0=13612 \quad 8 \quad 0
$$

$80 \mathrm{dr}$. of grass weigh

when dry - $24 \mathrm{dr}$.

The produce of the space, ditto - $96 \mathrm{dr}$.

$653400=408312 \quad 0$ 
oz. or lbs. per acre

The weight lost by the produce of one acre in drying $\quad-\quad$ - $\quad-\quad-\quad 952812 \quad 0$

$64 \mathrm{dr}$. of grass afford of nutritive matter $2 \mathrm{dr}$.

The produce of the

$68064=425 \quad 6 \quad 4$ space, ditto $-10 \mathrm{dr}$.

XCV. Phalaris canariensis. Engl. Bot. 1310.

Common canary grass. Nat. of Britain.

At the time of flowering, the produce from a clayey loam, is

Grass, 80 oz. The produce

$$
\text { per acre - - } 871200 \quad 0=54450 \quad 0 \quad 0
$$

$80 \mathrm{dr}$. of grass weigh

when dry - $26 \mathrm{dr}$. $\left.\begin{array}{l}\text { The produce oi the } \\ \text { space, ditto - } 416 \mathrm{dr} .\end{array}\right\} 283177 \mathrm{~S}=17697 \quad 98$

The produce in weight lost by drying $\quad-\quad \begin{array}{lll}36752 & 6 & 6\end{array}$ $64 \mathrm{dr}$. of grass afford

of nutritive matter $1.2 \mathrm{dr}$.

The produce of the

$2041812=1876212$ space, ditto - $30 \mathrm{dr}$.

XCVI. Melica cerrulea. Curt. Lond. Engl. Bot. 750. Purple melic grass. Nat. of Britain.

At the time of flowering, the produce from a light sandy soil, is

Grass, $11 \mathrm{oz}$. The produce

per acre

$119790 \quad 0=7486 \quad 14 \quad 0$ 
oz. or lbs. per acre

$80 \mathrm{dr}$. of grass weigh when dry $\quad-\quad 30 \mathrm{dr}$.

The produce of the space, ditto - $66 \mathrm{dr}$.

The weight lost by the produce of one acre in drying

64 ds. of grass afford

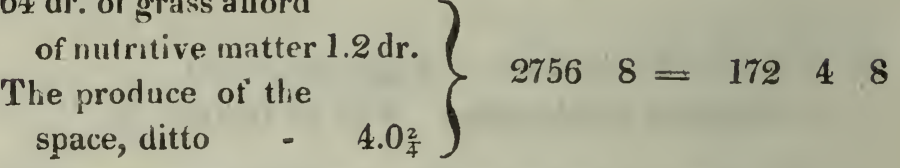

XCV1I. Drctylis cynosuroides. Linn. fil. fasci. 1, P. 17. American cock's foot grass. Nat. of N. America.

At the time of flowering, the produce from a clayey loam, is

Grass, 102 oz. The pro-

duce per acre - $\quad 111780 \quad 0=69423 \quad 10$

$80 \mathrm{dr}$. of grass weigh

when dry - $48 \mathrm{dr}$. $\left.\begin{array}{l}\text { when dry } \\ \begin{array}{c}\text { The produce of the } \\ \text { space, ditto }\end{array} \text { 979 } \mathrm{dr} \text {. } \mathrm{dr} \text {. }\end{array}\right\} \begin{array}{lll}666468 & 0=41654 \quad 4 \quad 0\end{array}$

The weight lost by the produce of one acre

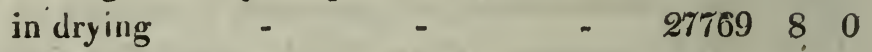
$64 \mathrm{dr}$. of grass afford of nutritive matter $1.3 \mathrm{dr}$. The produce of the space, ditto - $44.2 \frac{2}{4}$ 
Of the Time in which different Grasses produce Flowers and Seeds.

To decide positively the exact period or season, when a grass always comes into flower, and perfects its seed, will be found impracticable; for a variety of circumstances interfere. Each species seems to possess a peculiar life in which various periods may be distinctly marked, according to the varieties of its age, of the seasons, soils, exposures, and mode of culture.

The following Table, which shews the time of flowering, and the time of ripening the seed of those grasses growing at Woburn, which are mentioned in the Experiments, must therefore only be considered as serving for a test of comparison, for the different grasses, growing under the same circumstances.

\begin{tabular}{|c|c|c|}
\hline Names. & Time of flowering. & $\begin{array}{l}\text { Time of ripening } \\
\text { the Seed. }\end{array}$ \\
\hline Anthoxanthum odoratum & April 29 & June 21 \\
\hline Holcus odoratus & April 29 & June 25 \\
\hline Cynosurus cæruleus & April 30 & June 20 \\
\hline Alopecurus pratensis & May 20 & June 24 \\
\hline Alopecurus alpinus & May 20 & June 24 \\
\hline Poa alpina & May 30 & June 30 \\
\hline Poa pratensis & May 30 & July 14 \\
\hline Poa cærulea & May 30 & July \\
\hline Avena pubescens & June 13 & July \\
\hline Festuca hordiformis & June 13 & July \\
\hline Poa trivialis & June 13 & July \\
\hline Festuca glauca & June 13 & July \\
\hline Festuca glabra & June 16 & July \\
\hline Festuca rubra & June 20 & July \\
\hline Festuca ovina & June 24 & July \\
\hline Briza Media & June 24 & July \\
\hline Dactylis glomerata & June 24 & July \\
\hline Bromus tectorum & June 21 & July \\
\hline Festuca cambrica & June 28 & July \\
\hline Bromus diandrus & June 28 & July 16 \\
\hline
\end{tabular}




\begin{tabular}{|c|c|c|c|}
\hline Names. & Time of flowering. & $\begin{array}{l}\text { Time of rip } \\
\text { the See }\end{array}$ & $\begin{array}{l}\text { ipening } \\
\text { ed. }\end{array}$ \\
\hline Poa angustifulia & June 28 & July & 16 \\
\hline Avena elatior & June 28 & July & 16 \\
\hline Poa elatior & June 28 & July & 16 \\
\hline Festuca duriuscula & July 1 & July & 20 \\
\hline Milium effusum & July & July & 20 \\
\hline Festuca pratensis & July & July & 20 \\
\hline Lolium perenne & July & July & 20 \\
\hline Cynosurus cristatus & July & July & 28 \\
\hline Avena pratensis & July & July & 20 \\
\hline Bromus multiflorus & Juiy & July & 28 \\
\hline Festuca loliacea & July & July & 28 \\
\hline Poa cristata & July & July & 28 \\
\hline Festuca myurus & July & $J_{u} l_{y}$ & 28 \\
\hline Aira fl xuosa & July 6 & July & 28 \\
\hline Hordeum bulbosum & July 10 & July & 28 \\
\hline Festuca calamaria & July 10 & July & 28 \\
\hline Bromus littoreus & July 12 & Aug. & 6 \\
\hline Festuca elatior & July 12 & Aug. & 6 \\
\hline Nardus stricta & July & Aug. & 6 \\
\hline Iriticum, (species of) & July & Aug. & 10 \\
\hline Fentuca fluitans & July 14 & Aug. & 12 \\
\hline Festuca dumetorum & July 14 & July & 20 \\
\hline Holcus lanatus & July 14 & July & 26 \\
\hline Poa fertilis & July & July & 28 \\
\hline Arundo colorata & July & July & 28 \\
\hline Poa, (species of) & July 16 & July & 30 \\
\hline Cynosurus erucæformis & July 16 & July & 30 \\
\hline Phleum nodosum & July 16 & July & 30 \\
\hline Phleum pratense & July 16 & July & 30 \\
\hline Elynus arenarius & July 16 & July & 30 \\
\hline Elymus geniculatus & July 18 & July & 30 \\
\hline Trifolium pratense & July 18 & July & 30 \\
\hline Trilolium pratense & July 18 & Juiv & 30 \\
\hline Trifolium macrorhizum & July 18 & July & 30 \\
\hline Sangui iorba crnadensis & July 18 & July. & 30 \\
\hline Bunias orientalis & July 18 & July & 30 \\
\hline Medicago sativa & July 18 & Aug. & 6 \\
\hline Hedyarum onobrychis & July 18 & Auğ. & 8 \\
\hline Hordeum pratense & July 20 & Aug. & 8 \\
\hline Poa compressa & July 20 & Aug. & 8 \\
\hline
\end{tabular}




\begin{tabular}{|c|c|c|}
\hline Names. & Time of flowering. & $\begin{array}{l}\text { Tume of rupenusy } \\
\text { the Seed. }\end{array}$ \\
\hline Poa aquatica & July 20 & Aug. 8 \\
\hline Bromus cristatus & July 24 & Aug. 10 \\
\hline Elymus sibiricus & July 24 & Aug. 10 \\
\hline Aira caspitosa & July 24 & Aug. 10 \\
\hline Avena flavescens & July 24 & Aug. 15 \\
\hline Bromus sterilis & July & Aug. 20 \\
\hline Holcus mollis & July 24 & Aug. 20 \\
\hline Bromus inermis & July 24 & Aug. 20 \\
\hline Agrostis vulgaris & July 24 & Aug. 20 \\
\hline Agrostis palustris & July 28 & Aug. 28 \\
\hline Panicum dactylon & July 28 & Aug. 28 \\
\hline Agrostis stolonifera & July 28 & Aug. 2S \\
\hline Agrostis stolonifera (var.) & July 28 & Aug. 28 \\
\hline Agrostis canina & July 28 & Aug. $2 S$ \\
\hline Agrostis stricta & July 28 & Aug. 30 \\
\hline Festuca pennata & July 28 & Aug. 30 \\
\hline Panicum viride & Aug. 2 & Aug. 15 \\
\hline Panicum sanguinale & Aug. & $1 \mathrm{ug} .20$ \\
\hline Agrostis lobata & Aug. 6 & Aug. 20 \\
\hline Agrostis repens & Aug. 8 & Aug. 25 \\
\hline Agrostis fascicularis & Aug. 10 & Aug. 30 \\
\hline Agrostis nivea & Aug. 10 & Aug. 30 \\
\hline Triticum repens & Aug. 10 & Aug. 30 \\
\hline Alopecurus agrestis & Aug. 10 & Sept. 8 \\
\hline Bromus asper & Aug. 10 & Sept. 10 \\
\hline Agrostis mexicana & Aug. 15 & Sept. 25 \\
\hline Stipa pennata & Aug. 15 & Sept. 25 \\
\hline Melica cærulea & Aug. 20 & Sept. 30 \\
\hline Phalaris cananiensis & Aug. 50 & Sept. 30 \\
\hline Dactylis cynosuroides * & Aug. 30 & Oct. 20 \\
\hline
\end{tabular}

* In the experiments made on the quantity of nutritive matter in the grasses, cut at the time the seed was ripe, the seeds were always separated; and the calculations for nutritive matter, as is evident from the details. madl for grass and not hay. 
Of the different Soils referred to in the Appendix.

IN books on agriculture and gardening much uncertainty and confusion arises from the want of regular definitions of the various soils, to distinguish them specifically by the naines generally used: thus the term bog-earth, is almost constantly confounded with peat-moss, and heath-soil; also the term 'light loan,' ' heavy soil,' \&c. are given, without distinguishing whether that be 'light' from sand, or this 'heavy' from clay. In minute experiments, it is doubtless of consequence to bə as explicit as possible in those particulars. The following short descriptions of such soils as are mentioned in the details of the experiment are here given for the above purpose.

1st. By 'loam' is meant any of the earths combined with decayed animal, or vegetable matter.

2nd. ' Clayey-loam,' when the greatest proportion is clay.

3rd. 'Sandy-loam' when the greatest proportion is sand.

4th. 'Brown-loam' when the greatest proportion consists of decayed vegetable matter.

5th. ' Rich black loam,' when sand, clay, animal and vegetable matters are combined in unequal proportions, the clay greatly divided, being in the least proportion, and the sand and regretable matter in the greatest.

'The terus 'light sandy soil,' 'light brown loam,' \&c. are varieties of the above, as expressed. 
Observations on the chemical Composition of the nutritive Matter afforded by the Grasses in their different States. By the Editor.

I HAve made experiments on most of the soluble products supposed to contain the nutritive matter of the grasses, obtained by Mr. Sinclair; and I have analyzed a few of them. Minute details on this subject would be little interesting to the agriculturist, and would occupy a considerable space; I shall therefore content myself with mentioning some particular facts, and some general conclusions, which may tend to elucidate the inquiry respecting the fitness of the different grasses for permanent pas. ture, or for alternation, as green crops with grain.

The only substances which I have detected in the soluble matters procured from the grasses, are mucilage, sugar, bitter extract, a substance analogous to albumen, and different saline matters. Some of the products from the after-math crops gave feeble indications of the tanning principle.

The order in which these are nutritive has been mentioned in the First Lecture; the albumen, sugar, and mucilage, probably when cattle feed on grass or hay, are for the most part retained in the body of the animal; and the bitter principle, extract, saline matter, and tannin, when any exist, probably for the most part are voided in the excrement, with the woody fibre. 'The extractive matter obtained by boiling the fresh dung of cows, is extremely si- 
milar in chemical characters to that existing in the soluble products from the grasses. And some extract, obtained by Mr. Sinclair, from the dung of sheep and of deer, which had been feeding upon the Lolium perenne, Dactylis glomerata, and Trifolium repens, had qualities so analogous to those of the extractive matters obtained from the leaves of the grasses, that they might be mistaken for each other. The extract of the dung, after being kept for some weeks, had still the odour of hay. Suspecting that some undigested grass might have remained in the dung, which might have furnished mucilage and sugar, as well as bitter extract, I examined the soluble matter very carefully for these substances. It did not yield an atom of sugar, and scarcely a sensible quantity of mucilage.

Mr. Sinclair, in comparing the quantities of soluble matter afforded by the mixed leaves of the Lolium perenne, Dactylis glomerata, and Trifolium repens, and that obtained from the durg of cattle fed upon them, found their relative proportions as 50 to 13 .

It appears probable from these facts, that the bitter extract, though soluble in a large quantity of water, is very little nutritive; but probably it serves the purpose of preventing, to a certain extent, the fermentation of the other vegetable matters, or in modifying or assisting the function of digestion, and may thus be of considerable use in forming a constituent part of the food of cattle. A small quantity of bitter extract and saline matter is probably all that is neerled, and beyond this quantity the soluble matters must be more nutritive in proportion as they contain more albumen, sugar, and mucilage, and less nutritive in proportion, as they contain other substances.

In comparing the composition of the soluble products afforded by different crops from the same grass, I found, in 
all the trials I made, the largest quantity of truly nutritive matter, in the crop cut when the seed was ripe, and least bitter extract and saline matter; most extract and saline matter in the autumnal crop; and most saccharine matter, in proportion to the other ingredients, in the crop cut at the time of flowering. I shall give one instance :

100 parts of the soluble matter obtained from the Dactylis glomerata, cut in flower, afforded,

$\begin{array}{lllll}\text { Of sugar } & - & - & - & 18 \text { parts } \\ \text { Of mucilage } & - & - & - & 67\end{array}$

Of coloured extract, and saline matters, with some matter rendered insoluble by evaporation - 15

100 parts of the soluble matter from the seed crop afforded,

$\begin{array}{llllll}\text { Sugar - } & - & - & - & - & 9 \text { parts } \\ \text { Mucilage } & - & - & - & - & 85\end{array}$

Extract, insoluble, and saline matter 6

100 parts of soluble matter from the after-math crop give,

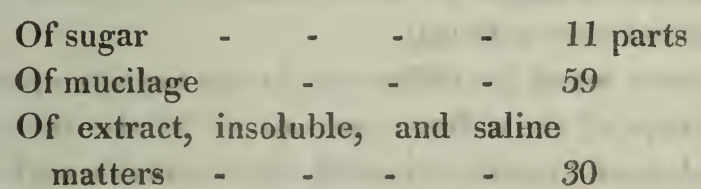

The: greater proportion of leaves in the spring, and particularly in the late autumnal crop, accounts for the difference in the quantity of extract; and the inferiority of the comparative quantity of sugar in the summer crop, 
probably depends upon the agency of light, which tends always in plants to convert saccharine matter into mucilage or starch.

Amongat the soluble matters afforded by the different grasses, that of the Elymus arenarius was remarkable for the quantity of saccharine matter it contained, amounting to more than one third of its weight. The soluble matters from the different species of Festuca, in general afforded more bitter extractive matter than those from the different species of Poa. The nutritive matter from the seed crop of the Poa compressa was almost pure muclage. The soluble matter of the seed crop of Phleum pratense, or meadow cat's tail, afforded more sugar than any of the Poa or Festuca species.

The soluble parts of the seed crop of the Holcus mollis and Holcus lanatus, contained no bitter extract, and consisted entirely of mucilage and sugar. Those of the Holcus odoratus afforded bitter extract, and a peculiar substance having an acrid taste, more soluble in alcohol than in water. All the soluble extracts of those grasses that are most liked by cattle, have either a saline or' subacid taste; that of the Holcus lanatus is similar in taste to gum arabic. Probably the Holcus lanatus, which is so common a grass in meadows, might be made palatable to cattle by being sprinkled over with salt.

I have found no. differences in the nutritive produce of the crops of the different grasses cut at the same season, which would render it possible to establish a scale of their nutritive powers; but probably the soluble matters of the after-math crop are always from one-sixth to one third less nutritive than those from the flower or seed crop. In the after-math the extractive and saline matters are certainly 
usually in excess; but the after-math hay mixed with summer hay, particularly that in which the fox-tail and soft grasses are abundant, would produce an excellent food.

Of the clovers, the soluble matter from the Dutch clover contains most mucilage, and most matter analogous to albumen: all the clovers contain more bitter extract and saline matter than the common proper grasses. When pure clover is to be mixed as fodder, it should be with summer hay, rather than after-math hay. 


\section{INDEX.}

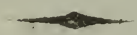

Page

Acids, account of those found in vegetables ......... 106

Age of trees, by what limited ................ 253

Alcohol, theory of its formation $\ldots \ldots \ldots \ldots \ldots \ldots$

Alburum, uses of $\ldots \ldots \ldots \ldots \ldots \ldots \ldots \ldots \ldots . \ldots . . \ldots 63$

Alkalies, method of ascertaining their presence in plants... 111

- effects produced by, in vegetation.......... 19

Animal substances, their cornposition, \&c........... 276

decomposition of .............. 274

Atmosphere, nature and constitution of .......... 206

Auimal matter, mode of ascertaining its existence in soils $\mathbf{1 6 7}$

Bark, its office and uses................. 57, 243

Barks, their relative value for tanning skin.......... 89

Blight in Corn, its cause . . . . . . . . . . . . . . . . . 265

Bread, its manufacture, theory of its production ....... 138

Burning, its use in improving soils.............. 346

Canker in trees, probable mode of curing ............ 264

Carbonic acid, a part of the atmosphere........... 210

Cements, on those obtained from limestone $\ldots \ldots \ldots . . . .326$

Chemistry, its application to agriculture......... 5

importance in agricultural pursuits..... 25

Combustibles, simple, referred to............... 45

Combustion, supporters of, mentioned............. 43 


\section{INDEX.}

Courses of crops, particular ones recommended........ 357

Corn, its tillering, theory of this operation.......... 234

Diseases of Plants, their causes discussed ......... 263

Earths, on those found in plants.............. 113

Electricity, its influence on vegetation............ 39

Elements chemical, of bodies................ 42

laws of their combinations ......... 51

Excrements, use of as manures................. 296

Fairy rings, their causes.................. 358

Fallowing, theory of ................ 23, 353

Fermentation, phænomena of ................. 131

Fly-turnip, plan for destroying or preventing......... 220

Flowers, their parts and office............... 68

Geology, referred to as teaching the nature of rocks.... 191

Grafting, general views on this process........... 253

Grasses, on those fit for pasture............... 361

Gravitation, its effects on plants............... 32

Green crops recommended................. 357

Gypsum, its use as a manure................ 329

Heat, its effects on vegetables..............38, 178

Husbandry drill, its advantages ............. 355

Ice, its anti-putrescent powers.............. 278

Irritation, theory of its effects................ 351

Irritability, vegetable, its existence doubted ......... 245

Land, causes of its fertility.................200

barrenness ................. 203

Leaves, their functions.................... 64

Light, its effect an vegetation $\ldots \ldots \ldots \ldots \ldots \ldots \ldots .223$ 


\section{INDEX.}

Limestone, its nature and uses.............21, 316

action in the soil ................ 22

mode of burning................ 328

magnesian, its peculiar properties........23, 322

Lime, mode of ascertaining the quantity, in limestones and soils ............................... 165 salts of, on the mode of detecting them in soils.. 171

Manures, on their applications ................ 269

how taken into the vegetable system........ 270 - fermentation of ................6, 302

-1 in what state to be used................ 304 animal ......................... 296

mineral............................ 321

vegetable........................ 280

saline ..................... 293, 313

Malting, theory of the process of .............. 216

Matter, powers of discussed ................ 31

Metals, account of.................... 47

Metallic oxides, those found in plants............ 114

Mildew, cause of ....................... 265

Meat, method of preserving it .............. 279

Oils, fixed, their nature and production............ 101

Oxygene, its presence in the atmosphere, and uses...... 212

necessary to germination............213, 233

Paring and burning, theory of their operation........ 346

Pasture, where advantageous................ 360

Plants, organization of ................ 55, 138

Plants, parasitical, described as the cause of disease in corn................................ 265

Peat mosses, on their formation................ 190

on their improvement............... 204

Putrefaction, methods of preventing ...........278 


\section{INDEX.}

Pith, nature of $\ldots \ldots \ldots \ldots \ldots \ldots \ldots \ldots \ldots \ldots \ldots \ldots$

Plants, parts of ........................ 55

Quicklime, injurious to soils.................. 317

Rocks, their number and arrangement, ............. 193

- those from which soils are derived, or on which they rest ............................ 197

Sap, cause of its ascent discussed ................ 239

- course of ........................ 9, 236

its composition discussed................. 147

Salts, their uses as manure ................293, 313

- on such as are found in vegetables............ 114

on those found in soils, account of ........... 157

Seerls, on those produced by crossing............. 258

- germination of .................... 213

- their nature and uses .................. 70

Simple substances described ................... 44

Soils, properties of $\ldots \ldots \ldots \ldots \ldots \ldots \ldots \ldots \ldots \ldots \ldots \ldots$ 178, 161

- composition of .................. 157, 175

- method of analysing, ................... 159

- formation of ...................... 188

- their constituent parts .................. 154

- improvement of ..................... 203

their classification ..................... 200

Subsoils, varieties of, and their effects............ 187

Soot, properties of as a manure................ 308

Sugar, mode of refining ................... 79

Tanning principle, its application to tanning......... 88

quantity in different barks........ 89

artificial. ....................... 92

Temperature of soils discussed................ 179

Trees, habits of, discussed................... 261 


\section{INDEX.}

. Page

Trees cause of their decay ................. 252

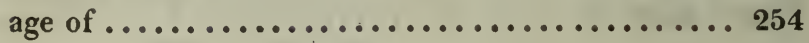

Urine, its use as a manure . . . . . . . . . . . . . . 293

Vegetables, their chemical composition ............. 73

- improvement of, by cultivation ......... 257

- renovation of the atmosphere ........... 230

- the causes of their growth discussed...... 250

Vegetable matter, mode of ascertaining its quantity in soils $\mathbf{1 6 7}$

its analysis .................... 119

- decomposition of, described........ 273

principles, their arrangement in plants ....... 138

life, phænomena of discussed............ 249

matter, decomposition of.............. 273

Vegetation, influenced by gravitation............. 32

- influence of light in ................ 235

progress of ...................221, 338

its effect on a soil .................. 357

Veins or mines, their situations ............... 196

Water, absorption of by soils................. 181

its state in the atmosphere .............. 206

Wheat, transplantation of .................. 235

crossing of ....................... 258

Wines, theory of their formation ............... 131

- quantity of spirits they contain ........... 135 


\section{INDEX TO THE APPENDIX.}

Agrostis canina, brown bent ............... 460

- canina var. mutica, awnless brown bent......4 460 fascicularis, tnfted-leaved bent........... 462

- lobata, lobed bent grass .............. 465

mexicana, mexican bent grass ........... 466

nivea, snowy bent grass .............. 462

pulustris, March bent grass ............ 456

repens, creeping rooted bent............. 465

strictu, upright bent grass .............461

stolonifera, fiorin creeping bent ..........458

stolonifera var. angustifolia, creeping bent narrow

leaves ........................ 459

vulgaris, fine bent grass .............. 455

Aira uquatica, water hair grass ................ 441

- crespitosa, turfy hair grass ............... 442

- flexuosa, waved mountain hair grass ........... 422

Alopecurus agrostis, slender fox-tail grass.......... 468

__... alpinus, alpine fox-tail grass .......... 385

prutensis, meadow fox-tail grass ......... 382

Anthoxanthum odoratum, sweet-scented vernal grass .... 378

Arundo colorata, striped-leaved reed grass........... 433

Avena elatior, tall oat grass................ 407

- flavescens, yellow oat grass............... 444

pratensis, meadow oat grass ...............417

pubescens, downy oat grass................ 386 


\section{INDEX.}

Briza media, quaking grass................. Fage

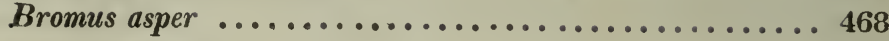

cristatus .......................441

diandrus ..........................404 404

erectus, upright perennial brome grass......... 410

inermis, awnless brome grass............. 454

littoreus, sea-side brome grass ............. 425

- multiflorus, many-flowering brome grass ...... 418

tectorum, nodding pannicled brome grass ...... 403

sterilis, barren brome grass............. 445

Bunias orientalis ...................... 434

Cynosurus caruleus, blue moor grass ............. 382

cristatus, crested dog's-tail grass......... 416

erucaformis, linear spiked dog's tail grass...... 449

Dactylis cynosuroides, American cock's-foot grass ......470

- glomerata, round-headed cock's-foot grass ..... 401

Elymus arenarius, upright sea lyme grass .......... 453

- geniculatus, pendulous sea lyme grass ........ 454 sibericus, Siberian lyme grass............ 442

Festuca calamaria, reed-like fescue grass........... 424

- cambrica ..........................4 404

duriuscula, hard fescue grass ............. 409

dumetorum, pubescent fescue grass.......... 431

elatior, tall fescue grass ............... 427

fluitans, lioating fescue grass ........... 429

glabra, smooth fescue grass............... 395

glauca, glancous fescue grass.............. 393

hordiformis, barley-like fescue grass ......... 390

loliacea, spiked fescue grass.............. 419

- myurus, wall fescue grass ............... 422

- ovina, sheep's fescue grass............... 398

__ pennata, spiked fescue grass .............. 463 


\section{INDEX.}

Page

Festuca pralensis, meadow fescue grass.............412 rubra, purple fescue grass .............. 397

Hedysarum onobrychis, sainfoin .............. 438

Hordeum bulbosum, bulbous barley grass .......... 423

- murinum, wall barley grass ............. 443

___ pratense, meadow barley grass............. 439

Holcus lanatus, meadow soft grass .............. 430

mollis, creeping soft grass .............. 446

odoratus, sweet scented soft grass ........... 380

Lolium perenne, perennial rye grass ............. 413

Medicago sativa, lucerne.................... 437

Melica carulea, purple malic grass.............. 469

Milium effusum, common millet grass............411

Nardus stricta, upright mat grass.............. 428

Panicum dactylon, creeping panic grass............457

- sunguinale, blood coloured panic grass...... 464 viride, green panic grass............... 463

Phalaris cananiensis, common canary grass.......... 469

Phleum nodosum, bulbous-stalked cat's-tail grass...... 450 pratense, meadow cat's-tail grass ........... 450

var. minor, meadow cat's-tail grass, var. smaller 452

Poa alpina, alpine meadow grass .............. 386

angustifolia, narrow-leaved meadow grass........ 405

aquatica, reed meadow grass .............. 440

carulea, v. p. pratense, short bluish meadow grass 389

compressa, flat-stalked meadow grass ......... 439

cristat $a$, crested meadow grass ............. 421

elatior, tall meadow grass................408

fertilis, fertile meadow grass.............. 432

var. $b$. fertile meadow grass, var. 1. ..... 448

maritima, sea meadow grass ............... 415

- pratensis, smooth-stalked meadow grass ........ 388 


\section{INDEX.}

Poa trivialis, roughish mage

Poa trivialis, roughish meadow grass $\ldots . \ldots \ldots \ldots . . .391$ Potirium sanguisorba, burnet .............. 434

Stipa pennata, long armed feather grass......... 466

Trifolium macrorhizum, long-rooted clover.......... 435

—pratense, broad-leaved cultivated clover....... 433

- repens, white clover................ 434

Triticum repens, creeping rooted wheat grass......... 467 $s p$. wheat grass................... 429

THE END. 






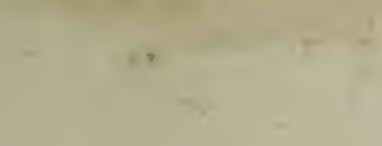

,

*
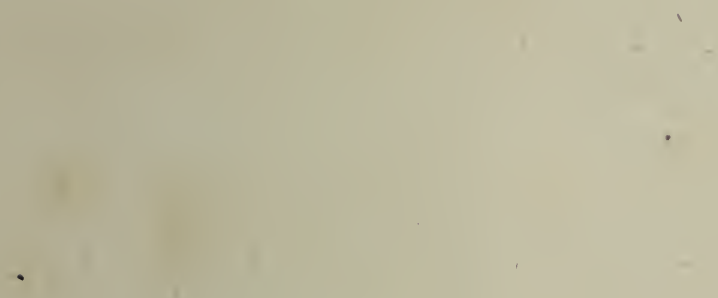
